A FEA e a USP respeitam os direitos autorais deste trabalho. Nós acreditamos que a melhor proteção contra o uso ilegílimo deste texto é a publicação online. Além de preservar o conteúdo motiva-nos oferecer à sociedade o conhecimento produzido no âmbito da universidade pública e dar publicidade ao esforço do pesquisador. Entretanto, caso não seja do interesse do autor manter o documento online, pedimos compreensão em relação à iniciativa e o contato pelo e-mail bibfea@usp.br para que possamos tomar as providências cabiveis (remoção da tese ou dissertação da BDTD). 


\begin{abstract}
UNIVERSIDADE DE SÃO PAULO
FACULDADE DE ECONOMIA, ADMINISTRAÇÃO E CONTABILIDADE

DEPARTAMENTO DE ECONOMIA

PROGRAMA DE PÓS-GRADUAÇÃO EM ECONOMLA
\end{abstract}

\title{
A UTILIZAÇÃO DAS OPERAÇÕES DE REDESCONTO PELOS BANCOS COM CARTEIRA COMERCIAL NO BRASL
}

\author{
Fernando Augusto da Cruz Paião Úmezú
}

Orientador: Prof. Dr. Márcio Issao Nakane

SÃO PAULO

2005 
Prof. Dr. Adolpho Jose Melfi

Reitor da Universidade de São Paulo

Profa. Dra. Maria Tereza Leme Fleury

Diretora da Faculdade de Economia, Administração e Contabilidade

Prof. Dr. Ricardo Abramovay

Chefe do Departamento de Economia

Prof. Dra. Basília Maria Baptista Aguirre

Coordenador do Programa de Pós-Graduação em Economia das Instituições e do Desenvolvimento 


\section{FERNANDO AUGUSTO DA CRUZ PAIÃO UMEZU}

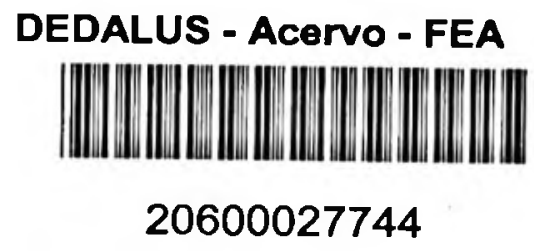

A UTILIZAÇÃO DAS OPERAÇÕ̃S DE REDESCONTO PELOS BANCOS COM CARTEIRA COMERCIAL NO BRASIL

Dissertação apresentada ao Departamento de Economia da Faculdade de Economia, Administração e Contabilidade da Universidade de São Paulo como requisito para a obtenção do título de Mestre em Economia.

Orientador: Prof. Dr. Márcio Issao Nakane

USP - FEA - SBD
DATA DA DEFESA $₫ 3,06,05$

\section{SÃo PaULO}

2005 
Dissertação defendida e aprovada, em 13.06.2005, no Programa de Pós-Graduação em Economia, pela seguinte comissão julgadora:

Prof. Dr. Marcio Issao Nakane

Prof. Dr. Naércio Aquino Menezes Filho

Prof. Dr. Ana Carla Abrão Costa

Umezí, Fernando Augusto da Cruz Paião

A utilização das operações de redesconto pelos bancos com carteira comercial no Brasil / Fernando Augusto da Cruz Paião Umezu. - São Paulo, 2005.

$138 \mathrm{p}$.

Dissertação (Mestrado) - Universidade de São Paulo, 2005

Bibliografia.

1. Bancos comerciais 2. Bancos comerciais I. Universidade de São Paulo. Faculdade de Economia, Administração e Contabilidade. II. Título. 
A Patricia,

pelo apoio em todo o curso do mestrado

e a Felipe Augusto,

por ter suportado minha “ausência” neste período 
Agradecimentos

Professor Márcio Issao Nakane que me conduziu com muita dedicação, paciência, equilíbrio e disposição.

Samuel Bracarense Costa, que foi meu orientador técnico no BACEN, pelo incentivo, sugestões e apoio administrativo.

Professor Fábio Kanczuk pelo apoio nas questơes administrativas junto à FEA.

Ana Carla Abrão Costa e Naércio de Aquino Menezes pelas sugestōes apresentadas no Exame de Qualificação.

José Antonio Marciano, Chefe do BACEN/DEBAN, Luiz Fernando Cardoso Maciel, Chefe Adjunto do BACEN/DEBAN, e Virginio Santos Neto, Gerente Técnico do BACEN/DEBAN/SP, pelo suporte técnico e pelo fornecimento dos dados.

Rafael Siracusa Neto, Sérgio Akira Fujii, Celso Gonçalves Morelli e Leonardo de Albuquerque Lima pelas informaçð̃es e indicação dos normativos sobre Redesconto, Sistema de Pagamentos e Depósitos Compulsórios.

Professores Basília Maria Aguirre, Antonio Gledson, André Portela, Gilberto Tadeu Lima, Heron Esvael do Carmo, Eduardo Haddad, Vera Lúcia Fava, Raúl Cristóvão dos Santos, Eduardo Soromenho, José Flávio Motta, Joe Akira Yoshino, Antonio Carlos Pedroso de Lima, Gérson Francisco, Raimundo Chiappin, José Carlos de Souza Santos e Hélio Zylberstein.

Amigos de curso Gabriel Garber e Sérgio Mikio Koyama (doutorado) pelo companheirismo nos trabalhos.

Finalmente, ao Banco Central do Brasil que tornou possível a realização deste projeto. 
"Viva como se fosse morrer amanhã, aprenda como se fosse viver para sempre."

Mahatma Ghandi 


\section{RESUMO}

Nesta dissertação analisamos o comportamento da demanda por redesconto over no Brasil. Fizemos um breve resumo histórico dos últimos normativos desde o início do Plano Real e construímos um modelo para o redesconto over assumindo que o comportamento intradia das reservas segue um processo estocástico de Levy. Utilizamos uma amostra composta por 122 instituições financeiras, para o periodo de 22 de abril de 2002 a 31 de agosto de 2004, para estimar a probabilidade de utilização do redesconto over (Probit e Logit com dados independentes e painel com efeitos aleatórios) e a demanda por redesconto over (Tobit com dados independentes e em painel e Heckit com dados independentes). Obtivemos como resultado que a obrigação de cumprir o compulsório sobre depósitos à vista aumenta a probabilidade de utilização do redesconto over. Houve também evidências da influência do dia do periodo de cumprimento na probabilidade de utilização do redesconto over, havendo coerência com os resultados obtidos por Queiroz (2004) e Costa Pinto e Coelho (2004) de que há excesso de liquidez para os três primeiros dias do periodo de cumprimento do compulsório sobre depósitos à vista. Finalmente, a taxa de redesconto over afeta negativamente a probabilidade de utilização do redesconto over, não sendo significante para a quantidade demandada de recursos. 


\section{ABSTRACT}

In this dissertation we analyse the behavior of the over discount demand in Brazil. We make a short historical review of the last resource financing regulation since the beginning of Real plan and set up a model that treats discount window as one of the possible sources of liquidity for a bank assuming that the intraday reserves follow a Levy process. We use a daily sample of 122 banks, between April 22, 2002, and August 31, 2004, to estimate the probability of over discount usage (pooled and random effects Logit and Probit) and its demand (pooled and random effects Tobit and pooled Heckit). We find that the obligation to keep compulsory reseves increases the probability of over discount usage. There is also evidence of influence of the mantainance period days on the probability of over discount operations occurance, corroborating the results in Queiroz (2004) and Costa Pinto e Coelho (2004). Finally, the over discount rate was found to yield a negative effect on the probability of over discount usage, being, in turn, insignificant for the amount of demanded resources. 


\section{SUMÁRIO}

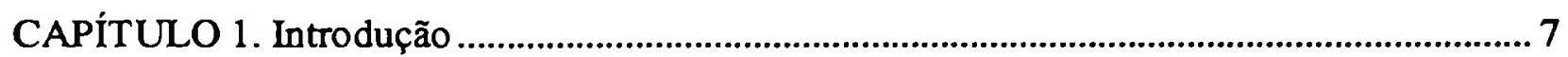

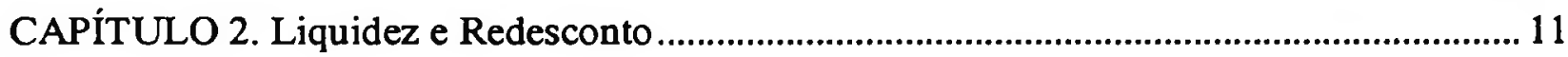

2.1. Os programas de fortalecimento do Sistema Financeiro Nacional .............................. 11

2.2. Formas de obtenção de liquidez ................................................................................ 19

2.3. Redesconto: do Plano Real ao novo Sistema de Pagamentos...................................... 24

CAPÍTULO 3. Modelo de Demanda por Redesconto ……………............................................ 34

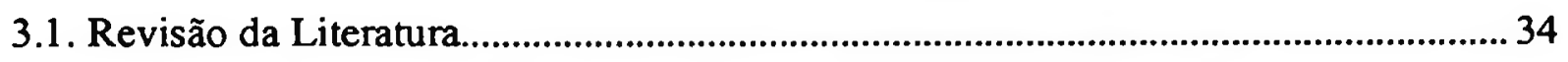

3.1.1. Modelos de demanda por moeda........................................................................ 34

3.1.2. Modelos de gerenciamento do saldo em reservas ao final do dia ....................... 37

3.1.3. Modelos de Demanda por Redesconto .................................................................... 38

3.2. Um Modelo de Demanda por Reservas........................................................................ 39

3.3. Um Modelo de Demanda por Redesconto …………….................................................. 45

CAPÍTULO 4. Modelos Econométricos.............................................................................. 47

4.1. Modelos Probit com dados em painel......................................................................... 47

4.2. Modelos Logit com dados em painel........................................................................ 50

4.3. Modelos Tobit com dados em painel........................................................................... 53

4.4. Modelo Heckit ....................................................................................................... 55

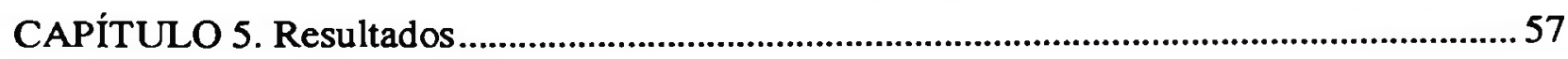

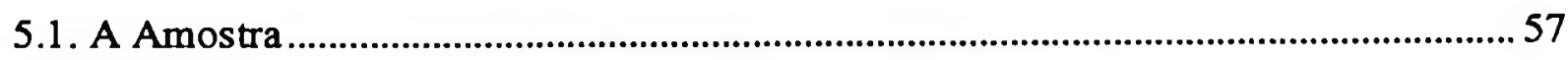

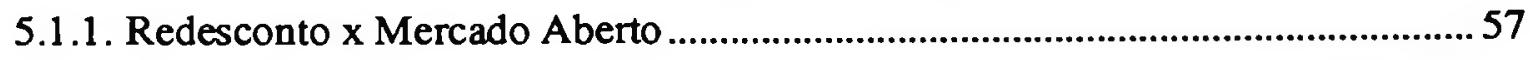

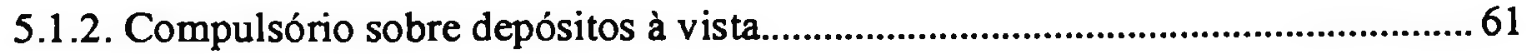

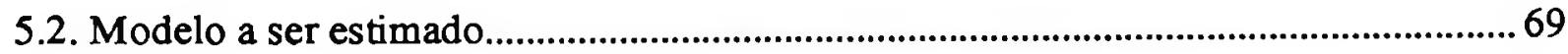

5.3. Probabilidade de utilização do Redesconto, Modelo Probit........................................... 78

5.4. Probabilidade de utilização do Redesconto, Modelo Logit .......................................... 90

5.5. Demanda por Redesconto, Modelo Tobit ..................................................................... 98

5.6. Efeitos Marginais...................................................................................................... 100

5.7. Demanda por Redesconto, Modelo Heckit .................................................................. 108

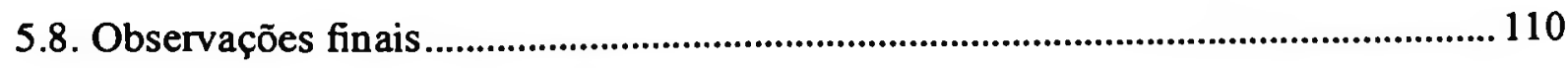




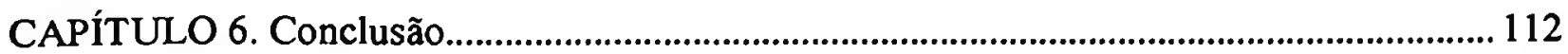

Referências Bibliográficas.........................................................................................116

APÊNDICE A. Resultados para a amostra de 01/07/2002 a 31/08/2004 .............................. 120

A.1. Probabilidade de utilização do Redesconto, modelo Probit...................................... 120

A.2. Probabilidade de utilização do Redesconto, modelo Logit........................................ 126

A.3. Demanda por Redesconto, modelo Tobit............................................................... 132

APÊNDICE B. Tabela Resumo dos normativos de Redesconto ............................................136 


\section{LISTA DE ABREVIATURAS E SIGLAS}

BACEN - Banco Central do Brasil

BB - Banco do Brasil

CEF - Caixa Econômica Federal

CETIP - Central de Custódia e Liquidação Financeira de Títulos Privados

COSIF - Plano de Contas das Instituições do Sistema Financeiro

DEBAN - Departamento de Operações Bancárias e Sistema de Pagamentos

DEMAB - Departamento do Mercado Aberto

FCVS - Fundo de Compensação de Variações Salariais

FGC - Fundo Garantidor de Crédito

IF - Instituição Financeira

IGC - Inspeção Global Consolidada

LRF - Lei de Responsabilidade Fiscal

MP - Medida Provisória

PROEF - Programa de Fortalecimento das Instituições Financeiras Federais

PROER - Programa de Estimulo a Reestruturação e Fortalecimento do Sistema Financeiro Nacional

PROES - Programa de Incentivo a Redução do Setor Público Estadual na Atividade Bancária

SELIC - Sistema Especial de Liquidação e Custódia

SFH - Sistema Financeiro de Habitação

SISBACEN - Sistema de Informações do Banco Central

STN - Secretaria do Tesouro Nacional 


\section{LISTA DE ILUSTRAÇÕES}

Figura 1 - TBC e TBAN

Figura 2 - Número de operações realizadas pelo DEMAB x número de operações realizadas pelo DEBAN.

Figura 3 - Volume (em bilhões de Reais) das operações realizadas pelo DEMAB x volume (em bilhões de Reais) das operações realizadas pelo DEBAN ...................................................59

Figura 4 - Periodos de cálculo e de movimentação para os grupos A e B ..................................62

Figura 5 - Média de Reservas, Grupo A em milhões de Reais ....................................................64

Figura 6 - Média de Reservas, Grupo B em milhões de Reais....................................................64

Figura 7 - Média de Reservas, Bancos sem exigibilidade no Compulsório sobre Depósitos a

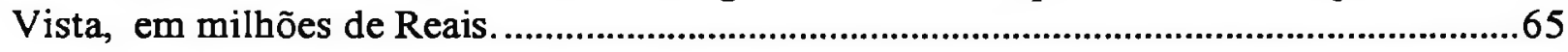

Figura 8 - Exigibilidade do Compulsório sobre Depósitos à Vista.............................................66

Figura 9 - Relação Reservas/Exigibilidade, Grupo A ...............................................................67

Figura 10 - Relação Reservas/Exigibilidade, Grupo B............................................................67

Figura 11 - Custo de Oportunidade do Redesconto Over (24/04/02 a 31/08/04) .......................75

Figura 12 - Custo de Oportunidade do Redesconto Over (01/07/02 a 31/08/04) .......................75

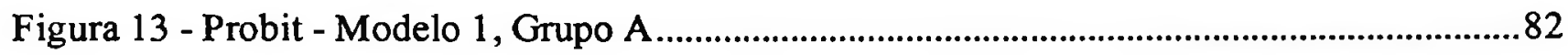

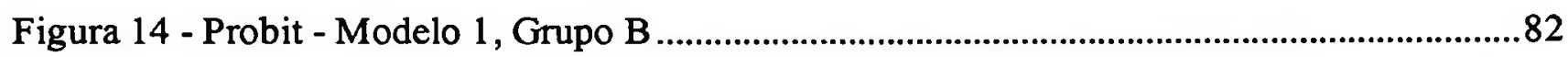

Figura 15 - Probit - Modelo 1, bancos sem exigibilidade de compulsório sobre depósitos à vista.

Figura 16 - Probit - Modelo 1, Q1 e Q3 ...............................................................................84

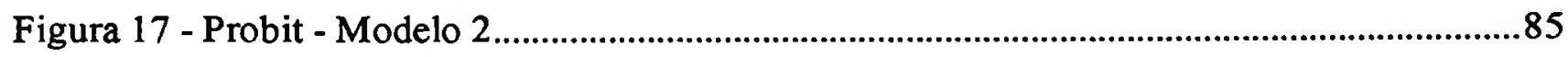

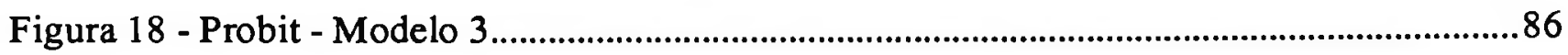

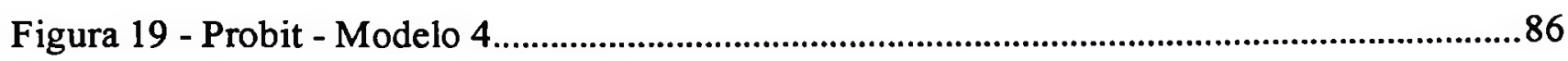

Figura 20 - Probit - Modelo 4, Q1 e Q3 ......................................................................................8 87

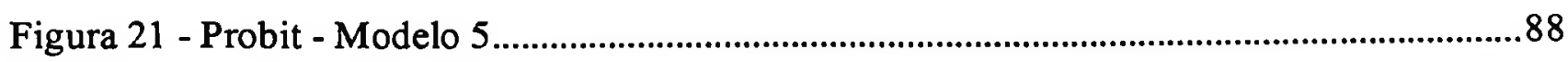

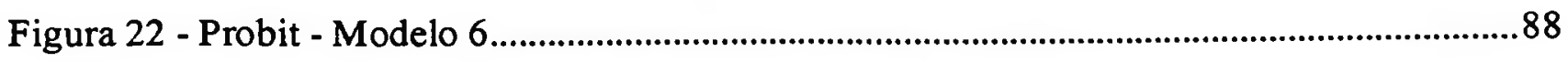




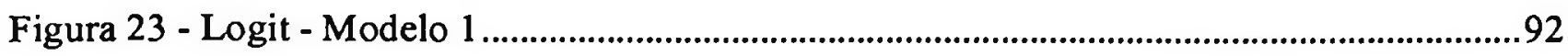

Figura 24 - Logit - Modelo 1, Q1 e Q3...................................................................................93

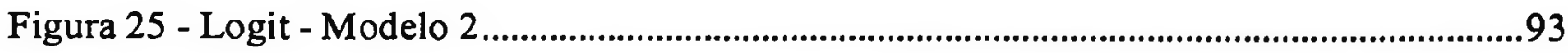

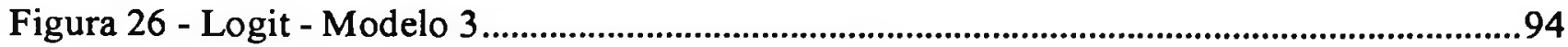

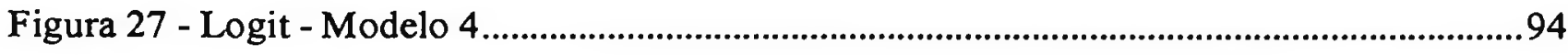

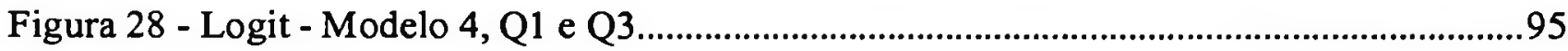

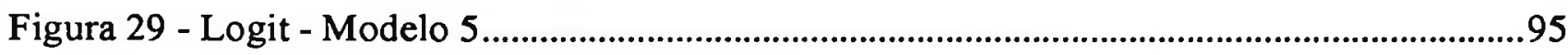

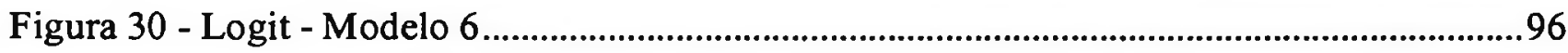

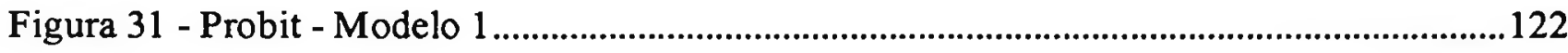

Figura 32 - Probit - Modelo 1, Q1 e Q3 ...............................................................................123

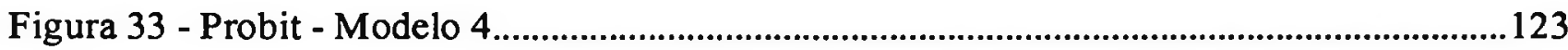

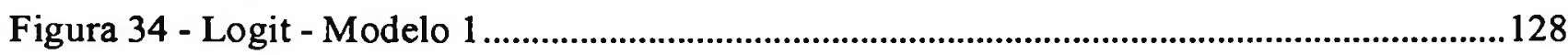

Figura 35 - Logit - Modelo 1, Q1 e Q3 .......................................................................................128

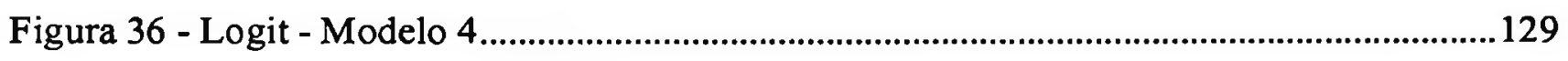




\section{LISTA DE TABELAS}

Tabela 1 - Resolução 2.288 - Encargos financeiros.......................................................................25

Tabela 2 - Resolução 2.308 - Encargos financeiros........................................................................27

Tabela 3 - Circular 2.869 - Encargos Financeiros..........................................................................28

Tabela 4 - Porte das IFs e operaçø̃es de redesconto........................................................................61

Tabela 5 - Ocorrências de operaç̃̃es de Redesconto .....................................................................77

Tabela 6 - Resultados do Modelo Probit .............................................................................................79

Tabela 7 - Probabilidade média para o modelo Probit.......................................................................8

Tabela 8 - Resultados do Modelo Logit ......................................................................................90

Tabela 9 - Probabilidade média para o modelo Logit.......................................................................92

Tabela 10 - Percentual de Observações Corretamente Preditas.........................................................96

Tabela 11 - Resultados do modelo Tobit.........................................................................................98

Tabela 12 - Efeitos Marginais - Modelo Probit..............................................................................102

Tabela 13 - Efeitos Marginais - Modelo Logit................................................................................104

Tabela 14 - Efeitos Marginais - Modelo Tobit................................................................................106

Tabela 15 - Resultados do Modelo Heckit ......................................................................................108

Tabela 16 - Resultados do Modelo Probit ......................................................................................120

Tabela 17 - Efeitos Marginais - Modelo Probit.................................................................................124

Tabela 18 - Resultados do Modelo Logit ...................................................................................126

Tabela 19 - Probabilidade Média - Modelos Probit e Logit...........................................................129

Tabela 20 - Efeitos Marginais - Modelo Logit..............................................................................130

Tabela 21 - Resultados do Modelo Tobit .....................................................................................132

Tabela 22 - Efeitos Marginais - Modelo Tobit.............................................................................134

Tabela 23 - Resumo dos normativos de redesconto a partir do Plano Real ..................................136 


\section{CAPÍTULO 1 - INTRODUÇÃO}

Os bancos centrais possuem três instrumentos para implementação de política monetária: reservas compulsórias, operações de mercado aberto e redesconto. As operações de redesconto, além de fazerem parte deste conjunto de instrumentos de política monetária, constituem um instrumento de assistência financeira.

A assistência financeira é o conjunto de linhas de crédito que o BACEN possui para socorrer os bancos, com a finalidade de evitar crises no sistema financeiro. Estas linhas de crédito incluem operações para atender problemas de liquidez momentânea (redesconto intradia e redesconto over), operações para atender problemas estruturais (redesconto) e os programas de fortalecimento do sistema financeiro nacional (PROER, PROES e PROEF).

O objeto de estudo deste trabalho é a demanda por redesconto over de instituições financeiras com carteira comercial. Como será visto nos capitulos 3 e 5, por existirem operações compromissadas de um dia no mercado aberto realizadas pelo próprio BACEN, o termo redesconto over não se restringirá às operações definidas pelos normativos de redesconto. Serão consideradas como redesconto over as operações definidas em normativo como redesconto over e as operações compromissadas de um dia de prazo realizadas junto ao BACEN após o horário usual de operações (após às 17 horas). As demais linhas de assistência financeira não serão objeto deste estudo dada a inexistência de ocorrências no periodo da avaliação empírica que se inicia em 22 de abril de 2002 com o início da vigência do novo sistema de pagamentos. 
Este trabalho possui dois objetivos. O primeiro é propor um modelo para demanda por redesconto over ${ }^{1}$ baseado em modelos de administração de reservas ${ }^{2}$ e controle ótimo e testá-lo empiricamente. A literatura apresenta diversos modelos para redesconto over. O modelo sugerido é inovador na medida em que associa o comportamento intradia e o comportamento ao longo do ciclo de manutenção das reservas às necessidades de liquidez de um dia das instituições financeiras.

A maior contribuição diz respeito à parte empírica. Não há registros de trabalhos empíricos com dados individualizados na literatura ${ }^{3}$. Tal fato se deve ao caráter sigiloso deste tipo de informação, o que nos obrigou a manter o compromisso junto ao BACEN de não divulgar os dados e a reportá-los de forma cuidadosa.

O segundo objetivo é avaliar empiricamente o modelo e testar a validade de algumas hipóteses. A primeira delas é a influência do período de cumprimento do compulsório sobre depósitos à vista sobre a probabilidade de utilizar o redesconto. Costa Pinto e Coelho (2004), aplicando a metodologia de Clouse \& Dow (2002) ao caso brasileiro, mostram que nos três dias em que o período de manutenção coincide com o periodo de cálculo (há incerteza sobre o valor da exigibilidade) a instituị̧ão mantém um excesso de reservas em relação a sua previsão de exigibilidade. Sendo assim, seria de se esperar que a probabilidade de utilização do redesconto nestes três dias fosse maior do que nos demais. Um segundo ponto que será avaliado é o efeito do aumento da taxa do redesconto over. A taxa do redesconto over pode ser entendida como

\footnotetext{
' Em principio, demanda por reservas e demanda por redesconto over são conceitos diferentes. No capítulo 3 será adotada a hipótese de que toda a demanda por reservas será atendida por operacões de redesconto (redesconto over e operações compromissadas) o que implicará na igualdade entre demanda por redesconto e demanda por reservas. ${ }^{2} \mathrm{O}$ modelo proposto neste trabalho é um modelo estatístico que associa um processo estocástico ao comportamento dos saldos das reservas. Não há, em principio, a preocupação em construir um modelo estrutural.

${ }^{3}$ Há poucos trabalhos com dados agregados. Um exemplo é Peristiani (1999).
} 
uma proxy para uma taxa de redesconto ${ }^{4}$. Isto é possivel dado que um aumento da sobretaxa do redesconto over causa, não necessariamente de imediato, um ajuste nas taxas praticadas pelo Departamento de Mercado Aberto DEMAB. Uma terceira hipótese a ser avaliada é o efeito da exigência de cumprimento do compulsório sobre depósitos à vista, ou seja, se esta exigência implica em um aumento ou não da probabilidade de utilização do redesconto.

Este trabalho está estruturado da seguinte forma: após esta introdução, no Capitulo 2, serão apresentadas formas de obtenção de liquidez que poderão estar inseridas ou não nas modalidades de assistência financeira. A primeira seção do capítulo traz uma descrição dos programas de fortalecimento do sistema financeiro (PROER, PROES e PROEF) criados pelo BACEN. Na segunda seção são mencionadas outras formas de obtenção de liquidez que incluem, por exemplo, operações realizadas no mercado interbancário. Uma resenha sobre os normativos de redesconto a partir do Plano Real encerra o capítulo.

Após construir o arcabouço em que o redesconto se insere, prosseguimos com os capitulos que tratarão dos objetivos deste trabalho. O Capítulo 3 traz o modelo de demanda por redesconto que é precedido por uma breve revisão da literatura sobre modelos de administração de reservas e de redesconto.

O Capítulo 4 apresenta os modelos econométricos utilizados. São descritos os modelos Probit, Logit e Tobit com dados em painel e o modelo Heckit.

No Capítulo 5, faz-se uma descrição da amostra utilizada e são apresentados os resultados obtidos. Como principais resultados temos que para o periodo em análise houve evidências da influência do periodo de cumprimento do compulsório sobre depósitos à vista

\footnotetext{
${ }^{4}$ Neste trabalho, Redesconto será definido como a soma do redesconto over com as operações de nivelamento. Esta
} 
sobre a demanda por reservas; a demanda por redesconto apresentou alta sensibilidade em relação à taxa do redesconto over e não houve seleção endógena em relação à demanda por redesconto.

O Capítulo 6 encerra este trabalho. Nele serão feitas a análise final, comentários e a conclusão. 


\section{CAPÍTULO 2 - LIQUIDEZ E REDESCONTO}

Este capítulo busca descrever o contexto em que o redesconto está inserido, conforme a legislação vigente no Brasil. Ele está dividido em três seções. A primeira mostra a importância da administração das reservas bancárias traçando um cenário do Sistema Financeiro Nacional após o Plano Real e os mecanismos criados para proteger e fortalecer as instituições financeiras privadas, públicas estaduais e públicas federais. A segunda seção descreve as formas básicas que as instituições financeiras possuem para obter liquidez. A última seção traz um breve resumo histórico sobre o redesconto a partir do Plano Real até a legislação vigente. Os normativos atuais foram elaborados para o contexto do novo sistema de pagamentos.

\subsection{Os programas de fortalecimento do Sistema Financeiro Nacional}

Após a implantação do Plano Real em junho de 1994 e com a significativa redução da inflação, as instituições financeiras foram obrigadas a reavaliar a maneira como administravam seu patrimônio e passaram a buscar novas formas de obtenção de receitas. Como conseqüência, vários bancos fecharam suas portas, foram comprados, incorporados ou sofreram alguma forma de intervenção pelo Banco Central do Brasil (BACEN). 
Em 03 de novembro de 1995, foram publicadas a Medida Provisória $\mathrm{n}^{\circ} 1.179^{5}$, pela Presidência da República, e a Resolução ${ }^{6} n^{\circ} 2.208$, pelo BACEN, instituindo o Programa de Estímulo a Reestruturação e Fortalecimento do Sistema Financeiro Nacional (PROER).

Esse programa tinha como principal objetivo assegurar liquidez e solvência ao Sistema Financeiro Nacional e resguardar os interesses de depositantes e investidores.

A implementação do PROER dar-se-ia por meio de reorganizações administrativas, operacionais e societárias de instituições financeiras previamente autorizadas pelo BACEN, que resultassem na transferência de controle ou na modificação de objeto social. O PROER compreendia linha especial de assistência financeira, liberação de recursos do recolhimento compulsório/encaixe obrigatório sobre recursos à vista para aquisição de CDB de emissão de instituições participantes do PROER, flexibilização do atendimento dos limites operacionais aplicáveis às instituições financeiras e diferimento dos gastos relativos aos custos, despesas e outros encargos com a reestruturação, reorganização ou modernização das instituições financeiras. A linha especial de assistência financeira vinculava-se a títulos ou operações de responsabilidade do Tesouro Nacional ou de entidades da administração federal indireta, perdas decorrentes de processo de saneamento, gastos com redimensionamento e reorganização administrativa e decorrentes de reestruturação e modernização de sistemas operacionais e desimobilização de ativos de propriedade da instituição participante. No caso de incorporação, havia um tratamento tributário diferenciado para as incorporações realizadas até 31 de dezembro de 1996: a instituição a ser incorporada contabilizaria como perda os créditos de dificil recuperação, adicionando-as ao lucro líquido para fins de determinação do lucro real e da base

\footnotetext{
${ }^{5}$ Que se tomaria a Lei ${ }^{\circ} 9.710$, de 19 de novembro de 1998.

- As resoluções são publicadas pelo BACEN, por delegacão do presidente do CMN.
} 
de cálculo da Contribuição Social sobre o Lucro Líquido. As instituições incorporadoras poderiam registrar como ágio, na aquisição do investimento, a diferença entre o valor de aquisição e o valor patrimonial da participação societária adquirida, podendo ser amortizado após a incorporação?.

No periodo de julho de 1994 a maio de 1997, sete instituições financeiras foram saneadas com recursos do PROER ${ }^{8}$. Os bancos Econômico, Nacional, Mercantil de Pernambuco, Banorte e Bamerindus, que estavam sob intervenção, realizaram operações de venda de ativos e passivos ${ }^{9}$ com o Banco Excel e a CEF, Unibanco, Rural, Bandeirantes e HSBC, CEF e BB, respectivamente. Dois bancos não estavam sob intervenção. Nestes casos foram realizadas operações de transferência de controle acionário: Antonio de Queiroz para o United e Martinelli para o Pontual.

Estima-se que o custo total incorrido pelo Govemo com a operacionalização do PROER pode ter chegado a $1,4 \%$ do $\mathrm{PIB}^{10}$. Este custo é inferior ao custo de crises bancárias em vários países desenvolvidos como os Estados Unidos $(5,1 \% \text { do PIB })^{11}$, da Suécia $(4,5 \%$ do PIB) e da Noruega (4,5\% do PIB). Comparado a outros países da América Latina, o custo fiscal do ajustamento é ainda menor: Argentina (13,0\% do PIB), Chile (19,6\%) e Venezuela (13,0\% do PIB). As provisões e reversões de provisões sobre créditos do PROER chegaram ao montante de R $\$ 7,9$ bilhões até o dia 30.06 .2002 . O custo final do programa só poderá ser apurado depois de

\footnotetext{
${ }^{7}$ Estes lançamentos contábeis implicavam na redução do lucro real, base para a cobrança do Imposto de Renda Pessoa Jurídica. Havia um limite para esse benefício por ano-base que era de $30 \%$ do lucro liquido ajustado. Este valor deveria compor a base de cálculo da Contribuição Social sobre o Lucro Líquido.

${ }^{8}$ Conforme Relatório de Atividades da Diretoria de Fiscalização - 1995-2002, disponivel no site www.bcb.gov.br.

9 Econômico com Excel e CEF; Nacional com Unibanco; Mercantil de Pernambuco com Rural; Banorte com Bandeirantes e Bamerindus com HSBC, CEF e BB.

${ }^{10}$ O Relatório de Atividades da Diretoria de Fiscalização - 1995-2002 aponta que o custo total, segundo estimativas do BACEN, situa-se na faixa de $0,9 \%$ a $1,4 \%$ do PIB, dependendo das hipóteses e da metodologia utilizada. Conforme o mesmo relatório, este custo é expressivamente inferior à média registrada em 40 paises ( $12,8 \%$ do PIB).
} 
concluídos os processos de liquidação extrajudicial das instituições que utilizaram as linhas de assistência do PROER ${ }^{12}$.

A lei do PROER ainda faz referência ao Fundo Garantidor de Crédito (FGC), criado pela Resolução $\mathrm{n}^{\circ} 2.197$, de 31 de agosto de 1995, declarando isenção do imposto de renda e da contribuição social do lucro líquido. O FGC é uma entidade privada, sem fins lucrativos, destinada a administrar mecanismo de proteção a titulares de créditos contra instituições financeiras. O FGC garante créditos relativos a depósitos à vista, depósitos de poupança, letras de câmbio, letras imobiliárias e letras hipotecárias, de emissão ou aceite de instituição financeira ou associação de poupança e empréstimo em funcionamento no país. As instituições participantes contribuem com $0,025 \%$ do montante mensalmente escriturado relativamente aos saldos das contas correspondentes às obrigações objeto de garantia.

Este fundo teve papel importante nas reestruturações ocorridas a partir de 1995. As incorporações do Banco Nacional ao Unibanco (novembro de 1995) e do Banco Econômico ao grupo Excel (abril de 1996) não contaram com recursos desse fundo. Nestes casos (modelo da cisão good bank/bad bank) o BACEN concedeu recursos do PROER mediante garantias em créditos contra o Fundo de Compensação de Variações Salariais (FCVS) das próprias instituições financeiras. A incorporação do Banorte pelo Banco Bamerindus (maio de 1996) deu-se basicamente com recursos do FGC. Em março de 1997, o Banco Bamerindus foi comprado pelo grupo HSBC. Como os recursos do fundo não eram suficientes para a operação,

\footnotetext{
${ }^{11}$ Fonte: Rojas-Suarez e Weisbrod (1995).

12 Ver metodologia no Relatório de Atividades da Diretoria de Fiscalização - 1995-2002.
} 
o BACEN viabilizou a operação com um financiamento do PROER, mediante garantia dos créditos a receber do $\mathrm{FGC}^{13}$.

O PROER ainda permanece em vigência, mas as liberações adicionais estão sujeitas aos constrangimentos estabelecidos pela Lei de Responsabilidade Fiscal (LRF) ${ }^{14}$.

Seguindo o mesmo principio foi criado o PROES, Programa de Incentivo a Redução do Setor Público Estadual na Atividade Bancária, pela Medida Provisória 1.514, de 07.08.1996. Este programa fazia parte do processo de reestruturação das finanças dos governos estaduais. Os bancos públicos foram fortemente afetados pela estabilidade monetária (perda das receitas de floating) e sua estrutura e forma de gestão dificultavam mudanças operacionais rápidas. O objetivo do PROES era o de resolver os problemas de liquidez e a deterioração patrimonial observada nos bancos estaduais. O PROES possibilitou a solução ordenada da questão da dívida fiscal dos estados por meio da privatização dos bancos estaduais.

Com exceção do Mato Grosso do Sul e de Tocantins, que não possuíam instituições financeiras sob seu controle, e da Paraíba e Distrito Federal, que não manifestaram interesse pelo programa, todas as demais unidades da federação aderiram ao PROES. A posição de setembro de 2002 indica que dez instituições optaram por extinção ou liquidação ordinária, catorze foram privatizadas (sete conduzidas pelos estados: Bandepe, Baneb, Banerj, Banestado, Bemge, Credireal e Paraiban; e sete conduzidas pela União: Banespa, BEA, BEC, BEG, BEM, BEP e BESC), cinco optaram pelo saneamento (Banese, Banestes, Banpará, Banrisul e Nossa Caixa) e dezesseis tornaram-se Agências de Fomento. A privatização dos bancos estaduais

\footnotetext{
${ }_{13}^{13}$ Detalhes em Lundberg (1999, p. 63).

${ }^{14}$ A LRF, Lei Complementar 101/2000, estabelece que "salvo mediante lei especifica, não poderão ser utilizados recursos públicos, inclusive de operações de crédito, para socorrer instituições do Sistema Financeiro Nacional,
} 
contribuiu com $\mathrm{R} \$ 10,5$ bilhões que foram utilizados para o abatimento das dividas dos estados com a União. Os desembolsos atingiram aproximadamente 5,7\% do PIB, mas considerando que os estados deverão reembolsar grande parte desse valor, o impacto fiscal deverá ser menor ${ }^{15}$.

O Programa de Fortalecimento das Instituições Financeiras Federais, PROEF, teve origem em 1995 com o BB, a CEF e o Banco Meridional do Brasil. Este programa oficialmente foi iniciado em junho de 2001 com a publicação da MP 2.155/01. No período de 1995 a 2001 foi realizado um diagnóstico e elaboradas propostas para saneamento dos bancos federais.

Na busca da real situação do $\mathrm{BB}$, da $\mathrm{CEF}^{16}$, do $\mathrm{BNB}$ e do Basa foram encontrados créditos de baixa liquidez ou de dificil recuperação em suas carteiras. Além disso foram analisadas pelo departamento de fiscalização do BACEN a estrutura organizacional e a qualidade de controles internos.

A Secretaria do Tesouro Nacional (STN $)^{17}$ apresentou um conjunto de medidas a serem adotadas para o saneamento das quatro instituições financeiras. Com a aprovação destas medidas pelo Governo Federal, foi publicada a MP 2.155/01.

O Governo Federal utilizou três instrumentos: transferência do risco de crédito para o Tesouro Nacional ou cessão de crédito para a Emgea - Empresa Gestora de Ativos; troca de ativos de pouca liquidez e baixa remuneração por ativos líquidos, remunerados à taxa de mercado; e aumento de capital (CEF, BNB e Basa).

ainda que mediante a concessão de empréstimos de recuperacão ou financiamentos para a mudança de controle acionário".

${ }^{15} \mathrm{O}$ impacto fiscal será aproximadamente o diferencial do custo médio de financiamento da divida mobiliária do governo federal e a taxa praticada nas operações aplicado sobre os desembolsos.

${ }^{\text {Po }}$ O processo da CEF foi mais complexo devido às suas atividades junto ao SFH e da necessidade de alterações na legislação.

${ }^{17}$ A STN participou do processo na condição de acionista controladora. 
A estimativa do impacto do PROEF na Dívida Líquida Ativa do Setor Público foi da ordem de $\mathrm{R} \$ 12,18$ bilhões. Em emissão de títulos o montante chegou a $\mathrm{R} \$ 62,39$ bilhões.

Além da questão financeira, foram recomendadas medidas para a melhoria de governança corporativa que incluiam a melhoria dos controles internos (criação de diretoria especifica e auditoria interna), melhoria do processo de avaliação de risco de crédito, mudanças na estrutura administrativa e desenvolvimento da área de tecnologia.

O PROER, o PROES e o PROEF estão inseridos em um processo de fortalecimento e proteção do Sistema Financeiro Nacional iniciado após o Plano Real. Além destes programas, iniciou-se um processo de aperfeiçoamento dos mecanismos de supervisão bancária. A Resolução $\mathrm{n}^{\circ} 2.099$, de 17 de agosto de 1994 marca a mudança no processo de supervisão e regulamentação bancária no Brasil.

O Departamento de Fiscalização do BACEN realiza a supervisão de duas formas. A primeira é a chamada Inspeção Global Consolidada (IGC) que surgiu em dezembro de 1996. Na IGC a supervisão é realizada em módulos (tesouraria, câmbio, operações de crédito entre outros) seguindo as recomendações do Comitê da Basiléia sobre supervisão em bases consolidadas. A segunda forma de supervisão é a supervisão indireta. Neste caso o acompanhamento é realizado por meio das informações prestadas pelas instituições.

Na seqüência deste processo de fortalecimento do Sistema Financeiro Nacional, em 22 de abril de 2002 entrou em funcionamento o novo Sistema de Pagamentos Brasileiro (SPB). Novas estruturas foram criadas para diminuir a possibilidade de crise sistêmica. A constituição 
de Clearings $^{18}$ (câmaras de ativos - moeda estrangeira, títulos de renda fixa ou títulos de renda variável - e de pagamentos) para garantir as operações nos diversos mercados, a impossibilidade de a Conta Reservas Bancárias ficar negativa durante o dia e a possibilidade de transferências on-line trouxeram mais segurança ao sistema financeiro forçando, mais uma vez, a revisão das práticas administrativas.

${ }^{18}$ Atualmente as Clearings existentes são: BMF-Câmbio, BMF-Derivativos, BMF-Ativos, CBLC, CETIP, CIP e TECBAN. 


\subsection{Formas de obtenção de liquidez}

Há três formas básicas de obtenção de recursos para as Instituições Financeiras (em periodos de crise ou não): operações no mercado interbancário, mercado internacional e as linhas de crédito do BACEN.

As Instituições Financeiras utilizam-se do Open Market (mercado secundário de títulos públicos e privados) para, via operações compromissadas (overnight), compor suas reservas bancárias. Convencionou-se chamar de mercado secundário ou Open Market o mercado em que os títulos são negociados após sua primeira colocação. O mercado primário é onde ocorre a primeira venda dos titulos pelo BACEN, por meio de leilões formais ou informais (go around, em que somente os dealers ${ }^{19}$ participam). As operações com títulos públicos federais, do Tesouro Nacional ou do Banco Central, são realizadas por meio do SELIC (Sistema Especial de Liquidação e Custódia) que controla e custodia os títulos e que está ligado diretamente ao DEMAB, subordinado à Diretoria de Política Monetária do BACEN. Estas operações podem ser de compra ou venda definitiva ou podem ser operacões compromissadas.

As operações compromissadas são uma das formas que os bancos possuem para administrar suas necessidades de caixa e reserva. São compostas por duas operações vinculadas: a primeira de venda (ou compra) de títulos, em $\mathrm{D}^{20}$, e a segunda (reversão) de compra (ou venda) dos mesmos títulos, em D+1, com a cobrança de uma taxa predeterminada pelas partes. Estas operações são liquidadas diretamente na conta de reservas bancárias.

As operações com títulos públicos da esfera estadual e municipal e com títulos privados são realizadas através de uma Clearing administrada pela CETIP (Central de Custódia e 
Liquidação Financeira de Títulos Privados). A CETIP realiza a custódia e liquidação financeira de diversos produtos: produtos de captação (CDB, RDB, CDI, Letra de Câmbio, etc), produtos de investimento (cotas de fundo de investimentos, contratos de negócios com ouro, cotas de fundos fechados, etc), produtos de capitalização/empréstimo (debêntures, export notes, commercial papers, etc), produtos de financiamento rural, produtos vinculados ao govemo e derivativos.

O Certificado de Depósito Interbancário (CDI ou DI) é um mecanismo de autoregulação das instituições financeiras. É um instrumento financeiro que permite a "troca" remunerada de reservas bancárias entre as instituições, servindo como um recurso para ajuste de reservas bancárias. As emissões do DI são exclusivamente escriturais, sendo obrigatório o registro e a liquidação financeira na CETIP. Existem limites de emissão (vinculados ao Patrimônio Líquido Ajustado - PLA) definidos por normativos do BACEN (Circular $\mathrm{n}^{\circ} 2.732$, de 1996).

Os bancos também possuem acesso a linhas de crédito internacionais. Podem contratar diretamente empréstimo no exterior bancos múltiplos (com carteira comercial, de investimento ou de desenvolvimento), bancos comerciais, bancos de investimento, bancos de desenvolvimento e o BNDES, sendo necessária a condição de "instituição autorizada a operar em câmbio". Os custos destes recursos são baseados na Libor mais um spread.

Na vigência da Resolução $n^{\circ} 63$, de 1967 , como os custos desta forma de captação eram baixos, os recursos captados tinham que ser aplicados em:

a) repasses interbancários;

${ }^{10}$ Dealers são instituições financeiras credenciadas a operar junto ao BACEN. 
b) operações de arrendamento mercantil;

c) aquisição de direitos creditórios oriundos de operações de crédito e de arrendamento mercantil, decorrentes de contratos celebrados no mercado interno, com variação cambial e lastreados nos recursos acima;

d) NBC-E, NTN-D e NTN-I'21;

e) depósitos constituídos em dólar em conta do BACEN junto a banqueiro no exterior.

Os recursos não repassados nestas formas ficavam depositados em moeda nacional no BACEN, sem remuneração.

Com a revogação da 63 (maneira informal pela qual era chamada esta resolução pelo mercado) pela Resolução $\mathrm{n}^{\circ} 2.770$, de 30 de agosto de 2000 , acabou-se com a obrigação de a instituição realizar os repasses mencionados.

Além dos empréstimos, há a possibilidade de obtenção de recurso por meio da emissão de títulos no exterior: notes (fixed rate notes, prefixados, e floating rate notes, flutuantes) e bônus. O termo bônus é usado para títulos com prazo superior a 10 anos e notes para títulos com prazo menor que 10 anos.

Após esgotar as formas anteriores de obtenção de recursos, quer para obter liquidez, quer para financiar saídas de caixa, o último recurso é o BACEN, tanto via DEMAB, quanto via DEBAN ${ }^{22}$.

\footnotetext{
${ }^{20} \mathrm{D} 0$ corresponde ao dia da operação original. $\mathrm{D}+\mathbf{n}$ corresponde ao n-ésimo dia útil após a operação original.

${ }^{21}$ NBC-E (notas do BACEN, tipo E); NTN-D e NTN-I (notas do Tesouro Nacional, tipo D e I) - são títulos públicos cambiais.
} 
Atualmente o BACEN disponibiliza mecanismos de liquidez intradia e overnight. Há quatro alternativas para obtenção de liquidez intradia:

a) recolhimento compulsório: a instituição pode utilizar seus depósitos compulsórios ao longo do dia para garantir que o saldo em reservas não fique negativo, sendo obrigada a recompô-los ao final do dia;

b) operações associadas: podem ser feitas operações associadas entre instituições com a finalidade de antecipar resultados de clearings.

c) mecanismo de resolução de Gridlocks: possibilidade de reordenamento da fila de lançamentos a crédito ou a débito em reservas;

d) Redesconto Intradia: operação compromissada entre o BACEN e a instituição financeira a taxa zero. Esta operação pode ser automaticamente convertida em uma operação de redesconto over na impossibilidade de não ser honrada.

Após a implementação do sistema de pagamentos, o DEMAB voltou a realizar operações compromissadas com prazo de um dia com as Instituições Financeiras (após as 17h) com a finalidade de conceder liquidez ao sistema ${ }^{23}$. Estas operações são realizadas a taxas intermediárias entre o interbancário e o redesconto, funcionando como um "redesconto alternativo" ${ }^{24}$.

Tradicionalmente, por apresentarem taxas acima das de mercado e por configurarem uma situação de potencial quebra, as linhas de redesconto são evitadas pelas instituições

\footnotetext{
${ }^{22}$ O DEMAB (Departamento de Operacões do Mercado Aberto) realiza operacões compromissadas com títulos públicos e o DEBAN (Departamento de Operações Bancárias e de Sistema de Pagamentos) realiza operações de redesconto.

${ }^{23}$ Estas operações são equivalentes às operações de "zeragem" realizadas pelo DEMAB em periodos anteriores.
} 
bancárias e somente são utilizadas em casos limites. Com exceção do período ${ }^{25}$ em que foram criadas as Taxas $\mathrm{TBC}^{26}$ e $\mathrm{TBAN}^{27}$, nos demais períodos, somente instituições com dificuldades é que solicitavam redesconto.

Tendo em vista que o cenário político e econômico sofre mudanças constantemente, há a necessidade, tanto para os investidores quanto para as autoridades monetárias, de se buscarem modelos para prever situações em que haja risco de quebra de um ou vários bancos. Neste contexto, torna-se fundamental avaliar os determinantes da demanda por reservas e a probabilidade de utilização das linhas de redesconto, em especial, por desempenhar um papel de sinalização para o BACEN, o Redesconto Over .

\footnotetext{
${ }^{24}$ Neste trabalho estas operaçōes serão chamadas de "operaçōes de nivelamento".

${ }^{25}$ Este período corresponde à vigência das Resoluçōes 2.288 , de 20 de junho de 1.996 , e 2308, de 28 de agosto de 1996.

${ }^{26}$ TBC é a sigla definida pela Resolução $n^{\circ} 2.288$ para Taxa Básica do Banco Central.

${ }^{27}$ TBAN é a sigla definida pela Resolução $\mathrm{n}^{\circ} 2.308$ para Taxa de Assistência do Banco Central.
} 


\section{Redesconto: do Plano Real ao novo Sistema de Pagamentos}

O normativo que regulava o redesconto no início do Plano Real era a Resolução $\mathrm{n}^{\circ}$ 1.786 , de $1^{\circ}$ de fevereiro de 1991 . Esta resolução criou duas linhas de assistência financeira: o Empréstimo de Liquidez e o Empréstimo Especial ${ }^{28}$.

A Resolução $n^{\circ} 1.786$ foi revogada pela Resolução $n^{\circ} 2.288$, de 20 de junho de 1996, que surtiria efeito nas operações realizadas ou repactuadas a partir de $1^{\circ}$ de julho de 1996 . Foram criadas duas modalidades de assistência financeira: o Empréstimo de Liquidez e o Empréstimo Especial de Médio Prazo. A novidade em relação à Res. $\mathrm{n}^{\circ} 1.786$ foi a criação do "Valor-Base" ${ }^{29}$ e a criação da TBC. Os encargos dependiam do valor da operação (em relação ao ValorBase), da freqüência de utilização e do tipo de garantias oferecidas. A Tabela 1 apresenta os valores definidos pela Res. $n^{\circ} 2.288$ para a modalidade de Empréstimo de Liquidez.

A taxa utilizada para as operações de redesconto era pré-fixada (TBC no caso de operações com titulos públicos federais livres) e não estava vinculada à Taxa SELIC. Assim, poderiam ocorrer situações em que as operações de redesconto seriam mais baratas que as operações realizadas no mercado secundário de títulos públicos. Isto de fato ocorreu no periodo de $1^{\circ}$ de julho de 1996 a 31 de dezembro de 1997. Neste período, o maior valor assumido pela TBC foi de 3,05\% a.a., enquanto que o menor valor da taxa SELIC foi de 18,78\% a.a. Em 2 de janeiro de 1998 a TBC foi elevada a um nível próximo à taxa SELIC, desestimulando a ocorrência de operações de Empréstimo de Liquidez. A taxa SELIC passou a oscilar em torno

\footnotetext{
${ }^{28}$ Um resumo dos normativos de redesconto contendo limites, prazos das operações, taxas e garantias encontra-se na Tabela 23.

${ }^{20}$ O Valor-Base foi definido como a média das exigibilidades de recolhimento compulsório/encaixe obrigatório sobre recursos à vista vigentes em periodos móveis de doze meses. Este valor era revisto no primeiro mês de cada trimestre civil, considerando o periodo encerrado no segundo mês do trimestre civil imediatamente anterior.
} 
do valor da TBC até 4 de setembro de 1998. A partir desta data, a TBC volta a descolar da taxa SELIC.

Tabela l-Resolução 2.288 - Encargos financeiros

\begin{tabular}{|c|c|c|c|}
\hline \multirow{2}{*}{$\begin{array}{l}\text { Freqüência de utilização, } \\
\text { considerado o período móvel } \\
\text { de } 60 \text { dias úteis }\end{array}$} & \multicolumn{3}{|c|}{ Garantias } \\
\hline & $\begin{array}{l}\text { Títulos públicos } \\
\text { federais livres, até o } \\
\text { valor-base }\end{array}$ & $\begin{array}{l}\text { Títulos públicos federais livres, } \\
\text { acima do valor-base, ou } \\
\text { garantias reais dadas por pessoa } \\
\text { fisica ou jurídica não financeira }\end{array}$ & Demais \\
\hline $\begin{array}{l}\text { A té } 15 \text { dias úteis, } \\
\text { consecutivos ou não }\end{array}$ & TBC & $\mathrm{TBC}+4 \%$ a.a. & $\mathrm{TBC}+8 \%$ a.a. \\
\hline $\begin{array}{l}\text { A cima de } 15 \text { e até } 30 \text { dias } \\
\text { úteis, consecutivos ou não }\end{array}$ & TBC & $\mathrm{TBC}+6 \%$ a.a. & $\mathrm{TBC}+9 \%$ a.a. \\
\hline $\begin{array}{l}\text { Acima de } 30 \text { dias úteis, } \\
\text { consecutivos ou não }\end{array}$ & TBC & $\mathrm{TBC}+8 \%$ a.a. & $\mathrm{TBC}+10 \%$ a.a. \\
\hline
\end{tabular}

Pouco depois de dois meses da publicação da Resolução $\mathrm{n}^{\circ} 2.288$, é publicada a Resolução $n^{\circ} 2.308$, em 28 de agosto de 1996 . Esta resolução teria efeitos a partir de $1^{\circ}$ de outubro de 1996 , data em que a Resolução $\mathrm{n}^{\circ} 2.288$ seria revogada (as operações em $\operatorname{ser}^{30}$ ainda manteriam as condições pactuadas).

Esta resolução fazia algumas alterações na Resolução $n^{\circ} 2.288$. São elas: 
a) Alteração na tabela de encargos financeiros do Empréstimo de Liquidez. Esta alteração é mostrada na Tabela 2.

b) Alteração dos encargos financeiros do Empréstimo Especial de Médio Prazo para TBAN mais $2 \%$ ao ano.

c) Definição do Valor-base. O valor-base passou a ser definido como a soma de percentual (a ser definido pelo BACEN) da média das exigibilidades de recolhimento compulsório/encaixe obrigatório sobre recursos à vista e percentual da média das exigibilidades de recolhimento compulsório/encaixe obrigatório sobre depósitos a prazo, recursos de aceites cambiais, cédulas pignoratícias de debêntures e titulos de emissão própria ${ }^{31}$.

${ }^{30}$ Operações em ser são operações que ainda não foram liquidadas.

${ }^{31}$ A Circular $n^{\circ} 2.712$, por exemplo, fixava en $100 \%$ o percentual de recolhimento compulsório e encaixe obrigatório sobre recursos à vista e em $30 \%$ o percentual da média das exigibilidades de recolhimento compulsório/encaixe obrigatório sobre depósitos a prazo, recursos de aceites cambiais, cédulas pignoratícias de debêntures e títulos de emissão própria. 
Tabela 2 - Resolução 2.308 - Encargos financeiros

\begin{tabular}{|c|c|c|c|c|}
\hline \multirow{2}{*}{$\begin{array}{l}\text { Freqüência de } \\
\text { utilização, considerado } \\
\text { o periodo móvel de } 60 \\
\text { dias úteis }\end{array}$} & \multicolumn{4}{|c|}{ Garantias } \\
\hline & $\begin{array}{l}\text { Títulos } \\
\text { públicos } \\
\text { federais livres, } \\
\text { até o valor-base }\end{array}$ & $\begin{array}{l}\text { Títulos públicos } \\
\text { federais livres, } \\
\text { acima do valor- } \\
\text { base }\end{array}$ & $\begin{array}{l}\text { Reais dadas por } \\
\text { pessoa física ou } \\
\text { jurídica não } \\
\text { financeira }\end{array}$ & Demais \\
\hline $\begin{array}{l}\text { A té } 15 \text { dias úteis, } \\
\text { consecutivos ou não }\end{array}$ & TBC & TBAN & TBAN $+2 \%$ a.a. & TBAN + 6\% a.a. \\
\hline $\begin{array}{l}\text { A cima de } 15 \text { e até } 30 \\
\text { dias úteis, consecutivos } \\
\text { ou não }\end{array}$ & TBC & TBAN & TBAN + $4 \%$ a.a. & TBAN + 7\% a.a. \\
\hline $\begin{array}{l}\text { Acima de } 30 \text { dias úteis, } \\
\text { consecutivos ou não }\end{array}$ & TBC & TBAN & TBAN $+6 \%$ a.a. & TBAN $+8 \%$ a.a. \\
\hline
\end{tabular}

Em 12 de agosto de 1998, é publicada a Circular $\mathrm{n}^{\circ} 2.830$. Esta circular marca o início da redução do valor-base. A partir $1^{\circ}$ de outubro de 1998 , os percentuais para o cálculo do valorbase passariam a ser de $15 \%$ para as duas bases de cálculo. As circulares seguintes (2.835, $2.841,2.849,2.856,2.866$ ) previam redução de $100 \%$ no valor-base (no período de 08 de 
setembro de 1998 a 04 de março de 1999), ou seja, as operações de Empréstimo de Liquidez passariam a ser "punitivas" 32 .

Em 04 de março de 1999, é extinto o valor-base (Circular n².869) e, a partir desta data, os encargos financeiros das duas linhas de crédito passam a ter como referência a Taxa SELIC.

O Empréstimo Especial de Médio Prazo passa a ter um encargo de SELIC mais $4 \%$ ao ano e o Empréstimo de Liquidez apresenta nova tabela (Tabela 3).

Tabela 3 - Circular 2.869 - Encargos Financeiros

\begin{tabular}{|c|c|c|c|}
\hline \multirow{2}{*}{$\begin{array}{l}\text { Freqüência de } \\
\text { utilização, considerado } \\
\text { o período móvel de } 60 \\
\text { dias úteis }\end{array}$} & \multicolumn{3}{|c|}{ Garantias } \\
\hline & $\begin{array}{l}\text { Títulos públicos } \\
\text { federais }\end{array}$ & $\begin{array}{l}\text { Reais dadas por pessoa } \\
\text { física ou jurídica não } \\
\text { financeira }\end{array}$ & Demais \\
\hline $\begin{array}{l}\text { A té } 15 \text { dias úteis, } \\
\text { consecutivos ou não }\end{array}$ & SELIC + $2 \%$ a.a. & SELIC $+4 \%$ a.a. & SELIC $+8 \%$ a.a. \\
\hline $\begin{array}{l}\text { A cima de } 15 \text { e até } 30 \\
\text { dias úteis, consecutivos } \\
\text { ou não }\end{array}$ & SELIC + $2 \%$ a.a. & SELIC $+6 \%$ a.a. & SELIC + 9\% a.a. \\
\hline $\begin{array}{l}\text { Acima de } 30 \text { dias úteis, } \\
\text { consecutivos ou não }\end{array}$ & SELIC $+2 \%$ a.a. & SELIC $+8 \%$ a.a. & SELIC + $10 \%$ a.a. \\
\hline
\end{tabular}

${ }^{32}$ Até então, desde a Resolução $\mathrm{n}^{\circ} 2.288$ e com a criação da TBC e posteriormente da TBAN, as operações de Empréstimo de Liquidez utilizando títulos públicos federais eram usadas para dar liquidez ao mercado (quando a 
O gráfico a seguir (Figura 1) compara os valores da TBC e da TBAN. No período de $1^{\circ}$ de julho de 1996 a 30 de setembro de 1996 só estão considerados os valores da TBC dado que a TBAN só passou a existir em $1^{\circ}$ de outubro de 1996. Verificamos que a TBAN é sempre maior que a TBC, o que era de se esperar considerando a estrutura de taxas de encargos financeiros. Observa-se um salto em 02 de janeiro de $1998,2,90 \%$ a a para $38 \%$ a.a para a TBC e de 3,15\% a.a. para $43,00 \%$ a.a. para a TBAN. Este salto é conseqüência da crise asiática ocorrida ao final do ano de 1997 e que trouxe muita instabilidade no mercado financeiro nacional.

Outra elevação da TBAN ocorre em setembro de 1998. No dia 03 de setembro ela aumenta para $29,75 \%$ a.a. (contra $25,75 \%$ do dia anterior) e no dia 11 de setembro ela sobe para 49,75\% a.a.. A TBC só volta a se aproximar da TBAN em 17 de dezembro quando passa 19 para $29 \%$ a.a. e a TBAN cai para $36 \%$ a.a. (já havia diminuído para $42,25 \%$ a.a. em 12 de novembro). Estas oscilações podem ser explicadas como sendo efeitos reflexos da crise russa no mercado financeiro nacional (as taxas aumentaram para conter a saida de capitais financeiros).

TBC era menor que a taxa SELIC). 
Figura 1 - TBC e TBAN

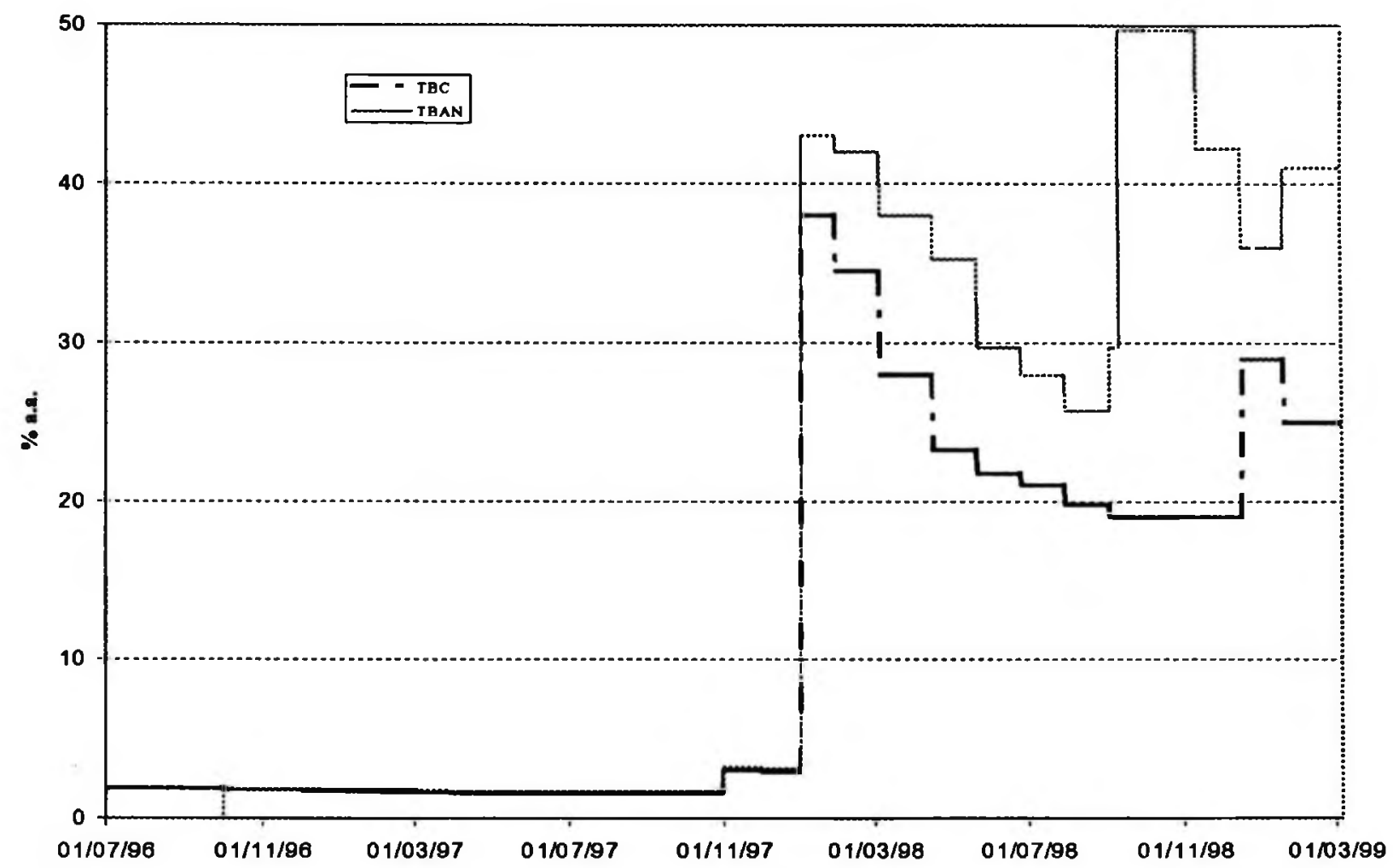

Tendo em vista as mudanças no sistema bancário em decorrência do projeto do Sistema de Pagamentos Brasileiro, em 26 de janeiro de 2000 foi publicada pelo BACEN a Resolução ${ }^{\circ}$ 2.685, que entraria em vigor no dia 14 de fevereiro do mesmo ano. Esta resolução institui o mecanismo de Redesconto nas modalidades de redesconto e compra, com compromisso de revenda, de títulos, de créditos e direitos creditórios integrantes do ativo dos bancos múltiplos com carteira comercial, dos bancos comerciais e das caixas econômicas.

A Tabela 23, no apêndice, traz um quadro com as principais características das modalidades de Redesconto descritas nesta seção. 
Ainda em decorrência do projeto do novo Sistema de Pagamentos, em 04 de abril de 2002 é publicada a Resolução $\mathrm{n}^{\circ}$ 2.949, que entraria em vigor em 22 de abril de 2002, revogando a Resolução $\mathrm{n}^{\circ} 2.685$ nesta data. Este é o período que será estudado no Capitulo 4 desta dissertação.

Essa resolução autorizava o BACEN a instituir o Redesconto, definindo duas modalidades: Redesconto e Compra com compromisso de revenda. Para regulamentar as operações de redesconto, foi publicada a Circular $\mathrm{n}^{\circ} 3.105$, de 05 de abril de 2002. O regulamento anexo definia que somente instituições financeiras titulares de conta Reservas Bancárias poderiam ter acesso às linhas de Redesconto. As operações foram definidas conforme a finalidade e o prazo:

a) intradia, destinada a atender necessidades de liquidez ao longo do dia;

b) de um dia útil, destinada a satisfazer necessidades de liquidez decorrentes de descasamento de curtíssimo prazo no fluxo de caixa;

c) de até quinze dias úteis, podendo ser recontratadas desde que o prazo total não ultrapasse quarenta e cinco dias úteis, destinada a satisfazer necessidades de liquidez provocadas pelo descasamento de curto prazo no fluxo de caixa e que não caracterizem desequilíbrio estrutural;

d) de até noventa dias corridos, podendo ser recontratadas desde que o prazo total não ultrapasse cento e oitenta dias corridos, destinadas a viabilizar o ajuste patrimonial de instituição com desequilibrio estrutural. 
As operações intradia e de até um dia são realizadas por meio de mensagens específicas constantes do Catálogo de Mensagens do SPB. As operações de até quinze dias úteis e de até noventa dias corridos exigem apresentação de documentação prévia para sua autorização. A modalidade de Redesconto restringe-se apenas às operações de até quinze dias úteis e de até noventa dias corridos e as operações intradia e de um dia útil contemplam exclusivamente títulos públicos federais.

Com relação à Compra com compromisso de revenda, a circular define os ativos que podem ser usados nesta modalidade:

a) títulos públicos federais registrados no SELIC, que integrem a posição de custódia própria da instituição;

b) outros titulos e valores mobiliários, créditos e direitos creditórios, preferencialmente com garantia real, e outros ativos.

Com relação aos títulos públicos federais, o BACEN divulgará diariamente os títulos aceitos nas operações ${ }^{33}$ e o preço de compra destes títulos. O preço de revenda nas operações intradia é o mesmo da compra. Nas operações de até um dia útil, o preço de revenda corresponde ao preço de compra acrescido da taxa fixada e válida na data da realização da operação. Quanto aos outros ativos que podem ser entregues como garantias, foram definidos alguns parâmetros para que o BACEN, a seu critério, determine o preço de compra e de revenda $O$ preço de compra varia conforme os ativos levando-se em conta o valor presente, $O$ valor de mercado, o risco de crédito, o prazo de vencimento, a liquidez e a volatilidade do preço de cada ativo, não podendo ser superior ao valor nominal atualizado. $\mathrm{O}$ preço de revenda

\footnotetext{
${ }^{33}$ Conforme a Carta-Circular n ${ }^{\circ} 3.009$, de 19 de abril de 2002.
} 
corresponde ao preço de compra acrescido da taxa SELIC mais a sobretaxa definida para o dia, com apuração diária.

A Carta-Circular $\mathrm{n}^{\circ} 3.009$, de 19 de abril de 2002 , define procedimentos operacionais para a realização das operações de redesconto. Foram fixados horários para a realização das operações $^{34}$ : para a operação intradia, das $6 \mathrm{~h} 30$ às $18 \mathrm{~h} 15$, para a operação de até um dia útil, das $17 \mathrm{~h} 45$ às $18 \mathrm{~h} 30$. Para as operações de até quinze dias úteis e de até noventa dias corridos, o horário é das $6 \mathrm{~h} 30$ às $18 \mathrm{~h} 30$, havendo necessidade de comunicacão até às $16 \mathrm{~h}$. Além disso, são apresentados exemplos de como são feitos os cálculos dos PUs de ida e de volta das operações.

A modalidade de Redesconto contempla títulos e valores mobiliários e direitos creditórios descontados integrantes do ativo da instituição financeira observando os mesmos critérios de avaliação de preço utilizados nas operações de compra com compromisso de revenda que não são realizadas com títulos públicos federais.

A Circular $n^{\circ} 3.120$, de 19 de abril de 2002, define as taxas a serem usadas nas operações de redesconto. São elas: Taxa SELIC mais $1 \%$ a.a. para operações de até um dia útil, Taxa SELIC mais $4 \%$ a.a., para operações de até quinze dias úteis e Taxa SELIC mais $2 \%$ a.a. para operações de até noventa dias corridas.

Esta mesma circular prevê alteração da taxa para as operações de até um dia útil que passaria a ser, a partir de primeiro de julho de 2002 , a Taxa SELIC acrescida de $6 \%$ a.a.

\footnotetext{
${ }^{34}$ Estes horários estão relacionados com a grade geral de horários que leva em consideração, além de outras coisas, os horários definidos para as compensações de cheques (diurnas e noturnas) e para o cumprimento de depósitos compulsórios.
} 


\section{CAPÍTULO 3 - MODELO DE DEMANDA POR REDESCONTO}

Este capitulo apresenta um modelo de demanda por reservas e um modelo de demanda por redesconto para um banco com carteira comercial. A hipótese fundamental do modelo de demanda por reservas é que o saldo da conta de reservas bancárias é um processo estocástico de Lévy $^{35}$. O modelo para o redesconto baseia-se na hipótese de que a demanda por redesconto ${ }^{36}$ segue o mesmo comportamento da demanda por reservas. A primeira seção traz uma breve descrição da literatura utilizada para a elaboração dos modelos, iniciando pelos modelos de gerenciamento intradia, passando para considerações sobre modelos de gerenciamento de saldo ao final do dia e finalizando com modelos sobre redesconto. Na seção seguinte será apresentado o modelo de demanda por reservas. Finalizando este capitulo, será formulado o modelo de redesconto que servirá como base para a investigação empírica do capítulo 5.

\subsection{Revisão da Literatura}

\subsubsection{Modelos de demanda por moeda}

Bar-Пlan (2004) sugere uma divisão dos modelos de demanda por moeda em duas categorias: modelos de demanda por moeda pelas famílias e modelos de demanda por moeda pelas firmas.

\footnotetext{
${ }^{35}$ Bar-Ilan (2004).

${ }^{36}$ Entende-se redesconto como toda operação compromissada de um dia realizada após o encerramento das atividades do mercado (após as 17h) e antes do fechamento da janela de operações do BACEN (até às 18h30). Como será discutido adiante, compreende duas operações: o Redesconto Over e as operações de "nivelamento" realizadas pelo DEMAB.
} 
Os modelos com base na demanda por moedas pelas familias têm origem nos artigos de Baumol (1952) e Tobin (1956). Estes modelos assumiam que o comportamento do indivíduo era racional e que as operações eram totalmente previsíveis. Havia um fluxo de gastos das famílias até que um nível mínimo fosse atingido. Quando este nível fosse atingido, ativos seriam convertidos em dinheiro para se iniciar um novo ciclo. Frenkel and Jovanovic (1980), Bar-Ilan (1990) e Chang (1999) propuseram extensões a estes modelos, inserindo variáveis estocásticas e o estoque de moeda seguiria um movimento browniano. Estes modelos, na terminologia da teoria de controle são chamados "one trigger - one target".

A segunda categoria de modelos teve origem no trabalho de Miller e Orr (1966). A diferença entre firmas e famílias é que, além dos gastos, as firmas possuem entradas de dinheiro em seu fluxo de caixa e há um maior número de transações financeiras. A hipótese de que o estoque de moeda segue um movimento browniano não é adequada dada a existência de transações de grande valor. Estes modelos são do tipo "two triggers - two targets".

Baseados nos princípios de seu artigo anterior de 1980, que teve como base os artigos de Baumol (1952) e Tobin (1956) e que incorporou alguns aspectos de Miller e Orr (1966), Frenkel e Jovanovic (1981) desenvolvem um modelo de demanda por reservas internacionais com ênfase no caráter estocástico das transações internacionais e nos recebimentos de moeda certos (não estocásticos). Assumem a hipótese de que variações nas reservas podem ser caracterizadas por uma equação estocástica (hipótese de que é um processo de Wiener) cujo resultado é que o saldo em reservas segue uma distribuição normal com média dada pelo saldo inicial do estoque de reservas descontado de uma tendência determinística e variância sendo uma função linear do tempo. A determinação do estoque ótimo de reservas leva em conta duas componentes de custo: o custo de ajustamento das reservas quando estas atingem um valor abaixo de um valor desejado 
(assume que este valor é zero) e recebimentos certos nas reservas. $O$ resultado final obtido para o estoque ótimo de reservas é que ele é proporcional ao custo fixo de ajustamento e inversamente proporcional à taxa de custo de se manter as reservas por unidade de tempo.

Bar-Ilan, Perry e Stadje (2004) apresentam um modelo geral de gerenciamento de reservas (demanda por dinheiro), com base em modelos de gerenciamento em reservas internacionais $^{37}$, considerando que o gerenciamento de reservas é um problema de controle ótimo de um processo estocástico do fluxo de dinheiro. Diferentemente da hipótese utilizada por Frenkel e Jovanovic (1981), consideram a hipótese de que o fluxo de caixa segue um processo estocástico de Lévy $^{38}$ dado pela composição de um Movimento Browniano (BM) com um Processo Composto de Poisson (CPP), elaboram um modelo de impulse control band (ICB). Este modelo considera a existência de dois níveis de operação e dois gatilhos, que são determinados pela minimização da função de custo esperado descontado. As penalizações existentes para o caso de a conta ficar negativa justificariam a existência do nivel inferior da banda, enquanto que o custo de oportunidade de não se emprestar o dinheiro justificaria a existência do nível superior.

Um resultado obtido para este modelo é de que tanto o nível ótimo do limite superior da banda quanto a função de custo são funções da volatilidade, resultado que é consistente com o de Frenkel e Jovanovic (1981). Outro resultado interessante é o de que, dado os gatilhos, os limites da banda podem ser escolhidos livremente e há um nível ótimo no qual as metas de saldo inferior e superior são iguais. Assim, não haveria uma faixa de operação, apenas dois gatilhos.

\footnotetext{
${ }^{37}$ Frenkel e Jovanovic (1981).

${ }^{38}$ Bar-Ilan et al. (2004) considera que o processo de Wiener não é adequado dado os "saltos" que podem ocorrer nas reservas.
} 


\subsubsection{Modelos de gerenciamento do saldo em reservas ao final do dia}

Dado que no Brasil o compulsório sobre Recursos à Vista tem período de cumprimento quinzenal, parece razoável esperar que as instituições apresentem uma certa regularidade na maneira de administrar os excessos ou deficiências diárias quanto à exigibilidade. Clouse e Dow (2002) propõem um modelo de administração ótima de reservas para bancos baseado na legislação vigente nos Estados Unidos. Seu modelo tem como hipóteses: (i) periodo de cumprimento de catorze dias, (ii) tratamento para finais de semana ${ }^{39}$; (iii) considera as regras de carryover $^{40}$; (iv) não há intersecção entre periodo de cálculo e periodo de cumprimento ${ }^{41}$; e (v) banco representativo. O modelo é resolvido por programação dinâmica com horizonte infinito. Os resultados obtidos foram: (i) o nível de reservas é significativamente baixo às sextas-feiras; (ii) houve uma pequena tendência (positiva) na demanda esperada por reservas durante 0 período de cumprimento; e (iii) há um aumento considerável na demanda por reservas no último dia do periodo de cumprimento.

Costa Pinto e Coelho (2004) aplicam a metodologia usada por Clouse e Dow (2002) para - Brasil, alterando hipóteses para atender a nossa legislação. O resultado da simulação mostra que os três primeiros dias do periodo de cumprimento possuem saldos superiores à média do período (no primeiro dia o saldo é maior que no segundo e no terceiro dias). Este efeito é

\footnotetext{
${ }^{39}$ Considera que o saldo de sábado e de domingo são definidos como iguais ao da sexta-feira que os antecede. Assim, a sexta-feira teria peso 3 nos cálculos.

${ }^{40}$ Uma tradução para a expressão carryover é "carregamento". Neste trabalho preferimos manter o termo em inglês. Carryover é a possibilidade de aproveitar o excesso de reservas (carryover positivo) ou poder compensar a falta de reservas (carryover negativo) do periodo anterior no periodo atual. Nos Estados Unidos são permitidos os dois tipos de carryover, enquanto que no Brasil apenas o carnyover positivo é permitido, dentro de limites definidos em normativos.

${ }^{41}$ No Brasil, os três primeiros dias do periodo de cumprimento coincidem com os três últimos dias do período de cálculo. Dessa forma, os bancos trabalham com estimativas para estes dias.
} 
reflexo da incerteza causada pela superposição dos periodos de cálculo e de cumprimento ${ }^{42}$. Os dois últimos dias também estão acima da média, indicando um efeito de compensação para atingir a exigibilidade do período. De uma forma mais geral o resultado é uma curva com forma de "U".

Borio (2001) elabora um modelo baseado na demanda por reservas e na oferta de recursos pelo banco central. A demanda por reservas está associada às exigências por parte do banco central com relação aos saldos em reserva. Discute a sensibilidade da demanda por reservas com relação à taxa de juros e propõe que no final do periodo de cumprimento a demanda por reservas converge para a média de reserva exigida. A margem de manobra na fase final do período de cumprimento torna-se cada vez mais restrita. Com relação à oferta de recursos pelo banco central, preocupa-se com dois aspectos: como ajustar a liquidez do sistema por meio do equilíbrio entre demanda e oferta de recursos; e como reforçar a influência que os ajustamentos de liquidez podem ter nas taxas de juros através dos mecanismos de sinalização aos participantes do mercado.

\subsubsection{Modelos de demanda por redesconto}

Peristiani (1994) propõe um modelo para o comportamento individual de um banco. Cada banco possui uma demanda nocional por crédito que é influenciada por fatores do mercado financeiro como taxa de redesconto e expectativas de taxa de juros. A demanda nocional é positiva e as instituições bancárias sempre buscam tomar empréstimos junto ao FED. Para conter esse desejo, o FED deve estabelecer normas para o acesso ao redesconto. Dadas estas regras formais, cada banco procura otimizar o uso do redesconto baseado em sua avaliação

\footnotetext{
${ }^{42}$ Os autores também fazem uma simulação para o caso em que não há superposição dos periodos chegando ao resultado de que o nivel de reservas é inferior à média para os três primeiros dias do período de cumprimento. $O$
} 
dos ganhos líquidos que poderá obter com a tomada dos recursos. Um banco realizará uma operação de redesconto quando sua demanda nocional exceder seu valor de reserva.

Em seu modelo inicial, o autor considera a situação em que o FED solicita garantias para empréstimos acima de um determinado valor $\left(\mathrm{C}_{\mathrm{t}}\right)$. Na apresentação do modelo que será testado, apesar de reconhecer que a demanda nocional poderá ser viesada a menor, o limite superior $\left(\mathrm{C}_{\mathrm{i}}\right)$ é retirado (considera-se que $\mathrm{C}_{\mathrm{t}}$ tende a infinito)

Uma observação importante diz respeito à escolha do momento da realização da operação. Conforme Angelini (2000), a escolha do momento da operação no mercado interbancário depende de informações sobre duas variáveis: o valor final do fechamento das clearings ou câmaras de compensação e da taxa de juros de curto prazo. Quando a principal fonte de incerteza é a taxa de juros de curto prazo, as instituições financeiras tendem a operar próximo ao final da janela de operações, quando o fechamento das clearings já foi observado. A situação inversa também vale, ou seja, quando a taxa do interbancário é mais volátil as operações são realizadas no início da janela quando as operações a crédito ou a débito ainda não foram realizadas.

\subsection{Um modelo de demanda por reservas}

Modelos de nivel ótimo de reservas internacionais ${ }^{43}$ baseados na administração dos balanços utilizam a hipótese de que o primeiro elemento que determina o nivel de reservas internacionais é o processo estocástico que governa os pagamentos e recebimentos. Dada a 
natureza similar, para modelar a demanda por reservas de instituições financeiras, utilizaremos a mesma hipótese, definindo qual o processo que governa os pagamentos e recebimentos da conta de Reservas.

Dada as características de cada tipo de lançamento e seu efeito nas reservas ao longo da janela de operações, formulamos a primeira hipótese do modelo.

HIPÓTESE 1: O saldo da conta de Reservas Bancárias ao longo de um dia $i$ é um processo estocástico definido pela combinação de dois Processos de Lévy: é a composição de um Movimento Browniano Padrão com um Processo de Poisson Composto.

Conforme determinação do BACEN, a instituição financeira não pode ter saldo negativo em nenhum momento do dia. A conta de reservas poderia ficar negativa por questões de descasamento entre recebimentos e pagamentos no fluxo de caixa. Para esta situação existem quatro soluções (utilização de compulsórios, operações associadas, redesconto intradia e mecanismo de resolução de gridlocks), todas associadas à liquidez intradia. Este tipo de demanda por reservas só é relevante para o nosso trabalho quando corresponde a um descasamento com periodo de pelo menos um dia.

HIPÓTESE $2^{44}$ : A instituição financeira toma a decisão ou avalia a quantidade de reservas necessárias apenas uma vez em cada dia e simultaneamente realiza a operação (SELIC ou Over).

\footnotetext{
${ }^{44}$ Exclui a possibilidade de reavaliações ou de um processo contínuo de avaliação.
} 
Assim, para um dia $j::^{45}$

\begin{tabular}{|l|ll|} 
& & \\
\hline & & \\
$R_{j}^{0}$ & $R_{j}^{\prime}$ & $R_{j}^{F}$ \\
$t_{0}$ & $t$ & $t_{F}$ \\
& & $G_{j}^{F}$
\end{tabular}

onde

$t_{0}$ é o horário de abertura da janela de operações diária;

$t_{F}$ é o horário de fechamento da janela de operações diária;

t é o momento da avaliação/decisão da necessidade de reservas (momento da operação de redesconto over ou operação com o SELIC) ${ }^{46}$;

$R_{j}^{0}$ é o saldo em reservas no instante $t_{0}$ do dia $j$, ou seja, é o saldo inicial em $j$;

$R_{j}^{t}$ é o saldo em reservas no instante $t$ do dia $j$;

$R_{j}^{F}$ é o saldo em reservas no instante $t_{F}$ do dia $j$, ou seja, é o saldo final em $j$;

$G_{j}^{F}$ é a meta para o saldo em reservas no dia $j^{47}$;

\footnotetext{
${ }^{45}$ Valimaki (2001).

${ }^{46}$ Angelini (2000) discute a escolha do momento da operacão pela instituição financeira. Quanto mais próximo da abertura da janela, melhor é a taxa e maior é a incerteza sobre o saldo final.

${ }^{47}$ Esta meta pode ser dada por modelos como os de Clouse e Dow (2002) ou Costa Pinto e Coetho (2004).
} 
com

$R_{j}^{0}=R_{j-1}^{F}$

$t_{0}<t<t_{F}{ }^{48}$

Temos dois intervalos de tempo na janela de operação.

(1) Para o intervalo $\alpha \equiv\left[t_{0} ; t\right]$

$R_{j}^{t}=R_{j}^{0}+U_{\alpha}+R_{j}^{P \alpha(+)} \cdot P_{\alpha}^{(+)}-R_{j}^{P \alpha(-)} \cdot P_{\alpha}^{(-)}=R_{j-1}^{F}+U_{\alpha}+R_{j}^{P \alpha(+)} \cdot P_{\alpha}^{(+)}-R_{j}^{P \alpha(-)} \cdot P_{\alpha}^{(-)}$

onde

$U_{\alpha} \sim N\left(\mu_{\alpha}, \sigma_{\alpha}^{2}\right)$

$P_{\alpha}^{(+)} \sim \operatorname{Poisson}\left(\lambda_{\alpha}^{(+)}\right)$

$P_{\alpha}^{(-)} \sim \operatorname{Poisson}\left(\lambda_{\alpha}^{(-)}\right)$

$R_{j}^{P \alpha(+)}$ é a média dos lançamentos a crédito na RB no intervalo $\alpha$

$R_{j}^{P \alpha(-)}$ é a média dos lançamentos a débito na RB no intervalo $\alpha$

A equação [2] mostra que o saldo em reservas em um dado momento do dia $j$ é igual ao saldo final em reservas do dia $j-1$ mais uma componente aleatória com média não

${ }^{48}$ Poderia ser $t_{0} \leq t \leq t_{F}$ (HIPÓTESE 2). 
necessariamente nula ${ }^{49}$, que representa o Movimento Browniano Padrão, e dois termos, um representado os lançamentos a crédito e outro os lançamentos a débito nas reservas bancárias, que representam a componente do Processo de Poisson Composto.

(2) Para o intervalo $\beta \equiv\left[t ; t_{F}\right]$

$$
R_{j}^{F}=R_{j}^{t}+U_{\beta}+R_{j}^{P \beta(+)} \cdot P_{\beta}^{(+)}-R_{j}^{P \beta(-)} \cdot P_{\beta}^{(-)}
$$

onde

$U_{\beta} \sim N\left(\mu_{\beta}, \sigma_{\beta}^{2}\right)$

$P_{\beta}^{(+)} \sim \operatorname{Poisson}\left(\lambda_{\beta}^{(+)}\right)$

$P_{\beta}^{(-)} \sim$ Poisson $\left(\lambda_{\beta}^{(-)}\right)$

$R_{j}^{P \beta(+)}$ é a média dos lançamentos a crédito na $\mathrm{RB}$ no intervalo $\beta$

$R_{j}^{P \beta(-)}$ é a média dos lançamentos a débito na $\mathrm{RB}$ no intervalo $\beta$

A demanda por reservas no dia $j$ é dada pela diferença entre a meta de fechamento e a expectativa do saldo final do dia no momento da decisão.

$D_{j}=-\min \left(0, \underset{t}{E}\left[R_{i}^{F}\right]-G_{j}\right)$

Substituindo [3] em [4]:

\footnotetext{
${ }^{49}$ Uma restrição ao valor da média será aplicada pela Hipótese 3.
} 
$D_{j}=-\min \left(0, \underset{t}{E}\left[R_{j}^{\prime}+U_{\beta}+R_{j}^{P \rho(+)} \cdot P_{\rho}^{(+)}+R_{j}^{P \rho(-)} \cdot P_{\beta}^{(-)}\right]-G_{j}\right)$

E substituindo [2] em [5]:

$D_{j}=-\min \left(0, \underset{t}{E}\left[R_{j-1}^{F}+U_{\alpha}+R_{j}^{P \alpha(+)} \cdot P_{\alpha}^{(+)}+R_{j}^{P \alpha(-)} \cdot P_{\alpha}^{(-)}+U_{\beta}+R_{j}^{P \beta(+)} \cdot P_{\beta}^{(+)}+R_{j}^{P \beta(-)} \cdot P_{\beta}^{(-)}\right]-G_{j}\right)$

Calculando a esperança, temos:

$D_{j}=-\min \left(0, R_{j-1}^{F}+\mu_{\alpha}+R_{j}^{P \alpha(+)} \cdot \lambda_{\alpha}^{(+)}+R_{j}^{P \alpha(-)} \cdot \lambda_{\alpha}^{(-)}+\mu_{\beta}+R_{j}^{P \beta(+)} \cdot \lambda_{\beta}^{(+)}+R_{j}^{P \beta(-)} \cdot \lambda_{\beta}^{(-)}-G_{j}\right)$

A equação [6] corresponde à equação geral da demanda por reservas.

Serão necessárias mais algumas hipóteses para chegar à equação a ser estimada ${ }^{50}$ no capitulo 4.

HIPÓTESE 3: IFs não são "sistematicamente devedoras ou credoras”, ou seja,

$\mu_{\alpha}=\mu_{\beta}=0$

e, portanto,

$U_{\alpha} \sim N\left(0, \sigma_{a}^{2}\right)$

$U_{\beta} \sim N\left(0, \sigma_{\beta}^{2}\right)$

Assim,

$D_{i}=-\min \left(0, R_{j-1}^{P}+R_{j}^{P \alpha(+)} \cdot \lambda_{\alpha}^{(+)}+R_{j}^{P \alpha(-)} \cdot \lambda_{\alpha}^{(-)}+R_{j}^{P \beta(+)} \cdot \lambda_{\beta}^{(+)}+R_{j}^{P \beta(-)} \cdot \lambda_{\beta}^{(-)}-G_{j}\right)$

${ }^{s 0}$ Hipóteses para que a dernanda não dependa do momento $t$ e dos intervalos $\alpha$ e $\beta$. 
HIPÓTESE 4: A freqüência de ocorrência dos lançamentos $v$ e o valor médio dos lançamentos a crédito ou a débito é igual para os 2 períodos.

Definindo o parâmetro $\lambda$ como $\lambda=v \cdot t$, se $v_{\alpha}=v_{\beta}=v_{i}$, temos:

$\lambda_{\alpha}+\lambda_{\beta}=\lambda_{i}$, onde $\lambda_{i}$ é o parâmetro da distribuição de Poisson para todo a janela de operações do dia $j$. Logo,

$$
R_{j}^{P \alpha(+)}=R_{j}^{P \beta(+)}=R_{j}^{(+)} \quad R_{j}^{P \alpha(-)}=R_{j}^{P \beta(-)}=R_{j}^{(-)}
$$

Assim,

$$
D_{j}=-\min \left(0, R_{j-1}^{F}+R_{j}^{(+)} \cdot \lambda_{j}^{(+)}+R_{j}^{(-)} \cdot \lambda_{j}^{(-)}-G_{j}\right)
$$

A equação [8] corresponde à equação da demanda por reservas, sob as hipóteses 1 a 4.

\subsection{Um modelo de demanda por redesconto}

Para obtermos a demanda por redesconto precisamos de uma hipótese adicional.

HIPÓTESE 5: A demanda por redesconto segue um comportamento similar ao da demanda por reservas.

Disso decorre:

$$
W_{j}=D_{j}=-\min \left(0, R_{j-1}^{F}+R_{j}^{(+)} \cdot \lambda_{j}^{(+)}+R_{j}^{(-)} \cdot \lambda_{j}^{(-)}-G_{j}\right)
$$


onde

$W_{j}$ é a demanda por redesconto no dia $i$.

\section{A equação [9] será estimada no Capitulo 5.}

Essa hipótese é conseqüência de uma questão empírica ${ }^{51}$. Conforme descrito no Capitulo 2, há várias altemativas ao redesconto. Em relação ao redesconto over, as alternativas são as operações realizadas pelo $\mathrm{DEMAB}^{52}$ e as operações no mercado interbancário. Para definir as operações de nivelamento realizadas pelo DEMAB e associá-las ao redesconto over, foi utilizado um critério de corte no horário de operações (as operações após às $17 \mathrm{~h}$ seriam operações de nivelamento). Isto foi possível graças a distribuição das operações ao longo da janela de operações. Para o mercado interbancário não foi possível fazer a distinção entre operações "normais" e operações cuja finalidade era a de obter liquidez por um dia.

\footnotetext{
SI Uma outra hipótese aceitável é a de que a demanda por reservas é totalmente atendida pelas operacões de redesconto. Esta é uma hipótese mais restritiva, razão pela qual não foi utilizada.

${ }^{52}$ No Capitulo 5, veremos que estas operações são financeiramente importantes.
} 


\section{CAPÍTULO 4 - MODELOS ECONOMÉTRICOS}

Estimaremos modelos de variável dependente binária (Probit e Logit), de variável limitada (Tobit) e variável dependente limitada considerando problemas de seleção (Heckit). Os dados utilizados têm estrutura de painel, ou seja, são observados diariamente um conjunto de 122 bancos ao longo do periodo 24 de abril de 2002 a 31 de agosto de 2004 .

Assim, neste capítulo serão apresentados os modelos de painel utilizados no trabalho (exceto para o modelo Heckit). Não serão discutidas as versões dos modelos para um único período de tempo. A apresentação segue, basicamente, Wooldridge (2002).

\subsection{Modelos Probit com dados em painel}

Os modelos Probit com dados em painel podem ser classificados em dois grupos:

a) sem características não observáveis:

O modelo Probit sem características não observáveis é dado pela equação:

$$
P\left(y_{i t}=1 / x_{i}\right)=P\left(y_{i t}=1 / x_{i t}\right)=\Phi\left(x_{i t} \beta\right)
$$

onde

$y$ é uma variável dependente binária;

$x$ é um vetor de variáveis explicativas; 
of é um vetor de coeficientes; e

$\Phi($.$) é a função de distribuição acumulada de uma variável aleatória com distribuição$ normal padrão, cuja função de densidade $\phi($.$) é dada por$

$$
\phi(z) \equiv \frac{1}{\sqrt{2 \pi}} \cdot e^{\frac{-z^{2}}{2}}
$$

Para este modelo, o estimador Pooled Probit é um estimador $\sqrt{N}$-consistente de $\beta$ e os efeitos marginais são obtidos de forma usual (neste caso é necessário calcular os erros padrão robustos). Esse estimador será utilizado no Capitulo 5.

b) com características não observáveis

O modelo Probit com caracteristicas não observáveis é dado pela equação:

$$
P\left(y_{i f}=1 / x_{i}, c_{i}\right)=P\left(y_{i f}=1 / x_{i r}, c_{i}\right)=\Phi\left(x_{i \ell} \beta+c_{i}\right)
$$

onde

$c$ é o efeito não observado.

A primeira igualdade da equação [11] diz que $\boldsymbol{x}_{i t}$ é estritamente exógeno condicionalmente em $c_{i}$. Isto exclui a possibilidade de variáveis dependentes defasadas no vetor $x_{i t}$.

Outras hipóteses adotadas são:

H1: $y_{i 1}, \ldots, y_{i T}$ são condicionalmente independentes em $\left(x_{i}, c_{i}\right) ; \mathrm{e}$ 
H2: $c_{i} / x_{i} \sim \operatorname{Normal}\left(0, \sigma_{c}^{2}\right)$.

Wooldridge (2002) apresenta seis estimadores para o modelo Probit com efeitos não observáveis:

1) Probit com efeitos fixos: $c_{i}$ necessita ser estimado conjuntamente com $\beta$, o que causa problemas de parâmetro incidental. Neste caso, os estimadores de $\beta$ são inconsistentes (este estimador não será utilizado nesta dissertação);

2) Probit com efeitos aleatórios: $c_{i}$ não faz parte da função de verossimilhança ${ }^{53}$ e, dessa forma, sob as hipóteses $\mathrm{H} 1$ e $\mathrm{H} 2, \beta$ e $\sigma_{c}^{2}$ são estimados consistentemente. A importância relativa do efeito não observado é medida por

$$
\rho \equiv \frac{\sigma_{c}^{2}}{\sigma_{c}^{2}+1}
$$

Este estimador será utilizado no Capítulo 5.

3) Pooled Probit: Este estimador de $\beta$ é consistente somente se $\sigma_{c}^{2}=0$, isto é, somente na ausência da componente não observável. É interessante observar que, mesmo na presença do componente não observável, os efeitos parciais médios são obtidos de maneira correta.

4) Generalized Estimating Equations (GEE): Neste estimador não se assume a hipótese H1. Especifica-se a variância de $y_{i}$ condicional a $x_{i}$ e estima-se $E\left(y_{i t} / x_{i t}\right)$ por Mínimos Quadrados Multivariados Ponderados Não-Linear ${ }^{54}$. O estimador de $\beta$ é consistente.

${ }^{53}$ A função de verossimilhança é dada por uma integral em relação à c. Ver Wooldridge (2002). 
5) Conditional MLE: H1 não é assumido. Assume-se uma distribuição para os erros e estima-se diretamente $y_{t} / x_{i t}$. Para $\mathrm{T}$ grande 0 problema é computacionalmente intensivo.

6) Variantes do modelo de Chamberlain: Modela-se $c_{i} / x_{i}$ e estima-se diretamente. Mundlak (1980) sugere a hipótese de normalidade de $c_{i} / x_{i}$ :

$$
c_{i} / x_{i} \sim \operatorname{Normal}\left(\psi+\bar{x}_{i} \xi, \sigma_{a}^{2}\right)
$$

onde

$\bar{x}_{i}$ é a média de $x_{i s}$;

$\sigma_{a}^{2}$ é variância de $a_{i}$ na equação $c_{i}=\psi+\bar{x}_{i} \xi+a_{i}$.

\subsection{Modelos Logit com dados em painel}

Da mesma forma que nos modelos Probit com dados em painel, os modelos Logit com dados em painel podem ser classificados em dois grupos:

a) sem características não observáveis:

O modelo Logit sem características não observáveis é dado pela equação:

$$
P\left(y_{i t}=1 / x_{i}\right)=P\left(y_{i t}=1 / x_{i t}\right)=\Lambda\left(x_{i t} \beta\right)
$$


onde

$\Lambda($.$) é a função de distribuição acumulada de uma variável aleatória com distribuição$ logística:

$$
\Lambda(z) \equiv \frac{e^{z}}{1+e^{z}}
$$

Da mesma forma que o estimador Pooled Probit, o estimador Pooled Logit é um estimador $\sqrt{N}$ - consistente de $\beta$ e os efeitos marginais são obtidos de forma usual (neste caso é necessário calcular os erros padrão robustos). Esse estimador será utilizado no Capitulo 5.

b) com características não observáveis:

O modelo Logit com características não observáveis é dado pela equação:

$$
P\left(y_{i t}=1 / x_{i}, c_{i}\right)=P\left(y_{i t}=1 / x_{i t}, c_{i}\right)=\Lambda\left(x_{i t} \beta+c_{i}\right)
$$

Como na equação [11], a primeira igualdade da equação [13] diz que $x_{i t}$ é estritamente exógeno condicionalmente em $c_{i}$.

Outras hipóteses adotadas são:

$\mathrm{H} 1: y_{i 1}, \ldots, y_{i T}$ são condicionalmente independentes em $\left(x_{i}, c_{i}\right) ; \mathrm{e}$

$\mathrm{H} 2: c_{i} / x_{i} \sim \operatorname{Normal}\left(0, \sigma_{c}^{2}\right)$.

Wooldridge (2002) descreve três estimadores para o modelo Logit com efeitos não observáveis: 
1) Logit com efeitos aleatórios: $c_{l}$ não faz parte da função de verossimilhança ${ }^{55}$ e, dessa forma, sob as hipóteses $\mathrm{H} 1$ e $\mathrm{H} 2, \beta$ e $\sigma_{c}^{2}$ são estimados consistentemente. Este estimador será utilizado no Capítulo 5.

2) Logit com efeitos fixos: Este é o estimador de máxima verossimilhança condicional a $x_{i}, c_{i}$ e $n_{i} \equiv \sum_{i=1}^{T} y_{i t}$.

A hipótese $\mathrm{H} 2$ não é necessária para se obter estimativas consistentes para $\beta$. Para este estimador não é possível obter os efeitos parciais médios.

3) Generalized Estimating Equations (GEE): Neste estimador não se assume a hipótese H1. Especifica-se a variância de $y_{i}$ condicional a $x_{i}$ e estima-se $E\left(y_{i t} / x_{i t}\right)$ por Mínimos Quadrados Multivariados Ponderados Não-Linear ${ }^{56}$. O estimador de $\beta$ é consistente.

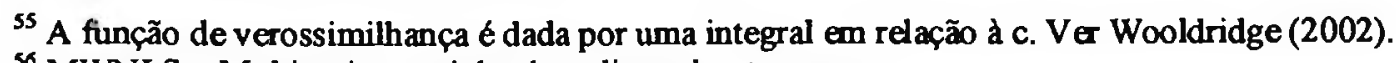

${ }^{56}$ MWNLS - Multivariate weighted nonlinear least squares. 


\subsection{Modelo Tobit com dados em painel}

O modelo Tobit ${ }^{57}$ faz parte de uma classe de modelos chamada Modelos de Regressão Censurada. Wooldridge (2002) sugere dois tipos de categorias: dados censurados (cujo exemplo básico é o top coding de renda familiar) e modelos de solução de canto.

A variável contínua demanda por redesconto é definida apenas para valores positivos ${ }^{58}$, conforme a equação [17]. Assim, para qualquer valor negativo que ela pudesse assumir é atribuído o valor zero. Esta variável é um exemplo de solução de canto.

São possíveis dois modelos:

a) sem características não observáveis

O modelo é

$$
\begin{aligned}
& y_{i t}=\max \left(0, x_{i t} \cdot \beta+u_{i t}\right) \\
& u_{i t} / x_{i t} \sim \operatorname{Normal}\left(0, \sigma^{2}\right)
\end{aligned}
$$

Neste modelo não é necessário assumir a hipótese de exogeneidade estrita. O estimador é o Pooled Tobit, que será utilizado no Capítulo 5 , e $\beta$ é estimado consistentemente e os efeitos parciais médios são obtidos de forma usual.

b) com características não observáveis

$$
\begin{aligned}
& y_{i t}=\max \left(0, x_{i t} \cdot \beta+c_{i}+u_{i t}\right) \\
& u_{i t} / x_{i \ell}, c_{i} \sim \operatorname{Normal}\left(0, \sigma_{u}^{2}\right)
\end{aligned}
$$

\footnotetext{
57 Tobit tipo I ou Tobit Padrão, conforme a taxonomia de Amemiya, 1985 (Wooldridge, 2002).

${ }^{58}$ Valores negativos indicariam excesso de reservas.
} 
A segunda equação indica exogeneidade estrita de $x_{i r}$ condicional em $c_{i}$. A seguir são descritos dois estimadores para o modelo Tobit com características não observáveis:

1) Modelo Tobit com efeitos aleatórios - Neste caso temos duas hipóteses adicionais:

$c_{i} / x_{i} \sim \operatorname{Normal}\left(0, \sigma_{c}^{2}\right)$

e $\quad y_{i 1}, \ldots, y_{i T}$ são independentes de $\left(x_{i}, c_{i}\right)$

Sob estas hipóteses, o estimador de efeitos aleatórios é $\sqrt{N}$-consistente para $\beta, \sigma_{u}^{2}$ e $\sigma_{c}^{2}$. Este estimador será utilizado no Capítulo 5, juntamente com o Pooled Tobit.

Uma medida da importância do efeito não observável é dada por $\rho=\frac{\sigma_{c}^{2}}{\sigma_{c}^{2}+\sigma_{u}^{2}}$.

2) Modelo Tobit Chamberlain de efeitos aleatórios - A hipótese de independência entre $x_{i}$ e $c_{i}$ é relaxada. Neste caso modela-se a relação entre $x_{i}$ e $c_{i}$ :

$c_{i} / x_{i} \sim \operatorname{Normal}\left(\psi+\bar{x}_{i} \xi, \sigma_{a}^{2}\right)$

e $\quad a_{i} / x_{i} \sim \operatorname{Normal}\left(0, \sigma_{a}^{2}\right)$ 


\subsection{Modelo Heckit}

O exemplo clássico do Modelo Heckit ${ }^{59}$ é o exemplo de Gronau (1974) sobre oferta de salário e força de trabalho. Neste exemplo, o salário ofertado só é observável para as pessoas que fazem parte do mercado de trabalho, havendo a possibilidade de ocorrer problemas de seleção $^{60}$ na amostra. Uma diferença entre este modelo e o modelo de dados censurados é que neste último a regra de censura é conhecida para todos os individuos da população, enquanto que no exemplo de Gronau não se conhece o salário de reserva (regra de censura) para um conjunto de indivíduos da população.

O modelo Heckit é definido por:

$$
y_{1}=x_{1} \cdot \beta_{1}+u_{1}
$$

$$
y_{2}=1\left[x \cdot \delta_{2}+v_{2}>0\right]
$$

tendo como hipótese:

(a) $x_{1}$ é um subconjunto de $x$;

(b) o vetor $x$ é sempre observado, $y_{1}$ é observado apenas quando $y_{2}=1$;

(c) $\left(u_{1}, v_{2}\right)$ são independentes de $x$ com média zero;

(d) $v_{2} \sim \operatorname{Normal}(0,1)$;

(e) $E\left(u_{1} / v_{2}\right)=\gamma_{1} \cdot v_{2}$

\footnotetext{
${ }^{59}$ Também chamado Tobit tipo II (Wooldridge 2002).
} 
O modelo Heckit pode ser estimado por duas formas. A primeira é por máxima verossimilhança. A segunda ${ }^{61}$ forma é realizada por meio de dois estágios. No primeiro estágio estima-se $\hat{\delta}_{2}$ da equação [17] utilizando o modelo Probit (máxima verossimilhança) e todas as observações. A partir dos valores de $\hat{\delta}_{2}$ estimamos a razão inversa de Mills $\left(\hat{\lambda}_{2}\right)$. No segundo estágio obtemos $\hat{\beta}_{1}$ e $\hat{\gamma}_{1}$ estimando a equação em que $y_{1}$ é a variável dependente e $x_{1}$ e $\hat{\lambda}_{2}$ são os regressores pelo Método dos Mínimos Quadrados Ordinários na amostra selecionada.

Note que, como $\hat{\lambda}_{2}$ é uma variável explicativa gerada no primeiro estágio, os desviospadrão devem ser corrigidos para levar em consideração este fato.

O Modelo Heckit será usado neste trabalho para avaliar se há problemas de seleção com a amostra de bancos ${ }^{62}$, ou seja, para avaliar se a seleção da amostra é exógena ou endógena. Porém, não foram estimadas versões deste modelo para dados em painel.

\footnotetext{
${ }^{60}$ Há problema de seleção quando a seleção é endógena. No caso de a seleção ser exógena, podem ser aplicados, sem problemas, modelos lineares.

${ }^{61}$ Que foi realizada neste trabalho.

${ }^{62}$ As definições de quais instituições financeiras iriam compor a amostra foi critério do BACEN.
} 


\section{CAPÍTULO 5 - RESULTADOS}

Este capítulo inicia-se por uma breve descrição da amostra que será estudada. Após esta descrição, serão apresentados os resultados obtidos a partir da estimação dos modelos apresentados no capitulo 4 .

\subsection{A Amostra}

Esta seção traz uma descrição em termos agregados da amostra utilizada para a análise empírica deste trabalho. Os dados foram fornecidos pelo Banco Central do Brasil e, por serem individuais, estão sujeitos ao sigilo previsto em lei. A amostra fornecida pelo BACEN é composta por 122 instituições bancárias que possuem carteira comercial. Os dados são diários, totalizando 597 dias no periodo de 24 de abril de 2002 a 31 de agosto de 2004.

\subsubsection{Redesconto x Mercado Aberto}

Tanto o DEMAB quanto o DEBAN realizam operações compromissadas de um dia útil com a finalidade de atender as necessidades de caixa das instituições financeiras. As diferenças entre estas operações é reflexo de sua natureza e finalidade. O DEMAB atua no mercado de títulos públicos e é um agente natural para a realização de operações compromissadas. $O$ DEBAN, dada sua função de monitorar as reservas das instituições financeiras, deve possuir instrumentos para que problemas de liquidez não causem quebras no sistema. Dessa forma, as operações realizadas com o DEBAN possuem normativos mais rigidos e de caráter mais 
restritivo que as do DEMAB. É de se esperar que o DEMAB seja a maior fonte de liquidez do sistema.

A Figura 2 compara a quantidade de operações de Nivelamento realizadas pelo DEMAB $^{63}$ com a quantidade de operações de Redesconto Over realizadas pelo DEBAN a partir da entrada em funcionamento do novo sistema de pagamentos (segundo trimestre de 2002) até o terceiro trimestre de $2004^{64}$. A Figura 3 confronta as operações realizadas pelos dois departamentos do BACEN, em termos de volume financeiro no mesmo periodo.

${ }^{63}$ As operaç̃̃es consideradas como operações de "nivelamento" do DEMAB são as operações que ocorreram após as $17 \mathrm{~h}$.

${ }^{\circ 4}$ A notação utilizada é "ano trimestre". Assim, 200303 corresponde ao terceiro trimestre de 2003. 
Figura 2 - Número de operaçōes realizadas pelo DEMAB x número de operações realizadas pelo DEBAN.

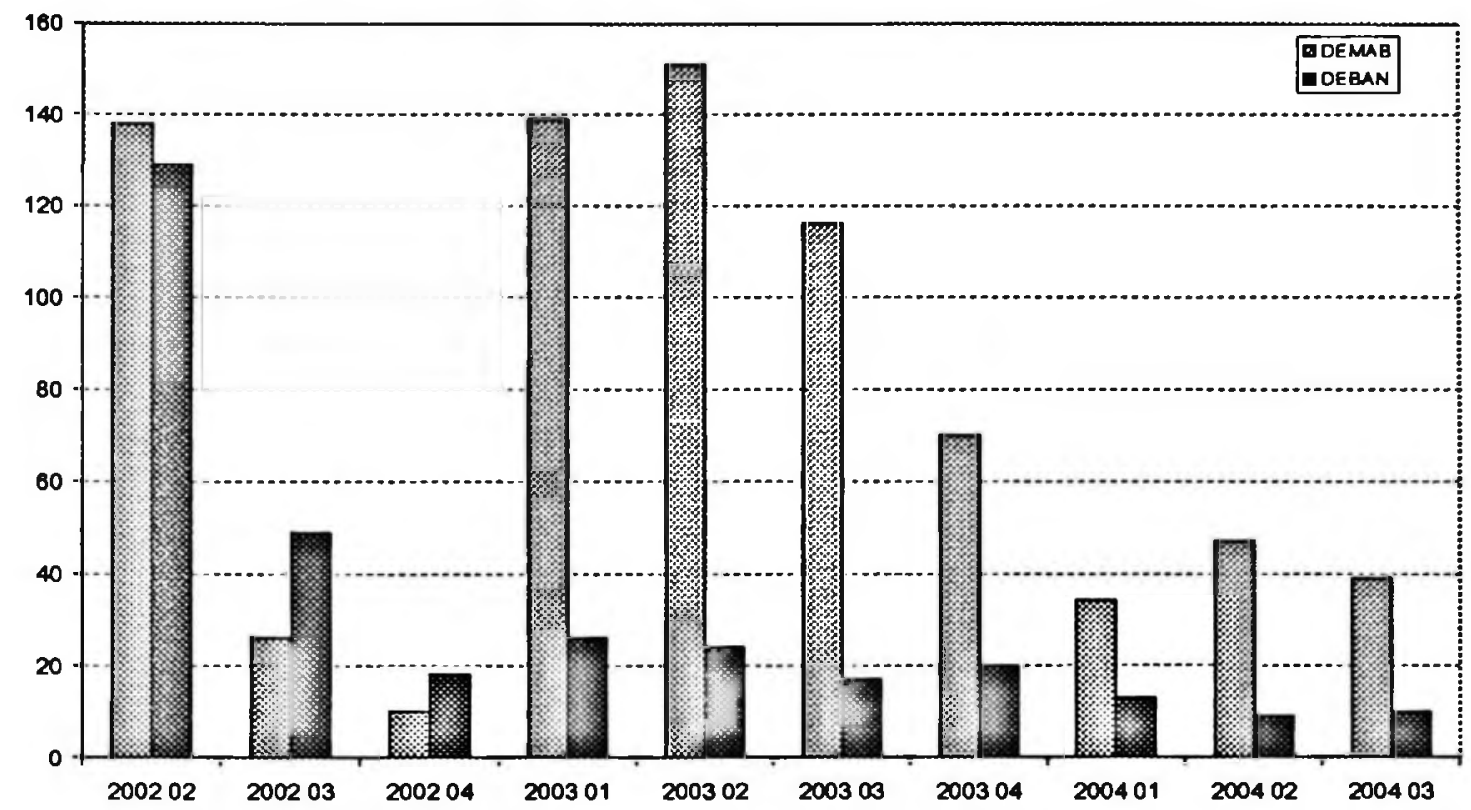

Figura 3 - Volume (em bilhões de Reais) das operações realizadas pelo DEMAB $x$ volume (em bilhões de Reais) das operações realizadas pelo DEBAN

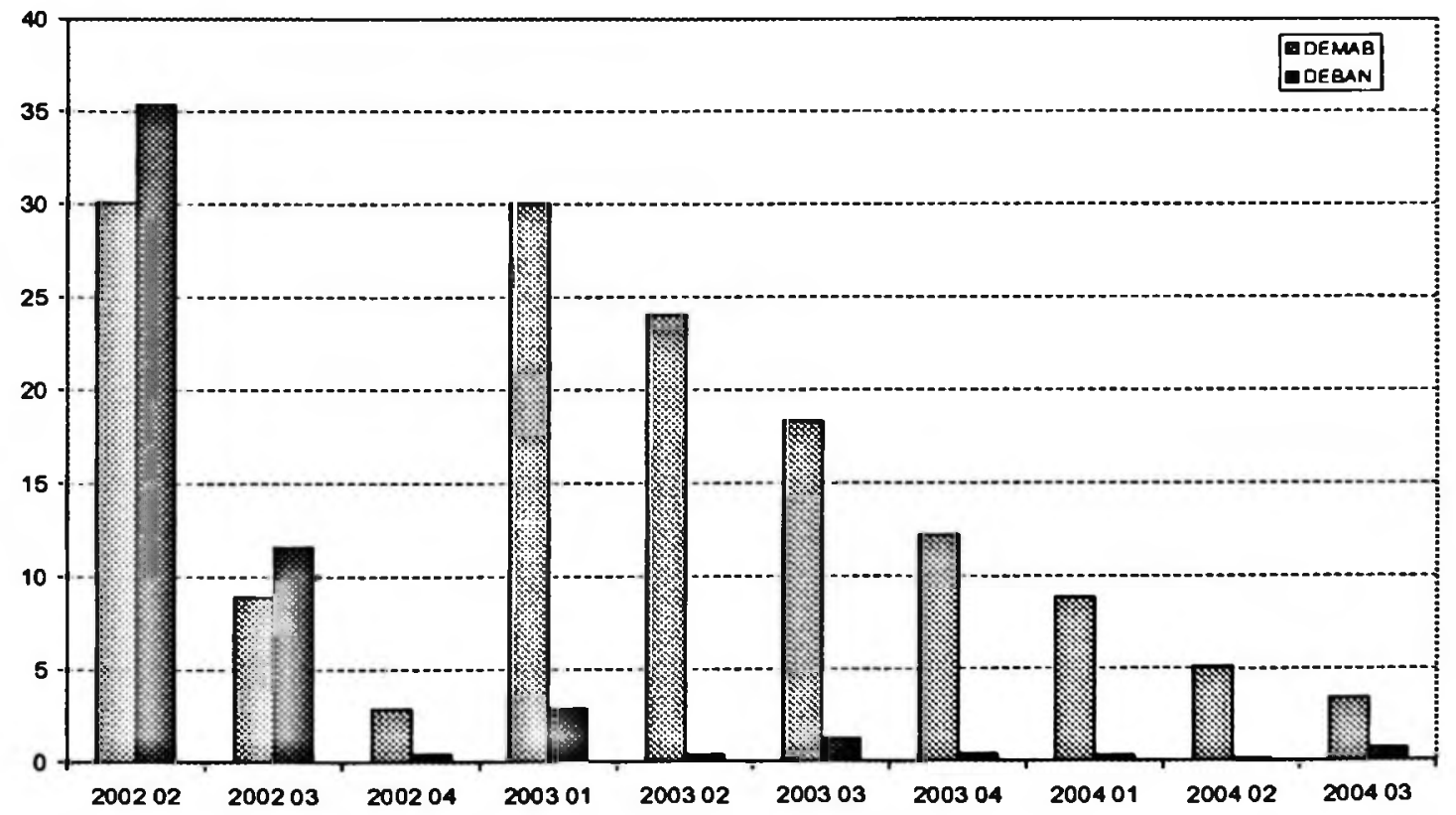


No ano de 2002, houve um equilíbrio entre as operações realizadas pelo DEMAB e pelo DEBAN, tanto em termos de quantidade das operações quanto em termos do volume financeiro movimentado ${ }^{65}$. A partir de 2003, o DEMAB passa a dominar as operações de um dia tanto em termos de quantidade de operações quanto em termos de volume financeiro ${ }^{66}$. Isto pode ser explicado pela rigidez da fixação da taxa do redesconto com relação às taxas praticadas pelo DEMAB. Neste período a taxa do Redesconto Over foi fixada em SELIC + $6 \%$ (a.a.) enquanto que as taxas praticadas pelo DEMAB eram definidas caso a caso em valores abaixo da taxa do redesconto.

Uma segunda observação diz respeito à queda das operações no DEMAB a partir do primeiro trimestre de 2003. Uma possível explicação pode estar relacionada à liquidez do sistema.

A tabela 4 mostra o volume financeiro e o número de operações de redesconto de acordo com tamanho das instituições financeiras medido pelas reservas bancárias para os anos de 2002, 2003 e 2004. Os bancos foram agrupados em quatro conjuntos. O Conjunto 1 (C1) contém os maiores bancos (25\% da amostra) em termos de reservas bancárias ( $1^{\circ}$ quartil), os demais conjuntos seguem o mesmo princípio, ou seja, o Conjunto 2 (C2) corresponde ao $2^{\circ}$ quartil, o Conjunto 3 (C3) ao $3^{\circ}$ quartil e o Conjunto 4 (C4) corresponde ao $4^{\circ}$ quartil. A tabela traz os valores médios ${ }^{67}$ e as medianas das reservas para cada conjunto (em milhões de Reais) e os respectivos valores médios e medianas do volume financeiro das operações de redesconto e número de operações realizadas.

\footnotetext{
${ }^{65}$ O DEBAN realizou $47 \%$ das operações e movimentou $47 \%$ do volume financeiro das operaç̃es em 2002.

${ }^{66}$ Considerando o periodo a partir do primeiro trimestre de 2003, o DEMAB tem uma média de $83 \%$ das operậ̃es realizadas e $94 \%$ do volume financeiro.

${ }^{67}$ Para cada banco foi calculado o valor médio das reservas no ano. Os bancos foram agrupados em conjuntos e para cada conjunto foi calculada a média e a mediana.
} 
Tabela 4 - Porte das IFs e operações de redesconto

\begin{tabular}{|c|c|c|c|c|c|c|c|c|c|c|}
\hline & \multicolumn{3}{|c|}{ Reservas } & \multicolumn{6}{|c|}{ Redesconto } \\
\hline & & \multirow{2}{*}{$\frac{2002}{\text { M Reais }}$} & \multirow{2}{*}{$\frac{2003}{\text { M Reais }}$} & \multirow{2}{*}{$\begin{array}{c}2004 \\
\text { M Reais }\end{array}$} & \multicolumn{2}{|c|}{2002} & \multicolumn{2}{|c|}{2003} & \multicolumn{2}{|c|}{2004} \\
\hline & & & & & M Reais & $\mathrm{N}^{\circ} \mathrm{OP}$ & M Reais & $\mathrm{N}^{\circ} \mathrm{OP}$ & M Reais & $\mathrm{N}^{\circ} \mathrm{OP}$ \\
\hline \multirow{2}{*}{$\mathrm{Cl}$} & Média & 662,14 & 791,22 & 823,31 & 10,20 & 95 & 8,23 & 195 & 3,31 & 77 \\
\hline & Mediana & 112,25 & 118,60 & 152,25 & 0,01 & $24,8 \%$ & 1,10 & $34.3 \%$ & 0.03 & $50.7 \%$ \\
\hline \multirow{2}{*}{$\mathrm{C} 2$} & Média & 5,27 & 1,42 & 1,05 & 0,13 & 126 & 2,50 & 167 & 0,25 & 28 \\
\hline & Mediana & 4,32 & 1,27 & 0,87 & 0,00 & $32,9 \%$ & 0,03 & $29,4 \%$ & 0,00 & $18.4 \%$ \\
\hline \multirow{2}{*}{ C3 } & Média & 1,00 & 0,41 & 0,28 & 3,35 & 83 & 1,59 & 135 & 0,37 & 28 \\
\hline & Mediana & 0,75 & 0.41 & 0,25 & 0,00 & $21,7 \%$ & 0,00 & $23,8 \%$ & 0.00 & $18,4 \%$ \\
\hline \multirow{2}{*}{$\mathrm{C} 4$} & Média & 0,19 & 0,11 & 0,09 & 2,24 & 79 & 0,35 & 71 & 0,02 & 19 \\
\hline & Mediana & 0,17 & 0,11 & 0,09 & 0,00 & $20,6 \%$ & 0,00 & $12,5 \%$ & 0,00 & $12,5 \%$ \\
\hline
\end{tabular}

Observamos que para os bancos menores (Conjunto 3 e Conjunto 4) os valores médios das operações de redesconto realizadas são superiores aos valores médios das reservas. Isto mostra a importância das operações de redesconto para os bancos com menor volume de reservas bancárias.

\subsubsection{Compulsório sobre Depósitos à Vista}

O compulsório sobre depósitos à vista merece atenção especial por ser um dos principais determinantes da meta do saldo de fechamento do dia. Segundo Queiroz (2004), a demanda por reservas relaciona-se com o cumprimento de exigibilidade de reservas e o comportamento dos bancos leva em conta o arcabouço regulamentar (duas características desta modalidade de compulsório são: cumprimento na própria conta de reservas da instituição financeira e alta volatilidade quando comparado aos demais compulsórios) ${ }^{68}$.

\footnotetext{
${ }^{68}$ Clouse e Dow (2002) e Costa Pinto e Coelho (2004) elaboram um modelo de administração ótima dos saldos em reservas ao final de cada dia levando em conta as características deste compulsório.
} 
Para efeito do compulsório sobre depósitos à vista, as instituições financeiras são divididas em dois grupos: Grupo A e Grupo B. A diferença entre os grupos é dada pela defasagem de uma semana existente nos períodos de cálculo e, conseqüentemente, nos períodos de movimentação ${ }^{69}$. A Figura 4 ilustra graficamente os periodos de cálculo e movimentação para os grupos $\mathrm{A}$ e $\mathrm{B}^{70}$.

Figura 4 - Periodos de cálculo e de movimentação para os grupos $A$ e B

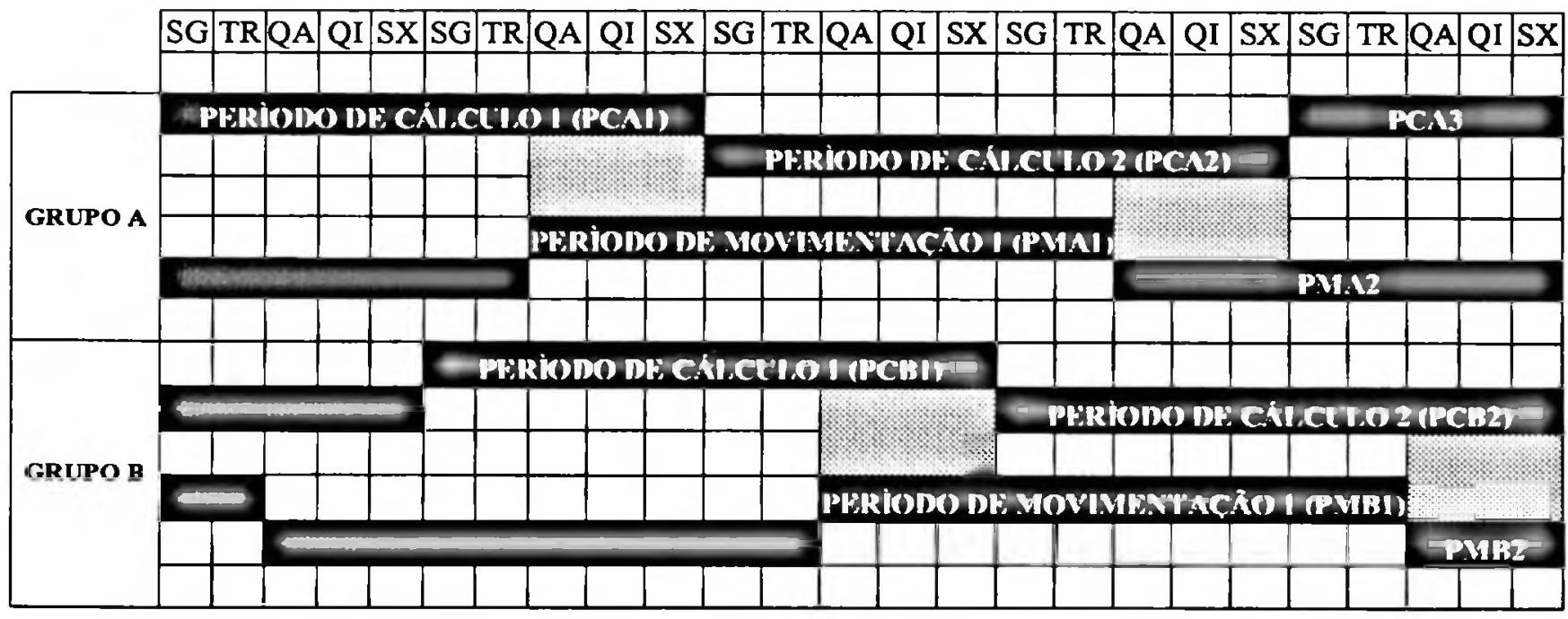

Há uma sobreposição do periodo de movimentação com o periodo de cálculo (o período de movimentação inicia-se sem o encerramento do periodo de cálculo). Este fato gera uma incerteza em relação ao nível de reserva requerida. Segundo Queiroz (2004), os bancos ficam em média com $3 \%$ a $8 \%$ de excesso de reservas nestes três dias, deixando para ajustar a média do requerimento de reservas nos últimos dias do periodo (ficam em média $3 \%$ abaixo do exigível). Costa Pinto e Coelho (2004) aplicam a metodologia de Clouse e Dow (2002) para modelar o comportamento ótimo dos bancos no seu gerenciamento de reservas. $O$ resultado

\footnotetext{
${ }^{69} \mathrm{O}$ periodo de movimentacão também é denominado periodo de cumprimento.

${ }^{70} \mathrm{Em}$ destaque, os dias em que há sobreposição entre período de cálculo e período de movimentação.
} 
obtido no modelo coincide com o comportamento observado por Queiroz (2004) de que há excesso de reservas nos dias em que há a sobreposição.

Algumas características específicas do compulsório sobre depósitos à vista são: cumprimento na própria conta de reservas da instituição (há contas específicas para os demais compulsórios); existem um valor médio a ser cumprido (exigibilidade) e um valor mínimo diário que é uma fração da exigibilidade (nos demais compulsórios há apenas um valor mínimo que é a própria exigibilidade); e possibilidade de aproveitamento de excessos em relação à média (carry over positivo) (não há esta possibilidade nos demais compulsórios).

A amostra utilizada no trabalho é composta por 122 instituições bancárias que possuem carteira comercial, sendo que 45 (37\%) pertencem ao grupo A, 50 (41\%) ao grupo B e 27 (22\%) não possuíram exigibilidade no compulsório sobre depósitos à vista (em todo o periodo).

As Figuras 5 e 6 mostram o valor médio das reservas para cada grupo. Observa-se um comportamento semelhante entre os grupos A e B, com exceção do periodo entre janeiro e março de 2004, quando o saldo das reservas do grupo B "descola" do saldo das reservas do grupo A. Entre fevereiro e agosto de 2003 observamos um nível de reservas agregado maior em relação ao nível de reservas no período complementar. Para os bancos sem exigibilidade no compulsório sobre depósitos à vista, observa-se, na Figura 7, um aumento na volatilidade do saldo em reservas a partir de janeiro de 2003. 
Figura 5 - Média de Reservas, Grupo A em milhões de Reais

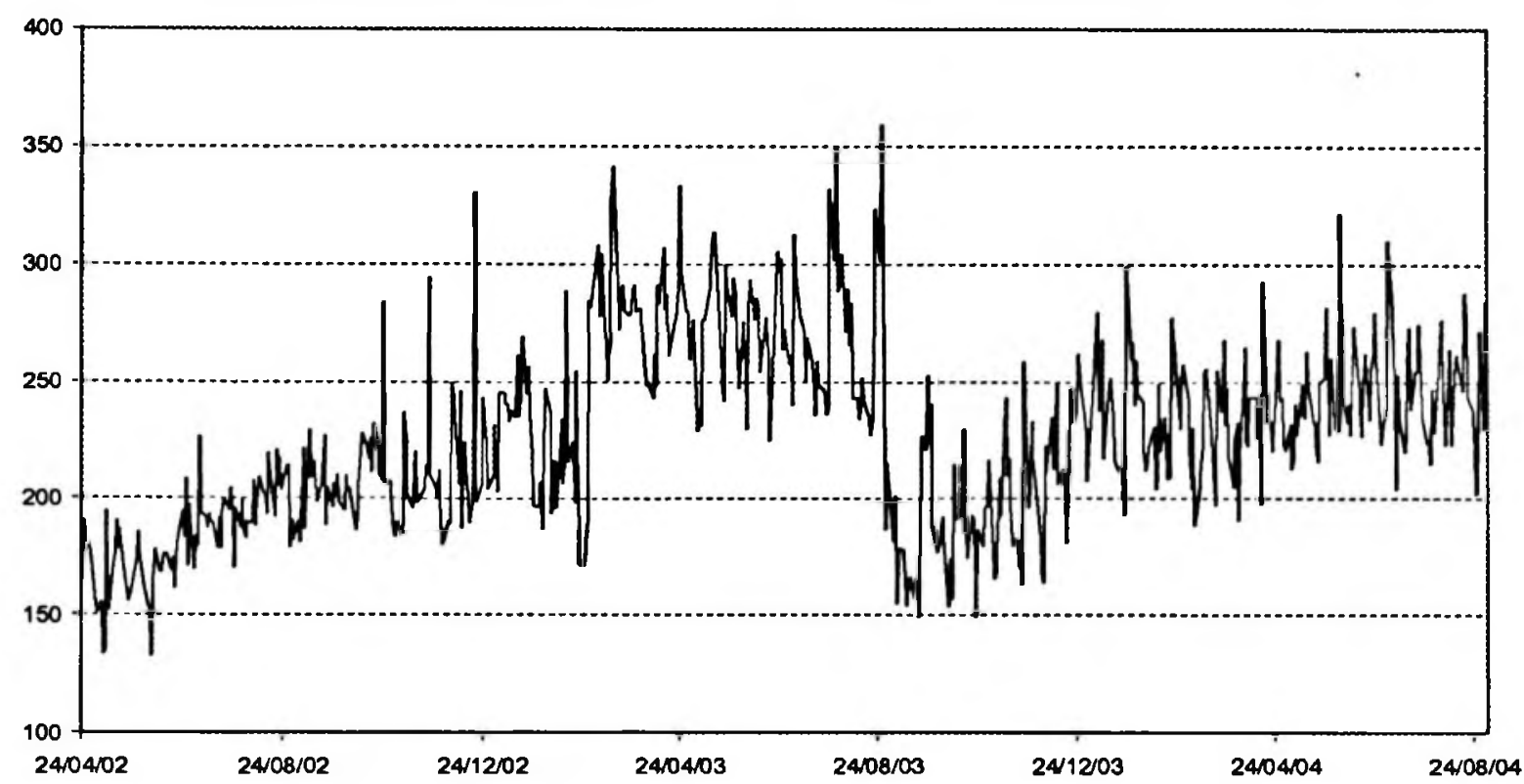

Figura 6 - Média de Reservas, Grupo B em milhões de Reais

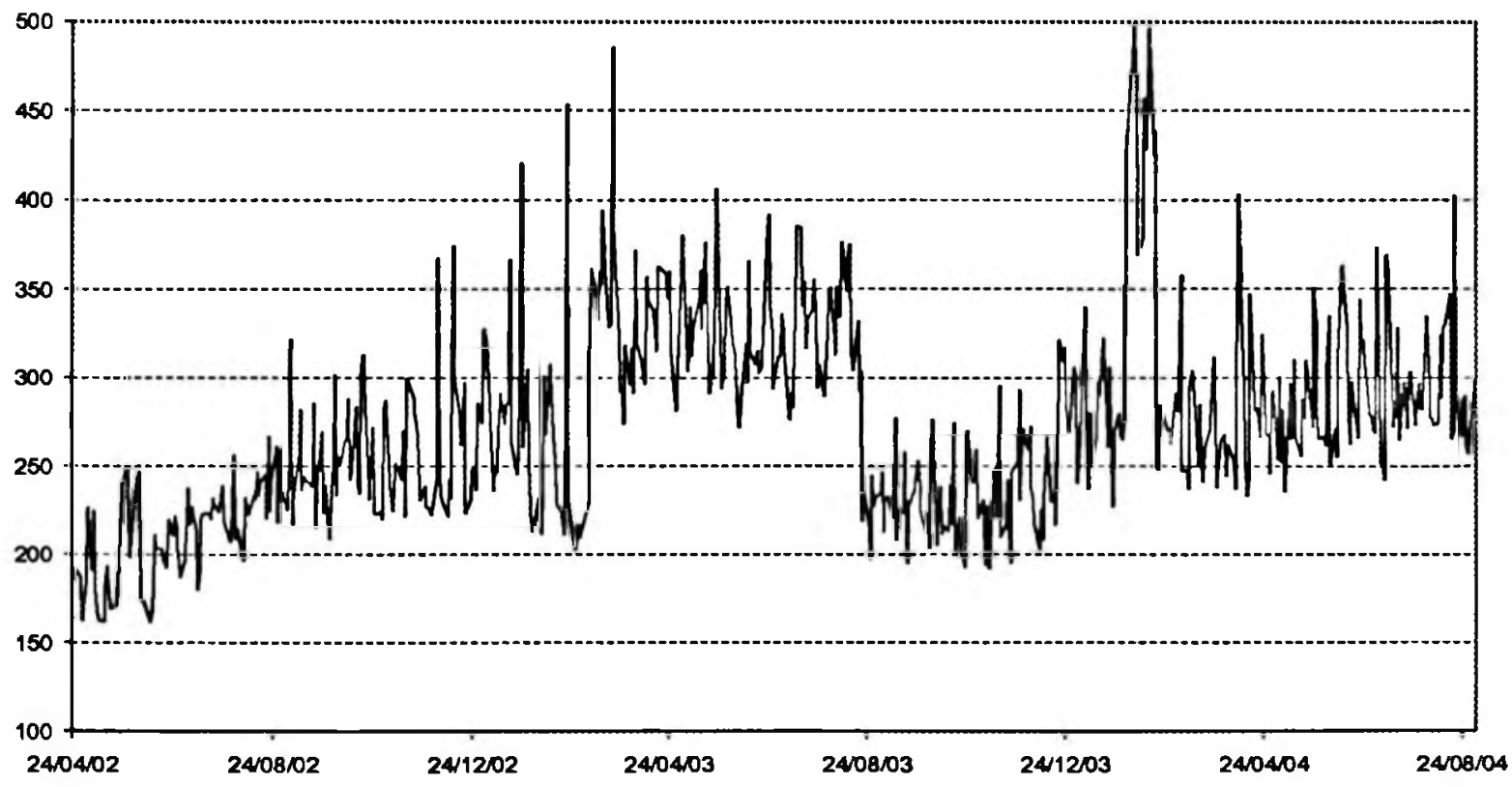


Figura 7 - Média de Reservas, Bancos sem exigibilidade no Compulsório sobre Depósitos a Vista, em milhões de Reais.

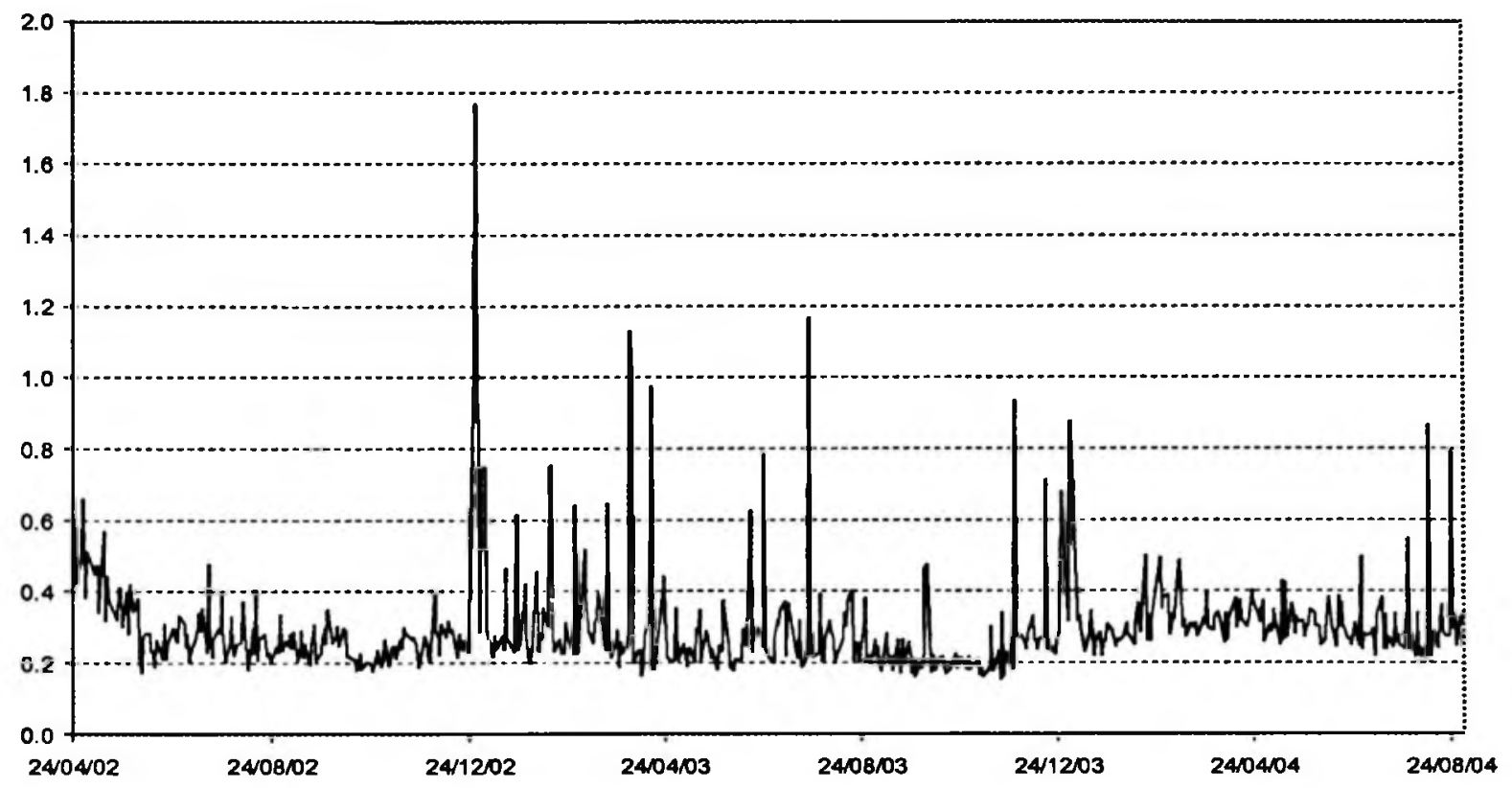

A Figura 8 ilustra de maneira simplificada os movimentos que ocorrem nas reservas dos bancos. A exigibilidade é o valor que as instituições devem manter na média em suas reservas. 
Figura 8 - Exigibilidade do Compulsório sobre Depósitos à Vista

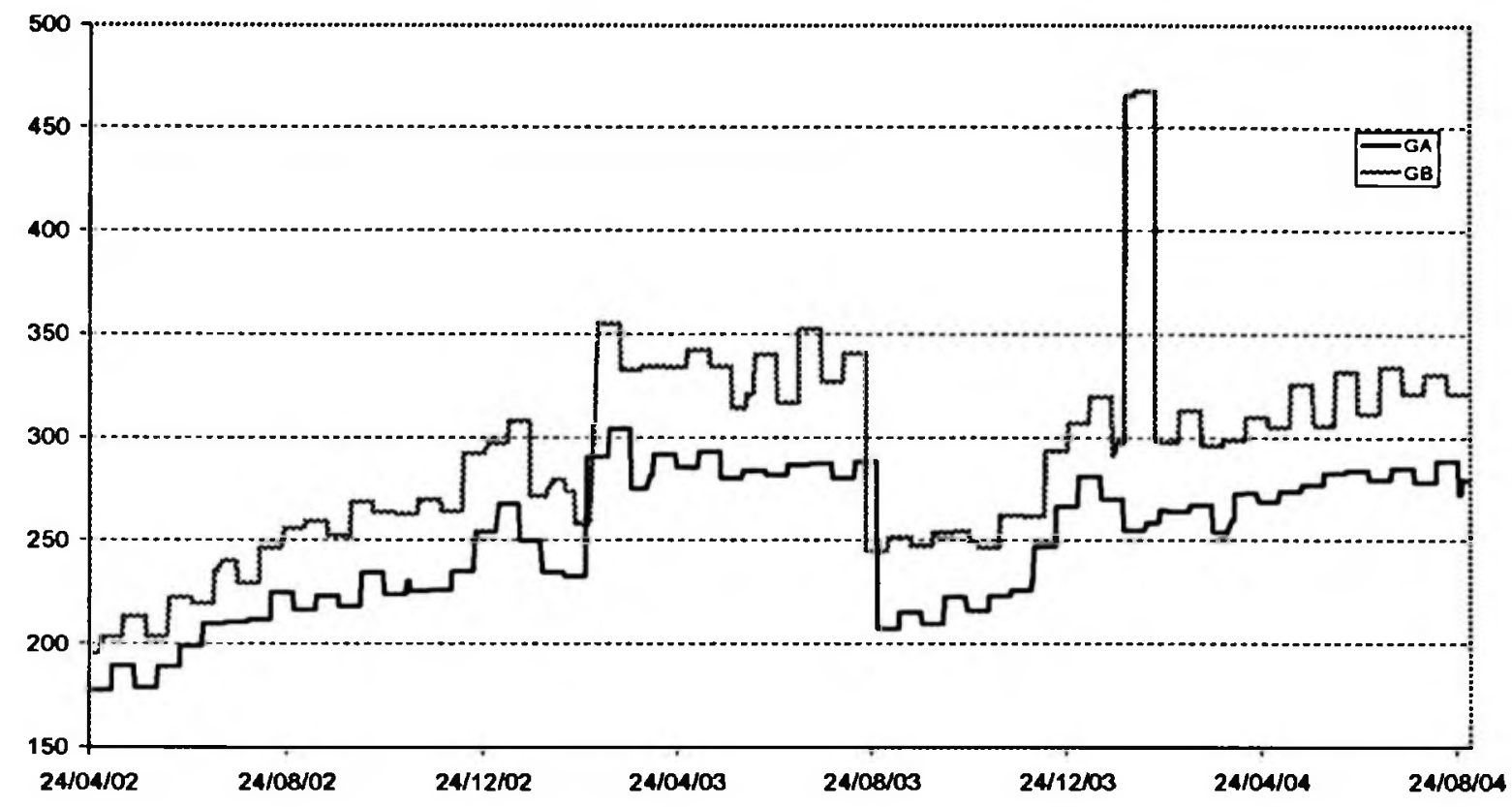

As Figuras 9 e 10 mostram a relação Reservas/Exigibilidade: 
Figura 9 - Relação Reservas/Exigibilidade, Grupo A

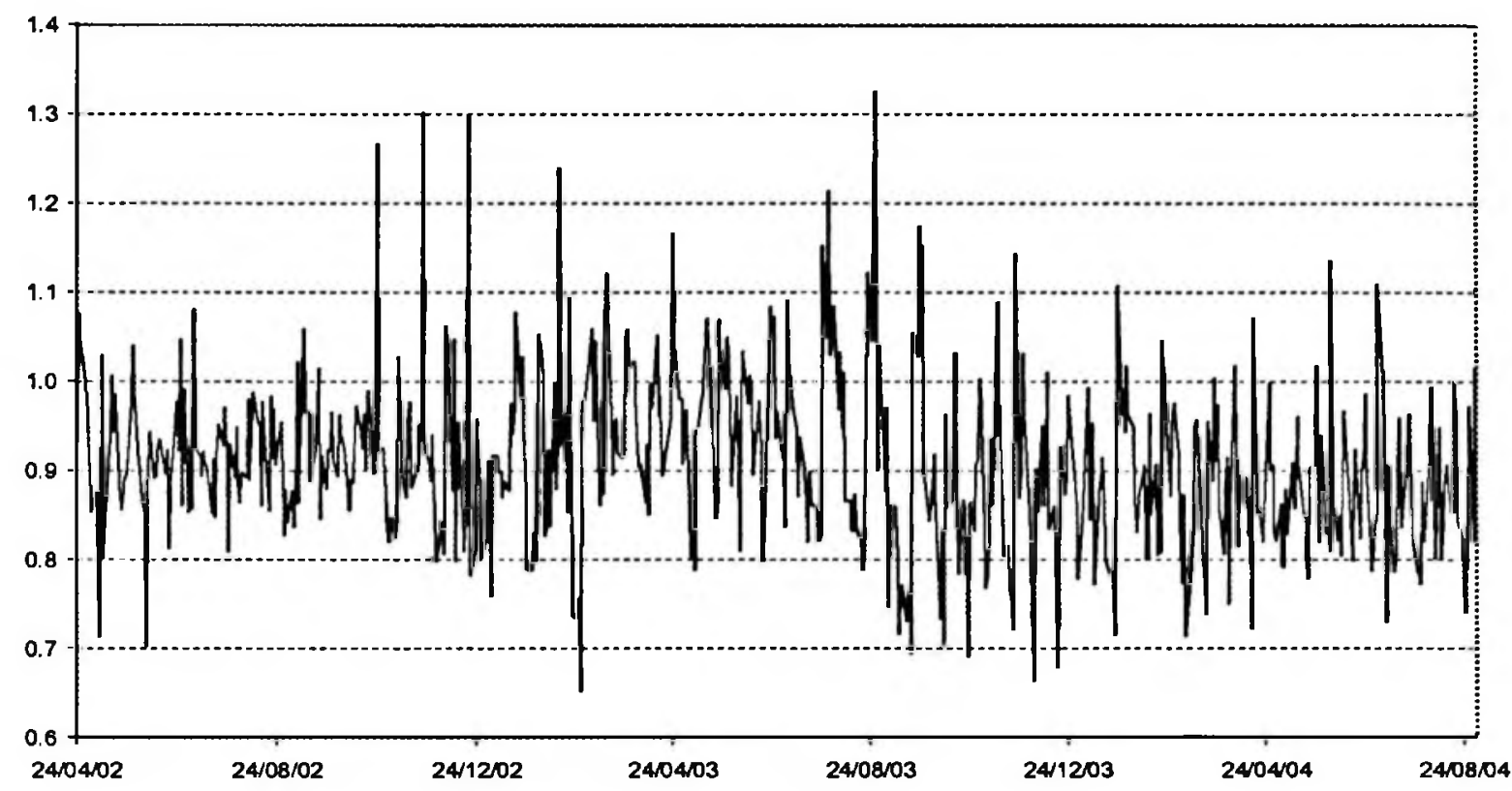

Figura 10 - Relação Reservas/Exigibilidade, Grupo B

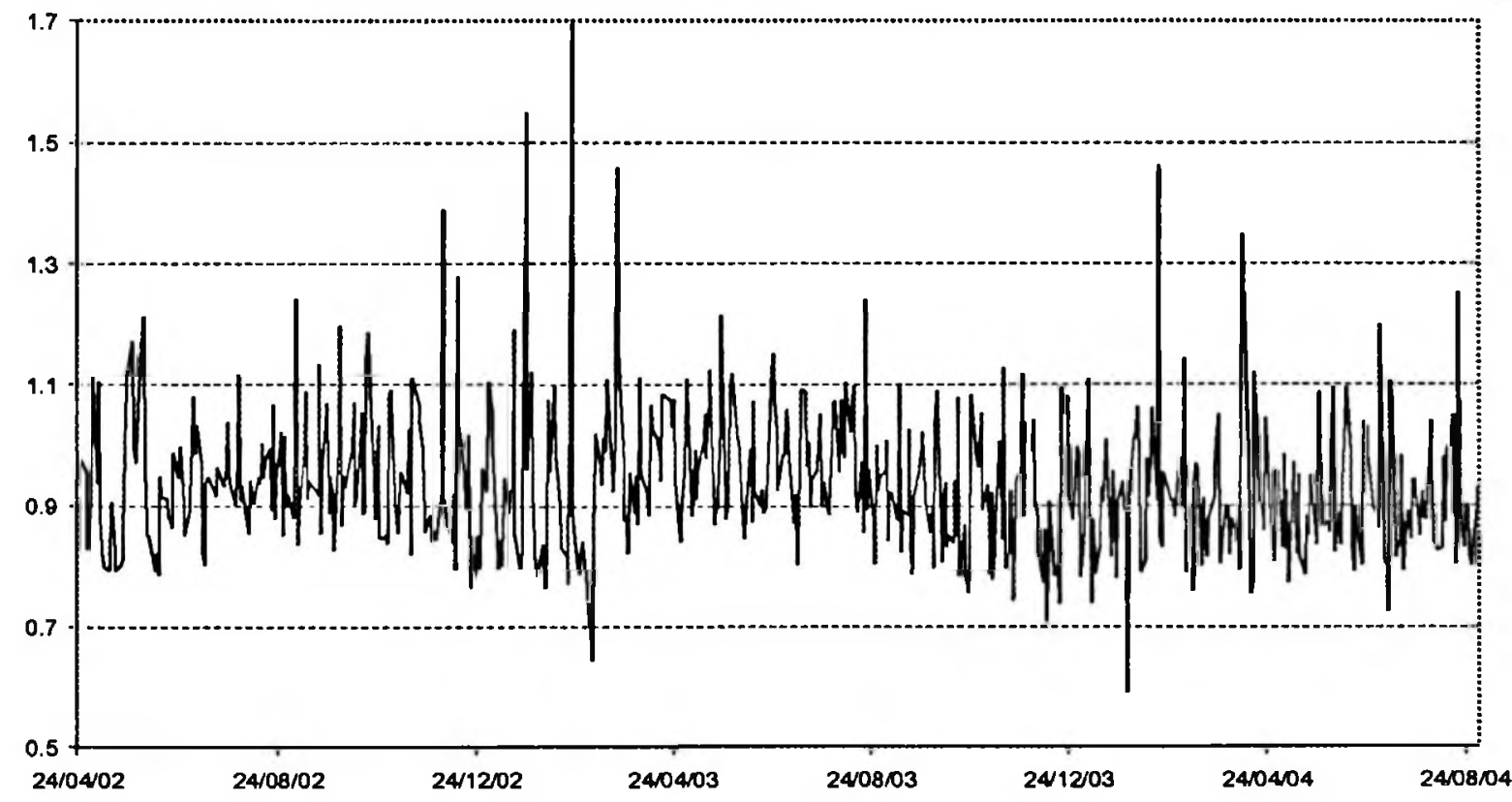


Queiroz (2004) estuda o comportamento diário do mercado brasileiro de reservas bancárias para o periodo de $1^{\circ}$ de outubro de 2000 a 9 de setembro de 2003 utilizando dados agregados sobre o excesso de reservas diárias. Com o objetivo de modelar choques assimétricos na volatilidade, utiliza o modelo EGARCH; além disso utiliza dummies para identificar os dias do periodo de movimentação e uma dummy para o dia das reuniões do COPOM. Aponta as seguintes características comuns aos grupos A e B: (i) na média os bancos deixam mais reservas no início do período de movimentação do que no final; (ii) a volatilidade no dia da reunião do COPOM é 2,2 vezes, em média, maior que a volatilidade de longo prazo; (iii) existe uma volatilidade de longo prazo próxima a $6 \%$ e os bancos de um dia para o outro absorvem impactos não esperados no seu gerenciamento de reservas; e (iv) existe mais incerteza no início do periodo do que no final. Aponta, também, características diferentes entre os grupos: (i) no grupo A, o comportamento de começar o período de movimentação com excesso de reservas e terminar com deficiência é mais bem definido e (ii) a margem diária permitida de desvio de saldo sobre o exigível parece não ser restritiva para os grandes bancos do grupo A e choquerestritiva no grupo $\mathrm{B}$. 


\subsection{Modelo a ser estimado}

A equação de demanda por redesconto (equação [9]), para um banco $i$, é:

$$
W_{i, t}=-\min \left(0, R_{i, t-1}^{F}+R_{i, t}^{(+)} \cdot \lambda_{i, l}^{(+)}+R_{i, t}^{(-)} \cdot \lambda_{i, t}^{(-)}-G_{i, t}\right)
$$

Para estimar esta equação serão utilizadas proxys e incluídos controles. A equação a ser estimada será:

$$
W_{i, t}=\theta_{1} \cdot R_{i, t-1}^{F}+\theta_{2} \cdot S C_{i,}+\theta_{3} \cdot S D_{i, s}+\sum_{j} \xi_{j}<G_{i, t}>+\sum_{k} \zeta_{k}<\text { controles }_{i,}>+u_{i t}
$$

onde

$W_{i, t}$ é a demanda por redesconto (ou o indicador de utilização de redesconto);

$R_{i,-1}^{F}$ é o saldo em reservas ao final do dia anterior;

$S C_{i}$ é o total de créditos na reserva bancária, servindo como proxy para $R_{i,}^{(+)} \cdot \lambda_{i,}^{(+)}$;

$S D_{i}$ é o total de débitos na reserva bancária, servindo como proxy para $R_{i, d}^{(-)} \cdot \lambda_{i,}^{(-)}$;

$<G_{i}>$ é o conjunto de variáveis associado à meta de fechamento;

$<$ controles $_{i}>$ é o conjunto de variáveis de controle;

$u_{i, s}$ é o termo aleatório.

Como hipótese temos que a demanda por reservas é totalmente atendida pelas operações de redesconto. As operações de redesconto ficam definidas como as operações realizadas pelo 
DEMAB (nivelamento) e pelo DEBAN (redesconto over). Assim, foram criadas duas variáveis para $W_{i, \downarrow}$ : dopd - dummy que assume valor 1 quando é realizada uma operação de redesconto over ou de nivelamento, que será utilizada nos modelos Probit, Logit e Heckit, In_DEM logaritmos da soma das operações de nivelamento e de redesconto over, que será utilizada no modelo Tobit e Heckit.

No modelo a ser estimado, $R_{i \perp-1}^{F}$ será definido pelo logaritmo do saldo em reservas no dia anterior, sendo representado pela variável ln_rsvL1. Como a equação da demanda (equação [5]) tem como base o saldo ao final do próprio dia, foi também utilizada a variável In_RSV, logaritmo do saldo em reservas no próprio dia, em algumas especificações.

$S C_{i}$ e $S D_{i}$ representam créditos e débitos que ocorrem na conta de reservas, seguindo um processo de Poisson Composto. Ao longo da janela de operações diversos tipos de mensagens são enviadas pela instituição financeira para o BACEN, para as Clearings e para outros bancos. Estas mensagens são agrupadas conforme o tipo de operação, como detalhado a seguir:

(1) STR - Sistema de Transferência de Reservas (transferências em tempo real no SPB, entre instituições detentoras da conta Reservas Bancárias). Será representada por 6 variáveis: In_st1 - logaritmo do módulo do valor líquido das operações se STR0003 e STR $0004^{71}$ na primeira subjanela de quatro horas, possuindo o mesmo sinal do valor líquido; In_st2 - construído da mesma maneira que a variável anterior para a segunda subjanela de quatro horas e ln_st3 - construida para a terceira subjanela de quatro horas. In_so1 - logaritmo do módulo do valor líquido das demais operações de STR para a 
primeira subjanela de quatro horas, possuindo o mesmo sinal do valor líquido, In_so2 construída para a segunda janela de quatro horas e In_so3 - construída para a terceira subjanela de quatro horas;

(2) SLB - Sistema de Lançamentos do BACEN (cobranças geradas pelo BACEN multas, tarifas e custos). Está incorporada na variável InCD_Ag;

(3) $\mathrm{CIR}$ - Operações relacionadas com movimentação de numerário (DEBAN/MECIR). Faz parte da variável InCD_Ag;

(4) RDC - Operações de Redesconto Intradia e Over junto ao BACEN;

(5) RCO - Recolhimento de compulsórios;

(6) STN - Lançamentos a débito ou a crédito relativos ao Tesouro Nacional. Faz parte da variável InCD_Ag;

(7) SEL - Operações com títulos permitidos pelo SELIC. Gera a variável ln_sel logaritmo do módulo do valor líquido das operações junto ao SELIC ${ }^{72}$, levando em conta o sinal do valor líquido;

(8) LDL - Liquidação multilateral de câmaras. Utilizada para a administração e liquidação de garantias;

(9) LTR - Liquidações brutas em tempo real e liquidações bilaterais de operações realizadas em câmaras;

(10) BMA - Câmara de Ativos da BM\&F. Gera a variável ln_ca;

"I Operaç̃̃es normalmente realizadas com a BMF Câmbio. 
(11) BMC - Câmara de Câmbio da BM\&F;

(12) BMD - Câmara de Derivativos da BM\&F;

(13) CBL - Utilização de serviços da CBLC;

(14) CTP - Operações com o CETIP;

(15) PAG - Câmara de serviços PAG/CIP. Gera a variável ln_cp.

Os grupos (8) LDL e (9) LTR correspondem a mensagens genéricas entre câmaras e instituições financeiras. Os grupos (11) a (14) correspondem a mensagens específicas da BMF, CBLC e CETIP. Estes seis grupos não foram incorporados a variável InCD_Ag por não terem sido disponibilizados pelo BACEN.

A variável ln_cp é definida como o logaritmo do módulo do valor líquido das operações com câmaras de pagamentos; In_ca é definida como o logaritmo do módulo do valor líquido das operações com câmaras de ativos, ambas levando em conta o sinal do valor líquido.

No modelo reduzido (regressões em painel) será utilizada a variável agregada $\mathbf{l n C D}$ _Ag que corresponde ao logaritmo do módulo da soma das variáveis $\ln \_s t 1, \ln \_s t 2, \ln \_s t 3, \ln \_s o 1$, ln_so2, ln_so3, ln_cp, ln_ca, ln_stn, ln_cire $\ln \_$slb $^{73}$, levando em conta o sinal da soma.

$<G_{i}>$ é o conjunto de variáveis associado à meta de fechamento, correspondendo à variável In_Exigivel e ao conjunto de dummies associadas à administração ótima das reservas dga, dgb, d1 s4, d1s5, d1s6, d2s2, d2s3, d2s4, d2s5, d2s6, d3s2 e d3s3.

\footnotetext{
${ }^{72}$ Exclui as operações de nivelamento.

${ }^{73}$ In_stn, ln_cir e ln_slb ocorrem nos itens (6), (3) e (2) respectivamente. Não foram incluidos no modelo original para evitar o problema de multicolinearidade.
} 
As dummies dga e dgb buscam captar o efeito de a instituição financeira pertencer a um dos dois grupos do compulsório sobre depósitos à vista. Quando ambas assumem o valor 0 , significa que a exigibilidade no compulsório sobre depósitos à vista foi nula em todo o periodo. As instituições que possuíram exigibilidade nula em parte do período em análise tiveram $\mathrm{dga}=$ 1 ou $\mathrm{dgb}=1$ para todo o período.

As variáveis d1s4, d1s5, d1s6, d2s2, d2s3, d2s4, d2s5, d2s6, d3s2, d3s3 são as dummies para cada dia do periodo de cumprimento do depósito compulsório sobre depósitos à vista. O primeiro número indica qual das três semanas a dummy se refere e o segundo número refere-se ao dia da semana (2 para segunda, 3 para terça, 4 para quarta, 5 para quinta e 6 para sexta-feira). O caso em que todas as dummies são nulas corresponde à situação em que não há exigibilidade no cumprimento do compulsório. Assim, quando alguma dessas dummies assume valor 1 (e as demais conseqüentemente valor 0 ), seu coeficiente pode ser interpretado como o acréscimo de probabilidade/demanda em relação à situação em que sua exigibilidade é nula.

As variáveis taxa_rdc, In_Exigivel, In_Comp e In_ExgComp formam o conjunto de variáveis de controle. ln_Exigível é o logaritmo das exigibilidades do compulsório sobre depósitos à vista. ln_Comp é o logaritmo do valor total que a instituição mantém vinculado em todos os compulsórios, exceto o de depósitos à vista. ln_ExgComp é o logaritmo do somatório de todas as exigibilidades em compulsórios, exceto depósitos à vista, de uma instituição. A variável taxa_rdc corresponde ao custo de oportunidade entre a taxa do redesconto e o CDI, ao ano.

$$
\left(1+i_{\text {OVER }}\right)=\left(1+i_{\text {SELIC }}\right) \cdot(1+\text { Penalização })
$$




$$
\left(1+\operatorname{tax} a_{-} r d c\right)=\left(1+i_{\text {OVER }}\right) /\left(1+i_{C D I}\right)
$$

As figuras 11 e 12 ilustram a trajetória da taxa do redesconto over em relação ao CDI (\%a.a.) no período em estudo. Observamos um pulso em 04 de junho de 2002 que foi conseqüência de uma queda mais acentuada na taxa do CDI (de aproximadamente $18,2 \%$ a.a. para $13,7 \%$ a.a.) em relação à taxa do SELIC (de aproximadamente $18,4 \%$ a.a. para $15,9 \%$ a.a.). O degrau ocorrido em $1^{\circ}$ de julho de 2002 é decorrência das alterações realizadas pela Circular 3.120 , de 19 de abril de $2002^{74}$. Durante o período de adaptação ao novo sistema de pagamentos (22 de abril de 2002 a $1^{\circ}$ de julho de 2002) a sobretaxa do redesconto teve um valor mais baixo que no período subseqüente ( $1 \%$ a.a. contra $6 \%$ a.a.).

\footnotetext{
${ }^{74}$ Em vista da relevância que a variável taxa_rdc apresenta nas regresões do trabalho, o apêndice reporta os resultados para o subperiodo que se inicia $\mathrm{em} 1^{\circ}$ de julho de 2002
} 
Figura 11 - Custo de Oportunidade do Redesconto Over (24/04/02 a 31/08/04)

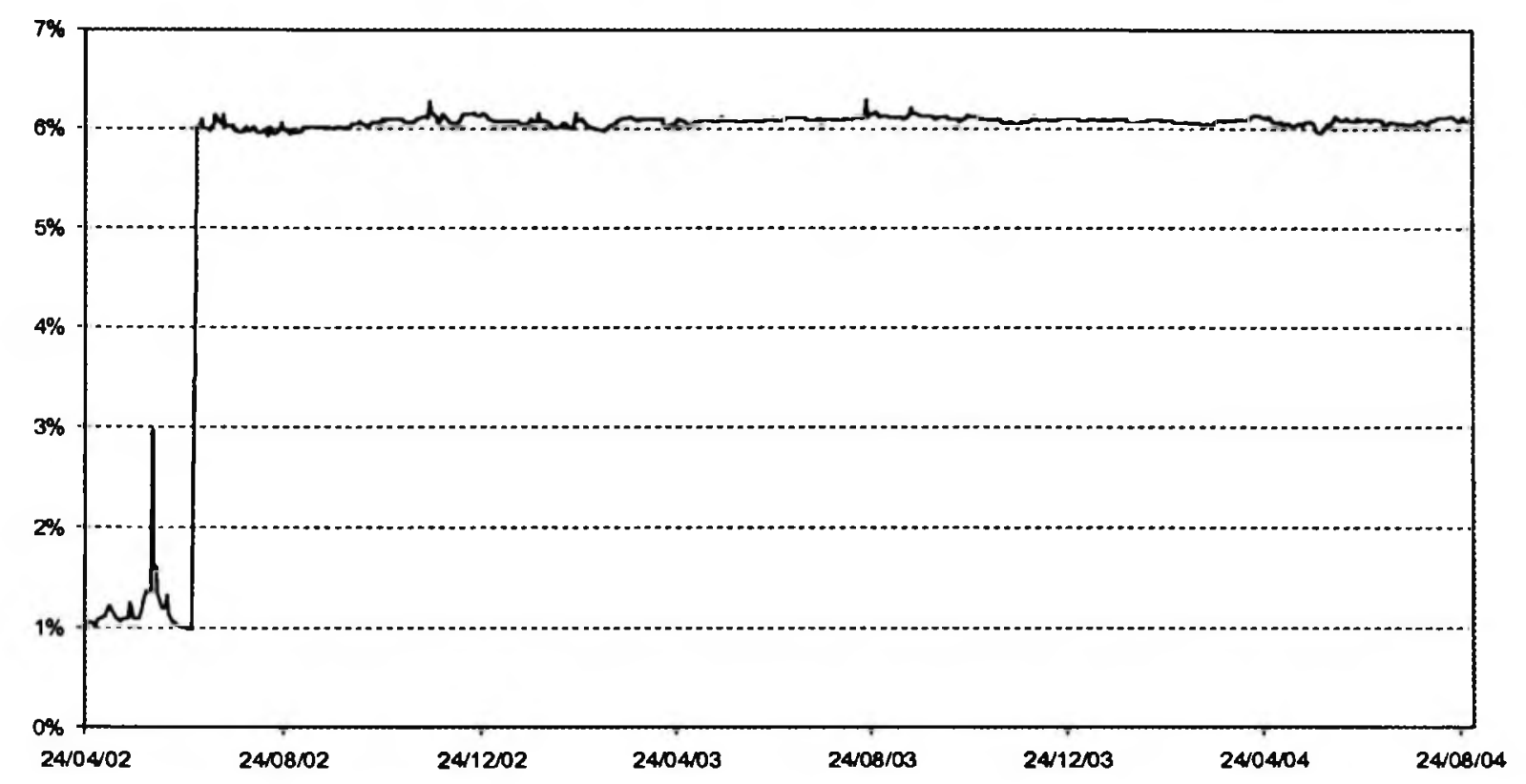

Figura 12 - Custo de Oportunidade do Redesconto Over (01/07/02 a 31/08/04)

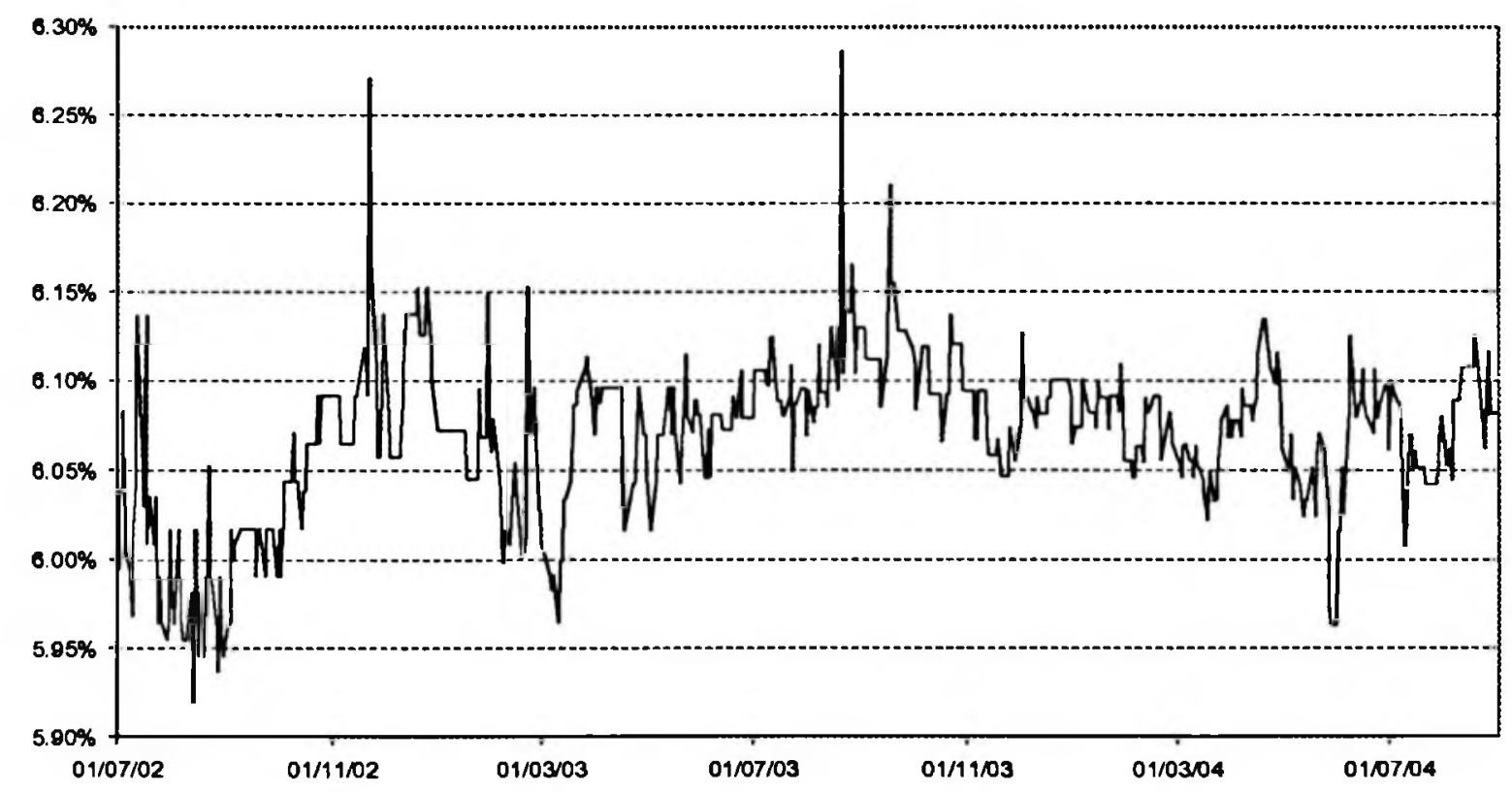


Definidas as variáveis que compõem os blocos da equação [19], a equação a ser estimada é:

$$
\begin{aligned}
& W_{i, t}=\sigma_{1}+\sigma_{2} \cdot \ln \_R V+\sigma_{3} \cdot \ln n_{-} s e l+\sigma_{4} \cdot \ln n_{-} c p+\sigma_{5} \cdot \ln \_c a+\sigma_{6} \cdot \ln \_s t 1+\sigma_{7} \cdot \ln \_s t 2+ \\
& +\theta_{\mathrm{g}} \cdot \ln \mathrm{n}_{-} s t 3+\theta_{9} \cdot \ln _{-} s o 1+\theta_{10} \cdot \ln _{-} s o 2+\theta_{11} \cdot \ln \ln _{-} s o 3+\xi_{1} \cdot \ln \_ \text {Exigivel }+\zeta_{1} \cdot d g a+ \\
& +\zeta_{2} \cdot d g b+\xi_{2} \cdot d 1 s 4+\xi_{3} \cdot d 1 s 5+\xi_{4} \cdot d 1 s 6+\xi_{5} \cdot d 2 s 2+\xi_{6} \cdot d 2 s 3+\xi_{7} \cdot d 2 s 4+ \\
& +\xi_{8} \cdot d 2 s 5+\xi_{9} \cdot d 2 s 6+\xi_{10} \cdot d 3 s 2+\xi_{11} \cdot d 3 s 3+\zeta_{3} \cdot \operatorname{tax} a_{-} r d c+\zeta_{4} \cdot \ln { }_{-} \text {Comp }+ \\
& +\zeta_{s} \cdot \ln \_ \text {ExgComp }+u_{i t}
\end{aligned}
$$

De acordo com o modelo, variáveis que aumentam o saldo ao final do dia diminuiriam a demanda por reservas e diminuiriam a probabilidade de utilização de redesconto tendo, portanto, coeficiente com sinal negativo. Assim, teríamos os seguintes sinais esperados para os coeficientes:

(1) ln_RSV e ln_rsvLl: coeficiente negativo;

(2) ln_sel, ln_cp, ln_ca, ln_st1, ln_st2, ln_st3, ln_so1, ln_so2, ln_so3, assumindo valores positivos para os lançamentos a crédito e negativos para os lançamentos a débito: coeficiente negativo;

(3) lnCD_Ag espera-se um coeficiente negativo.

(4) dga e dgb, dummies para os grupos do compulsório sobre depósitos à vista. Se os coeficientes forem positivos, há a indicação de que a exigência do cumprimento do depósito compulsório sobre depósitos à vista aumenta a probabilidade de utilizar o redesconto over. Uma informação que se espera obter é qual o dia do período de cumprimento com maior probabilidade de utilizar o redesconto over. 
(5) Para ln_Comp e ln_ExgComp espera-se um coeficiente positivo.

A equação [19] será estimada em duas formas: modelos de probabilidade (Probit e Logit), onde a variável $W_{i, s}$ é binária (1 quando utiliza redesconto e 0 quando não utiliza) e os modelos de demanda (Tobit e Heckit), onde a variável $W_{i,}$ é contínua (valor utilizado em redesconto). Para as duas formas serão estimados dois grupos de modelos (Pooled e efeitos aleatórios $^{75}$ ) e em cada grupo serão estimadas três formas funcionais diferentes (combinações do saldo em reservas ${ }^{76}$ ). Assim, teremos seis modelos para o Probit, seis modelos para o Logit, seis modelos para o Tobit e três modelos para o Heckit.

A tabela a seguir mostra a freqüência de ocorrência de operações de redesconto (variável $W_{i, ~}$ binária). Observa-se que as operações de nivelamento representam mais que o dobro das operações de redesconto over. Em oito casos as duas operações foram realizadas pela mesma instituição no mesmo dia.

Tabela 5 - Ocorrências de operações de Redesconto

\begin{tabular}{|l|r|r|r|r|r|}
\hline Operação & \multicolumn{2}{|c|}{0} & \multicolumn{1}{c|}{ Total } \\
\hline Over & 65.133 & $99,51 \%$ & 324 & $0,49 \%$ & 65.457 \\
\hline Nivelamento & 64.670 & $98,80 \%$ & 787 & $1,20 \%$ & 65.457 \\
\hline Redesconto & 64.354 & $98,31 \%$ & 1.103 & $1,69 \%$ & 65.457 \\
\hline
\end{tabular}

No período, o valor médio das operações de Redesconto Over foi de R\$168.938.233,00, enquanto que para as operações de nivelamento o valor médio foi de R\$191.152.961,33 e para a combinação destas duas operações a média foi de $\mathrm{R} \$ 186.013 .969,11$.

\footnotetext{
${ }^{75}$ Nos modelos de efeitos aleatórios foi utilizada a variável lnCD_Ag. Foi necessário utilizar uma variável agregada porque ocorreram problemas de travamento e de demora para convergência (mais de vinte e cinco iteracões). Para o modelo Heckit não foram estimados modelos de painel.

${ }^{76} \mathrm{O}$ primeiro modelo utiliza o saldo em reservas defasado em um periodo, o segundo apenas o saldo em reserva do próprio dia e o terceiro utiliza ambos.
} 


\section{Probabilidade de utilização do Redesconto, modelo Probit.}

A Tabela 6 traz os resultados obtidos por este modelo. Os modelos 1 a 3 utilizam o estimador Pooled Probit, ao passo que os modelos 4 a 6 utilizam o modelo Probit de efeitos aleatórios, ambos apresentados no capitulo 4. Cada célula da tabela traz em sua primeira linha o valor estimado do coeficiente da variável indicada na primeira coluna. $\mathrm{Na}$ segunda linha da célula estão o erro-padrão e, entre parênteses, a estatística z. Os desvios padrões reportados são robustos à presença de heterocedasticidade.

A taxa do redesconto (taxa_rdc), as dummies para o periodo de cumprimento (d1s4, d1s5, d1s6, d2s2, d2s3, d2s4, d2s5, d2s6, d3s2 e d3s3) e o agregado dos compulsórios (não incluindo os depósitos à vista - ln_Comp e ln_ExgComp) foram significativas a $1 \%$ para os 6 modelos.

A variável ln_ExgComp apresentou coeficiente com sinal contrário ao esperado nos seis modelos, indicando que quanto maior a exigibilidade agregada, menor a probabilidade de utilizar o Redesconto Over. Uma possível explicação pode estar no fato de que está variável é altamente correlacionada com a variável ln_Comp (correlação igual a 0,9643).

Com relação ao periodo de cumprimento, os dois dias com maior probabilidade são as duas segundas-feiras (quarto e nono dias do período), seguidos pelo segundo e terceiro dias do periodo (quando ainda não se sabe com exatidão a exigibilidade do compulsório sobre depósitos à vista).

Nos modelos 4, 5 e 6 (Probit efeitos aleatórios) as dummies de grupo, os saldos em reservas e a exigibilidade do compulsório sobre depósitos à vista não foram significativas ao nível de 5\%. 
O teste para a presença de efeitos não observados é reportado na última linha da tabela. Para os modelos 4, 5 e 6, ao nível de $1 \%$, rejeitou-se a hipótese nula de que $\rho=0^{77}$. Portanto, ao nível de $1 \%$, não se pode deprezar os efeitos não observáveis.

Tabela 6 - Resultados do Modelo Probit

\begin{tabular}{|c|c|c|c|c|c|c|}
\hline Variável & MODELO 1 & MODELO 2 & MODELO 3 & MODELO 4 & MODELO 5 & MODELO 6 \\
\hline \multirow{2}{*}{ dga } & 0,637 & 0,734 & 0,815 & $-0,088$ & 0,020 & 0,005 \\
\hline & $0,173 \quad(3,69)$ & $0,176 \quad(4,18)$ & $0,180 \quad(4,52)$ & $0,234 \quad(-0,38)$ & $0,248 \quad(0,08)$ & $0,287 \quad(0,02)$ \\
\hline \multirow{2}{*}{ dgb } & 0,553 & 0,652 & 0,730 & -0.066 & 0.044 & $-0,055$ \\
\hline & $0,174 \quad(3,18)$ & $0,177 \quad(3,69)$ & $0,181 \quad(4,03)$ & $0,235 \quad(-0,28)$ & $0,249 \quad(0.18)$ & $0,290 \quad(-0,19)$ \\
\hline \multirow{2}{*}{ taxa_rdc } & $-0,119$ & $-0,118$ & $-0,119$ & $-0,139$ & $-0,139$ & $-0,138$ \\
\hline & $0,007 \quad(-16,54)$ & $0,007 \quad(-16,58)$ & $0,007 \quad(-16,52)$ & $0,008 \quad(-16,75)$ & $0,008 \quad(-16,77)$ & $0,008 \quad(-16,45)$ \\
\hline \multirow{2}{*}{ ln_RSV } & - & 0,070 & 0,053 & - & 0,003 & -0.006 \\
\hline & - & $0,012 \quad(6,02)$ & $0,018 \quad(3,04)$ & - & $0,017 \quad(0,17)$ & $0,021 \quad(-0,27)$ \\
\hline \multirow{2}{*}{ ln_rsvLl } & 0,062 & - & 0,025 & -0.005 & - & -0.016 \\
\hline & $0,011 \quad(5,52)$ & $-\quad-$ & $0,017 \quad(1,47)$ & $0,016 \quad(-0,31)$ & $-\quad-$ & $0,020 \quad(-0,81)$ \\
\hline In Frigivel & $-0,050$ & $-0,058$ & $-0,065$ & 0,000 & $-0,008$ & 0,004 \\
\hline -Eagivel & $0,012 \quad(-4,05)$ & $0,013 \quad(-4,59)$ & $0,013 \quad(-4,95)$ & $0,018 \quad(0,03)$ & $0,019 \quad(-0,44)$ & $(0,18)$ \\
\hline In Comn & 0,055 & 0,055 & 0,056 & 0,060 & 0,061 & 0,103 \\
\hline 10_-соше & $0,007 \quad(8,27)$ & $0,007 \quad(8,36)$ & $0,007 \quad(8,44)$ & $0,008 \quad(7,09)$ & $0,008 \quad(7,31)$ & $0,011 \quad(8,94)$ \\
\hline In Exor & $-0,058$ & $-0,058$ & $-0,059$ & $-0,076$ & $-0,076$ & $-0,079$ \\
\hline & $0,006 \quad(-8,90)$ & $0,006 \quad(-8,99)$ & $0,007 \quad(-9,09)$ & $0,008 \quad(-9,82)$ & $0,008 \quad(-9,96)$ & $0,010 \quad(-7,99)$ \\
\hline d l c 4 & 0,516 & 0,508 & 0,509 & 0,955 & 1,409 & 0,973 \\
\hline 0134 & $0,071 \quad(7,26)$ & $0,071 \quad(7,15)$ & $0,071 \quad(7,16)$ & $0,094 \quad(10,14)$ & $0,102 \quad(13,76)$ & $0,168 \quad(5,79)$ \\
\hline$d=5$ & 0,566 & 0,564 & 0,559 & 1,009 & 1,467 & 1,030 \\
\hline 0135 & $0,069 \quad(8,17)$ & $0,069 \quad(8,11)$ & $0,069 \quad(8,07)$ & $0,093 \quad(10,83)$ & $0,102 \quad(14,40)$ & $0,168 \quad(6,13)$ \\
\hline$d 1=6$ & 0,641 & 0,642 & 0,636 & 1,093 & 1,551 & 1,112 \\
\hline diso & $0,068 \quad(9,45)$ & $0,068 \quad(9,45)$ & $0,068 \quad(9,38)$ & $0,091 \quad(11,97)$ & $0,100 \quad(15,53)$ & $0,167 \quad(6,66)$ \\
\hline (4)? & 0,752 & 0,751 & 0,746 & 1,241 & 1,699 & 1,260 \\
\hline ULS2 & $0,066 \quad(11,38)$ & $0,066 \quad(11,35)$ & $0,066 \quad(11,29)$ & $0,090 \quad(13,85)$ & $0,099 \quad(17,19)$ & $0,166 \quad(7,59)$ \\
\hline $\mathrm{d} 2 \mathrm{c} 3$ & 0,540 & 0,538 & 0,533 & 0,980 & 1,439 & 0,993 \\
\hline a 253 & $0,070 \quad(7,76)$ & $0,070 \quad(7,73)$ & $0,069 \quad(7,67)$ & $0,093 \quad(10,49)$ & $0,102 \quad(14,08)$ & $0,168 \quad(5,90)$ \\
\hline $12 \sigma$ & 0,461 & 0,466 & 0,456 & 0,864 & 1,325 & 0,876 \\
\hline d 284 & $0,072 \quad(6,37)$ & $0,072 \quad(6,47)$ & $0,072 \quad(6,31)$ & $0,096 \quad(8,98)$ & $0,104 \quad(12,74)$ & $0,170 \quad(5,16)$ \\
\hline$d^{\prime}$ & 0,542 & 0,543 & 0,537 & 0,972 & 1,431 & 0,989 \\
\hline aLso & $0,070 \quad(7,75)$ & $0,070 \quad(7,77)$ & $0,070 \quad(7,69)$ & $0,094 \quad(10,38)$ & $0,102 \quad(14,04)$ & $0,168 \quad(5,91)$ \\
\hline & 0,558 & 0,560 & 0,554 & 1,004 & 1,463 & 1,018 \\
\hline a 2 so & $0,069 \quad(8,10)$ & $0,069 \quad(8,10)$ & $0,069 \quad(8,04)$ & $0,093 \quad(10,82)$ & $0,101 \quad(14,48)$ & $0,167 \quad(6,10)$ \\
\hline
\end{tabular}

${ }^{77} \rho$ é uma medida da importância relativa do efeito não observado e é definido como $\rho=\sigma_{c}^{2} /\left(\sigma_{c}^{2}+1\right)$, onde $\sigma_{C}^{2}$ é a variância da componente não observável. 


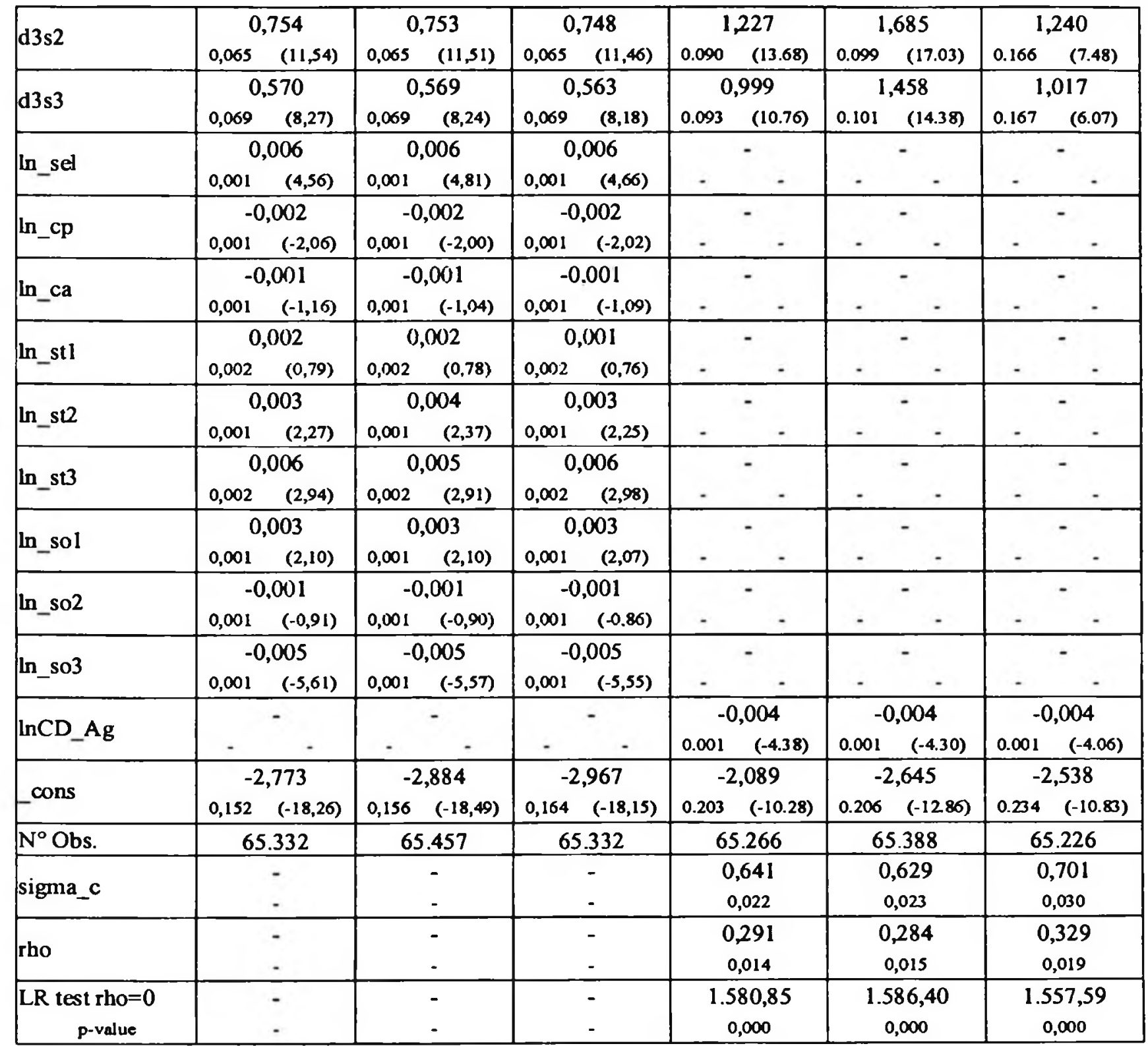

As Figuras $^{78} 13,14$ e 15 mostram o valor médio das probabilidades de utilização diária do Redesconto Over, considerando o Modelo 1 e a distribuição por grupo no compulsório sobre depósitos à vista. Observa-se o efeito da diminuição da taxa do redesconto ocorrida em $1^{\circ}$ de

\footnotetext{
${ }^{78}$ Apenas para o Modelo 1 do Probit foram feitos gráficos por grupos (A e B) de cumprimento do compulsório sobre depósitos à vista. Como os resultados não foram discrepantes, para os demais essa separação não foi realizada.
} 
julho de 2002. Outra observação diz respeito à influência do dia do período de cumprimento do compulsório sobre depósitos à vista. 
Figura 13 - Probit - Modelo I, Grupo A

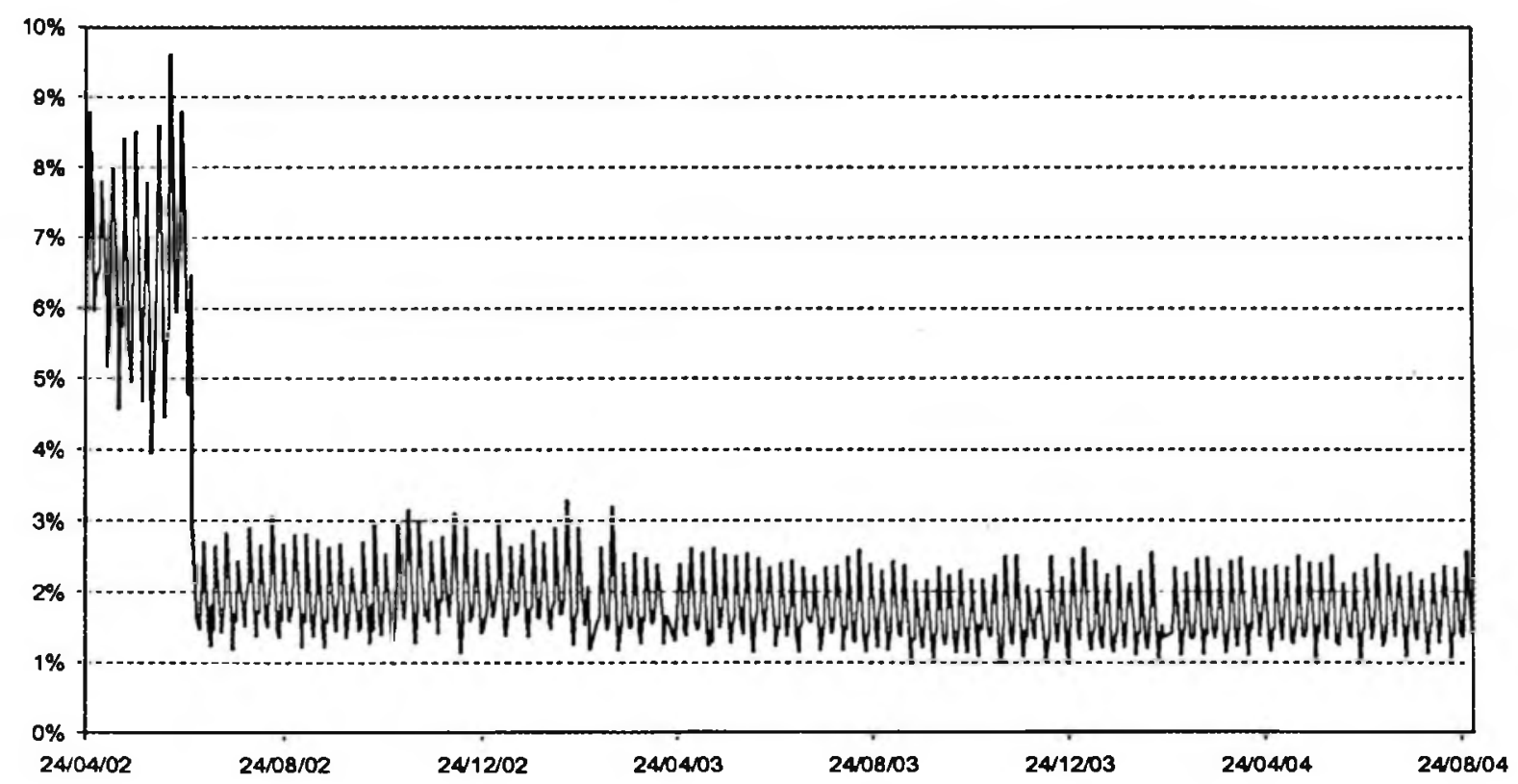

Figura 14 - Probit - Modelo 1, Grupo B

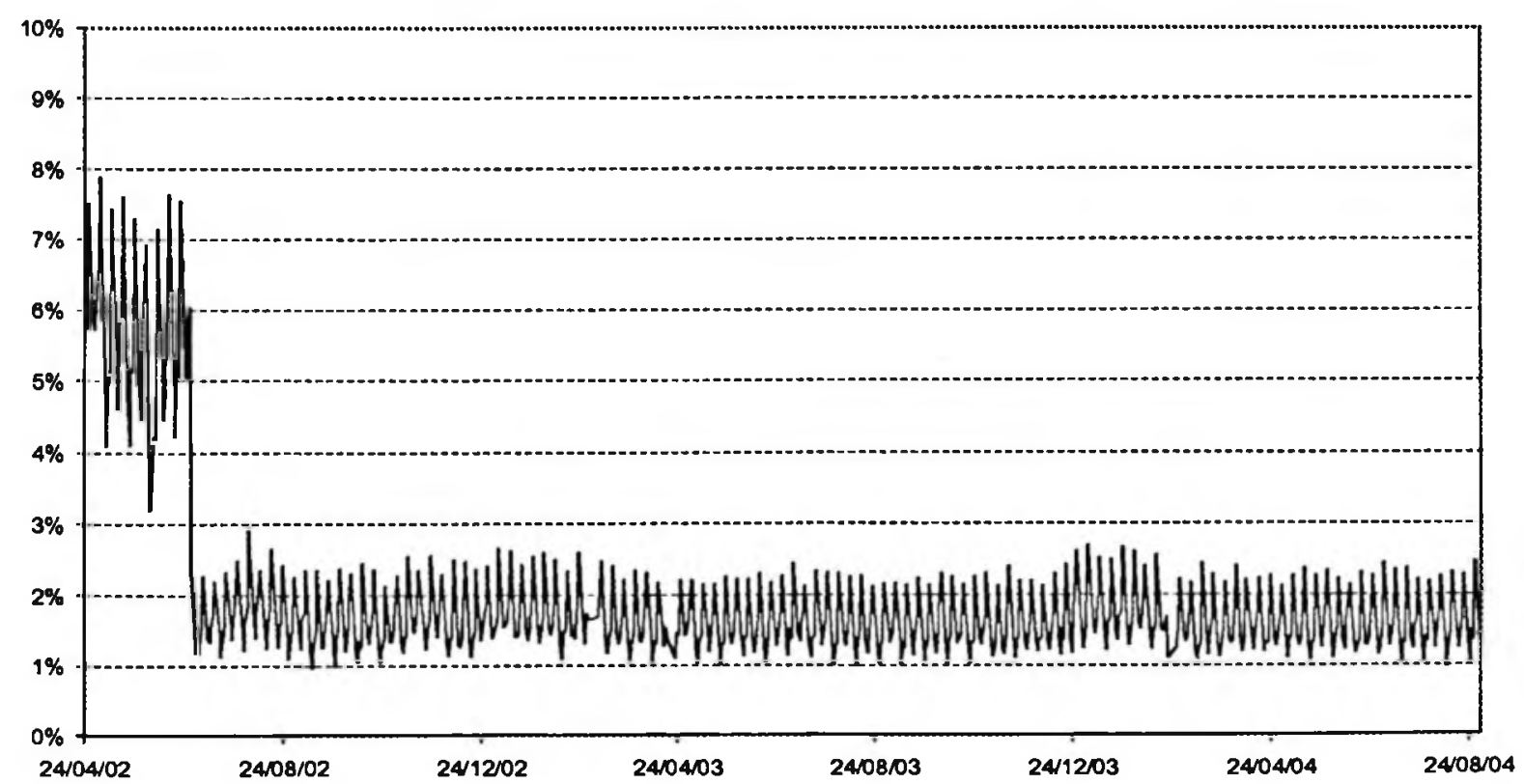


Figura 15 - Probit - Modelo 1, bancos sem exigibilidade de compulsório sobre depósitos à vista.

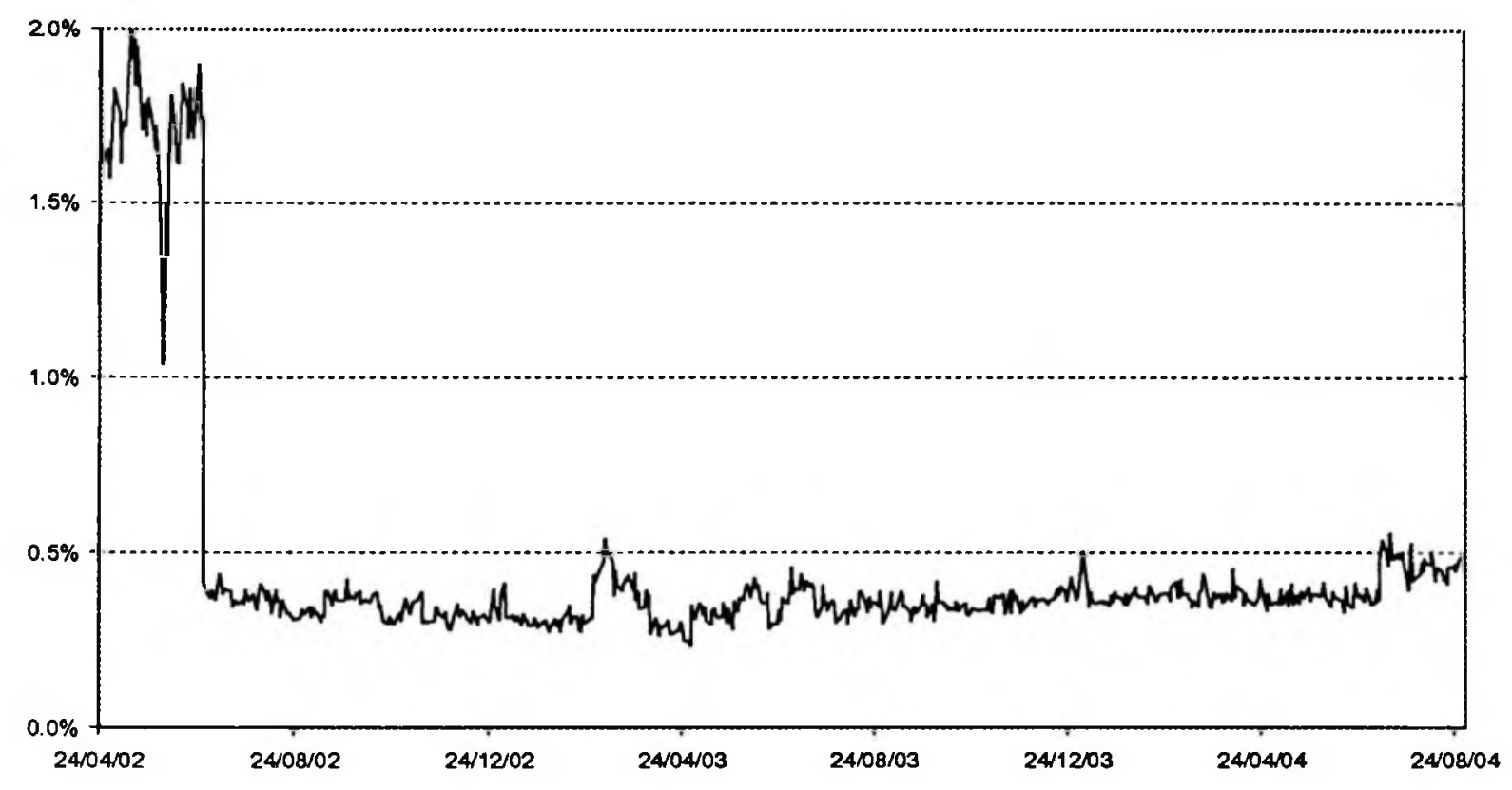

A Figura 16 apresenta as probabilidades de utilização do redesconto de acordo com os quartis de distribuição para o Probit - Modelo 1, considerando todos as 122 instituições financeiras da amostra. Q1 representa o banco situado no primeiro quartil em relação à probabilidade de utilização de redesconto estimada pelo modelo em cada dia da amostra e Q3 o banco situado no terceiro quartil. Dessa forma, em cada dia Q1 será representado por uma instituição financeira que não necessariamente é a mesma dos outros dias do período (Q3 segue o mesmo princípio). 
Figura 16 - Probit - Modelo 1, QI e Q3

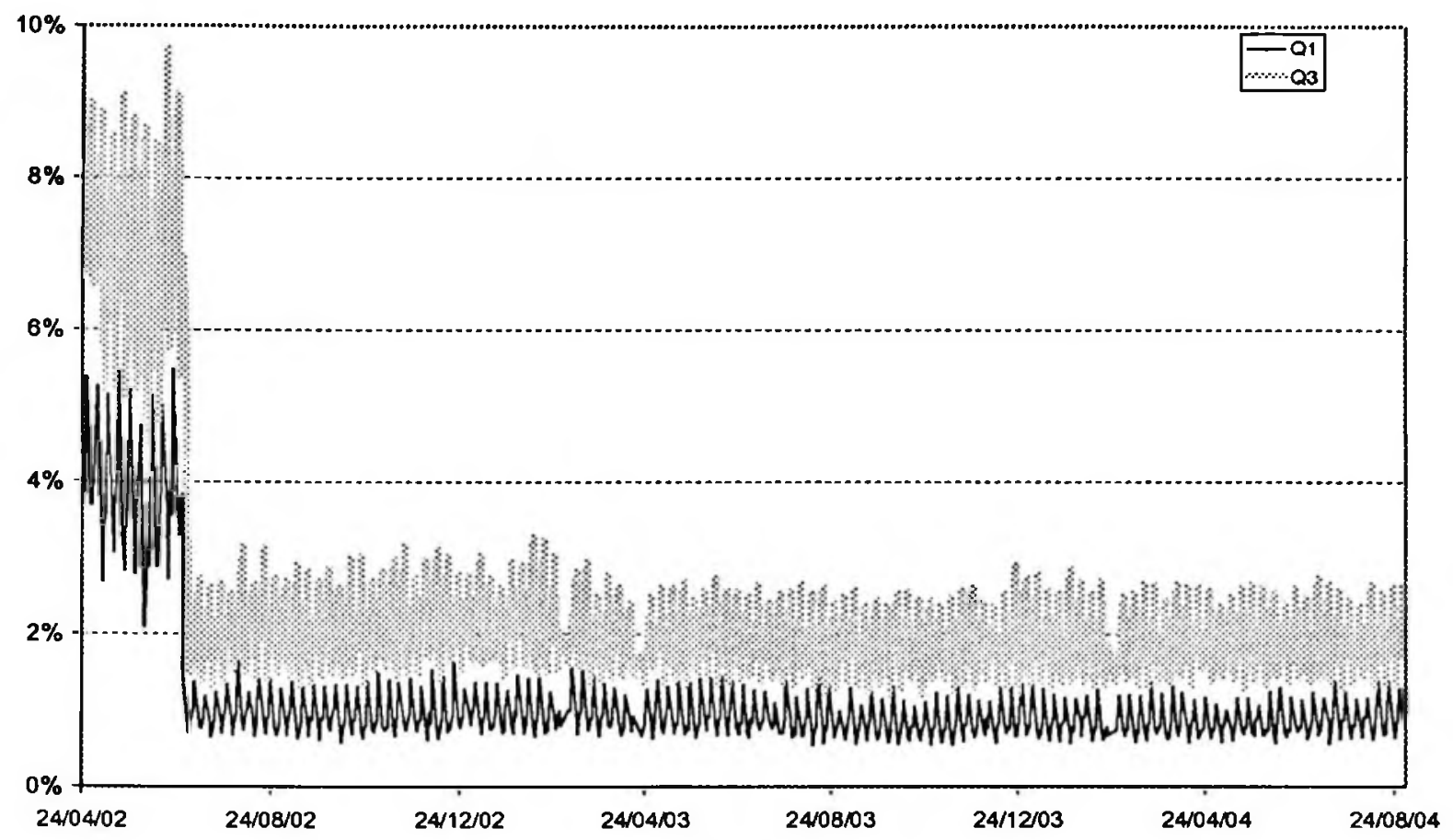

Observamos que a "volatilidade relativa" 79 de Q3 é menor do que a "volatilidade relativa" de Q1 nos dois períodos (Periodol ${ }^{80}$ : de 24/04/2002 até 28/06/2002 - 20,2\% contra 22,7\% - e Período 2: de 01/07/2002 até 31/08/2004 - 25,5\% contra $26,9 \%$ ) e que ela aumenta na passagem do primeiro para o segundo periodo. Isto decorre do fato de que a diferença entre as médias é muito maior do que a diferença entre os desvios-padrões, tornando o nível de probabilidade o fator determinante da "volatilidade relativa".

\footnotetext{
79 Definimos a "volatilidade absoluta" como o desvio padrão e a "volatilidade relativa" como a relação entre a "volatilidade absoluta" e a média.

${ }^{80}$ Estes períodos foram definidos com base na alteraç̃̃o da sobretaxa do redesconto.
} 
A seguir, nas Figuras 17 a 22, apresentamos os gráficos dos modelos 2, 3, 4, 5 e 6 das médias de probabilidades e do modelo 4 com a distinção entre os bancos Q1 e Q3, sem fazer diferenciação entre os grupos do compulsório sobre depósitos à vista.

Figura 17 - Probit - Modelo 2

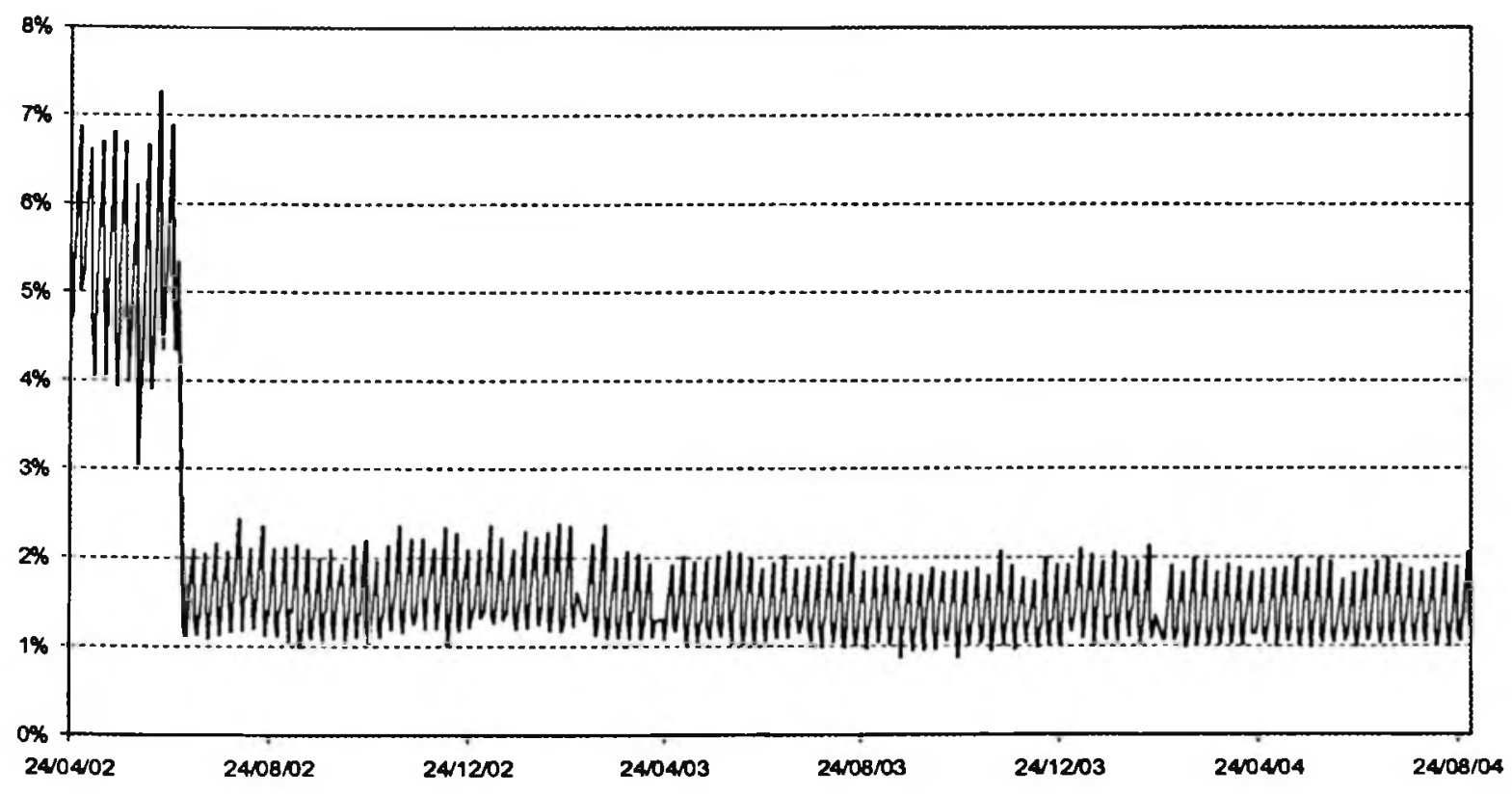


Figura 18 - Probit - Modelo 3

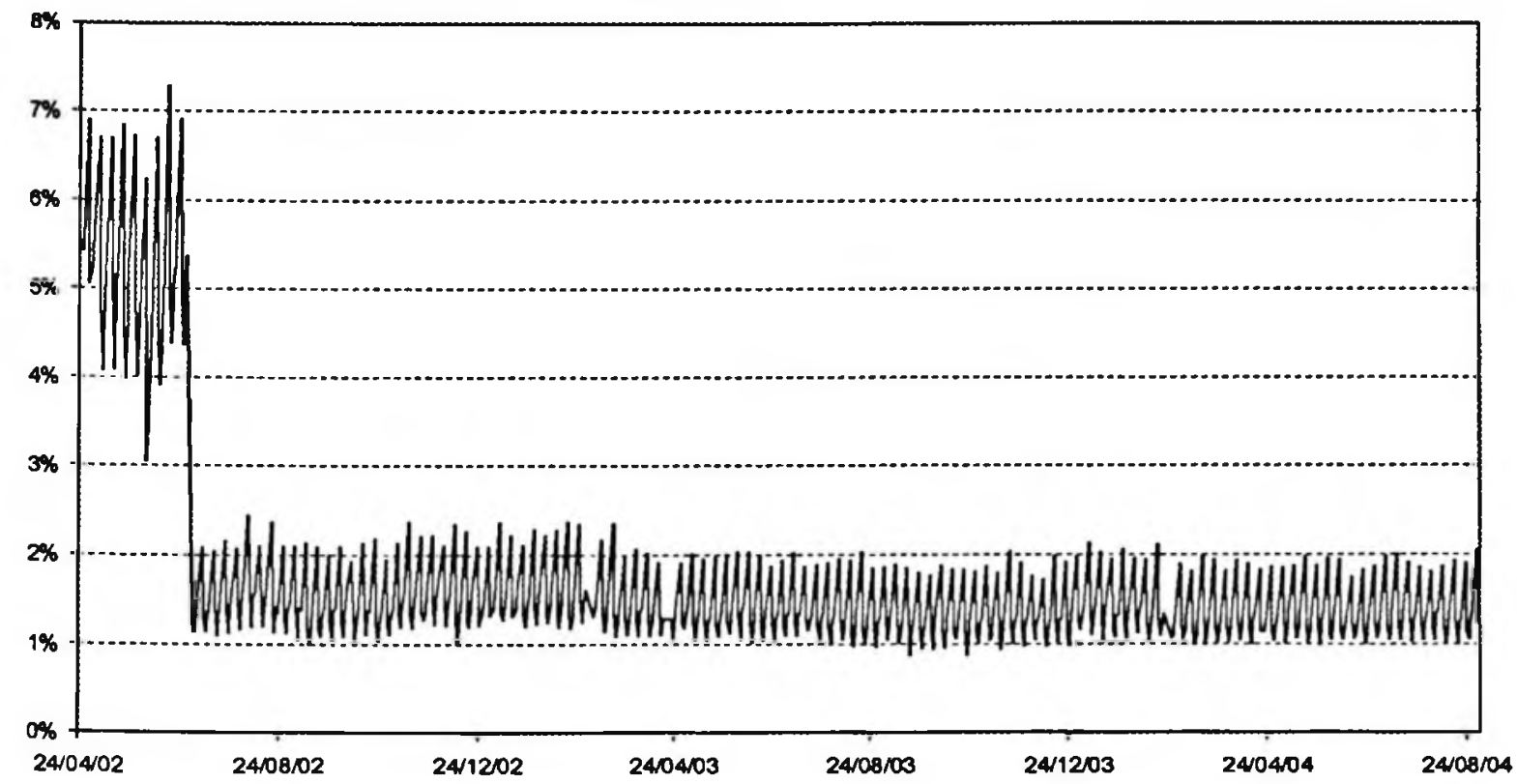

Figura 19 - Probit - Modelo 4

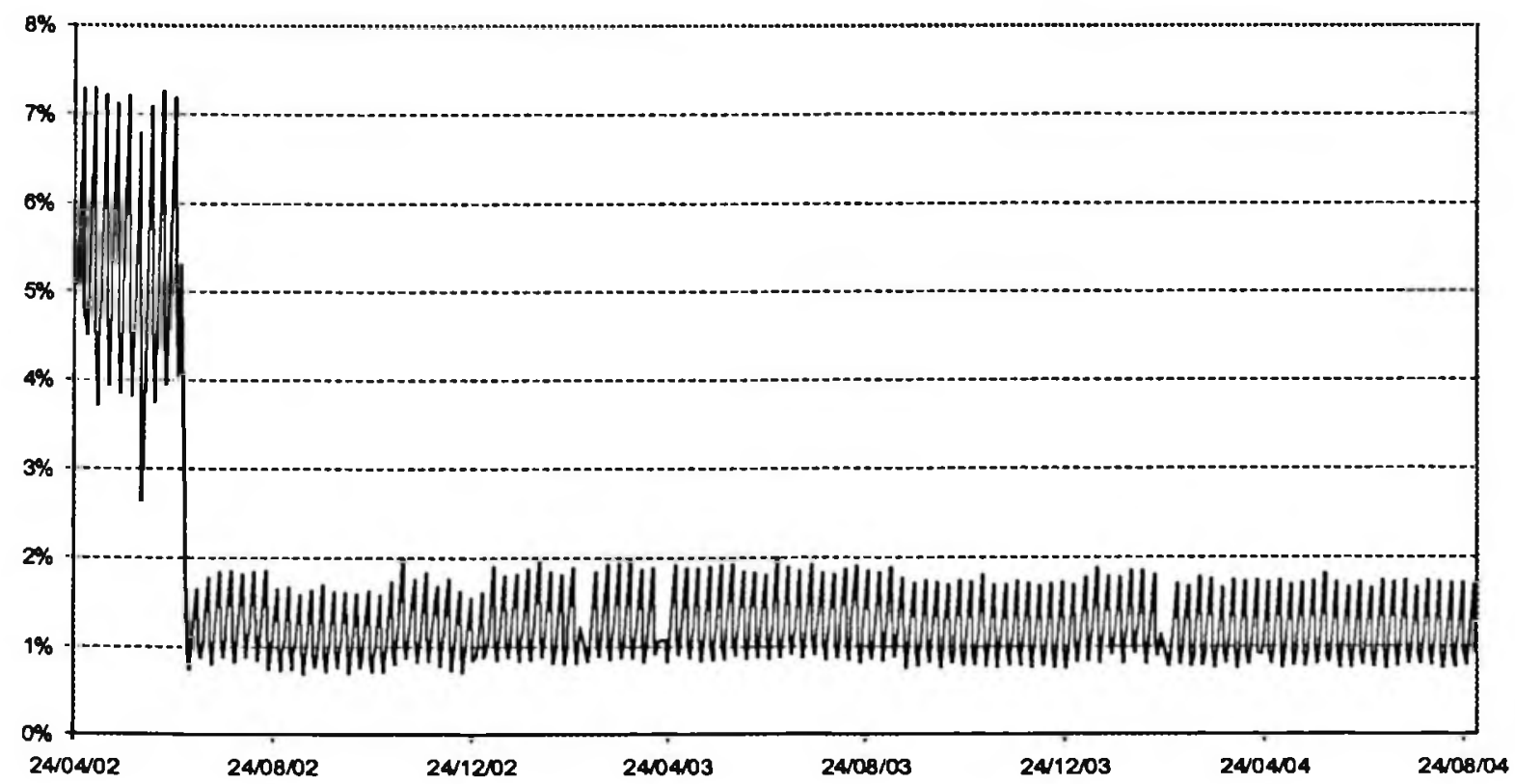


Figura 20 - Probit - Modelo 4, QI e Q3

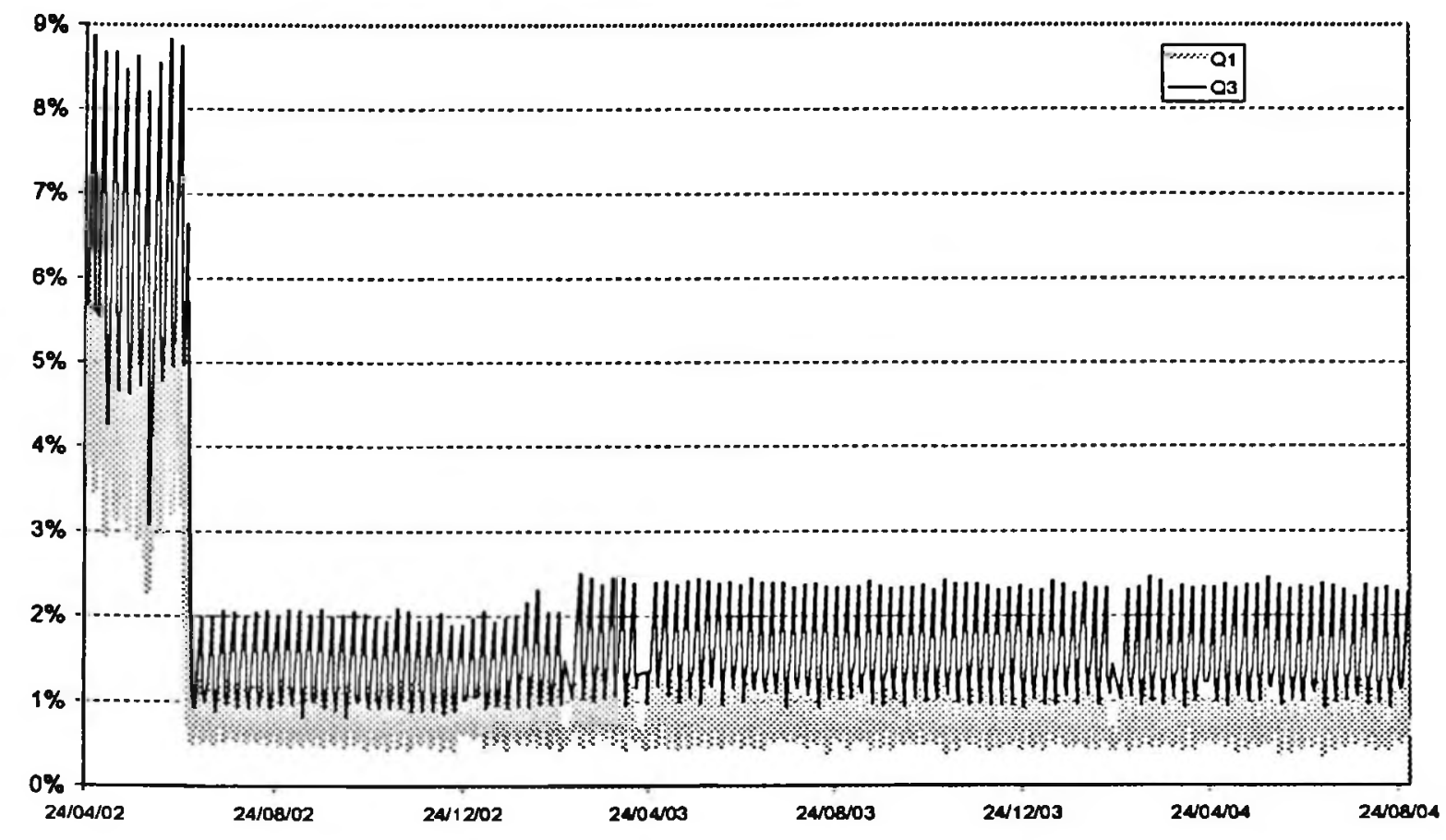


Figura 21 - Probit - Modelo 5

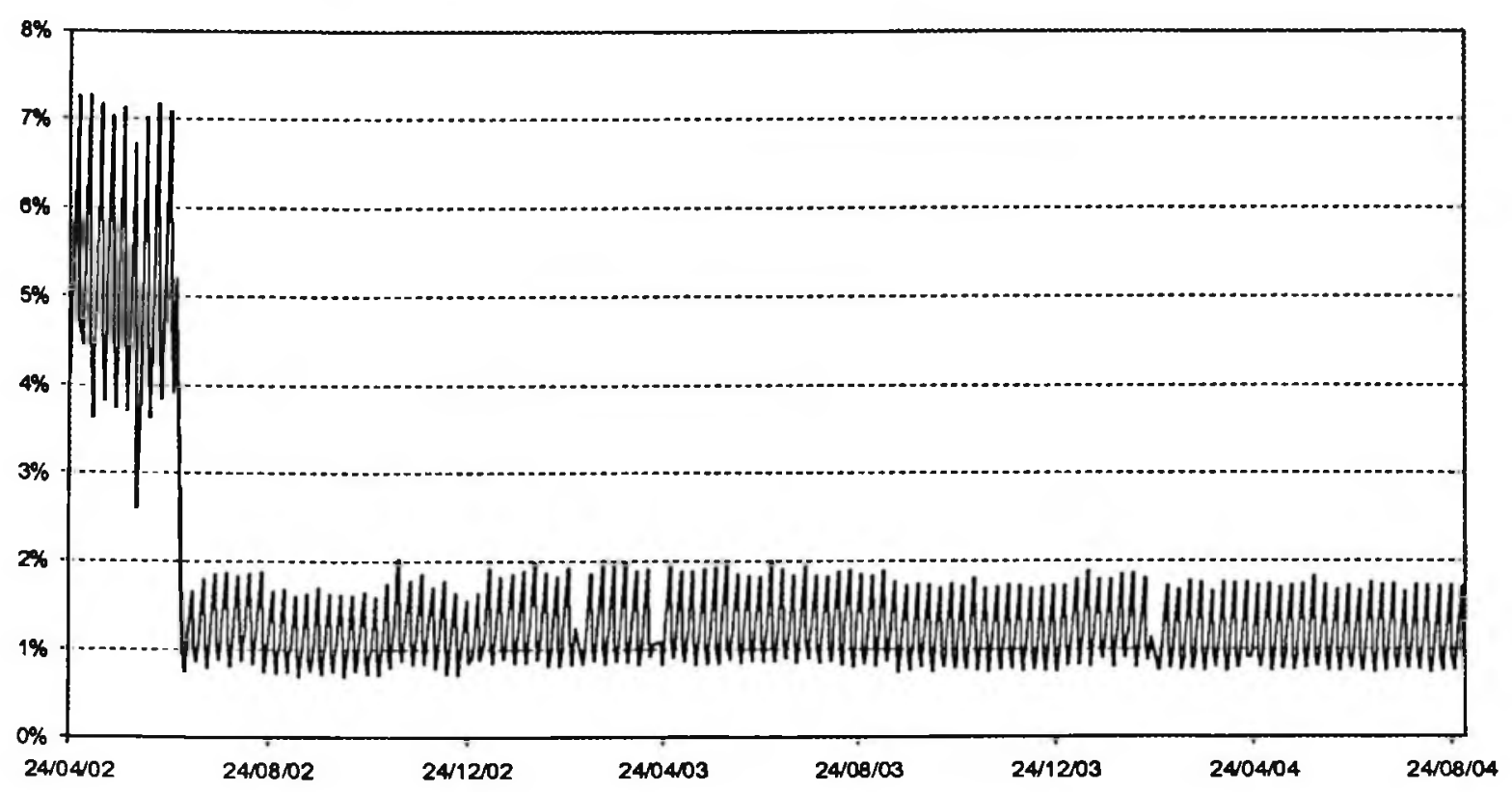

Figura 22 - Probit - Modelo 6

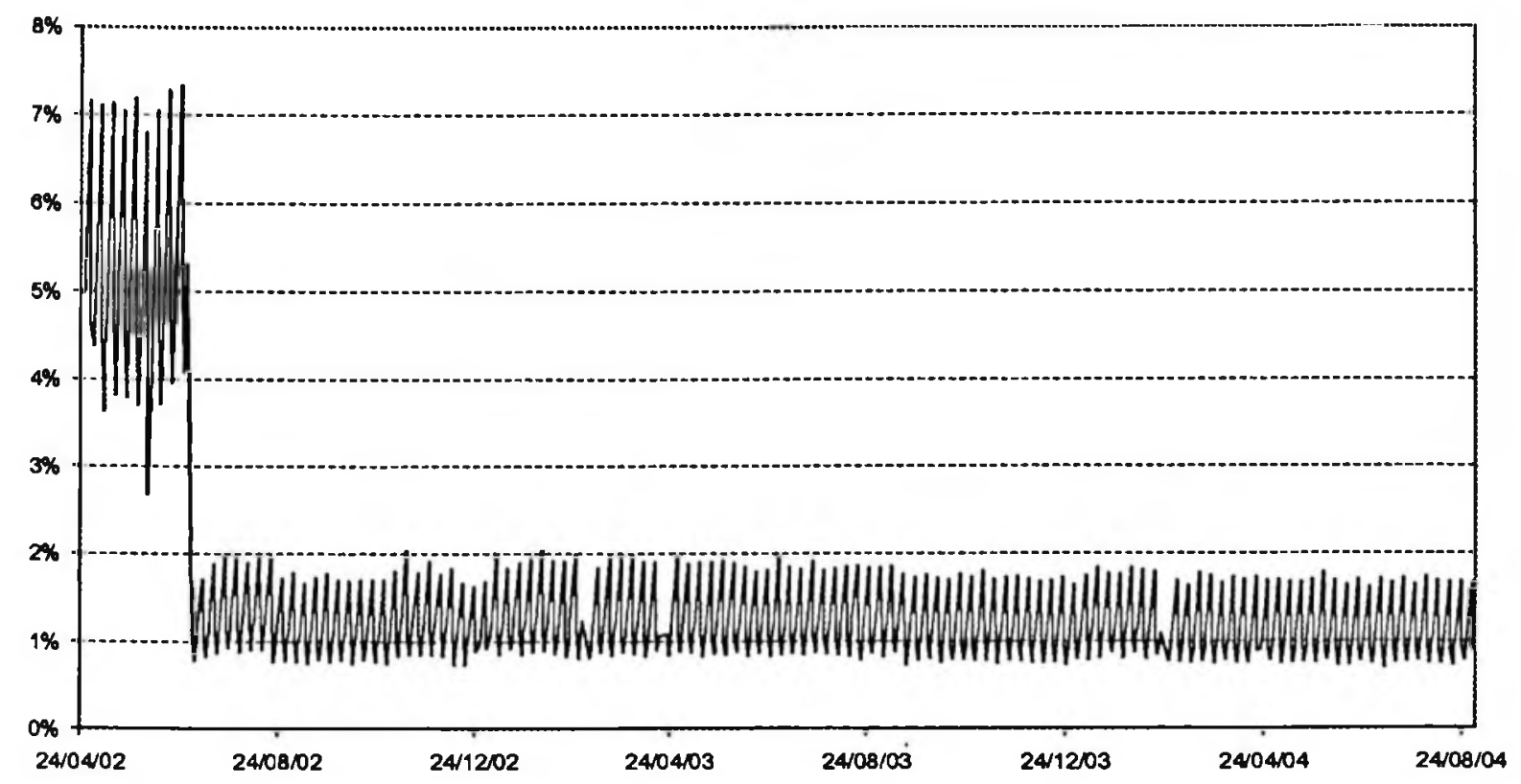


A Tabela 7 mostra a variação do valor médio da probabilidade para os seis modelos.

Tabela 7 - Probabilidade média para o modelo Probit

\begin{tabular}{|c|c|c|}
\hline \multirow{2}{*}{ Modelo } & \multicolumn{2}{|c|}{ Probabilidade Média } \\
\cline { 2 - 3 } & $22 / 04 / 02$ a $28 / 06 / 02$ & $01 / 07 / 02$ a 31/08/04 \\
\hline 1 & $5,13 \%$ & $1,39 \%$ \\
\hline 2 & $5,09 \%$ & $1,39 \%$ \\
\hline 3 & $5,12 \%$ & $1,39 \%$ \\
\hline 4 & $5,02 \%$ & $1,14 \%$ \\
\hline 5 & $4,91 \%$ & $1,13 \%$ \\
\hline 6 & $4,98 \%$ & $1,14 \%$ \\
\hline
\end{tabular}

Podemos observar que os modelos 1,2 e 3 apresentam probabilidades de utilização do redesconto ligeiramente maiores que os modelos em painel $(4,5$ e 6$)$. Observa-se também a queda nas probabilidades de utilização do redesconto após $1^{\circ}$ de julho de 2002 . No apêndice A são apresentados os resultados das estimativas para este segundo sub periodo. 


\subsection{Probabilidade de utilização do Redesconto, modelo Logit.}

Foram feitas regressões para o modelo Logit com as mesmas formas funcionais do modelo Probit. Os resultados estão na Tabela 8 e seguem a mesma ordenação de modelos e a mesma representação de coeficientes, erros-padrão e estatística z que a Tabela 6. Assim, os modelos 1 a 3 correpondem ao estimador Pooled Logit enquanto os modelos 4 a 6 correspondem ao caso do modelo Logit de efeitos aleatórios.

Tabela 8 - Resultados do Modelo Logit

\begin{tabular}{|c|c|c|c|c|c|c|}
\hline Variável & MODELO 1 & MODELO 2 & MODELO 3 & MODELO 4 & MODELO 5 & MODELO 6 \\
\hline \multirow{2}{*}{ dga } & 1,524 & 1,760 & 1,949 & $-1,127$ & 0,950 & $-0,372$ \\
\hline & $0,431 \quad(3,54)$ & $0,437 \quad(4,03)$ & $0,450 \quad(4,33)$ & $0,546 \quad(-2,07)$ & $0,496 \quad(1,91)$ & $0,548 \quad(-0,68)$ \\
\hline \multirow{2}{*}{ dgb } & 1,317 & 1,558 & 1,740 & $-1,468$ & 0,800 & $-0,163$ \\
\hline & $0,435 \quad(3,03)$ & $0,440 \quad(3,54)$ & $0,454 \quad(3,83)$ & $0,548 \quad(-2,68)$ & $0,493 \quad(1,62)$ & $0,544 \quad(-0,30)$ \\
\hline \multirow{2}{*}{ taxa_rdc } & $-0,275$ & $-0,274$ & $-0,275$ & $-0,313$ & $-0,307$ & $-0,325$ \\
\hline & $0,016 \quad(-16,91)$ & $0,016 \quad(-16,97)$ & $0,016 \quad(-16,90)$ & $0,017 \quad(-17,93)$ & $0,017 \quad(-17,70)$ & $0,018 \quad(-18,38)$ \\
\hline \multirow{2}{*}{ In_RSV } & - & 0,170 & 0,130 & - & $-0,023$ & $-0,006$ \\
\hline & & $0,030 \quad(5,70)$ & $0,045 \quad(2,89)$ & - & $0,036 \quad(-0,63)$ & $0,045 \quad(-0,13)$ \\
\hline \multirow{2}{*}{ ln_rsvLl } & 0,149 & - & 0,059 & $-0,071$ & - & $-0,036$ \\
\hline & $0,029 \quad(5,22)$ & - & $0,043 \quad(1,37)$ & $0,038 \quad(-1,87)$ & - & $0,044 \quad(-0,81)$ \\
\hline In Exigivel & $-0,121$ & $-0,141$ & $-0,157$ & 0,101 & $-0,061$ & 0,004 \\
\hline n_Exigivel & $0,031 \quad(-3,88)$ & $0,032 \quad(-4,42)$ & $0,033 \quad(-4,73)$ & $0,041 \quad(2,45)$ & $0,038 \quad(-1,61)$ & $0,042 \quad(0,11)$ \\
\hline In Comn & 0,133 & 0,133 & 0,134 & 0,182 & 0,145 & 0,129 \\
\hline & $0,015 \quad(8,64)$ & $0,015 \quad(8,69)$ & $0,015 \quad(8,74)$ & $0,018 \quad(10,28)$ & $0,018 \quad(7,91)$ & $0,017 \quad(7,52)$ \\
\hline $\ln E_{x}$ & $-0,141$ & $-0,141$ & $-0,142$ & $-0,193$ & $-0,156$ & $-0,150$ \\
\hline U_ExgCOाா & $0,015 \quad(-9,49)$ & $0,015 \quad(-9,54)$ & $0,015 \quad(-9,63)$ & $0,017 \quad(-11,64)$ & $0,016 \quad(-9,85)$ & $0,015 \quad(-9,71)$ \\
\hline d1s4 & 1,411 & 1,386 & 1,391 & 1,804 & 2,900 & 1,892 \\
\hline & $0,189 \quad(7,45)$ & $0,189 \quad(7,33)$ & $0,189 \quad(7,36)$ & $0,239 \quad(7,54)$ & $0,253 \quad(11,48)$ & $0,237 \quad(7,97)$ \\
\hline d1s5 & 1,553 & 1,543 & 1,532 & 1,962 & 3,071 & 2,050 \\
\hline & $0,184 \quad(8,43)$ & $0,185 \quad(8,36)$ & $0,184 \quad(8,33)$ & $0,235 \quad(8,33)$ & $0,250 \quad(12,28)$ & $0,234 \quad(8,77)$ \\
\hline d1s6 & 1,731 & 1,729 & 1,715 & 2,142 & 3,245 & 2,228 \\
\hline & $0,180 \quad(9,62)$ & $0,180 \quad(9,61)$ & $0,179 \quad(9,56)$ & $0,232 \quad(9,23)$ & $0,246 \quad(13,19)$ & $0,230 \quad(9,69)$ \\
\hline d2s 2 & 1,974 & 1,967 & 1,954 & 2,412 & 3,516 & 2,503 \\
\hline & $0,175 \quad(11,30)$ & $0,175 \quad(11,25)$ & $0,174 \quad(11,21)$ & $0,228 \quad(10,56)$ & $0,243 \quad(14,45)$ & $0,226 \quad(11,05)$ \\
\hline$d 2 s 3$ & 1,501 & 1,495 & 1,481 & 1,878 & 2,981 & 1,963 \\
\hline & $0,186 \quad(8,08)$ & $0,185 \quad(8,06)$ & $0,185 \quad(8,01)$ & $0,238 \quad(7,90)$ & $0,251 \quad(11,80)$ & $0,236 \quad(8,33)$ \\
\hline d2s 4 & 1,286 & 1,293 & 1,271 & 1,638 & 2,751 & 1,719 \\
\hline & $0,194 \quad(6,63)$ & $0,192 \quad(6,72)$ & $0,193 \quad(6,57)$ & $0,244 \quad(6,71)$ & $0,256 \quad(10,77)$ & $0,242 \quad(7,11)$ \\
\hline d2s 5 & 1,500 & 1,501 & 1,487 & 1,895 & 3,002 & 1,983 \\
\hline & $0,186 \quad(8,08)$ & $0,185 \quad(8,12)$ & $0,185 \quad(8,05)$ & $0,237 \quad(7,99)$ & $0,251 \quad(11,98)$ & $0,235 \quad(8,44)$ \\
\hline
\end{tabular}




\begin{tabular}{|c|c|c|c|c|c|c|}
\hline \multirow{2}{*}{$\mathrm{d} 2 \mathrm{~s} 6$} & 1,527 & 1,526 & 1,512 & 1,918 & 3,023 & 2,004 \\
\hline & $0,182 \quad(8,38)$ & $0,183 \quad(8,36)$ & $0,182 \quad(8,32)$ & $0,236 \quad(8,13)$ & $0,249 \quad(12,14)$ & $0,233 \quad(8,58)$ \\
\hline \multirow{2}{*}{ d3s2 } & 1,989 & 1,984 & 1,973 & 2,406 & 3,513 & 2,497 \\
\hline & $0,172 \quad(11,54)$ & $0,172 \quad(11,52)$ & $0,172 \quad(11,49)$ & $0,228 \quad(10,55)$ & $0,242 \quad(14,49)$ & $0,226 \quad(11,06)$ \\
\hline \multirow{2}{*}{ d3s 3} & 1,561 & 1,555 & 1,543 & 1,911 & 3,020 & 1,997 \\
\hline & $0,183 \quad(8,52)$ & $0,183 \quad(8,49)$ & $0,183 \quad(8,45)$ & $0,236 \quad(8,10)$ & $0,250 \quad(12,10)$ & $0,234 \quad(8,54)$ \\
\hline \multirow{2}{*}{ ln_sed } & 0,013 & 0,014 & 0,014 & - & - & - \\
\hline & $0, \infty 3 \quad(4,39)$ & $0,003 \quad(4,64)$ & $0,003 \quad(4,49)$ & - & - & - \\
\hline $\ln \mathrm{cp}$ & $-0,004$ & $-0,004$ & $-0,004$ & - & - & - \\
\hline & $0, \infty 02 \quad(-1,74)$ & $0,002 \quad(-1,70)$ & $0,002 \quad(-1,72)$ & - & - & - \\
\hline $\ln \mathrm{ca}$ & $-0,003$ & $-0,003$ & $-0,003$ & - & - & - \\
\hline & $0,002 \quad(-1,18)$ & $0,002 \quad(-1,06)$ & $0,002 \quad(-1,12)$ & - & - & - \\
\hline In stl & 0,004 & 0,004 & 0,004 & - & - & - \\
\hline$-\cdots$ & $0,005 \quad(0,89)$ & $0,005 \quad(0,91)$ & $0,005 \quad(0,88)$ & - & - & - \\
\hline $\ln s t 2$ & 0,008 & 0,008 & 0,008 & - & - & - \\
\hline 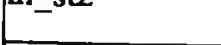 & $0,004 \quad(2,22)$ & $0,004 \quad(2,31)$ & $0,004 \quad(2,19)$ & - & - & - \\
\hline In st3 & 0,013 & 0,013 & 0,013 & - & - & - \\
\hline alisw & $0,005 \quad(2,81)$ & $0,005 \quad(2,74)$ & $0,005 \quad(2,84)$ & - & - & - \\
\hline $\ln$ sol & 0,007 & 0,008 & 0,007 & - & - & - \\
\hline & $0,003 \quad(2,29)$ & $0,003 \quad(2,32)$ & $0,003 \quad(2,29)$ & - & - & - \\
\hline $\ln \mathrm{so} 2$ & $-0,002$ & $-0,002$ & $-0,002$ & - & - & - \\
\hline & $0,002 \quad(-0,84)$ & $0,002 \quad(-0,80)$ & $0,002 \quad(-0,76)$ & - & - & - \\
\hline $\ln$ so3 & $-0,013$ & $-0,013$ & $-0,013$ & - & - & - \\
\hline & $0,002 \quad(-5,48)$ & $0,002 \quad(-5,45)$ & $0,002 \quad(-5,42)$ & $-\quad-$ & $-\quad-$ & - \\
\hline $\ln C D A g$ & - & - & - & $-0,009$ & $-0,009$ & $-0,009$ \\
\hline & $-\quad-$ & $-\quad-$ & $-\quad-$ & $0,002 \quad(-4,11)$ & $0,002 \quad(-4,10)$ & $0,002 \quad(-4,26)$ \\
\hline cons & $-5,882$ & $-6,147$ & $-6,347$ & $-4,543$ & $-6,072$ & $-4,364$ \\
\hline - Wis & $0,382 \quad(-15,41)$ & $0,391 \quad(-15,72)$ & $0,411 \quad(-15,43)$ & $0,472 \quad(-9,63)$ & $0,454 \quad(-13,37)$ & $0,479 \quad(-9,12)$ \\
\hline $\mathrm{N}^{\circ}$ Obs. & 65.332 & 65.457 & 65.332 & 65.266 & 65.388 & 65.266 \\
\hline sigma_c & - & - & - & 1,065 & 1,404 & 1,260 \\
\hline & - & - & - & 0,044 & 0,061 & 0,045 \\
\hline rho & - & - & - & 0,256 & 0,375 & 0,326 \\
\hline LR test rho $=0$ & - & - & - & $\begin{array}{c}0,015 \\
1.592,32\end{array}$ & $\begin{array}{c}0,020 \\
1.601,98\end{array}$ & $\begin{array}{c}0,016 \\
1.617,11\end{array}$ \\
\hline p-value & - & - & - & 0,000 & 0,000 & 0,000 \\
\hline
\end{tabular}

Os resultados, no que diz respeito à significância e ao sinal dos coeficientes, obtidos pelo modelo Logit foram equivalentes ao do modelo Probit. Da mesma forma que no modelo Probit, a hipótese de que $\rho=0$ é rejeitada a $1 \%$, ou seja, não se pode rejeitar a hipótese de efeitos não observáveis. A Tabela 9 mostra as probabilidades médias de utilização do redesconto calculadas 
pelo modelo Logit. Os resultados são bem próximos ao modelo Probit para os modelos 1,2 e 3 . Para os modelos em painel, as probabilidades do modelo Logit são menores do que $50 \%$ do valor obtido no modelo Probit.

Tabela 9 - Probabilidade média para o modelo Logit

\begin{tabular}{|c|c|c|}
\hline \multirow{2}{*}{ Modelo } & \multicolumn{2}{|c|}{ Probabilidade Média } \\
\cline { 2 - 3 } & $22 / 04 / 02$ a $28 / 06 / 02$ & $01 / 07 / 02$ a 31/08/04 \\
\hline 1 & $5,07 \%$ & $1,40 \%$ \\
\hline 2 & $5,03 \%$ & $1,40 \%$ \\
\hline 3 & $5,07 \%$ & $1,40 \%$ \\
\hline \hline 4 & $1,81 \%$ & $0,41 \%$ \\
\hline 5 & $1,72 \%$ & $0,40 \%$ \\
\hline 6 & $2,12 \%$ & $0,49 \%$ \\
\hline
\end{tabular}

As Figuras 23 a 30 mostram as probabilidades estimadas em cada um dos modelos Logit.

Figura 23 - Logit - Modelo 1

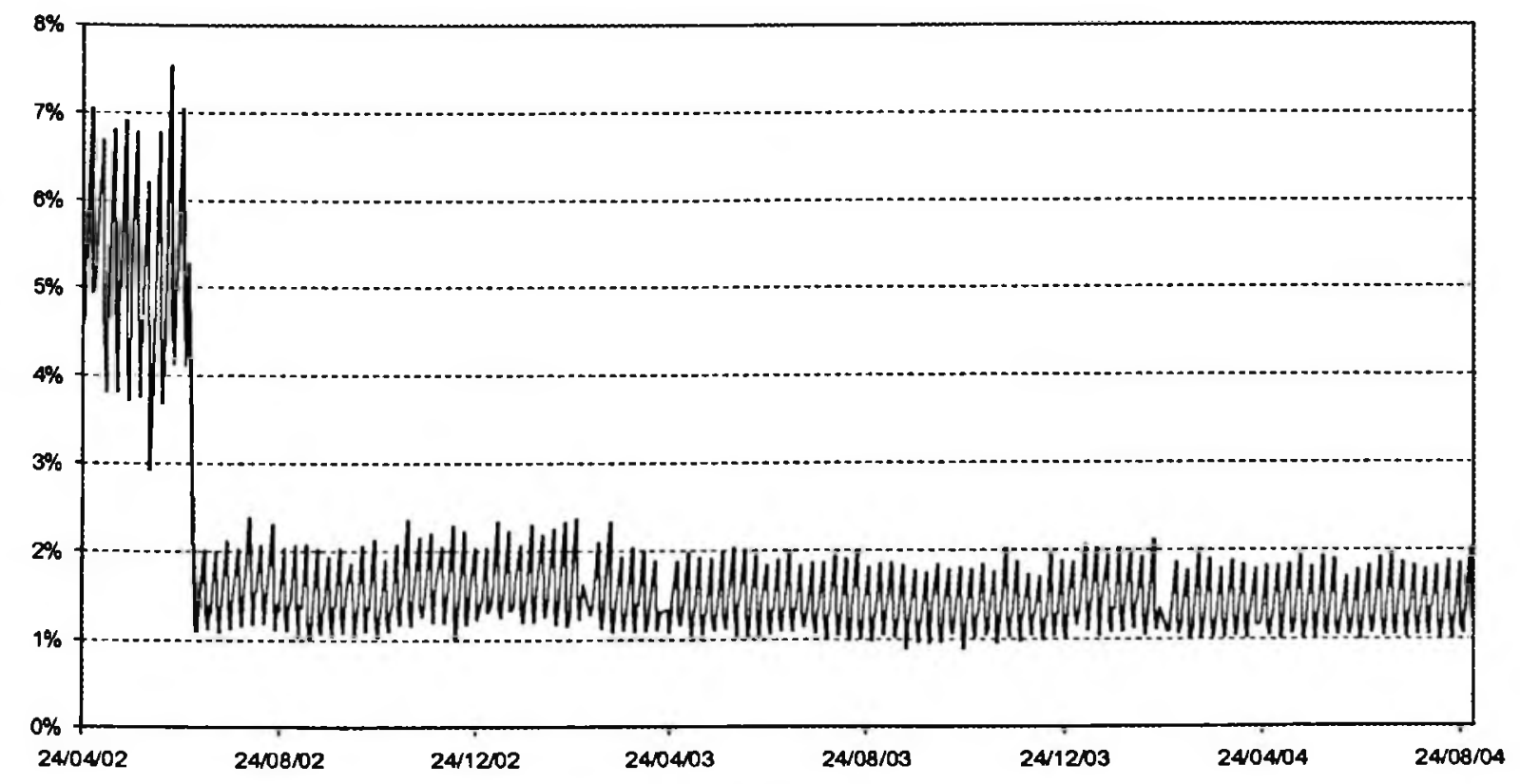


Figura 24 - Logit-Modelo 1, Q1 e Q3

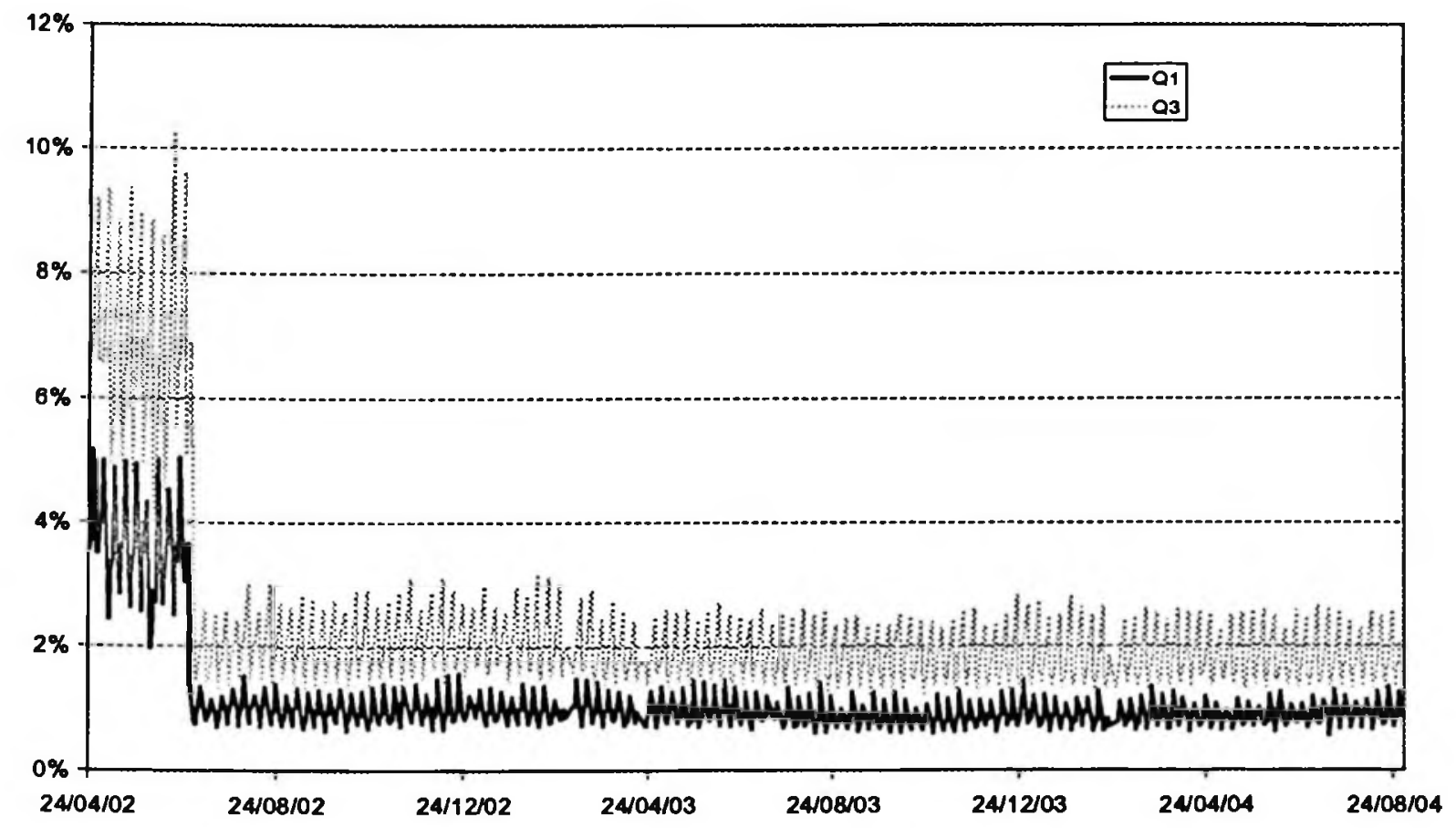

Figura 25 - Logit - Modelo 2

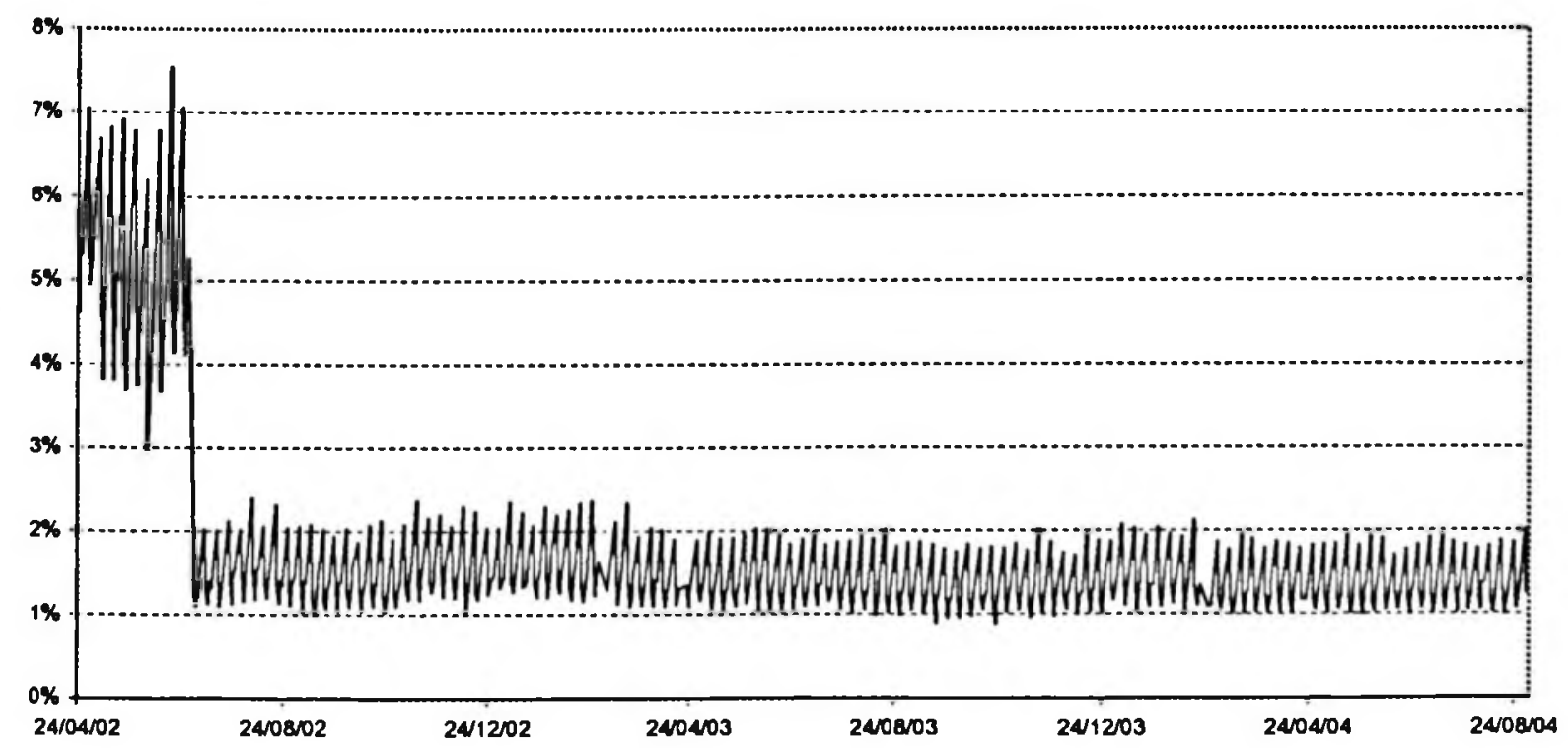


Figura 26 - Logit - Modelo 3

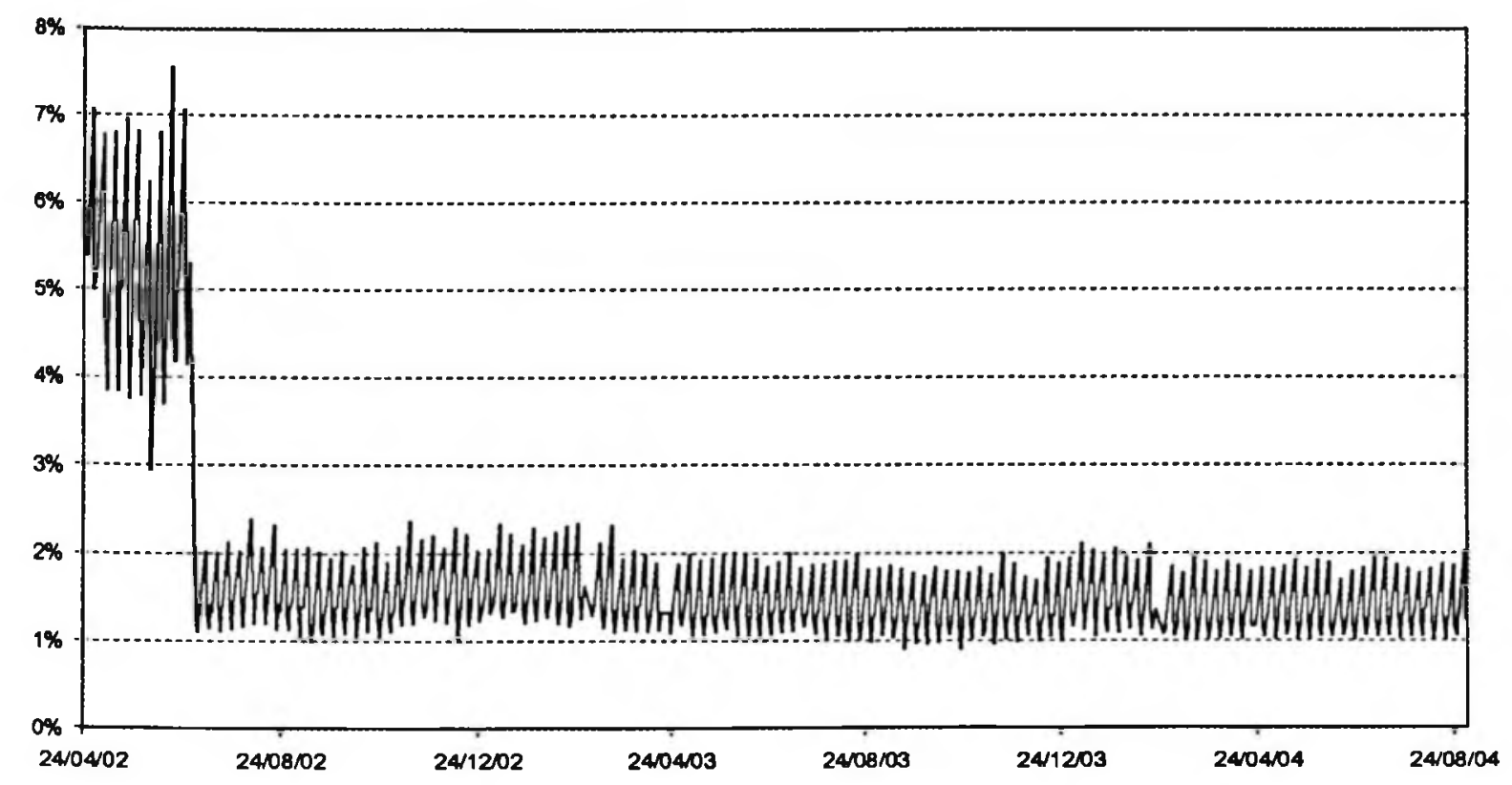

Figura 27 - Logit - Modelo 4

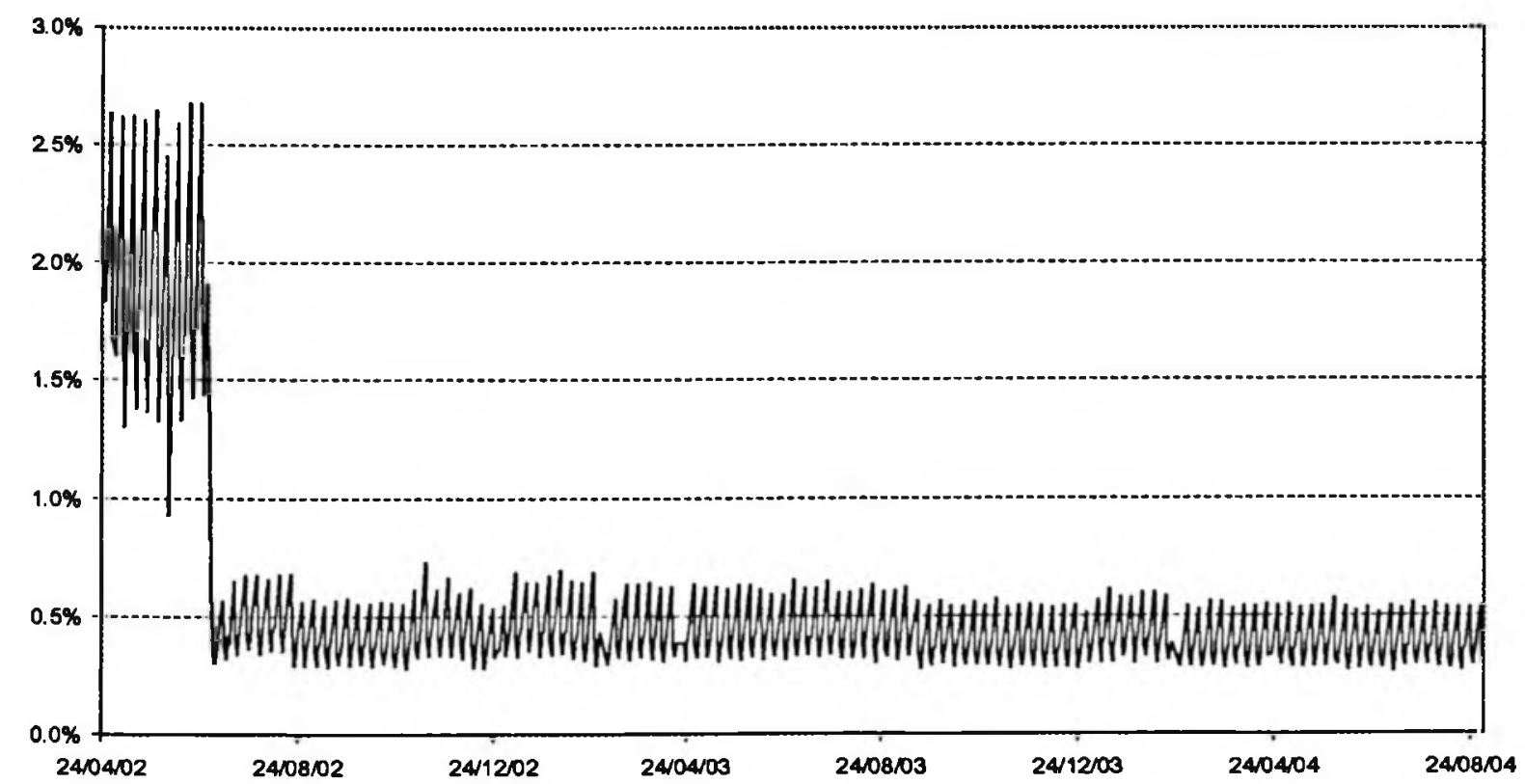


Figura 28 - Logit - Modelo 4, Q1 e Q3

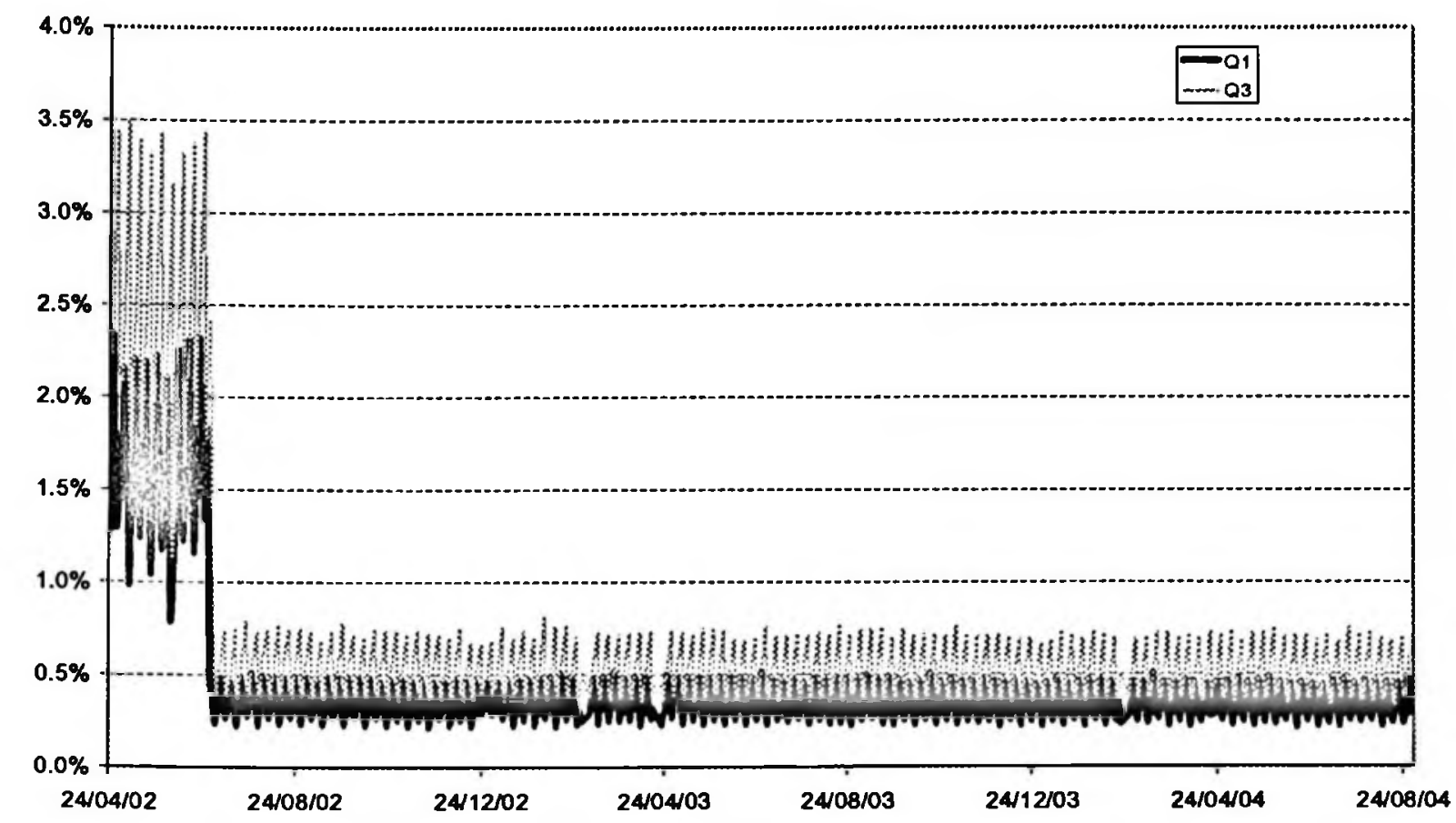

Figura 29 - Logit - Modelo 5

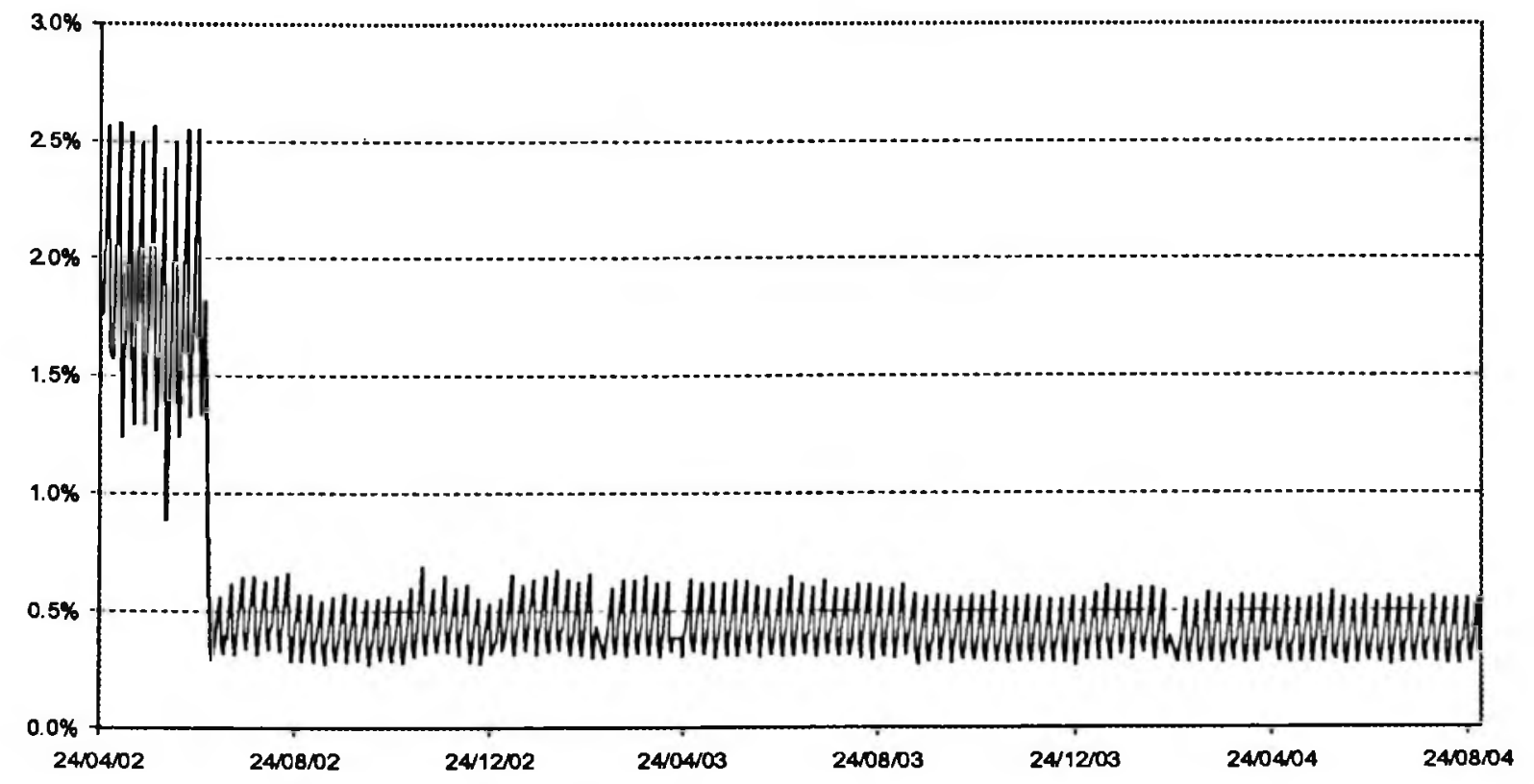


Figura 30 - Logit - Modelo 6

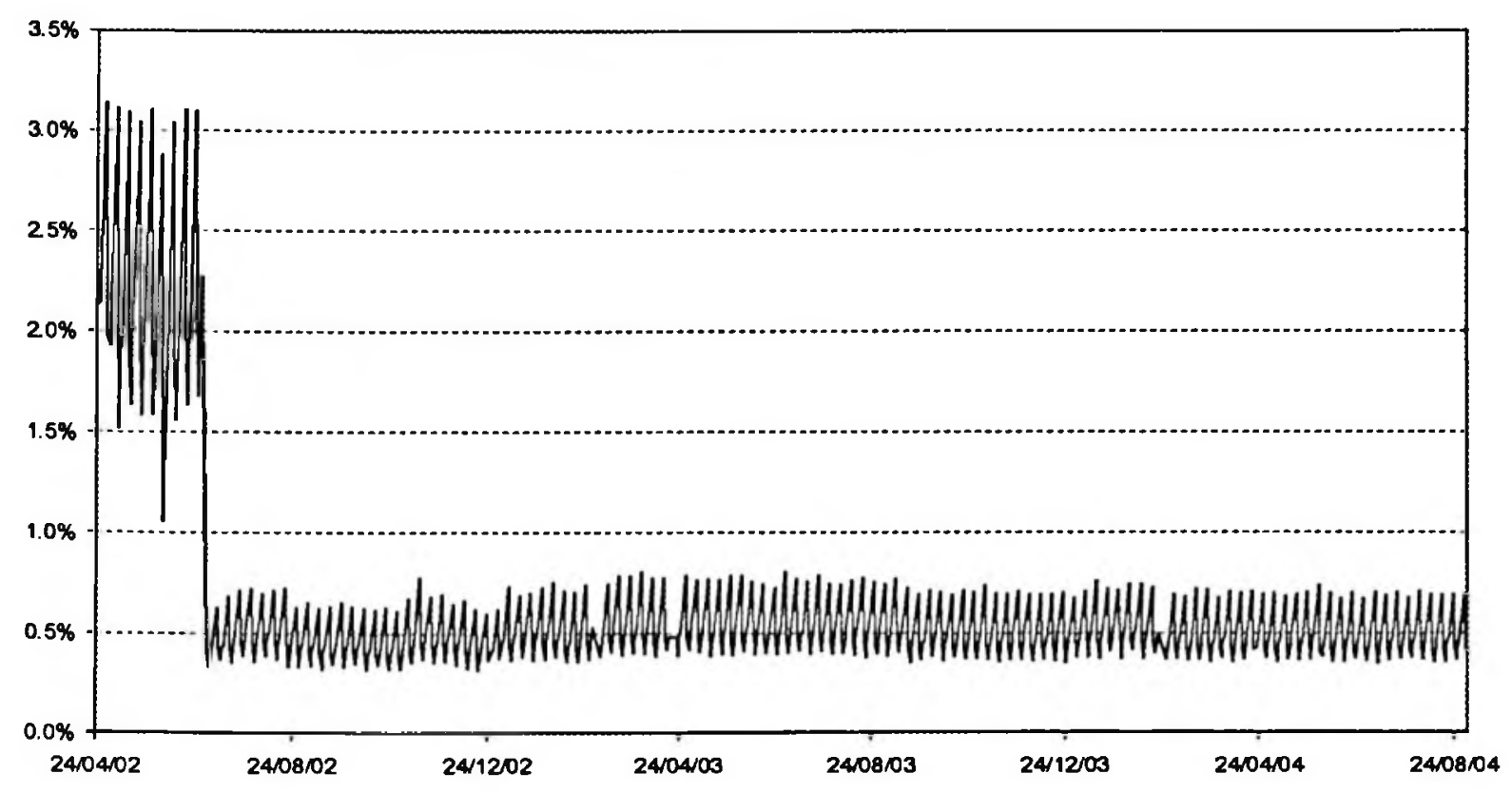

A porcentagem de resultados corretamente previstos, tanto para o modelo Probit quanto para o modelo Logit encontram-se na Tabela 10.

Tabela 10 - Percentual de Observações Corretamente Preditas

\begin{tabular}{|c|c|c|c|c|}
\cline { 2 - 5 } \multicolumn{2}{c|}{} & \multicolumn{3}{c|}{ \% Corretamente Predita } \\
\hline \multirow{4}{*}{ Modelo } & dopd =0 & dopd =1 & dopd \\
\cline { 2 - 5 } & 1 & 99,81 & 0,36 & 98,14 \\
\cline { 2 - 5 } & 2 & 100,0 & 0,00 & 98,31 \\
\cline { 2 - 5 } & 3 & 99,81 & 0,36 & 98,14 \\
\cline { 2 - 5 } & 4 & 99,71 & 0,36 & 98,04 \\
\cline { 2 - 5 } & 5 & 100,0 & 0,00 & 98,21 \\
\hline \multirow{4}{*}{ PROBIT } & 6 & 99,71 & 0,36 & 98,04 \\
\cline { 2 - 5 } & 1 & 99,81 & 0,36 & 98,13 \\
\cline { 2 - 5 } & 2 & 100,0 & 0,00 & 98,31 \\
\cline { 2 - 5 } & 3 & 99,81 & 0,36 & 98,14 \\
\cline { 2 - 5 } & 4 & 99,71 & 0,36 & 98,04 \\
\cline { 2 - 5 } & 5 & 100,0 & 0,00 & 98,21 \\
\cline { 2 - 5 } & 6 & 99,71 & 0,36 & 98,04 \\
\hline
\end{tabular}


Todos os doze modelos apresentam resultados superiores a $98 \%$ de acerto, sendo que os modelos em painel apresentam resultados inferiores aos dos modelos sem a estrutura de painel.

A principio este resultado parece ser bom. Contudo, quando observamos os resultados na situação em que a variável dopd assume o valor "l" (quando ocorre operação de redesconto), verificamos que o melhor resultado obtido é de $0,36 \%$ de acertos. Este fraco desempenho pode ser explicado pela grande quantidade de zeros na variável binária $(98,31 \%)$. O excesso de zeros (em relação à quantidade de uns) torna o valor de referência de 50\% muito alto, subestimando a previsão de uns ${ }^{81}$.

\footnotetext{
${ }^{81}$ Diminuindo o valor de referência de 0,5000 para 0,0169 (proporção de zeros), temos que o desempenho médio para o modelo Probit é de $71 \%$ contra $80 \%$ do modelo Logit. Quando a variável binária assume o valor um, 0 desempenho médio do modelo Probit é de $56 \%$ contra $42 \%$ do modelo Logit.
} 


\subsection{Demanda por Redesconto, modelo Tobit.}

Para as regressões do modelo Tobit a variável dependente binária foi substituida por uma variável continua definida como a soma das operações de redesconto over com as operações de nivelamento. A Tabela 11, que segue o mesmo padrão das Tabelas 6 e 8, apresenta os resultados das regressões. Os modelos 1 a 3 correpondem ao estimador Pooled Tobit enquanto os modelos 4 a 6 correspondem ao caso do modelo Tobit de efeitos aleatórios.

Tabela 11 - Resultados do modelo Tobit

\begin{tabular}{|c|c|c|c|c|c|c|}
\hline Variável & MODELO 1 & MODELO 2 & MODELO 3 & MODELO 4 & MODELO 5 & MODELO 6 \\
\hline \multirow{2}{*}{ dga } & 26,094 & 30,043 & 33,514 & $-18,716$ & $-10,448$ & $-3,542$ \\
\hline & $7,146 \quad(3,65)$ & $(4,17)$ & $(4,45)$ & $(-2,31)$ & $8,672 \quad(-1,20)$ & $8,632 \quad(-0,41)$ \\
\hline \multirow{2}{*}{ dgb } & 22,717 & 26,748 & 30,110 & $-13,470$ & $-1,940$ & 1,824 \\
\hline & $7,120 \quad(3,19)$ & $7,175 \quad(3,73)$ & $(4,01)$ & $(-1,68)$ & $8,291 \quad(-0,23)$ & $(0,22)$ \\
\hline \multirow{2}{*}{ taxa_rdc } & $-4,831$ & $-4,803$ & $-4,820$ & $-4,781$ & $-4,758$ & $-4,778$ \\
\hline & $0,320 \quad(-15,08)$ & $0,318 \quad(-15,11)$ & $0,320 \quad(-15, \infty)$ & $0,308 \quad(-15,50)$ & $0,306 \quad(-15,53)$ & $0,309 \quad(-15,45)$ \\
\hline \multirow{2}{*}{ ln_RSV } & & 2,953 & 2,219 & - & $-0,049$ & 0,240 \\
\hline & $-\quad-$ & $(5,91)$ & $0,691 \quad(3,21)$ & $\cdot$ & $0,536 \quad(-0,09)$ & $0,665 \quad(0,36)$ \\
\hline \multirow{2}{*}{ In_rsvLl } & 2,592 & - & 1,061 & $-0,371$ & - & $-0,279$ \\
\hline & $0,491 \quad(5,28)$ & - & $(1,57)$ & $0,541 \quad(-0,69)$ & - & $0,657 \quad(-0,42)$ \\
\hline In Exigivel & $-2,065$ & $-2,403$ & $-2,695$ & 0,996 & 0,230 & $-0,187$ \\
\hline & $0,523 \quad(-3,95)$ & $0,529 \quad(-4,54)$ & $0,561 \quad(-4,80)$ & $(1,66)$ & $(0,37)$ & $0,647 \quad(-0,29)$ \\
\hline In Comn & 2,251 & 2,273 & 2,298 & 2,508 & 2,640 & 2,055 \\
\hline & $0,270 \quad(8,33)$ & $0,270 \quad(8,42)$ & $(8,49)$ & $(8,24)$ & $0,319 \quad(8,28)$ & $0,288 \quad(7,15)$ \\
\hline Exgr & $-2,374$ & $-2,397$ & $-2,427$ & $-1,997$ & $-1,903$ & $-2,327$ \\
\hline-2.0 & $0,260 \quad(-9,11)$ & $0,260 \quad(-9,21)$ & $0,261 \quad(-9,30)$ & $0,276 \quad(-7,24)$ & $0,287 \quad(-6,63)$ & $0,268 \quad(-8,69)$ \\
\hline s4 & 21,598 & 21,279 & 21,290 & 9,284 & 8,351 & 28,608 \\
\hline (2) & $2,861 \quad(7,55)$ & $2,852 \quad(7,46)$ & $(7,45)$ & $3,522 \quad(2,64)$ & $3,655 \quad(2,28)$ & $3,795 \quad(7,54)$ \\
\hline d $1 \mathrm{~s} 5$ & 23,546 & 23,442 & 23,227 & 11,378 & 10,602 & 30,760 \\
\hline & $2,819 \quad(8,35)$ & $2,816 \quad(8,32)$ & $(8,25)$ & $(3,26)$ & $(2,92)$ & $(8,15)$ \\
\hline d 1 s 6 & 26,667 & 26,700 & 26,441 & 14,394 & 13,414 & 33,603 \\
\hline & $2,759 \quad(9,67)$ & $2,755 \quad(9,69)$ & $2,755 \quad(9,60)$ & $3,435 \quad(4,19)$ & $3,578 \quad(3,75)$ & $3,742 \quad(8,98)$ \\
\hline$d 2 s 2$ & 31,208 & 31,167 & 30,934 & 19,593 & 18,725 & 38,870 \\
\hline & $2,725 \quad(11,45)$ & $2,721 \quad(11,45)$ & $2,720 \quad(11,37)$ & $3,387 \quad(5,78)$ & $3,531 \quad(5,30)$ & $3,724 \quad(10,44)$ \\
\hline$d 2 s 3$ & 22,447 & 22,384 & 22,137 & 10,467 & 9,621 & 29,760 \\
\hline (5) & $2,840 \quad(7,90)$ & $2,838 \quad(7,89)$ & $2,837 \quad(7,80)$ & $3,500 \quad(2,99)$ & $3,639 \quad(2,64)$ & $3,789 \quad(7,85)$ \\
\hline$d 2 s 4$ & 19,378 & 19,568 & 19,160 & 6,353 & 5,615 & 25,584 \\
\hline & $2,922 \quad(6,63)$ & $2,898 \quad(6,75)$ & $2,918 \quad(6,57)$ & $(1,77)$ & $(1,51)$ & $3,809 \quad(6,66)$ \\
\hline d2s 5 & 22,572 & 22,601 & 22,346 & 9,989 & 9,080 & 29,287 \\
\hline & $2,836 \quad(7,96)$ & $2,834 \quad(7,98)$ & $(7,89)$ & $(2,85)$ & $(2,49)$ & $(7,75)$ \\
\hline
\end{tabular}




\begin{tabular}{|c|c|c|c|c|c|c|}
\hline \multirow{2}{*}{ d2s6 } & 23,254 & 23,358 & 23,089 & 11,181 & 10,272 & 30,493 \\
\hline & $2,813 \quad(8,27)$ & $2,808 \quad(8,32)$ & $2,809 \quad(8,22)$ & $3,477 \quad(3,22)$ & $3,615 \quad(2,84)$ & $3,764 \quad(8,10)$ \\
\hline \multirow{2}{*}{ d3s 2} & 31,341 & 31,306 & 31,086 & 18,977 & 18,147 & 38,353 \\
\hline & $2,724 \quad(11,51)$ & $2,721 \quad(11,51)$ & $2,720 \quad(11,43)$ & $3,392 \quad(5,60)$ & $3,536 \quad(5,13)$ & $3,718 \quad(10,32)$ \\
\hline \multirow{2}{*}{$\mathrm{d} 3 \mathrm{~s} 3$} & 23,763 & 23,709 & 23,477 & 11,175 & 10,347 & 30,488 \\
\hline & $2,819 \quad(8,43)$ & $2,816 \quad(8,42)$ & $2,816 \quad(8,34)$ & $3,480 \quad(3,21)$ & $3,622 \quad(2,86)$ & $3,768 \quad(8,09)$ \\
\hline \multirow{2}{*}{ ln_sed } & 0,229 & 0,241 & 0,234 & - & - & - \\
\hline & $0,049 \quad(4,70)$ & $0,049 \quad(4,96)$ & $0,049 \quad(4,80)$ & - & - & - \\
\hline \multirow{2}{*}{ ln_cp } & $-0,080$ & $-0,077$ & $-0,078$ & - & - & - \\
\hline & $0,038 \quad(-2,13)$ & $0,038 \quad(-2,00)$ & $0,038 \quad(-2,08)$ & - & - & - \\
\hline $\ln \mathrm{ca}$ & $-0,045$ & $-0,039$ & $-0,042$ & - & - & - \\
\hline & $0,038 \quad(-1,17)$ & $0,038 \quad(-1,03)$ & $0,038 \quad(-1,09)$ & - & - & - \\
\hline $\ln s t 1$ & 0,058 & 0,057 & 0,056 & - & - & - \\
\hline & $0,079 \quad(0,73)$ & $0,079 \quad(0,72)$ & $0,079 \quad(0,70)$ & - & - & - \\
\hline $\ln s t 2$ & 0,144 & 0,149 & 0,142 & - & - & - \\
\hline W_-3e & $0,059 \quad(2,42)$ & $0,059 \quad(2,52)$ & $0,059 \quad(2,40)$ & - & - & - \\
\hline Ln $\mathrm{st} \mathrm{s}$ & 0,224 & 0,222 & 0,227 & - & - & - \\
\hline W _ D & $0,071 \quad(3,13)$ & $0,071 \quad(3,12)$ & $0,071 \quad(3,19)$ & - & - & - \\
\hline In sol & 0,109 & 0,109 & 0,107 & - & - & - \\
\hline & $0,050 \quad(2,20)$ & $0,050 \quad(2,19)$ & $0,050 \quad(2,16)$ & - & - & - \\
\hline $\ln$ so 2 & $-0,035$ & $-0,034$ & $-0,033$ & - & - & - \\
\hline W_SOL & $0,039 \quad(-0,89)$ & $0,039 \quad(-0,88)$ & $0,039 \quad(-0,84)$ & - & - & - \\
\hline In so3 & $-0,219$ & $-0,217$ & $-0,216$ & - & - & - \\
\hline III-SOS & $0,039 \quad(-5,62)$ & $0,039 \quad(-5,59)$ & $0,039 \quad(-5,55)$ & $-\quad-$ & $-\quad-$ & $-\quad-$ \\
\hline $\ln C D A g$ & - & - & - & $-0,052$ & $-0,059$ & $-0,061$ \\
\hline & $-\quad-$ & $-\quad-$ & $-\quad-$ & $0,015 \quad(-3,37)$ & $0,015 \quad(-3,86)$ & $0,015 \quad(-4,13)$ \\
\hline cons & $-115,636$ & $-120,104$ & $-123,689$ & $-76,017$ & $-81,189$ & $-88,365$ \\
\hline$-\infty$ & $7,033 \quad(-16,44)$ & $7,189 \quad(-16,71)$ & $7,609 \quad(-16,26)$ & $7,137 \quad(-10,65)$ & $7,192 \quad(-11,29)$ & $7,730 \quad(-11,43)$ \\
\hline $\mathrm{N}^{\circ}$ Obs. & 65.332 & 65.457 & \begin{tabular}{|l|}
65.332 \\
\end{tabular} & 65.266 & 65.388 & 65.266 \\
\hline sigma_c & - & - & - & $\begin{array}{c}13,513 \\
0,568\end{array}$ & $\begin{array}{c}0,326 \\
0,000\end{array}$ & $\begin{array}{c}0,180 \\
- \\
\end{array}$ \\
\hline sigma_u & - & - & - & $\begin{array}{c}35,026 \\
0,971\end{array}$ & $\begin{array}{c}41,510 \\
1,304\end{array}$ & $\begin{array}{c}41,703 \\
1,308\end{array}$ \\
\hline rho & - & - & - & $\begin{array}{l}0,130 \\
0,008\end{array}$ & 0,00006 & $\begin{array}{c}0,00002 \\
.\end{array}$ \\
\hline
\end{tabular}

Em termos de significância e sinais de coeficientes os resultados foram semelhantes ao dos modelos Probit e Logit. Para os modelos 5 e 6, o software não forneceu valores para o desvio padrão de $\sigma_{c}^{2}$. 


\subsection{Efeitos Marginais}

As tabelas 12 a 14 reportam os efeitos marginais para os modelos Probit, Logit e Tobit. Cada célula das tabelas traz em sua primeira linha o valor estimado do efeito marginal e na segunda linha o desvio padrão e a estatística $z$ da variável indicada na primeira coluna. Os efeitos marginais foram calculados para os valores amostrais médios das variáveis explicativas; para os modelos com estimadores de efeitos aleatórios (4 a 6), além disso, os efeitos foram calculados para $c_{i}=0$. Para as dummies o valor estimado representa o efeito da variação de 0 para 1 na probabilidade da utilização do redesconto.

Para os modelos Probit, os efeitos marginais da taxa de redesconto foram significativos ao nivel de $1 \%$. Observa-se que para um aumento de 1 ponto percentual (p.p.), a probabilidade de utilização de redesconto reduz-se em 0,38 p.p. nos modelos 1 a 3 (Pooled Probit) e entre 0,28 p.p e 0,34 p.p. nos modelos 4 a 6 (Probit com efeitos aleatórios).

O agregado dos compulsórios (exceto Depósitos à Vista) e a exigibilidade agregada destes mesmos compulsórios foram significativas, ao nível de $1 \%$, para os seis modelos e apresentaram efeitos compensatórios entre si. Assim, o aumento em 1 p.p. na exibilidade agregada de todos os compulsórios (exceto Depósitos à Vista) diminui a probabilidade de utilização do redesconto entre 0,15 p.p. a 0,19 p.p. e o aumento em 1 p.p. no cumprimento agregado destes compulsórios aumenta a probabilidade de utilização do redesconto entre 0,12 p.p. a 0,22p.p..

Um conjunto de variáveis que também foi significativa ao nivel de $1 \%$ para os seis modelos foi o de dummies de dia do periodo de cumprimento do compulsório sobre Depósitos à Vista. Os modelos 1 a 3 apresentaram efeitos marginais menores que os efeitos marginais dos 
modelos 4 a 6 (na média aproximadamente 2,8 vezes menor). Considerando os seis modelos, os dias com maiores efeitos marginais foram as duas segundas-feiras (d2s2 e d3s2) e a primeira sexta-feira do período de cumprimento. $O$ fato de $\mathrm{o}$ dia do período de cumprimento do compulsório sobre Depósitos à Vista ser a primeira sexta-feira (dia em que a instituição finaiceira trabalha com projeções da exigibilidade), implica que a probabilidade de utilização do redesconto neste dia é em torno de 3,8 p.p. (modelos 1 a 3) e entre 7,5 p.p. e 14,9 p.p. (modelos 4 a 6) do que no caso em que a instituição financeira não tivesse exigibilidade no compulsório sobre Depósitos à Vista. Para as segundas-feiras ter-se-ia aproximadamente entre 4,88 p.p. e 4,98 p.p. para os modelos 1 a 3 e entre 9,42 p.p. e 18,37 p.p. para os modelos 4 a 6 (observa-se que o modelo 5 superestima os valores dos efeitos marginais quando comparado aos demais modelos.

Efeito semelhante pode ser visto nas dummies de grupos do compulsório sobre Depósitos à Vista. Para os modelos 4 a 6, estas dummies não foram significativas ao nível de 10\%. Nos modelos 1 a 3, ao nível de $1 \%$, verifica-se que participar do grupo A aumenta entre 3,27 p.p. a 4,77 p.p. a probabilidade de utilizar o Redesconto (em relação a não participar de nenhum grupo). Para a participação no grupo B o aumento da probabilidade esta entre 2,72 p.p. e 4,11 p.p..

As variáveis de lançamento na conta de reservas nos modelos 1 a 3 foram, em sua maioria, não significativas a $10 \%$. As variáveis significativas (ln_sel, In_st3 e ln_so3) apresentaram efeitos marginais de pequena magnitude (não superior a 0,02 p.p.) e apenas $\mathbf{l n} \_s 03$ apresentou sinal coerente com o esperado. 
Tabela 12 - Efeitos Marginais - Modelo Probit

\begin{tabular}{|c|c|c|c|c|c|c|}
\hline Variável & MODELO 1 & MODELO 2 & MODELO 3 & MODELO 4 & MODELO 5 & MODELO 6 \\
\hline \multirow[t]{2}{*}{$\mathrm{dga}^{*}$} & 0,0327 & 0,0405 & 0,0477 & $-0,0020$ & 0,0004 & 0,0001 \\
\hline & $0,0131 \quad(2,50)$ & $0,0150 \quad(2,70)$ & $0,0169 \quad(2,82)$ & $0,0050 \quad(-0,40)$ & $0,0051 \quad(0,08)$ & $0,0062 \quad(0,02)$ \\
\hline \multirow{2}{*}{ dgb* } & 0,0272 & 0,0346 & 0,0411 & $-0,0015$ & 0,0009 & $-0,0011$ \\
\hline & $0,0122 \quad(2,22)$ & $0,0141 \quad(2,45)$ & $0,0160 \quad(2,57)$ & $0,0052 \quad(-0,30)$ & $0,0054 \quad(0,17)$ & $0,0056 \quad(-0,20)$ \\
\hline \multirow{2}{*}{ taxa_rdc } & $-0,0038$ & $-0,0038$ & $-0,0038$ & $-0,0034$ & $-0,0028$ & $-0,0029$ \\
\hline & $0,0002 \quad(-15,85)$ & $0,0002 \quad(-15,90)$ & $0,0002 \quad(-15,82)$ & $0,0003 \quad(-12,12)$ & $0,0003 \quad(-10,73)$ & $0,0004 \quad(-8,27)$ \\
\hline \multirow{2}{*}{ ln_RSV } & - & 0,0023 & 0,0017 & - & 0,0001 & $-0,0001$ \\
\hline & - & $0,0004 \quad(6,10)$ & $0,0006 \quad(3,05)$ & - & $0,0004 \quad(0,17)$ & $0,0004 \quad(-0,27)$ \\
\hline n rs & 0,0020 & - & 0,0008 & $-0,0001$ & - & $-0,0003$ \\
\hline & $0,0004 \quad(5,60)$ & - & $0,0005 \quad(1,47)$ & $0,0004 \quad(-0,31)$ & - & $0,0004 \quad(-0,82)$ \\
\hline$n \in$ & $-0,0016$ & $-0,0019$ & $-0,0021$ & $1,2 \mathrm{E}-05$ & $-0,0002$ & 0,0001 \\
\hline L_L & $0,0004 \quad(-4,09)$ & $0,0004 \quad(-4,64)$ & $0,0004 \quad(-5,01)$ & $0,0004 \quad(0,03)$ & $0,0004 \quad(-0,43)$ & $0,0005 \quad(0,18)$ \\
\hline In Comp & 0,0018 & 0,0018 & 0,0018 & 0,0015 & 0,0012 & 0,0022 \\
\hline & $0,0002 \quad(8,70)$ & $0,0002 \quad(8,78)$ & $0,0002 \quad(8,85)$ & $0,0002 \quad(6,59)$ & $0,0002 \quad(6,44)$ & $0,0004 \quad(5,83)$ \\
\hline $\mathrm{aE}$ & $-0,0019$ & $-0,0019$ & $-0,0019$ & $-0,0019$ & $-0,0015$ & $-0,0017$ \\
\hline U_Ex & $0,0002 \quad(-9,38)$ & $0,0002 \quad(-9,45)$ & $0,0002 \quad(-9,55)$ & $0,0002 \quad(-8,74)$ & $0,0002 \quad(-8,50)$ & $0,0003 \quad(-5,28)$ \\
\hline d) & 0,0273 & 0,0266 & 0,0266 & 0,0614 & 0,1200 & 0,0574 \\
\hline & $0,0054 \quad(5,06)$ & $0,0053 \quad(5,01)$ & $0,0053 \quad(5,02)$ & $0,0110 \quad(5,59)$ & $0,0173 \quad(6,94)$ & $0,0166 \quad(3,45)$ \\
\hline d $155^{*}$ & 0,0314 & 0,0311 & 0,0306 & 0,0684 & 0,1319 & 0,0643 \\
\hline 11SJ" & $0,0056 \quad(5,58)$ & $0,0056 \quad(5,54)$ & $0,0056 \quad(5,52)$ & $0,0117 \quad(5,87)$ & $0,0182 \quad(7,23)$ & $0,0179 \quad(3,59)$ \\
\hline dls6* & 0,0381 & 0,0381 & 0,0375 & 0,0799 & 0,1490 & 0,0749 \\
\hline & $0,0061 \quad(6,24)$ & $0,0061 \quad(6,23)$ & $0,0060 \quad(6,20)$ & $0,0126 \quad(6,36)$ & $0,0191 \quad(7,79)$ & $0,0195 \quad(3,83)$ \\
\hline $\mathrm{d} 2 \mathrm{~s} 2 *$ & 0,0497 & 0,0494 & 0,0488 & 0,1039 & 0,1837 & 0,0976 \\
\hline & $0,0069 \quad(7,17)$ & $0,0069 \quad(7,14)$ & $0,0069 \quad(7,12)$ & $0,0145 \quad(7,15)$ & $0,0212 \quad(8,65)$ & $0,0279 \quad(3,50)$ \\
\hline d2s $3 *$ & 0,0291 & 0,0289 & 0,0284 & 0,0644 & 0,1254 & 0,0594 \\
\hline 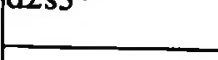 & $0,0054 \quad(5,38)$ & $0,0054 \quad(5,36)$ & $0,0053 \quad(5,33)$ & $0,0112 \quad(5,75)$ & $0,0177 \quad(7,10)$ & $0,0169 \quad(3,51)$ \\
\hline d2s $4 *$ & 0,0231 & 0,0234 & 0,0227 & 0,0509 & 0,1046 & 0,0469 \\
\hline & $0,0051 \quad(4,58)$ & $0,0051 \quad(4,63)$ & $0,0050 \quad(4,54)$ & $0,0100 \quad(5,11)$ & $0,0161 \quad(6,49)$ & $0,0147 \quad(3,18)$ \\
\hline $12 s 5^{*}$ & 0,0294 & 0,0294 & 0,0288 & 0,0636 & 0,1245 & 0,0593 \\
\hline $0<35$ & $0,0055 \quad(5,36)$ & $0,0055 \quad(5,36)$ & $0,0054 \quad(5,33)$ & $0,0112 \quad(5,69)$ & $0,0176 \quad(7,06)$ & $0,0169 \quad(3,50)$ \\
\hline d $2 s^{* *}$ & 0,0306 & 0,0308 & 0,0302 & 0,0676 & 0,1303 & 0,0626 \\
\hline & $0,0055 \quad(5,55)$ & $0,0056 \quad(5,54)$ & $0,0055 \quad(5,52)$ & $0,0115 \quad(5,88)$ & $0,0179 \quad(7,28)$ & $0,0174 \quad(3,60)$ \\
\hline d3s2* & 0,0498 & 0,0496 & 0,0490 & 0,1014 & 0,1802 & 0,0942 \\
\hline & $0,0068 \quad(7,29)$ & $0,0068 \quad(7,27)$ & $0,0068 \quad(7,26)$ & $0,0143 \quad(7, \infty 9)$ & $0,0210 \quad(8,59)$ & $0,0272 \quad(3,47)$ \\
\hline d3s3* & 0,0316 & 0,0314 & 0,0309 & 0,0669 & 0,1292 & 0,0624 \\
\hline & $0,0056 \quad(5,64)$ & $0,0056 \quad(5,63)$ & $0,0055 \quad(5,60)$ & $0,0114 \quad(5,86)$ & $0,0178 \quad(7,24)$ & $0,0174 \quad(3,59)$ \\
\hline & $1,8 \mathrm{E}-04$ & $1,9 \mathrm{E}-04$ & $1,8 \mathrm{E}-04$ & - & - & - \\
\hline - _ou & $4,0 \mathrm{E}-05 \quad(4,56)$ & $4,0 \mathrm{E}-05 \quad(4,80)$ & $4,0 \mathrm{E}-05 \quad(4,66)$ & - & - & - \\
\hline & $-6,3 \mathrm{E}-05$ & $-6,1 \mathrm{E}-05$ & $-6,1 E-05$ & - & - & - \\
\hline & $3,0 \mathrm{E}-05 \quad(-2,05)$ & $3,0 \mathrm{E}-05 \quad(-2, \infty)$ & $3,0 \mathrm{E}-05 \quad(-2,02)$ & - & - & - \\
\hline & $-3,7 E-05$ & $-3,3 \mathrm{E}-05$ & $-3,5 \mathrm{E}-05$ & - & - & - \\
\hline & $3,0 \mathrm{E}-05 \quad(-1,16)$ & $3,0 \mathrm{E}-05 \quad(-1,04)$ & $3,0 \mathrm{E}-05 \quad(-1,09)$ & - & - & - \\
\hline & $5,0 \mathrm{E}-05$ & $4,9 \mathrm{E}-05$ & $4,8 \mathrm{E}-05$ & - & - & - \\
\hline & $6,0 \mathrm{E}-05 \quad(0,80)$ & $6,0 \mathrm{E}-05 \quad(0,79)$ & $6,0 \mathrm{E}-05 \quad(0,77)$ & - & - & - \\
\hline
\end{tabular}




\begin{tabular}{|c|c|c|c|c|c|c|}
\hline \multirow{2}{*}{$\ln$ _st2 } & $1,1 \mathrm{E}-04$ & $1,1 \mathrm{E}-04$ & $1,1 \mathrm{E}-04$ & - & - & - \\
\hline & $5,0 E-05 \quad(2,27)$ & $5,0 \mathrm{E}-0 \mathrm{~S} \quad(2,37)$ & $5,0 E-05 \quad(2,25)$ & - & - & - \\
\hline \multirow{2}{*}{ ln_st3 } & $1,8 \mathrm{E}-04$ & $1,8 \mathrm{E}-04$ & $1,8 \mathrm{E}-04$ & - & - & - \\
\hline & $6,0 \mathrm{E}-05 \quad(2,93)$ & $6,0 \mathrm{E}-05 \quad(2,90)$ & $6,0 \mathrm{E}-05 \quad(2,97)$ & - & - & - \\
\hline \multirow{2}{*}{ ln_sol } & $8,7 \mathrm{E}-05$ & $8,6 \mathrm{E}-05$ & $8,5 \mathrm{E}-05$ & - & - & - \\
\hline & $4,0 E-05 \quad(2,11)$ & $4,0 \mathrm{E}-05 \quad(2,10)$ & $4,0 \mathrm{E}-05 \quad(2,08)$ & - & - & - \\
\hline \multirow{2}{*}{ ln_so2 } & $-2,9 E-05$ & $-2,8 \mathrm{E}-05$ & $-2,7 \mathrm{E}-05$ & - & - & - \\
\hline & $3,0 \mathrm{E}-05 \quad(-0,91)$ & $3,0 \mathrm{E}-05 \quad(-0,90)$ & $3,0 E-05 \quad(-0,80)$ & - & - & - \\
\hline \multirow{2}{*}{ ln_so3 } & $-1,7 \mathrm{E}-04$ & $-1,7 \mathrm{E}-04$ & $-1,7 \mathrm{E}-04$ & - & - & - \\
\hline & $3,0 \mathrm{E}-05 \quad(-5,62)$ & $3,0 E-05 \quad(-5,58)$ & $3,0 E-05 \quad(-5,55)$ & - & - & - \\
\hline $\ln C D A g$ & \multirow[t]{2}{*}{-} & \multirow[t]{2}{*}{-} & - & $-1,0 \mathrm{E}-04$ & $-8,1 \mathrm{E}-05$ & $-8,1 \mathrm{E}-05$ \\
\hline & & & - & $2,0 \mathrm{E}-05 \quad(-4,27)$ & $2,0 \mathrm{E}-05 \quad(-4,15)$ & $2,0 \mathrm{E}-0 \mathrm{~S} \quad(-3,78)$ \\
\hline $\mathrm{N}^{\circ}$ Obs. & 65.332 & 65.457 & 65.332 & 65.266 & 65.388 & 65.266 \\
\hline
\end{tabular}

$\left(^{*}\right)$ Efeito marginal para variação do valor da variável dummy de 0 para 1 .

De uma maneira geral, os resultados obtidos pelos modelos Logit foram semelhantes aos dos modelos Probit. A diferença ocorreu na magnitude dos efeitos marginais. Os efeitos marginais estimados para o modelo Logit foram menores do que os estimados pelo modelo Probit, com exceção do efeito dos dias do período de cumprimento do compulsório sobre depósitos à vista.

Nos modelos Logit, os efeitos marginais da taxa de redesconto indicaram que para um aumento de 1 p.p. na taxa de redesconto, a probabilidade de utilização de redesconto reduz-se em 0,33 p.p. nos modelos 1 a 3 (contra 0,38 p.p. dos modelos Probit) e entre 0,09 p.p e 0,14 p.p. nos modelos 4 a 6 (contra 0,28 p.p. a 0,34 p.p. dos modelos Probit).

Os efeitos marginais dos dias do periodo de cumprimento foram maiores nos modelos Logit do que nos modelos Probit. Os dias com maior efeito marginal foram os mesmos: a primeira sexta-feira (4,61 p.p. contra 3,81 p.p. pela exigência de cumprimento no dia) e as duas segundas-feiras (5,95 p.p. e 6,04 p.p. contra 4,97 p.p e 4,98 p.p.). 
Tabela 13 - Efeitos Marginais - Modelo Logit

\begin{tabular}{|c|c|c|c|c|c|c|}
\hline Variável & MODELO 1 & MODELO 2 & MODELO 3 & MODELO 4 & MODELO 5 & MODELO 6 \\
\hline \multirow{2}{*}{ dga* } & 0,0310 & 0,0392 & 0,0468 & $-0,0029$ & 0,0038 & $-0,0014$ \\
\hline & $0,0140 \quad(2,22)$ & $0,0166 \quad(2,36)$ & $0,0194 \quad(2,41)$ & $0,0011 \quad(-2,78)$ & $0,0028 \quad(1,36)$ & $0,0018 \quad(-0,76)$ \\
\hline \multirow{2}{*}{ dgb* } & 0,0253 & 0,0329 & 0,0396 & $-0,0035$ & 0,0030 & $-0,0006$ \\
\hline & $0,0127 \quad(1,99)$ & $0,0152 \quad(2,16)$ & $0,0178 \quad(2,22)$ & $0,0009 \quad(-3,87)$ & $0,0025 \quad(1,21)$ & $0,0021 \quad(-0,32)$ \\
\hline \multirow{2}{*}{ taxa_rdc } & $-0,0033$ & $-0,0033$ & $-0,0033$ & $-0,0011$ & $-0,0009$ & $-0,0014$ \\
\hline & $0,0002 \quad(-15,76)$ & $0,0002 \quad(-15,87)$ & $0,0002 \quad(-15,80)$ & $0,0001 \quad(-7,57)$ & $0,0001 \quad(-7,25)$ & $0,0001 \quad(-10,04)$ \\
\hline \multirow{2}{*}{ In_RSV } & - & 0,0020 & 0,0015 & - & $-0,0001$ & 0,0000 \\
\hline & - & 0,0004 & 0,0005 & - & $0,0001 \quad(-0,63)$ & $0,0002 \quad(-0,13)$ \\
\hline In rsy & 0,0018 & - & 0,0007 & $-0,0002$ & - & $-0,0001$ \\
\hline$\omega_{-} 130$ & $0,0003 \quad(5,25)$ & $-\quad-$ & $0,0005 \quad(1,37)$ & $0,0001 \quad(-1,85)$ & $-\quad-$ & $0,0002 \quad(-0,81)$ \\
\hline ln Exigivel & $-0,0014$ & $-0,0017$ & $-0,0019$ & 0,0004 & $-0,0002$ & 0,0000 \\
\hline & $0,0004 \quad(-3,90)$ & $0,0004 \quad(-4,45)$ & $0,0004 \quad(-4,76)$ & $0,0001 \quad(2,53)$ & $0,0001 \quad(-1,54)$ & 0,0002 \\
\hline In Comp & 0,0016 & 0,0016 & 0,0016 & 0,0006 & 0,0004 & 0,0005 \\
\hline __c & $0,0002 \quad(9,09)$ & $0,0002 \quad(9,08)$ & $0,0002 \quad(9,11)$ & $0,0001 \quad(7,23)$ & $0,0001 \quad(5,85)$ & $0,0001 \quad(6,33)$ \\
\hline In ExpComn & $-0,0017$ & $-0,0017$ & $-0,0017$ & $-0,0007$ & $-0,0004$ & $-0,0006$ \\
\hline & $0,0002 \quad(-9,98)$ & $0,0002 \quad(-9,97)$ & $0,0002 \quad(-10,03)$ & $0,0001 \quad(-8,04)$ & $0,0001 \quad(-6,39)$ & $0,0001 \quad(-7,61)$ \\
\hline d1s4* & 0,0320 & 0,0310 & 0,0311 & 0,0150 & 0,0377 & 0,0199 \\
\hline & $0,0069 \quad(4,65)$ & $0,0067 \quad(4,60)$ & $0,0067 \quad(4,62)$ & $0,0040 \quad(3,77)$ & $0,0082 \quad(4,62)$ & $0,0049 \quad(4,09)$ \\
\hline dls5* & 0,0379 & 0,0374 & 0,0368 & 0,0178 & 0,0444 & 0,0236 \\
\hline & $0,0075 \quad(5,08)$ & $0,0074 \quad(5,05)$ & $0,0073 \quad(5,05)$ & $0,0045 \quad(3,95)$ & $0,0093 \quad(4,77)$ & $0,0055 \quad(4,30)$ \\
\hline dl s6* & 0,0461 & 0,0458 & 0,0451 & 0,0214 & 0,0518 & 0,0282 \\
\hline & $0,0083 \quad(5,56)$ & $0,0083 \quad(5,55)$ & $0,0081 \quad(5,55)$ & $0,0052 \quad(4,14)$ & $0,0104 \quad(4,97)$ & $0,0062 \quad(4,54)$ \\
\hline d2s2* & 0,0595 & 0,0588 & 0,0580 & 0,0281 & 0,0661 & 0,0371 \\
\hline & $0,0097 \quad(6,16)$ & $0,0096 \quad(6,14)$ & $0,0095 \quad(6,13)$ & $0,0064 \quad(4,38)$ & $0,0127 \quad(5,20)$ & $0,0077 \quad(4,83)$ \\
\hline d2s3* & 0,0356 & 0,0352 & 0,0346 & 0,0162 & 0,0405 & 0,0214 \\
\hline & $0,0072 \quad(4,96)$ & $0,0071 \quad(4,95)$ & $0,0070 \quad(4,94)$ & $0,0042 \quad(3,86)$ & $0,0086 \quad(4,71)$ & $0,0051 \quad(4,20)$ \\
\hline$d 2 s 4^{*}$ & 0,0275 & 0,0276 & 0,0268 & 0,0124 & 0,0327 & 0,0165 \\
\hline $0234^{\circ}$ & $0,0064 \quad(4,29)$ & $0,0064 \quad(4,34)$ & $0,0063 \quad(4,26)$ & $0,0035 \quad(3,55)$ & $0,0073 \quad(4,48)$ & $0,0043 \quad(3,85)$ \\
\hline$d 2 s 5^{*}$ & 0,0357 & 0,0356 & 0,0349 & 0,0166 & 0,0416 & 0,0220 \\
\hline 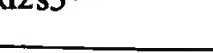 & $0,0072 \quad(4,94)$ & $0,0072 \quad(4,97)$ & $0,0071 \quad(4,94)$ & $0,0043 \quad(3,88)$ & $0,0088 \quad(4,72)$ & $0,0052 \quad(4,22)$ \\
\hline$d 2 s 6^{*}$ & 0,0367 & 0,0365 & 0,0359 & 0,0169 & 0,0422 & 0,0224 \\
\hline & $0,0072 \quad(5,10)$ & $0,0072 \quad(5,08)$ & $0,0071 \quad(5,08)$ & $0,0043 \quad(3,92)$ & $0,0088 \quad(4,78)$ & $0,0052 \quad(4,28)$ \\
\hline d3s2* & 0,0604 & 0,0599 & 0,0591 & 0,0280 & 0,0659 & 0,0368 \\
\hline (2502 & $0,0096 \quad(6,31)$ & $0,0095 \quad(6,30)$ & $0,0094 \quad(6,30)$ & $0,0064 \quad(4,38)$ & $0,0127 \quad(5,21)$ & $0,0076 \quad(4,84)$ \\
\hline d3s3* & 0,0381 & 0,0377 & 0,0371 & 0,0168 & 0,0420 & 0,0222 \\
\hline & $0,0074 \quad(5,15)$ & $0,0074 \quad(5,13)$ & $0,0072 \quad(5,13)$ & $0,0043 \quad(3,91)$ & $0,0088 \quad(4,76)$ & $0,0052 \quad(4,27)$ \\
\hline ln_sel & $1,6 \mathrm{E}-04$ & $1,7 \mathrm{E}-04$ & $1,6 \mathrm{E}-04$ & - & - & - \\
\hline - & $4,0 \mathrm{E}-05 \quad(4,38)$ & $4,0 \mathrm{E}-05 \quad(4,63)$ & $4,0 \mathrm{E}-05 \quad(4,48)$ & - & - & - \\
\hline $\ln \mathrm{cp}$ & $-4,9 \mathrm{E}-05$ & $-4,7 \mathrm{E}-05$ & $-4,8 \mathrm{E}-05$ & - & - & - \\
\hline & $3,0 \mathrm{E}-05 \quad(-1,73)$ & $3,0 \mathrm{E}-05 \quad(-1,69)$ & $3,0 \mathrm{E}-05 \quad(-1,71)$ & - & - & - \\
\hline ln_ca & $-3,5 \mathrm{E}-05$ & $-3,1 \mathrm{E}-05$ & $-3,3 \mathrm{E}-05$ & - & - & - \\
\hline & $3,0 \mathrm{E}-05 \quad(-1,18)$ & $3,0 \mathrm{E}-05 \quad(-1,06)$ & $3,0 \mathrm{E}-05 \quad(-1,12)$ & - & - & - \\
\hline In_st1 & $5,0 \mathrm{E}-05$ & $5,1 \mathrm{E}-05$ & $4,9 \mathrm{E}-05$ & - & - & - \\
\hline & $6,0 \mathrm{E}-05 \quad(0,90)$ & $6,0 \mathrm{E}-05 \quad(0,92)$ & $6,0 \mathrm{E}-05 \quad(0,88)$ & - & - & - \\
\hline
\end{tabular}




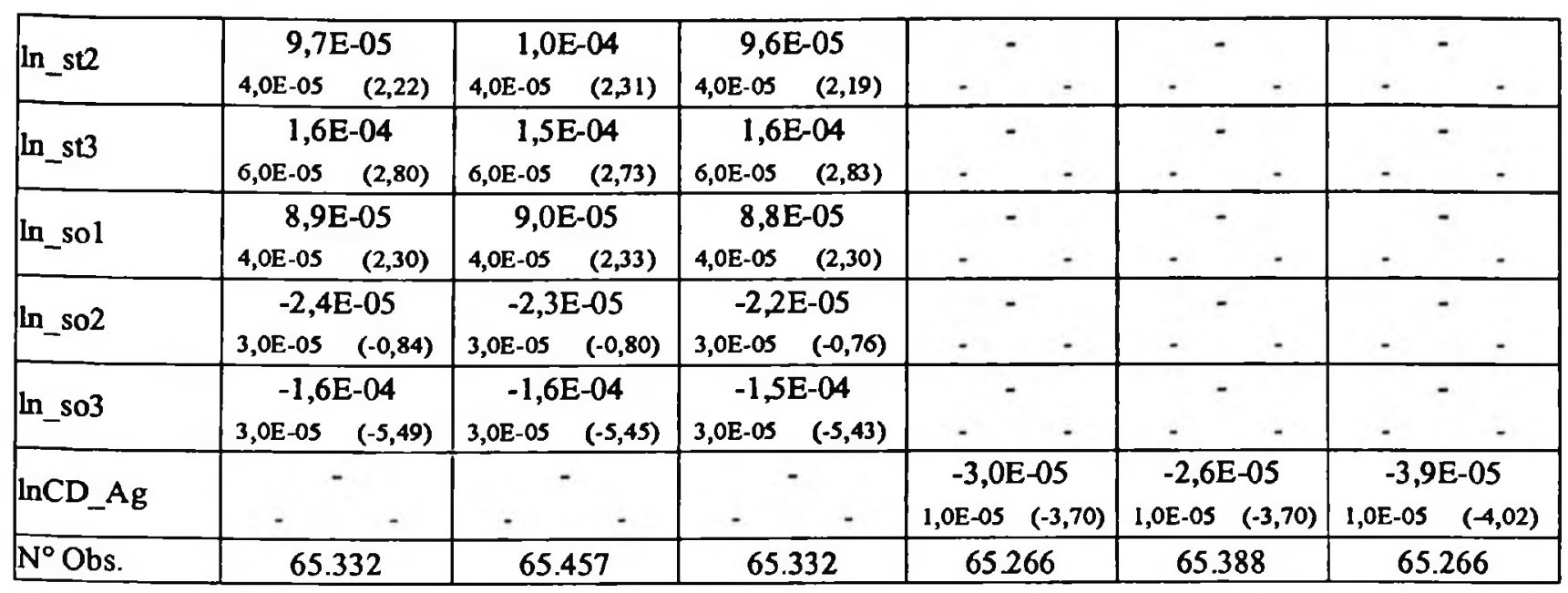

(*) Efeito marginal para variação do valor da variável dummy de 0 para 1.

Para os modelos Tobit, foram estimados os efeitos marginais para as esperanças da variável dependente ln_DEM, condicionais às variáveis explicativas e ao efeito não observado ser igual a zero $\left(E\left[y / x, c_{i}=0\right]\right)^{82}$. Estes efeitos foram coerentes com os efeitos obtidos pelos modelos Probit e Logit.

Os efeitos marginais da taxa de redesconto foram significativos ao nível de $1 \%$. Um aumento de 1 p.p. na taxa de redesconto implica em uma queda na demanda por redesconto entre R\$ $120.049,86$ a R\$ 191.515,57. Os modelos 4 a 6 foram menos sensíveis à taxa de redesconto do que os modelos 1 a 3 .

Os efeitos marginais estimados para o agregado dos compulsórios (exceto Depósitos à Vista) e a exigibilidade agregada destes mesmos compulsórios foram significativas, ao nível de $1 \%$.

As dummies de dias do período de cumprimento, exceto para o modelo 4, apresentaram efeitos marginais significativos ao nivel de $1 \%$. No modelo 4 , os efeitos marginais foram 
significativos a 5\%, com exceção do efeito marginal da dummy dls4 (significante a 10\%). As duas segundas-feiras e a primeira sexta-feira foram os dias com maior impacto sobre a demanda por redesconto. Nos modelos 1 a 3 a demanda por redesconto, dada a exigibilidade de cumprimento do compulsório sobre depósitos à vista, seria de aproximadamente $\mathrm{R} \$$ 2.960.000,00 na segunda segunda-feira; R\$ $2.836 .000,00$ na primeira segunda-feira e R\$ 2.207.000,00 na primeira sexta-feira do periodo de cumprimento. Para os modelos 4 a 6 , estes valores diminuem para aproximadamente $R \$ 1.316 .000,00, R \$ 1.370 .000,000$ e $R \$ 871.000,00$, respectivamente.

Tabela 14 - Efeitos Marginais - Modelo Tobit

\begin{tabular}{|c|c|c|c|c|c|c|}
\hline Variável & MODELO 1 & MODELO 2 & MODELO 3 & MODELO 4 & MODELO 5 & MODELO 6 \\
\hline \multirow{2}{*}{ dga* } & 0,5768 & 0,7251 & 0,8763 & 0,1392 & 0,0648 & 0,0899 \\
\hline & $0,2513 \quad(2,29)$ & $0,2932 \quad(2,47)$ & $0,3487 \quad(2,51)$ & $0,1107 \quad(1,26)$ & $0,1029 \quad(0,63)$ & $0,1159 \quad(0,78)$ \\
\hline \multirow{2}{*}{ dgb* } & 0,4762 & 0,6152 & 0,7500 & 0,1599 & 0,0858 & 0,1118 \\
\hline & $0,2285 \quad(2,08)$ & $0,2691 \quad(2,29)$ & $0,3207 \quad(2,34)$ & $0,1221 \quad(1,31)$ & $0,1101 \quad(0,78)$ & $0,1242 \quad(0,90)$ \\
\hline \multirow{2}{*}{ taxa_rdc } & $-0,0611$ & $-0,0605$ & $-0,0606$ & $-0,0383$ & $-0,0490$ & $-0,0493$ \\
\hline & $0,0041 \quad(-14,74)$ & $0,0041 \quad(-14,74)$ & $0,0041 \quad(-14,67)$ & $0,0033 \quad(-11,56)$ & $0,0037 \quad(-13,19)$ & $0,0039 \quad(-12,82)$ \\
\hline \multirow{2}{*}{ In_RSV } & & 0,0372 & 0,0279 & - & 0,0180 & 0,0141 \\
\hline & & $0,0062 \quad(5,99)$ & $0,0087 \quad(3,22)$ & - & $0,0057 \quad(3,18)$ & $0,0080 \quad(1,77)$ \\
\hline \multirow{2}{*}{ In_rsvLl } & 0,0328 & \multirow[t]{2}{*}{-} & 0,0133 & $-0,0026$ & - & 0,0061 \\
\hline & $0,0062 \quad(5,33)$ & & $0,0085 \quad(1,57)$ & $0,0044 \quad(-0,60)$ & $-\quad \quad-$ & $0,0079 \quad(0,78)$ \\
\hline In Exigivel & $-0,0261$ & $-0,0303$ & $-0,0339$ & $-0,0076$ & $-0,0089$ & $-0,0107$ \\
\hline W_CXigivel & $0,0066 \quad(-3,97)$ & $0,0066 \quad(-4,58)$ & $0,0070 \quad(-4,84)$ & $0,0048 \quad(-1,59)$ & $0,0060 \quad(-1,48)$ & $0,0064 \quad(-1,67)$ \\
\hline $\ln \mathrm{Co}$ & 0,0285 & 0,0286 & 0,0289 & 0,0247 & 0,0316 & 0,0318 \\
\hline III_Comp & $0,0033 \quad(8,51)$ & $0,0033 \quad(8,60)$ & $0,0033 \quad(8,67)$ & $0,0027 \quad(9,10)$ & $0,0030 \quad(10,59)$ & $0,0031 \quad(10,43)$ \\
\hline $\mathrm{OCO}$ & $-0,0300$ & $-0,0302$ & $-0,0305$ & $-0,0155$ & $-0,0256$ & $-0,0259$ \\
\hline 11_exgComp & $0,0032 \quad(-9,33)$ & $0,0032 \quad(-9,43)$ & $0,0032 \quad(-9,52)$ & $0,0024 \quad(-6,54)$ & $0,0028 \quad(-9,26)$ & $0,0028 \quad(-9,21)$ \\
\hline & 0,4974 & 0,4836 & 0,4834 & 0,0248 & 0,2379 & 0,2408 \\
\hline a1s4" & $0,1013 \quad(4,91)$ & $0,0992 \quad(4,88)$ & $0,0994 \quad(4,86)$ & $0,0366 \quad(0,68)$ & $0,0683 \quad(3,48)$ & $0,0691 \quad(3,48)$ \\
\hline d1s5* & 0,5740 & 0,5679 & 0,5581 & 0,0446 & 0,3019 & 0,3017 \\
\hline ל כמנה & $0,1085 \quad(5,29)$ & $0,1077 \quad(5,27)$ & $0,1065 \quad(5,24)$ & $0,0405 \quad(1,10)$ & $0,0755 \quad(4, \infty)$ & $0,0756 \quad(3,99)$ \\
\hline d 1 s $6^{*}$ & 0,7090 & 0,7084 & 0,6949 & 0,0770 & 0,3786 & 0,3777 \\
\hline uiso & $0,1201 \quad(5,91)$ & $0,1198 \quad(5,91)$ & $0,1183 \quad(5,87)$ & $0,0470 \quad(1,64)$ & $0,0830 \quad(4,56)$ & $0,0830 \quad(4,55)$ \\
\hline d2s $2 *$ & 0,9450 & 0,9400 & 0,9249 & 0,1544 & 0,5786 & 0,5780 \\
\hline & $0,1415 \quad(6,68)$ & $0,1408 \quad(6,68)$ & $0,1392 \quad(6,64)$ & $0,0625 \quad(2,47)$ & $0,1040 \quad(5,56)$ & $0,1041 \quad(5,55)$ \\
\hline$d 2 s 3^{*}$ & 0,5284 & 0,5242 & 0,5137 & 0,0315 & 0,2789 & 0,2785 \\
\hline
\end{tabular}

${ }^{82} \mathrm{O}$ valor médio da variável Demanda por Redesconto, incluindo as observações em que seu valor é nulo, é RS $3.134 .461,00$. 


\begin{tabular}{|c|c|c|c|c|c|c|c|c|c|c|c|c|}
\hline & 0,1039 & $(5,09)$ & 0,1033 & $(5,08)$ & 0,1019 & $(5,04)$ & 0,0377 & $(0,83)$ & 0,0726 & $(3,84)$ & 0,0726 & $(3,83)$ \\
\hline \multirow{2}{*}{ d2s $4 *$} & \multicolumn{2}{|c|}{0,4188} & \multicolumn{2}{|c|}{0,4234} & \multicolumn{2}{|c|}{0,4092} & \multicolumn{2}{|c|}{$-0,0037$} & \multicolumn{2}{|c|}{0,1790} & \multicolumn{2}{|c|}{0,1765} \\
\hline & 0,0941 & $(4,45)$ & 0,0937 & $(4,52)$ & 0,0926 & $(4,42)$ & 0,0308 & $(-0,12)$ & 0,0611 & $(2,93)$ & 0,0613 & $(2,88)$ \\
\hline \multirow{2}{*}{$\mathrm{d} 2 \mathrm{~s} 5^{*}$} & \multicolumn{2}{|c|}{0,5349} & \multicolumn{2}{|c|}{0,5342} & \multicolumn{2}{|c|}{0,5233} & \multicolumn{2}{|c|}{0,0289} & \multicolumn{2}{|c|}{0,2626} & \multicolumn{2}{|c|}{0,2620} \\
\hline & 0,1048 & $(5,10)$ & 0,1046 & $(5,11)$ & 0,1032 & $(5,07)$ & 0,0374 & $(0,77)$ & 0,0711 & $(3,69)$ & 0,0712 & $(3,68)$ \\
\hline \multirow{2}{*}{$\mathrm{d} 2 \mathrm{~s} 6^{*}$} & \multicolumn{2}{|c|}{0,5605} & \multicolumn{2}{|c|}{0,5629} & \multicolumn{2}{|c|}{0,5510} & \multicolumn{2}{|c|}{0,0410} & \multicolumn{2}{|c|}{0,2834} & \multicolumn{2}{|c|}{0,2826} \\
\hline & 0,1065 & $(5,26)$ & 0,1065 & $(5,29)$ & 0,1051 & $(5,24)$ & 0,0396 & $(1,04)$ & 0,0729 & $(3,89)$ & 0,0730 & $(3,87)$ \\
\hline \multirow{2}{*}{ d3s $2 *$} & \multicolumn{2}{|c|}{0,9523} & \multicolumn{2}{|c|}{0,9476} & \multicolumn{2}{|c|}{0,9332} & \multicolumn{2}{|c|}{0,1437} & \multicolumn{2}{|c|}{0,5579} & & 577 \\
\hline & 0,1421 & $(6,70)$ & 0,1415 & $(6,70)$ & 0,1400 & $(6,67)$ & 0,0604 & $(2,38)$ & 0,1021 & $(5,47)$ & 0,1022 & $(5,46)$ \\
\hline d $3 s 3 *$ & & 307 & & 766 & & 561 & & 107 & & 73 & & 371 \\
\hline 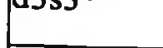 & 0,1089 & $(5,33)$ & 0,1083 & $(5,33)$ & 0,1070 & $(5,29)$ & 0,0396 & $(1,03)$ & 0,0735 & $(3,91)$ & 0,0736 & $(3,90)$ \\
\hline $\ln s e l$ & & 029 & & 030 & & 29 & & & & & & \\
\hline & 0,0006 & $(4,69)$ & 0,0006 & $(4,95)$ & 0,0006 & $(4,80)$ & - & - & - & - & - & - \\
\hline $\ln \mathrm{cp}$ & & 010 & -0 & 010 & & 010 & & & & & & \\
\hline 10_cp & 0,0005 & $(-2,13)$ & 0,0005 & $(-2,06)$ & 0,0005 & $(-2,08)$ & - & - & - & - & - & - \\
\hline ln ca & -0 & 006 & -0 & 005 & -0 & 005 & & & & & & \\
\hline & 0,0005 & $(-1,17)$ & 0,0005 & $(-1,04)$ & 0,0005 & $(-1,09)$ & - & - & - & - & - & - \\
\hline In stl & & 007 & 0, & 007 & & 07 & & & & & & \\
\hline & 0,0010 & $(0,74)$ & 0,0010 & $(0,73)$ & 0,0010 & $(0,71)$ & - & - & - & - & - & - \\
\hline $\ln s t 2$ & & 18 & 0, & 019 & & 18 & & & & & & 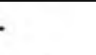 \\
\hline & 0,0008 & $(2,42)$ & 0,0008 & $(2,53)$ & 0,0008 & $(2,40)$ & - & - & - & - & - & - \\
\hline $\ln s t 3$ & & 28 & & 028 & & 328 & & & & & & \\
\hline II_SL & 0,0009 & $(3,12)$ & 0,0009 & $(3,11)$ & 0,0009 & $(3,18)$ & - & - & - & - & - & - \\
\hline In sol & & 914 & 0,0 & 014 & & 13 & & & & & & \\
\hline II_SOI & 0,0006 & $(2,20)$ & 0,0006 & $(2,19)$ & 0,0006 & $(2,16)$ & - & - & - & - & - & - \\
\hline $\ln s 02$ & -0 & 004 & -0 & 004 & -0 , & 004 & & & & & & 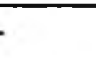 \\
\hline & 0,0005 & $(-0,89)$ & 0,0005 & $(-0,88)$ & 0,0005 & $(-0,84)$ & - & - & - & - & - & - \\
\hline $\ln \operatorname{so} 3$ & -0 & 028 & -0 & 027 & -0 & 027 & & & & & & \\
\hline HIISOJ & 0,0005 & $(-5,64)$ & 0,0005 & $(-5,60)$ & 0,0005 & $(-5,57)$ & - & - & - & - & - & - \\
\hline $\ln C D A g$ & & & & & & & -0 & 011 & & 018 & -0 & 018 \\
\hline HCD_Ag & - & - & - & - & - & - & 0,0003 & $(-4,13)$ & 0,000 & $(-4,47)$ & 0,0004 & $(-4,51)$ \\
\hline $\mathrm{N}^{\circ}$ Obs. & & 32 & 65 & 457 & & 32 & & 66 & & 88 & & 266 \\
\hline
\end{tabular}

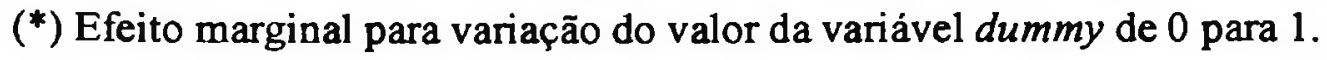




\subsection{Demanda por Redesconto, modelo Heckit.}

O procedimento adotado foi o de ajustar primeiro a equação de seleção (primeiro estágio) para depois, no segundo estágio, reduzir a equação até que todos os coeficientes fossem significativos ao nível de $5 \%$. Em todas as regressões a razão inversa de Mills foi não significativa a $5 \%^{83}$. Os três modelos estimados seguem o mesmo padrão dos modelos 1,2 e 3 estimados pelo Probit, Logit e Tobit, ou seja, o modelo 1 tem como regressor o saldo em reservas ao final do próprio dia; no modelo 2, o saldo em reservas ao final do dia anterior; e no modelo 3, ambos. Os três modelos foram estimados sem considerar a estrutura de painel. A tabela a seguir traz o resultado dos modelos finais.

Tabela 15 - Resultados do Modelo Heckit

\begin{tabular}{|c|c|c|c|c|c|c|}
\hline \multirow{2}{*}{ Variável } & \multicolumn{2}{|c|}{ MODELO 1} & \multicolumn{2}{|c|}{ MODELO 2} & \multicolumn{2}{|c|}{ MODELO 3} \\
\hline & Eq. Seleção & Demanda & Eq. Seleção & Demanda & Eq. Seleção & Demanda \\
\hline \multirow{2}{*}{ dga } & 0,677 & - & 0,736 & - & 0,731 & - \\
\hline & $0,172 \quad(3,93)$ & - & $0,173 \quad(4,24)$ & - & $0,174 \quad(4,21)$ & - \\
\hline \multirow{2}{*}{ dgb } & 0,576 & - & 0,636 & - & 0,630 & - \\
\hline & $0,172 \quad(3,34)$ & - & $0,173 \quad(3,67)$ & - & $0,174 \quad(3,63)$ & - \\
\hline \multirow{2}{*}{ taxa_rdc } & $-0,114$ & - & $-0,113$ & - & $-0,112$ & - \\
\hline & $0, \infty 7 \quad(-16,03)$ & - & $0,007 \quad(-16,07)$ & - & $0,007 \quad(-15,78)$ & - \\
\hline \multirow{2}{*}{ ln_RSV } & 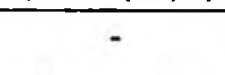 & - & 0,070 & 0,382 & 0,069 & 0,207 \\
\hline & - & - & $0,012 \quad(5,77)$ & $0,039 \quad(9,90)$ & $0,012 \quad(5,74)$ & $0,079 \quad(2,61)$ \\
\hline \multirow{2}{*}{ ln_rsvLl } & 0,064 & 0,383 & - & - & - & 0,202 \\
\hline & $0,012 \quad(5,40)$ & $0,039 \quad(9,84)$ & - $\quad-$ & $-\quad-$ & $-\quad-$ & $0,079 \quad(2,54)$ \\
\hline Exigiv & $-0,051$ & $-0,046$ & $-0,056$ & $-0,045$ & $-0,056$ & $-0,054$ \\
\hline 111_cxigivel & $0,013 \quad(-4,06)$ & $0,015 \quad(-3,05)$ & $0,013 \quad(-4,42)$ & $0,015 \quad(-3,03)$ & $0,013 \quad(-4,38)$ & $0,015 \quad(-3,55)$ \\
\hline In Comm & 0,053 & - & 0,053 & - & 0,053 & - \\
\hline & $0,006 \quad(8,15)$ & - & $0,006 \quad(8,19)$ & - & $0,006 \quad(8,18)$ & - \\
\hline ExaCo & $-0,056$ & $-0,062$ & $-0,056$ & $-0,061$ & $-0,056$ & $-0,061$ \\
\hline HO_ExgComp & $0,006 \quad(-9,05)$ & $0,012 \quad(-5,12)$ & $0,006 \quad(-9,10)$ & $0,012 \quad(-5,09)$ & $0,006 \quad(-9,10)$ & $0,012 \quad(-5,12)$ \\
\hline d 184 & 0,539 & 4,121 & 0,532 & 4,200 & 0,528 & 4,110 \\
\hline & $0,068 \quad(7,89)$ & $0,406 \quad(10,15)$ & $0,068 \quad(7,80)$ & $0,403 \quad(10,41)$ & $0,068 \quad(7,73)$ & $0,405 \quad(10,14)$ \\
\hline
\end{tabular}

${ }^{83}$ Os valores mais próximos do corte em $p$-value igual a 0,050 foram 0.053 e 0,074, não rejeitando a hipótese nula (Razão inversa de Mills = 0). Os desvios-padrão na equação da demanda estão corrigidos em função da razão inversa de Mills ser uma variável gerada na primeira etapa. 


\begin{tabular}{|c|c|c|c|c|c|c|}
\hline \multirow{2}{*}{ dis5 } & 0,581 & 3,717 & 0,580 & 3,793 & 0,580 & 3,692 \\
\hline & $0,067 \quad(8,68)$ & $0,419 \quad(8,87)$ & $0,067 \quad(8,66)$ & $0,416 \quad(9,12)$ & $0,067 \quad(8,66)$ & $0,419 \quad(8,81)$ \\
\hline \multirow{2}{*}{ d1 s6 } & 0,656 & 4,301 & 0,659 & 4,381 & 0,659 & 4,285 \\
\hline & $0,065 \quad(10,11)$ & $0,413 \quad(10,40)$ & $0,065 \quad(10,15)$ & $0,411 \quad(10,66)$ & $0,065 \quad(10,16)$ & $0,415 \quad(10,33)$ \\
\hline \multirow{2}{*}{$\mathrm{d} 2 \mathrm{~s} 2$} & 0,763 & 4,064 & 0,764 & 4,145 & 0,763 & 4,047 \\
\hline & $0,063 \quad(12,07)$ & $0,414 \quad(9,81)$ & $0,063 \quad(12,08)$ & $0,411 \quad(10,08)$ & $0,063 \quad(12,08)$ & $0,415 \quad(9,74)$ \\
\hline \multirow{2}{*}{$\mathrm{d} 2 \mathrm{~s} 3$} & 0,548 & 3,674 & 0,547 & 3,723 & 0,547 & 3,644 \\
\hline & $0,068 \quad(8,10)$ & $0,417 \quad(8,82)$ & $0,068 \quad(8,09)$ & $0,415 \quad(8,98)$ & $0,068 \quad(8,10)$ & $0,417 \quad(8,74)$ \\
\hline \multirow{2}{*}{ d2s4 } & 0,461 & 4,322 & 0,467 & 4,470 & 0,453 & 4,334 \\
\hline & $0,070 \quad(6,56)$ & $0,415 \quad(10,42)$ & $0,070 \quad(6,71)$ & $0,411 \quad(10,87)$ & $0,070 \quad(6,47)$ & $0,414 \quad(10,47)$ \\
\hline d2s5 & 0,560 & 4,042 & 0,562 & 4,072 & 0,562 & 4,005 \\
\hline 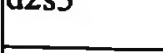 & $0,068 \quad(8,29)$ & $0,418 \quad(9,68)$ & $0,067 \quad(8,33)$ & $0,416 \quad(9,78)$ & $0,067 \quad(8,33)$ & $0,419 \quad(9,57)$ \\
\hline $\mathrm{d} 2 \mathrm{~s} 6$ & 0,572 & 4,104 & 0,575 & 4,233 & 0,575 & 4,124 \\
\hline & $0,067 \quad(8,55)$ & $0,414 \quad(9,91)$ & $0,067 \quad(8,61)$ & $0,411 \quad(10,29)$ & $0,067 \quad(8,61)$ & $0,415 \quad(9,93)$ \\
\hline d3s2 & 0,771 & 4,434 & 0,771 & 4,497 & 0,771 & 4,399 \\
\hline avs & $0,063 \quad(12,20)$ & $0,418 \quad(10,60)$ & $0,063 \quad(12,21)$ & $0,416 \quad(10,82)$ & $0,063 \quad(12,21)$ & $0,420 \quad(10,48)$ \\
\hline d3s3 & 0,575 & 4,051 & 0,574 & 4,122 & 0,574 & 4,028 \\
\hline 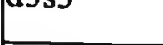 & $0,067 \quad(8,57)$ & $0,414 \quad(9,78)$ & $0,067 \quad(8,50)$ & $0,412 \quad(10,01)$ & $0,067 \quad(8,57)$ & $0,415 \quad(9,71)$ \\
\hline $\ln C D \quad A g$ & $-0,004$ & - & $-0,004$ & - & $-0,004$ & - \\
\hline & $0,001 \quad(-4,60)$ & - & $0,001 \quad(-4,29)$ & - & $0,001 \quad(-4,36)$ & - \\
\hline cons & $-2,821$ & 9,145 & $-2,891$ & 9,058 & $-2,894$ & 9,022 \\
\hline Cous & $0,152 \quad(-18,56)$ & $1,022 \quad(8,95)$ & $0,155 \quad(-18,71)$ & $1,027 \quad(8,82)$ & $0,155 \quad(-18,72)$ & $1,038 \quad(8,69)$ \\
\hline Mills & - & 0,002 & - & 0,008 & - & $-0,070$ \\
\hline & - & $0,304 \quad(0,01)$ & - & $0,301 \quad(0,03)$ & - & $0,308 \quad(-0,23)$ \\
\hline $\mathrm{N}^{\circ}$ Obs. & 65 & & 65. & & & 84 \\
\hline
\end{tabular}

Apesar de a razão inversa de Mills não ter sido significante ao nivel de 5\%, podemos extrair algumas observações.

A primeira observação diz respeito à taxa do redesconto (taxa_rdc). Em todas as regressões dos modelos Probit, Logit e Tobit a taxa de redesconto foi expressivamente significante ${ }^{84}$. No modelo Heckit ela foi significante apenas na equação de seleção indicando que dado que há a necessidade de recursos over, a taxa (preço) destes recursos não é relevante para a decisão sobre o volume de recursos demandados.

\footnotetext{
${ }^{84}$ Quando não mencionado, a significância é de 5\%.
} 
Da mesma forma, as dummies de grupo do compulsório sobre depósitos à vista, ln_Comp e lnCD_Ag seguem a mesma interpretação. Esta variáveis seriam relevantes para a seleção da operação, mas uma vez que a operação está definida, deixam de ser fatores de determinação da demanda.

\subsection{Observações finais}

Este capítulo apresentou a parte empírica do trabalho. Com base nos modelos apresentados no Capitulo 4, foram estimados os modelos Probit, Logit, Tobit (Pooled e Efeitos Aleatórios) e o modelo Heckit.

Nos modelos Probit e Logit, para as variáveis que foram significativas a $1 \%$, os resultados foram qualitativamente semelhantes, havendo diferença apenas na magnitude dos coeficientes e dos efeitos marginais. Para análise foram considerados três grupos de resultados possíveis. O primeiro grupo foi formado pelas variáveis significativas nos seis modelos: taxa_rdc, ln_Comp, ln_ExgComp e todas as dummies de dias do período de cumprimento. Neste grupo apenas a variável ln_ExgComp exibiu sinal diferente do esperado, possivelmente pela alta corelação com ln_Comp. O segundo grupo foi formado pelas variáveis que foram significativas nos modelos 1, 2 e 3 e não significativas nos modelos 4, 5 e 6: dga, dgb, ln_RSV, ln_rsvLl, ln_Exigivel. Como, ao nível de $1 \%$, não se rejeitou a presença dos efeitos não observáveis, os resultados destas variáveis não podem ser considerados da mesma forma que os resultados do grupo de variáveis anterior. Neste grupo, a variável ln_Exigível apresentou sinal contrário ao esperado. O terceiro grupo foi formado pelas variáveis que não eram comuns a todos os seis modelos: ln_sel, ln_cp, ln_ca, ln_st $1, \ln \_s t 2, \ln \_s t 3, \ln s \mathrm{~s} 1, \ln \_s 02, \ln \_s 03$ e lnCD_Ag. Destas 
variáveis, apenas ln_sel, ln_st3, In_so3 e lnCD_Ag foram significativas ao nível de $1 \%$, sendo apenas os sinais de ln_so3 e lnCD_Ag compatíveis com o esperado.

Com relação aos efeitos marginais, os modelos Logit tenderam a subestimar os efeitos com exceção das dummies de dias do período de cumprimento do compulsório sobre depósitos à vista.

Do ponto de vista de previsão de resultados, os modelos apresentaram baixo percentual de acertos para a ocorrência do redesconto $($ dopd $=1)$. Na situação em que o valor de referência foi definido como a proporção de zeros na amostra, o melhor resultado foi obtido pelo modelo Probit (56\%).

Os modelos de demanda (Tobit) apresentaram resultados coerentes com os modelos de probabilidade. Foi possível observar quanto a demanda por redesconto é afetada pela variação absoluta das variáveis explicativas (no caso das dummies, quanto a ocorrência do estado "1" implica em aumento da demanda por redesconto). No modelo Heckit foi possível identificar quais variáveis são relevantes na seleção (taxa_rdc) e quais são relevantes na quantidade demandada. 


\section{CAPÍTULO 6 - CONCLUSÃO}

Este trabalho teve como objetivos elaborar um modelo para a demanda por redesconto e para a probabilidade de utilização do redesconto e avaliá-los empiricamente.

Inicialmente foi apresentado o contexto em que se insere o redesconto. De forma resumida foram descritos o PROER, o PROES e o PROEF - programas criados pelo Governo Federal para garantir a estabilidade e o fortalecimento do Sistema Financeiro Nacional. A estratégia adotada pelo Govemo foi a de separar as instituições financeiras em três grupos pelo critério de governança, buscando atender suas caracteristicas especificas. O PROER foi o programa criado para atender às instituições financeiras privadas, o PROES aos bancos estaduais e o PROEF aos bancos federais. Na seqüência foram descritos os mecanismos que os bancos possuem para obter reservas e resolver seus problemas de liquidez.

No terceiro capítulo, foram resumidos os normativos sobre o redesconto em vigência a partir do Plano Real. É possivel verificar as fases em que o BACEN buscava aumentar a liquidez via redesconto observando as facilidades (por exemplo, a criação de linhas de redesconto que utilizavam títulos públicos federais como garantia) ou estímulos (diminuição da taxa de redesconto) criados.

Montado o cenário em que o redesconto se insere, foi apresentado o modelo de demanda por redesconto. O modelo é inspirado nos modelos de administração de reservas internacionais e baseia-se no comportamento intradia da conta de Reservas Bancárias. Parte-se das hipóteses de 
que o saldo da conta de Reservas Bancárias segue um Processo de Levy ${ }^{85}$ e de que a administração do saldo em reservas durante o periodo de cumprimento do compulsório sobre depósitos à vista é relevante para a determinação da demanda.

A seguir vem a parte empírica. É feito um breve resumo da Metodologia. Os modelos utilizados foram o Probit, o Logit, o Tobit, com dados em painel e estimadores Pooled e de efeitos aleatórios, e o Heckit. Foi inserida uma seção com estatísticas descritivas da amostra. A amostra foi composta por 122 instituições financeiras para o periodo de 22 de abril de 2002 a 31 de agosto de 2004, tendo sido fornecidos dados individuais (por instituição financeira) de caráter sigiloso como saldo em reservas, valor das operações de redesconto e de nivelamento entre outros. Foi verificado que as operações de nivelamento realizadas pelo DEMAB são relevantes para a definição de redesconto.

Os principais resultados obtidos foram:

1) Evidências da influência do periodo de cumprimento do compulsório sobre depósitos à vista sobre a demanda por reservas. Em particular, as duas segundas-feiras do periodo de cumprimento ( $\mathrm{d} 2 \mathrm{~s} 2$ e d3s2) e o último dia em que se cumpre o compulsório sem a certeza sobre o valor da exigibilidade (d1 s6) são os dias com maior probabilidade de utilização do redesconto over. Os dias com menor probabilidade de utilização de redesconto foram as duas quartas-feiras do periodo (d1s4 e d2s4). Estes resultados são compatíveis com os resultados de Costa Pinto e Coelho (2004).

2) Houve uma alta sensibilidade da demanda por redesconto over em relação à taxa do redesconto. Mesmo considerando as operações de nivelamento realizadas pelo SELIC, esta

\footnotetext{
${ }^{85}$ Essa hipótese é válida mesmo para os bancos pequenos que têm controle quase total dos lançamentos em suas
} 
variável afeta de forma significativa a probabilidade de utilização do redesconto over. Isto pode ser explicado por uma alta correlação entre as taxas de redesconto e a taxa cobrada pelo SELIC.

3) No que diz respeito à previsão, os modelos econométricos utilizados não tiveram um bom desempenho. A explicação para isto pode estar no fato de que a quantidade de zeros da variável binária dependente $(98,31 \%)$ é muito maior que o número de uns $(1,69 \%)$.

4) Os modelos de demanda apresentaram resultados semelhantes aos modelos de probabilidade. O modelo Heckit descartou ao nível de $5 \%$ a possibilidade de seleção endógena da amostra e, como conseqüência, indicou como adequado o modelo de Minimos Quadrados Ordinários para a demanda. Nestas condições, na equação de demanda, algumas variáveis como a taxa de redesconto e o agregado dos lançamentos a crédito/débito passaram a ser não significativas. Isto indica que estas variáveis explicam apenas a possivel seleção, não sendo o volume de demanda no redesconto sensivel às suas variações.

5) Os efeitos marginais estimados no Capítulo 5 permitiram a comparação entre os modelos Probit e Logit e permitiram estimar o impacto de variações na demanda por redesconto no modelo Tobit. Com relação aos modelos de probabilidade, a taxa de redesconto apresentou uma faixa de variação relativamente grande, sendo que para cada 1 p.p. de variação obteve-se: Pooled Probit (média de -0,38 p.p.); Probit Efeitos Aleatórios (média de -0,30 p.p.); Pooled Logit (média de $-0,33$ p.p.) e Logit Efeitos Aleatórios (média de $-0,11$ p.p.). Nos modelos de demanda, o valor máximo para a variação de 1 p.p. na taxa de redesconto foi de $R \$ 208.258,10$ (Tobit, modelo 1). Para os dias com maior probabilidade de utilização do redesconto o resultado foi: primeira sexta-feira do período (média de 6,96 p.p. para os modelos Probit e 3,97 p.p. para 
os modelos Logit); primeira segunda-feira (8,89 p.p. e 5,12 p.p.) e para a segunda segunda-feira (8,73 p.p. e 5,17 p.p.). Nos modelos de demanda, o impacto do dia do periodo de cumprimento do compulsório sobre depósitos à vista varia entre aproximadamente R\$ $1.460 .000,00$ e R\$ 3.206.000,00 nas segundas-feiras e R\$ $947.000,00$ e R\$ $2.400 .000,00$ na primeira sexta-feira.

6) Os resultados reportados no apêndice (amostra reduzida para o período de $1^{\circ}$ de julho de 2002 a 31 de agosto de 2004) reforçam os resultados obtidos neste trabalho. Neste período a sobretaxa de redesconto ficou fixada em $6 \%$ a.a. Em termos qualitativos os resultados foram iguais, sendo diferentes apenas na intensidade.

Este trabalho não teve a pretensão de esgotar o estudo empírico sobre o redesconto, sendo apenas um primeiro passo de um longo percurso a ser caminhado. Há outros métodos a serem utilizados e outras perguntas a serem respondidas. 


\section{REFERÊNCIAS BIBLIOGRÁFICAS}

AMEMTYA, T. (1985), Advanced Econometrics, Cambridge: Harvard University Press.

ANGELINI, P. (2000), "Are banks risk averse ? Intraday timing of operations in the interbank market", Journal of Money, Credit, and Banking, 32, 54-73.

BANCO CENTRAL DO BRASIL (2002), Relatório de Atividades da Diretoria de Fiscalização.

BAR-ILAN, A. (1990), "Overdraft and the demand for money", The American Economic Review, 80, 1201-1216.

BAR-ILAN, A., PERRY, D., STADJE, W. B. (2004), “A generalized impulse control model of cash management", Joumal of Economic Dynamics \& Control, 28, $1013-1033$.

BAUMOL, W. J. (1952), "The transactions demand for cash: An inventory theoretical approach", The Quarterly Journal of Economics, 66, 545-556.

BORIO, C. (2001), “Comparing monetary policy operating procedures across de United States, Japan and the euro area", Bank for International Settlements, BIS Papers 9.

CHANG, F. (1999), "Homogeneity and the transactions demand for money", Journal of Money, Credit and Banking, 31, 720-730.

CLOUSE, J. A., DOW JR., J. P. (2002), “A computational model of bank's optimal reserve management policy", Journal of Economic Dynamics \& Control, 26, 1787-1814.

COSTA PINTO, J. C., COELHO, C. A. (2004), "Modelagem do comportamento ótimo dos bancos no mercado de reservas brasileiro", Não publicado. 
FRENKEL, J. A., JOVANOVIC, B. (1980), "On transactions and precautionay demand for money", The Quarterly Journal of Economics, 95, 25-43.

FRENKEL, J. A., JOVANOVIC, B. (1981), "Optimal international reserves: A stochastic framework", The Economic Joumal, 91, 507-514.

GRONAU, R. (1974), “Wage comparisions - A selectivity bias", Journal of Political Economy, 82, 1119-1143.

LUNDBERG, E. L. (1999), "Saneamento do sistema financeiro", em SADDI, J. (organizador), Intervenção e Liquidação Extrajucial no Sistema Financeiro Nacional - 25 anos da Lei 6.024/74, Editora Textonovo, 53-70.

MILLER, M., ORR, D. (1966), “A model of the demand for money by firms", The Quarterly Journal of Economics, 81, 413-435.

PERISTIANI, S. (1994), "An empirical investigation of the determinants of discount window borrowing: A disaggregate analysis", Journal of Banking \& Finance, 18, 183-197.

ROJAS-SUAREZ, L., WEISBROD, S. R. (1995), Banking Crisis in Latin America: Experience and Issues, Inter-American Development Bank.

QUEIROZ, M. F. (2004), Gerenciamento das Reservas Bancárias - Contágio, Previsibilidade do Comportamento Diário dos Bancos e Expectativa, Tese de Doutorado, Universidade de Brasília.

TOBIN, J. (1956), "The interest-elasticity of transactions demand for cash", Review of Economics and Statistics, 38, 241-247 
VALIMAKI, T. (2001), "Fixed rate tenders and overnight money market equilibrium", Bank of Finland, Bank of Finland Discussion Papers 8-2001.

WOOLDRIDGE, J. M. (2002), Econometric Analysis of Cross Section and Panel Data, Cambridge:The MIT Press.

\section{Normativos - CMN e BACEN}

Resolução $n^{\circ}$ 63, de 21 de agosto de 1967

Resolução $\mathrm{n}^{\circ} 1.786$, de 01 de fevereiro de 1991

Resolução $\mathrm{n}^{\circ} 2.197$, de 31 de agosto de 1995

Resolução $n^{\circ} 2.208$, de 03 de novembro de 1995

Resolução $\mathrm{n}^{\circ} 2.211$, de 16 de novembro de 1995

Resolução ${ }^{\circ} 2.288$, de 20 de junho de 1996

Resolução $\mathrm{n}^{\circ} 2.308$, de 28 de agosto de 1996

Resolução $\mathrm{n}^{\circ} 2.365$, de 28 de fevereiro de 1997

Resolução $\mathrm{n}^{\circ} 2.685$, de 26 de janeiro de 2000

Resolução $\mathrm{n}^{\circ} 2.770$, de 30 de agosto de 2000

Resolução $\mathrm{n}^{\circ} 2.949$, de 04 de abril de 2002

Circular $\mathrm{n}^{\circ} 2.712$, de 28 de agosto de 1996

Circular $n^{\circ} 2.724$, de 30 de setembro de 1996

Circular n².830, de 12 de agosto de 1998

Circular n $n^{\circ} 2.835$, de 04 de setembro de 1998

Circular n² 2.841, de 23 de setembro de 1998

Circular $n^{\circ} 2.849$, de 11 de novembro de 1998

Circular $\mathrm{n}^{\circ} 2.962$, de 26 de janeiro de 2000

Circular $n^{\circ} 2.965$, de 08 de fevereiro de 2000

Circular $\mathrm{n}^{\circ} 2.966$, de 08 de fevereiro de 2000

Circular n 2.979, de 26 de abril de 2000

Circular $n^{\circ} 3.038$, de 06 de junho de 2001 
Circular $n^{\circ} 3.105$, de 05 de abril de 2002

Circular $n^{\circ} 3.120$, de 19 de abril de 2002

Carta-Circular n ${ }^{\circ} 3.009$, de 19 de abril de 2002

Comunicado $\mathrm{n}^{\circ} 7.292$, de 16 de fevereiro de 2000

Comunicado $\mathrm{n}^{\circ} 7.382$, de 22 de março de 2000

Comunicado $\mathrm{n}^{\circ} 7.464$, de 19 de abril de 2000

\section{Leis}

Lei $n^{\circ} 9.710$, de 19 de novembro de 1998

Medida Provisória n ${ }^{\circ} 1.179$, de 03 de novembro de 1995 


\section{APÊNDICE A - RESULTADOS PARA AMOSTRA DE 01/07/2002 A} $31 / 08 / 2004$

Este apêndice apresenta os resultados das regressões realizadas no Capitulo 5 para uma amostra com período de $1^{\circ}$ de julho de 2002 a 31 de agosto de $2004^{86}$. A Circ. 3.120 , que define as taxas a serem aplicadas nas operações de redesconto, previa que a partir de $1^{\circ}$ de julho de 2002 a sobretaxa das operações de um dia passaria de $1 \%$ a.a. para $6 \%$ a.a., valor que permance até hoje. Tal fato poderia configurar uma quebra de regime.

\section{A.1. Probabilidade de utilização do Redesconto, modelo Probit.}

A tabela a seguir ${ }^{87}$ mostra os resultados das regressões do modelo Probit.

Do ponto de vista qualitativo, os resultados foram semelhantes aos das regressões para o periodo todo da amostra.

A taxa de redesconto foi significativa a $5 \%$ para os modelos 1 a 3 e a $1 \%$ para os modelos 4 a 6 . Os coeficientes estimados para esta variável neste periodo foram maiores (em módulo) do que no periodo todo.

Tabela 16 - Resultados do Modelo Probit

\begin{tabular}{|c|c|c|c|c|c|c|}
\hline Variável & MODELO 1 & MODELO 2 & MODELO 3 & MODELO 4 & MODELO 5 & MODELO 6 \\
\hline \multirow{2}{*}{ dga } & 0,797 & 0,864 & 0,954 & 0,316 & 0,297 & 0,342 \\
\hline & $0,197 \quad(4,05)$ & $0,200 \quad(4,32)$ & $0,205 \quad(4,65)$ & $0.280 \quad(1.13)$ & $0.286 \quad(1.04)$ & $0.310 \quad(1.10)$ \\
\hline dgb & 0,679 & 0,745 & 0,836 & 0,220 & 0,201 & 0,245 \\
\hline
\end{tabular}

\footnotetext{
${ }^{86}$ Para esse periodo o número de instituições financeiras da amostra se reduz para 121.

${ }^{87}$ A tabela contém os mesmos modelos e segue o mesmo padrão de apresentaç̃o da Tabela 6.
} 


\begin{tabular}{|c|c|c|c|c|c|c|}
\hline & $(3,48)$ & $(3,76)$ & $(4,10)$ & $(0.78)$ & $(0.70)$ & $(0.79)$ \\
\hline \multirow{2}{*}{ taxa_rdc } & $-0,697$ & $-0,704$ & $-0,691$ & $-1,174$ & $-1,176$ & $-1,173$ \\
\hline & $0,326 \quad(-2,14)$ & $0,328 \quad(-2,15)$ & $0,327 \quad(-2,11)$ & $0.352 \quad(-3.33)$ & $0.352 \quad(-3.34)$ & $0.352 \quad(-3.33)$ \\
\hline \multirow{2}{*}{$\ln \_$RSV } & - & 0,068 & 0,047 & - & 0,007 & 0,004 \\
\hline & - & $0,012 \quad(5,42)$ & $0,018 \quad(2,60)$ & - & $0.020 \quad(0.37)$ & $0.022 \quad(0.18)$ \\
\hline \multirow{2}{*}{ ln_rsvLl } & 0,061 & - & 0,028 & 0,009 & - & 0,007 \\
\hline & $0,012 \quad(5,18)$ & - & $0,017 \quad(1,62)$ & $0.019 \quad(0.47)$ & - & $0.021 \quad(0.34)$ \\
\hline \multirow{2}{*}{ In_Exigivel } & $-0,059$ & $-0,065$ & $-0,072$ & $-0,021$ & $-0,019$ & $-0,023$ \\
\hline & $0,014 \quad(-4,32)$ & $0,014 \quad(-4,61)$ & $0,015 \quad(-4,96)$ & $0.021 \quad(-1.00)$ & $0.022 \quad(-0.89)$ & $0.024 \quad(-0.97)$ \\
\hline In Comp & 0,064 & 0,065 & 0,065 & 0,079 & 0,079 & 0,079 \\
\hline H_conisp & $0,007 \quad(9,08)$ & $0,007 \quad(9,17)$ & $0,007 \quad(9,23)$ & $0.010 \quad(8.22)$ & $0.010 \quad(8.17)$ & $0.010 \quad(8.11)$ \\
\hline In ExpComn & $-0,062$ & $-0,062$ & $-0,063$ & $-0,070$ & $-0,070$ & $-0,070$ \\
\hline & $0,007 \quad(-9,13)$ & $0,007 \quad(-9,23)$ & $0,007 \quad(-9,31)$ & $0.008 \quad(-8.67)$ & $0.008 \quad(-8.65)$ & $0.008 \quad(-8.55)$ \\
\hline dis4 & 0,524 & 0,522 & 0,516 & 0,751 & 0,753 & 0,749 \\
\hline$[107$ & $0,079 \quad(6,62)$ & $0,079 \quad(6,58)$ & $0,079 \quad(6,53)$ & $0.113 \quad(6.64)$ & $0.114 \quad(6.63)$ & $0.113 \quad(6.62)$ \\
\hline dis5 & 0,541 & 0,540 & 0,535 & 0,765 & 0,767 & 0,763 \\
\hline (2) & $\begin{array}{ll}0,079 & (6,89) \\
\end{array}$ & $0,079 \quad(6,84)$ & $0,079 \quad(6,81)$ & $0.113 \quad(6.77)$ & $0.114 \quad(6.76)$ & $0.113 \quad(6.74)$ \\
\hline d1s6 & 0,626 & 0,628 & 0,621 & 0,858 & 0,860 & 0,856 \\
\hline 000 & $0,077 \quad(8,14)$ & $0,077 \quad(8,13)$ & $0,077 \quad(8,09)$ & $0.111 \quad(7.74)$ & $0.111 \quad(7.74)$ & $0.111 \quad(7.73)$ \\
\hline d2s2 & 0,751 & 0,750 & 0,745 & 1,021 & 1,024 & 1,019 \\
\hline 0 & $0,074 \quad(10,09)$ & $0,075 \quad(10,04)$ & $0,074 \quad(10,01)$ & $0.109 \quad(9.41)$ & $0.109 \quad(9.39)$ & $0.109 \quad(9.39)$ \\
\hline d2s3 & 0,490 & 0,488 & 0,482 & 0,701 & 0,703 & 0,699 \\
\hline & $0,080 \quad(6,15)$ & $0,080 \quad(6,11)$ & $0,080 \quad(6,07)$ & $0.114 \quad(6.17)$ & $0.114 \quad(6.16)$ & $0.114 \quad(6.14)$ \\
\hline$d 2 \mathrm{~s} 4$ & 0,440 & 0,442 & 0,435 & 0,627 & 0,629 & 0,625 \\
\hline & $0,082 \quad(5,38)$ & $0,082 \quad(5,39)$ & $0,082 \quad(5,33)$ & $0.116 \quad(5.42)$ & $0.116 \quad(5.43)$ & $0.116 \quad(5.40)$ \\
\hline d2s 5 & 0,487 & 0,489 & 0,483 & 0,699 & 0,701 & 0,697 \\
\hline Sב & $0,080 \quad(6,05)$ & $0,081 \quad(6,06)$ & $0,080 \quad(6,01)$ & $0.114 \quad(6.11)$ & $0.115 \quad(6.12)$ & $0.114 \quad(6.10)$ \\
\hline d2s 6 & 0,525 & 0,527 & 0,521 & 0,752 & 0,755 & 0,751 \\
\hline & $0,079 \quad(6,64)$ & $0,079 \quad(6,64)$ & $0,079 \quad(6,60)$ & $0.113 \quad(6.67)$ & $0.113 \quad(6.68)$ & $0.113 \quad(6.66)$ \\
\hline d3s2 & 0,751 & 0,750 & 0,745 & 1,010 & 1,012 & 1,008 \\
\hline 0032 & $0,074 \quad(10,19)$ & $0,074 \quad(10,15)$ & $0,074 \quad(10,13)$ & $0.109 \quad(9.29)$ & $0.109 \quad(9.28)$ & $0.109 \quad(9.27)$ \\
\hline d3s3 & 0,537 & 0,534 & 0,529 & 0,744 & 0,746 & 0,742 \\
\hline & $0,078 \quad(6,85)$ & $0,078 \quad(6,80)$ & $0,078 \quad(6,77)$ & $0.113 \quad(6.60)$ & $0.113 \quad(6.58)$ & (6.57) \\
\hline In sed & 0,007 & 0,007 & 0,007 & - & - & - \\
\hline & $0,001 \quad(5,08)$ & $0,001 \quad(5,17)$ & $0,001 \quad(5,15)$ & - & - & - \\
\hline $\ln \mathrm{cp}$ & $-0,002$ & $-0,002$ & $-0,002$ & - & - & - \\
\hline & $0,001 \quad(-1,64)$ & $0,001 \quad(-1,61)$ & $0,001 \quad(-1,63)$ & - & - & - \\
\hline In_ca & $-0,001$ & $-0,001$ & $-0,001$ & - & - & - \\
\hline & $0,001 \quad(-0,57)$ & $0,001 \quad(-0,49)$ & $0,001 \quad(-0,51)$ & - & - & - \\
\hline In stl & 0,001 & 0,001 & 0,001 & - & - & - \\
\hline & $0,002 \quad(0,45)$ & $0,002 \quad(0,43)$ & $0,002 \quad(0,42)$ & - & - & - \\
\hline In_st2 & 0,003 & 0,003 & 0,003 & - & - & - \\
\hline & $0,002 \quad(1,90)$ & $0,002 \quad(1,90)$ & $0,002 \quad(1,88)$ & - & - & - \\
\hline ln st 3 & 0,007 & 0,007 & 0,007 & - & - & - \\
\hline & $0,002 \quad(3,19)$ & $0,002 \quad(3,23)$ & $0,002 \quad(3,22)$ & - & - & - \\
\hline |n_sol & 0,002 & 0,002 & 0,002 & - & - & - \\
\hline
\end{tabular}




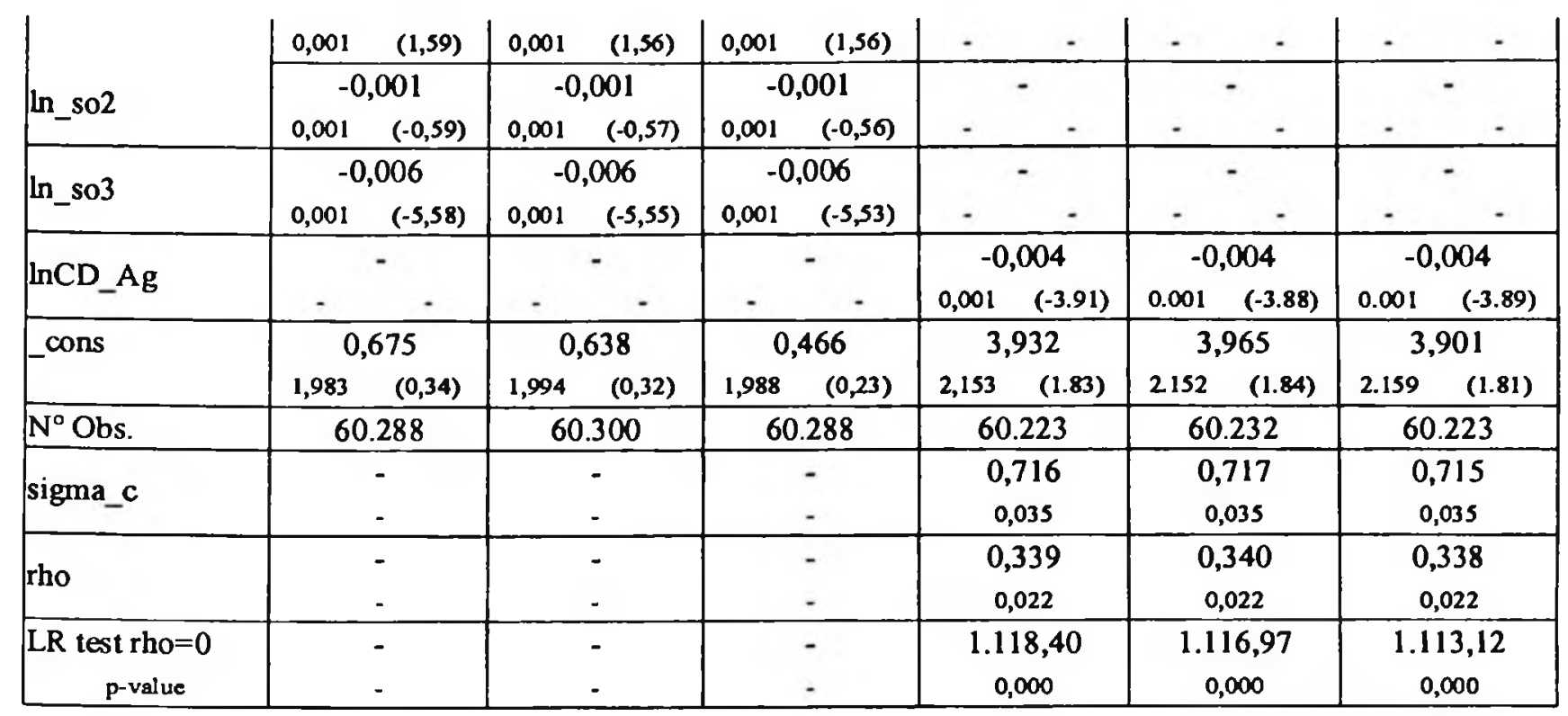

As Figura 31 a 33 trazem as probabilidades de utilização do redesconto over para os modelos Probit.

Figura 31 - Probit - Modelo I

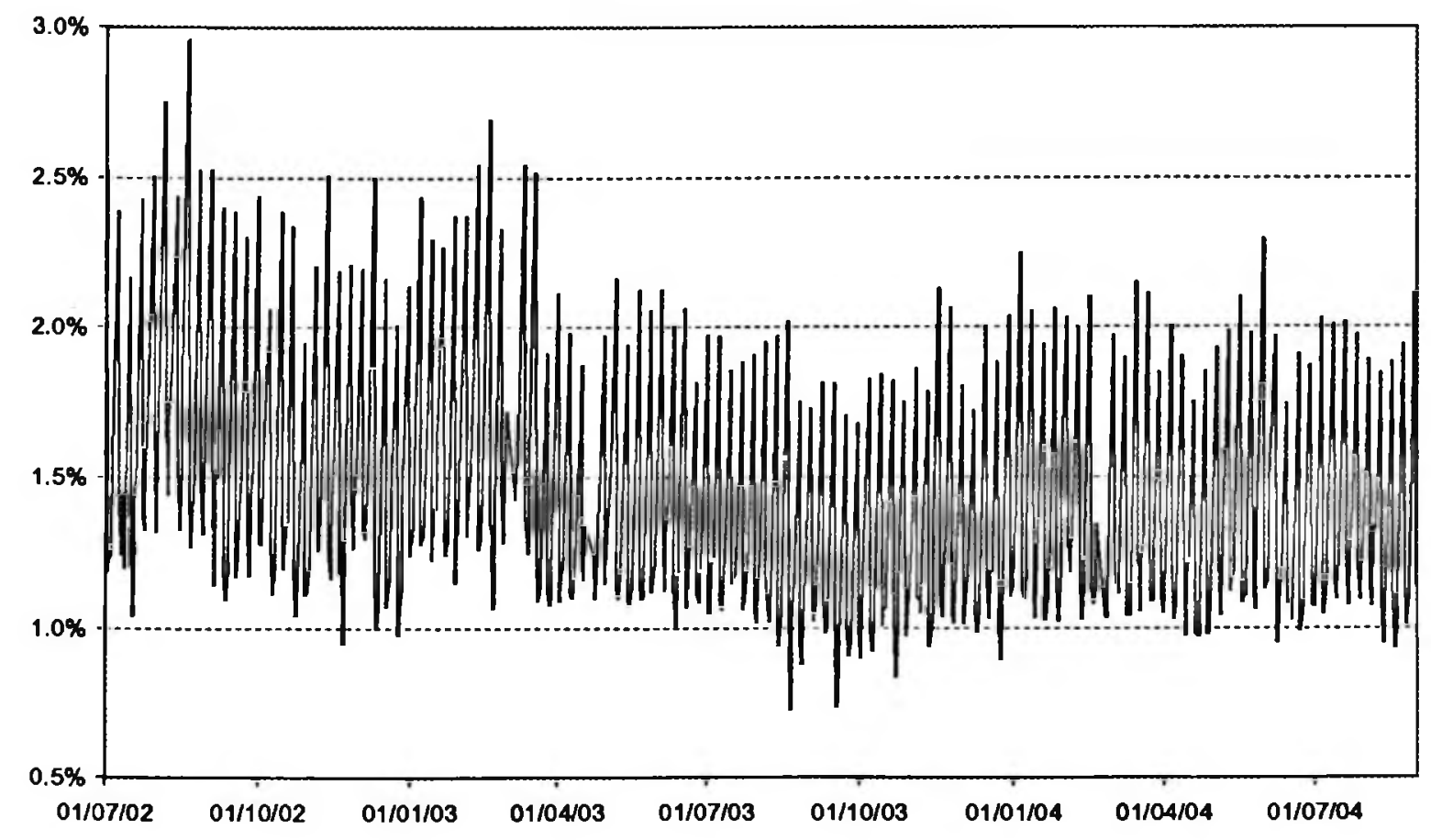


Figura 32 - Probit - Modelo 1, Q1 e Q3

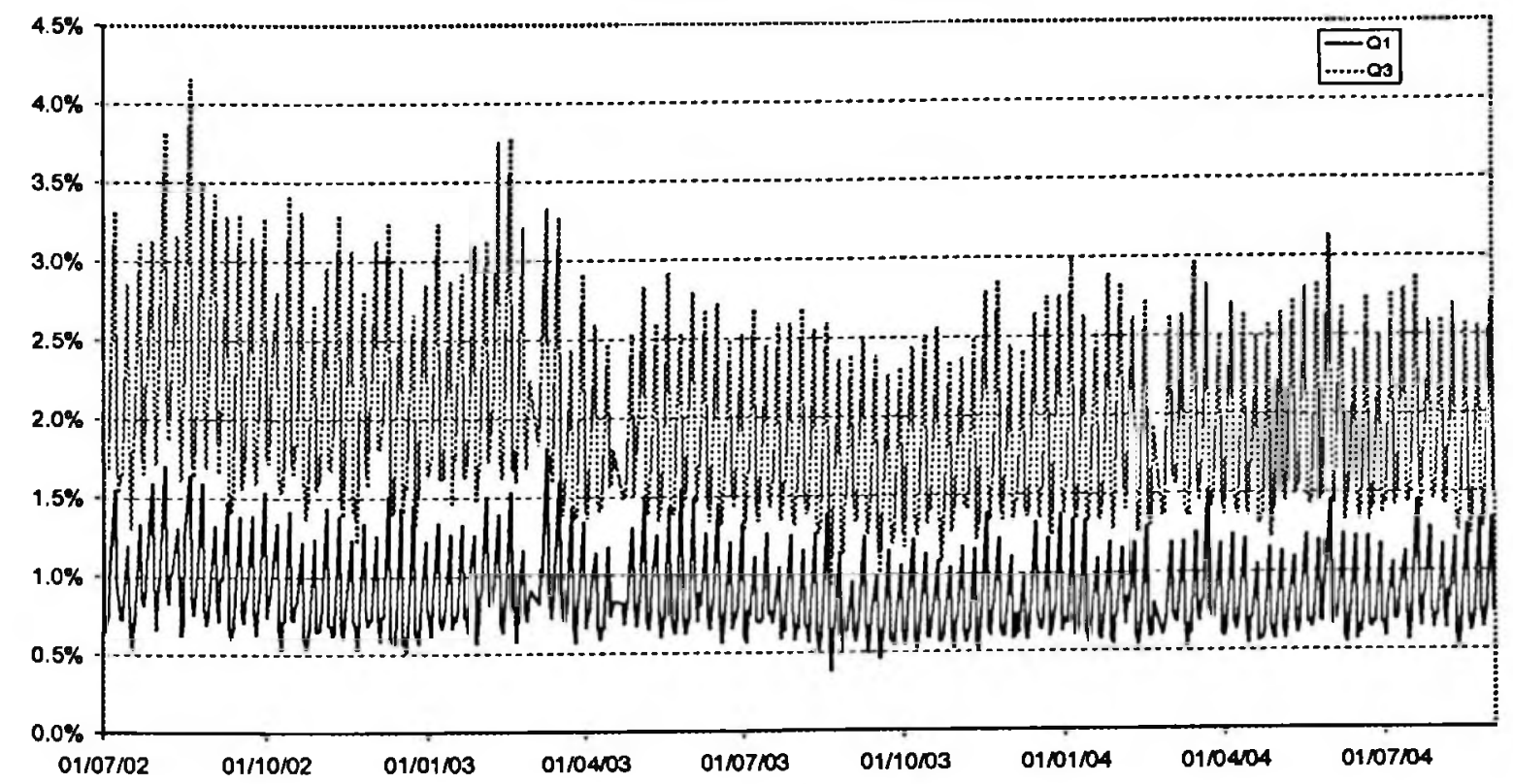

Figura 33 - Probit - Modelo 4

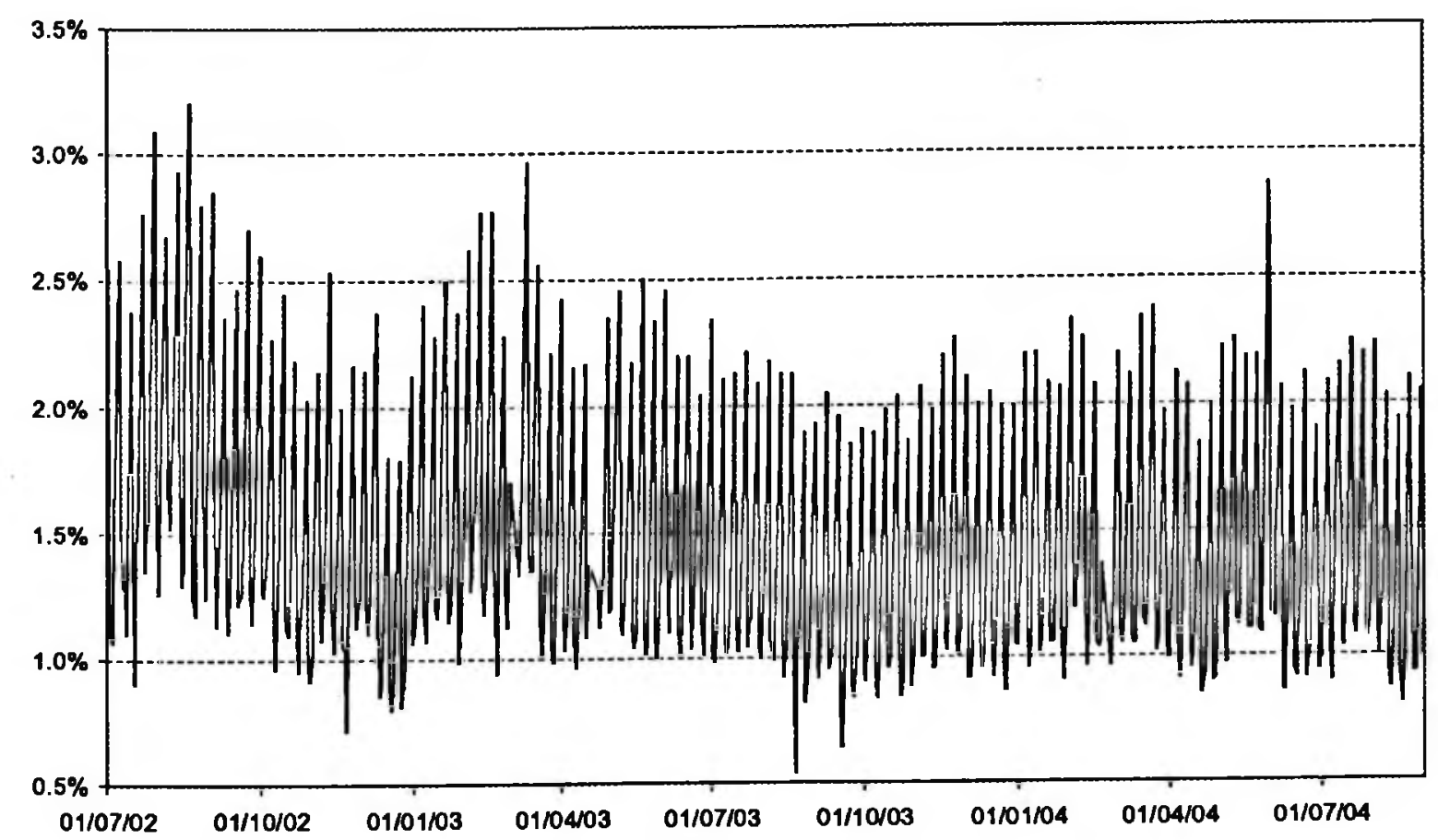


A tabela 17 traz os efeitos marginais dos modelos Probit ${ }^{88}$. Em relação aos resultados obtidos pelos mesmos modelos com amostra a partir de 22 de abril de 2002, observa-se que a probabilidade de utilização do redesconto fica mais sensível à variações da taxa de redesconto: para um aumento de 1 p.p. na taxa de redesconto haveria uma queda em média de 2,55 p.p. na probabilidade contra 0,34 p.p. no periodo iniciado em 22 de abril de $2002^{89}$.

Os efeitos marginais dos dias do período de cumprimento do compulsório sobre depósitos à vista é menor do que os efeitos marginais obtidos na amostra iniciada em 22 de abril de 2002. Os dias com maior probabilidade de utilização continuam os mesmos: as duas segundas-feiras do periodo (ambas com 4,44 p.p.) e a primeira sexta-feira (3,28 p.p.).

Tabela 17 - Efeitos Marginais - Modelo Probit

\begin{tabular}{|c|c|c|c|c|c|c|}
\hline Variável & 1ODELO 1 & MODELO 2 & MODELO 3 & MODELO 4 & MODELO 5 & MODELO 6 \\
\hline \multirow{2}{*}{ dga* } & 0,0420 & 0,0479 & 0,0568 & 0,0108 & 0,0100 & 0,0119 \\
\hline & $0,0169 \quad(2,49)$ & $0,0186 \quad(2,57)$ & $0,0213 \quad(2,67)$ & $0,0121 \quad(0.89)$ & $0.0121 \quad(0.83)$ & $0.0140 \quad(0.85)$ \\
\hline \multirow{2}{*}{ dgb* } & 0,0334 & 0,0387 & 0,0467 & 0,0070 & 0,0063 & 0,0080 \\
\hline & $0150 \quad(2,23)$ & $0,0166 \quad(2,33)$ & $0,0192 \quad(2,44)$ & $0,0107 \quad(0.65)$ & $0.0107 \quad(0.59)$ & $0.0124 \quad(0.65)$ \\
\hline \multirow{2}{*}{ taxa_rdc } & $-0,0196$ & $-0,0197$ & $-0,0194$ & $-0,0314$ & $-0,0314$ & $-0,0314$ \\
\hline & $0,0092 \quad(-2,14)$ & $0,0092 \quad(-2,15)$ & $0,0092 \quad(-2,11)$ & $0,0096 \quad(-3.26)$ & $0.0096 \quad(-3.27)$ & $0.0096 \quad(-3.27)$ \\
\hline \multirow{2}{*}{ In_RSV } & - & 0,0019 & 0,0013 & & 0,0002 & 0,0001 \\
\hline & - & $0,0004 \quad(5,44)$ & $0,0005 \quad(2,59)$ & - & $0.0005 \quad(0.37)$ & $0.0006 \quad(0.18)$ \\
\hline \multirow{2}{*}{ ln_rsvLl } & 0,0017 & - & 0,0008 & 0,0002 & - & 0,0002 \\
\hline & $0,0003 \quad(5,23)$ & - & $0,0005 \quad(1,63)$ & $0,0005 \quad(0.47)$ & - & $0.0006 \quad(0.34)$ \\
\hline In Exigivel & $-0,0017$ & $-0,0018$ & $-0,0020$ & $-0,0006$ & $-0,0005$ & $-0,0006$ \\
\hline & $0,0004 \quad(-4,36)$ & $0,0004 \quad(-4,64)$ & $0,0004 \quad(-5,01)$ & $0,0006 \quad(-0.98)$ & $0.0006 \quad(-0.88)$ & $0.0007 \quad(-0.95)$ \\
\hline $\ln \mathrm{C}$ & 0,0018 & 0,0018 & 0,0018 & 0,0021 & 0,0021 & 0,0021 \\
\hline & $0,0002 \quad(9,82)$ & $0,0002 \quad(9,90)$ & 0,0002 & $0,0003 \quad(7.46)$ & $0.0003 \quad(7.38)$ & 0.0003 \\
\hline $\ln$ & $-0,0017$ & $-0,0017$ & $-0,0018$ & $-0,0019$ & $-0,0019$ & $-0,0019$ \\
\hline m_Exgcomp & $0,0002 \quad(-9,79)$ & $0,0002 \quad(-9,87)$ & $0,0002 \quad(-9,94)$ & $0,0003 \quad(-7.43)$ & $0.0003 \quad(-7.38)$ & $0.0003 \quad(-7.28)$ \\
\hline d & 0,0248 & 0,0246 & 0,0242 & 0,0426 & 0,0428 & 0,0425 \\
\hline & $0,0054 \quad(4,59)$ & $0,0054 \quad(4,56)$ & $0,0053 \quad(4,54)$ & $0,0113 \quad(3.77)$ & $0.0114 \quad(3.76)$ & $0.0112 \quad(3.78)$ \\
\hline & 0,0261 & 0,0260 & 0,0256 & 0,0441 & 0,0443 & 0,0440 \\
\hline & $0,0055 \quad(4,73)$ & $0,0055 \quad(4,70)$ & $0,0055 \quad(4,69)$ & $0,0116 \quad(3.82)$ & $0.0116 \quad(3.81)$ & $0.0115 \quad(3.83)$ \\
\hline d $1 s 6^{*}$ & 0,0328 & 0,0328 & 0,0323 & 0,0540 & 0,0542 & 0,0539 \\
\hline
\end{tabular}

\footnotetext{
${ }^{88}$ A tabela contém os mesmos modelos e segue o mesmo padrão de apresentação da Tabela 12.

${ }^{89}$ Observar que, para os modelos 1 a 3 para a amostra iniciada em $1^{\circ}$ de julho de 2002 , os efeitos margimais da taxa de redesconto são significativos ao nivel de $5 \%$.
} 


\begin{tabular}{|c|c|c|c|c|c|c|}
\hline & $(5,37)$ & 0,0061 & $(5,34)$ & $(4,20)$ & $0,0130 \quad(4,19)$ & $0,0128 \quad(4,21)$ \\
\hline \multirow{2}{*}{ d2s2* } & 0,0444 & 0,0442 & 0,0437 & 0,0749 & 0,0751 & 0,0747 \\
\hline & $0,0070 \quad(6,31)$ & $0, \infty 071 \quad(6,27)$ & $0,0070 \quad(6,27)$ & $0,0156 \quad(4,80)$ & $0,0157 \quad(4,78)$ & $0,0155 \quad(4,82)$ \\
\hline \multirow{2}{*}{ d2s3* } & 0,0224 & 0,0222 & 0,0218 & 0,0378 & 0,0379 & 0,0377 \\
\hline & $0,0052 \quad(4,35)$ & $0,0051 \quad(4,32)$ & $0,0051 \quad(4,31)$ & $0,0105 \quad(3,61)$ & $0,0106 \quad(3,59)$ & $0,0104 \quad(3,61)$ \\
\hline \multirow{2}{*}{$\mathrm{d} 2 \mathrm{~s} 4^{*}$} & 0,0192 & 0,0192 & 0,0188 & 0,0314 & 0,0316 & 0,0313 \\
\hline & $0,0049 \quad(3,90)$ & $0,0049 \quad(3,89)$ & $0,0049 \quad(3,87)$ & $0,0095 \quad(3,31)$ & $0,0096 \quad(3,31)$ & $0,0095 \quad(3,31)$ \\
\hline \multirow{2}{*}{$\mathrm{d} 2 \mathrm{~s} 5^{*}$} & 0,0223 & 0,0223 & 0,0219 & 0,0377 & 0,0379 & 0,0376 \\
\hline & $0,0052 \quad(4,27)$ & $0,0052 \quad(4,27)$ & $0,0052 \quad(4,25)$ & $0,0106 \quad(3,57)$ & $0,0106 \quad(3,56)$ & $0,0105 \quad(3,58)$ \\
\hline d2s $66^{*}$ & 0,0249 & 0,0250 & 0,0245 & 0,0427 & 0,0429 & 0,0426 \\
\hline $0<50$ & $0,0054 \quad(4,59)$ & $0,0055 \quad(4,58)$ & $0,0054 \quad(4,57)$ & $0,0113 \quad(3,80)$ & $0,0113 \quad(3,79)$ & $0,0112 \quad(3,81)$ \\
\hline d3s2* & 0,0444 & 0,0442 & 0,0437 & 0,0733 & 0,0735 & 0,0731 \\
\hline Cuss & $0,0069 \quad(6,40)$ & $0,0069 \quad(6,37)$ & $0,0069 \quad(6,37)$ & $0,0154 \quad(4,76)$ & $0,0155 \quad(4,74)$ & $0,0153 \quad(4,78)$ \\
\hline & 0,0257 & 0,0254 & 0,0251 & 0,0418 & 0,0420 & 0,0417 \\
\hline assis & $0,0055 \quad(4,72)$ & $0,0054 \quad(4,69)$ & $0,0054 \quad(4,68)$ & $0,0111 \quad(3,77)$ & $0,0112 \quad(3,76)$ & $0,0110 \quad(3,78)$ \\
\hline In sel & $2,0 \mathrm{E}-04$ & $2,1 \mathrm{E}-04$ & $2,1 \mathrm{E}-04$ & - & - & - \\
\hline _-d & $4,0 \mathrm{E}-05 \quad(5,08)$ & $4,0 E-05 \quad(5,18)$ & $4,0 E-05 \quad(5,16)$ & - & - & - \\
\hline $\ln c n$ & $-4,9 \mathrm{E}-05$ & $-4,7 \mathrm{E}-05$ & $-4,8 \mathrm{E}-05$ & - & - & - \\
\hline [a-_es & $3,0 \mathrm{E}-05 \quad(-1,64)$ & $3,0 \mathrm{E}-05 \quad(-1,60)$ & $3,0 \mathrm{E}-05 \quad(-1,63)$ & - & - & - \\
\hline $\ln \mathrm{ca}$ & $-1,7 \mathrm{E}-05$ & $-1,5 \mathrm{E}-05$ & $-1,5 \mathrm{E}-05$ & - & - & - \\
\hline M_ca & $3,0 \mathrm{E}-05 \quad(-0,57)$ & 3,0 E-05 $\quad(-0,49)$ & $3,0 \mathrm{E}-05 \quad(-0,51)$ & - & - & - \\
\hline $\ln s t 1$ & $2,6 \mathrm{E}-05$ & $2,5 \mathrm{E}-05$ & $2,5 \mathrm{E}-05$ & - & - & - \\
\hline W_atis & $6,0 \mathrm{E}-05 \quad(0,45)$ & $6,0 \mathrm{E}-05 \quad(0,43)$ & $6,0 \mathrm{E}-05 \quad(0,42)$ & - & - & - \\
\hline & $8,7 \mathrm{E}-05$ & $8,7 \mathrm{E}-05$ & $8,6 \mathrm{E}-05$ & - & - & - \\
\hline In_sL & $5,0 \mathrm{E}-05 \quad(1,90)$ & $5,0 \mathrm{E}-05 \quad(1,90)$ & $5,0 \mathrm{E}-05 \quad(1,88)$ & - & - & - \\
\hline $\ln \mathrm{st} 3$ & $1,9 \mathrm{E}-04$ & $1,9 \mathrm{E}-04$ & $1,9 \mathrm{E}-04$ & - & - & - \\
\hline [arow & $6,0 \mathrm{E}-05 \quad(3,19)$ & $6,0 \mathrm{E}-05 \quad(3,23)$ & $6,0 \mathrm{E}-05 \quad(3,22)$ & - & - & - \\
\hline ln sol & $6,1 \mathrm{E}-05$ & $6,0 \mathrm{E}-05$ & $5,9 \mathrm{E}-05$ & - & - & - \\
\hline III_SOI & 4,0E-05 $\quad(1,59)$ & $4,0 \mathrm{E}-05 \quad(1,57)$ & $4,0 \mathrm{E}-05 \quad(1,57)$ & - & - & $\cdot$ \\
\hline ln $\mathrm{so}_{2}$ & $-1,8 \mathrm{E}-05$ & $-1,7 \mathrm{E}-05$ & $-1,7 \mathrm{E}-05$ & - & - & - \\
\hline _ _ 302 & $3,0 \mathrm{E}-05 \quad(-0,59)$ & $3,0 E-05 \quad(-0,57)$ & $3,0 \mathrm{E}-05 \quad(-0,56)$ & - & - & - \\
\hline $\ln 503$ & $-1,6 \mathrm{E}-04$ & $-1,6 \mathrm{E}-04$ & $-1,6 \mathrm{E}-04$ & - & - & - \\
\hline _ _ SOS & $3,0 \mathrm{E}-05 \quad(-5,60)$ & $3,0 \mathrm{E}-05 \quad(-5,57)$ & $3,0 \mathrm{E}-05 \quad(-5,55)$ & $-\quad-$ & $-\quad-$ & $-\quad-$ \\
\hline & - & - & - & $-1,1 E-04$ & $-1,1 \mathrm{E}-04$ & $-1,1 \mathrm{E}-04$ \\
\hline WC- & - & - & - & $3,0 \mathrm{E}-05 \quad(-3,80)$ & $3,0 \mathrm{E}-05 \quad(-3,78)$ & $3,0 \mathrm{E}-05 \quad(-3,79)$ \\
\hline$N^{\circ}$ Obs. & 60.288 & 60.300 & 60.288 & 60.223 & 60.232 & 60.223 \\
\hline
\end{tabular}

(*) Efeito marginal para variação do valor da variável dummy de 0 para 1 . 


\section{A.2. Probabilidade de utilização do Redesconto, modelo Logit.}

A tabela a seguir ${ }^{90}$ mostra os resultados das regressões do modelo Logit. De modo geral, os resultados foram semelhantes aos obtidos pela amostra original.

Tabela 18 - Resultados do Modelo Logit

\begin{tabular}{|c|c|c|c|c|c|c|}
\hline Variável & MODELO 1 & MODELO 2 & MODELO 3 & MODELO 4 & MODELO 5 & MODELO 6 \\
\hline \multirow{2}{*}{ dga } & 1.978 & 2,101 & 2,328 & $-0,516$ & 0,316 & $-0,453$ \\
\hline & $0,518 \quad(3,82)$ & $0,525 \quad(4,00)$ & $0,544 \quad(4,28)$ & $0,596 \quad(-0,87)$ & $0,567 \quad(0,56)$ & $0,628 \quad(-0,72)$ \\
\hline \multirow{2}{*}{ dgb } & 1,673 & 1,795 & 2,022 & 0,135 & 0,297 & $-0,616$ \\
\hline & $0,511 \quad(3,27)$ & $0,518 \quad(3,46)$ & $0,538 \quad(3,76)$ & $0,582 \quad(0,23)$ & $0,584 \quad(0,51)$ & $0,661 \quad(-0,93)$ \\
\hline \multirow{2}{*}{ taxa_rdc } & $-1,669$ & $-1,667$ & $-1,649$ & $-2,648$ & $-2,577$ & $-2,500$ \\
\hline & $0,827 \quad(-2,02)$ & $0,828 \quad(-2,01)$ & $0,827 \quad(-1,99)$ & $0,822 \quad(-3,22)$ & $0,819 \quad(-3,15)$ & $0,817 \quad(-3,06)$ \\
\hline \multirow{2}{*}{ In_RSV } & & 0,157 & 0,105 & & $-0,009$ & 0,008 \\
\hline & - & $0,033 \quad(4,73)$ & $0,047 \quad(2,25)$ & - & $0,040 \quad(-0,22)$ & $0,049 \quad(0,16)$ \\
\hline In rsvi 1 & 0,145 & - & 0,072 & $-0,010$ & - & 0,008 \\
\hline & $0,031 \quad(4,62)$ & - & $(1,62)$ & $(-0,26)$ & - & $(0,16)$ \\
\hline Fri & $-0,146$ & $-0,156$ & $-0,175$ & $-0,003$ & $-0,021$ & 0,036 \\
\hline 11-Cxig & $0,036 \quad(-4,01)$ & $0,037 \quad(-4,20)$ & $0,039 \quad(-4,49)$ & $0,043 \quad(-0,07)$ & $0,043 \quad(-0,49)$ & $0,049 \quad(0,73)$ \\
\hline In Comn & 0,159 & 0,160 & 0,160 & 0,231 & 0,342 & 0,172 \\
\hline & $0,016 \quad(9,74)$ & $0,016 \quad(9,79)$ & $0,016 \quad(9,78)$ & $0,020 \quad(11,55)$ & $0,025 \quad(13,60)$ & $0,020 \quad(8,53)$ \\
\hline In ExpComn & $-0,151$ & $-0,152$ & $-0,152$ & $-0,170$ & $-0,198$ & $-0,154$ \\
\hline & $0,015 \quad(-10,03)$ & $0,015 \quad(-10,10)$ & $0,015 \quad(-10,10)$ & $0,016 \quad(-10,34)$ & $0,018 \quad(-11,29)$ & $0,017 \quad(-9,11)$ \\
\hline d1s4 & 1,494 & 1,487 & 1,470 & 0,964 & 0,620 & 1,457 \\
\hline & $0,217 \quad(6,87)$ & $0,218 \quad(6,82)$ & $0,217 \quad(6,77)$ & $0,352 \quad(2,74)$ & $0,316 \quad(1,96)$ & $0,341 \quad(4,28)$ \\
\hline d1s 5 & 1,551 & 1,544 & 1,529 & 1,021 & 0,681 & 1,515 \\
\hline & $0,216 \quad(7,17)$ & $0,218 \quad(7,10)$ & $0,216 \quad(7,07)$ & $0,351 \quad(2,91)$ & $0,316 \quad(2,16)$ & $0,340 \quad(4,46)$ \\
\hline d1s 6 & 1,759 & 1,758 & 1,740 & 1,232 & 0,888 & 1,722 \\
\hline & $0,211 \quad(8,32)$ & $0,212 \quad(8,30)$ & $0,211 \quad(8,25)$ & $0,347 \quad(3,55)$ & $0,311 \quad(2,85)$ & $0,336 \quad(5,13)$ \\
\hline$d 2 s 2$ & 2,043 & 2,035 & 2,020 & 1,539 & 1,192 & 2,027 \\
\hline & $0,204 \quad(10,02)$ & $0,205 \quad(9,94)$ & $0,204 \quad(9,91)$ & $0,343 \quad(4,49)$ & $(3,89)$ & $(6,11)$ \\
\hline 53 & 1,421 & 1,414 & 1,399 & 0,848 & 0,506 & 1,339 \\
\hline & $0,220 \quad(6,45)$ & $0,221 \quad(6,40)$ & $0,220 \quad(6,36)$ & $0,354 \quad(2,40)$ & $0,319 \quad(1,59)$ & $0,343 \quad(3,91)$ \\
\hline & 1,278 & 1,279 & 1,260 & 0,703 & 0,362 & 1,196 \\
\hline & $0,226 \quad(5,65)$ & $0,227 \quad(5,64)$ & $0,225 \quad(5,59)$ & $0,358 \quad(1,96)$ & $0,322 \quad(1,12)$ & $0,346 \quad(3,45)$ \\
\hline d2s 5 & 1,406 & 1,406 & 1,389 & 0,867 & 0,525 & 1,359 \\
\hline uLs & $0,222 \quad(6,35)$ & $0,222 \quad(6,33)$ & $0,221 \quad(6,28)$ & $0,354 \quad(2,45)$ & $0,319 \quad(1,65)$ & $(3,97)$ \\
\hline d $2 \mathrm{~s} 6$ & 1,486 & 1,485 & 1,468 & 0,944 & 0,603 & 1,438 \\
\hline & $0,217 \quad(6,86)$ & $0,218 \quad(6,83)$ & $0,216 \quad(6,79)$ & $0,352 \quad(2,68)$ & $0,316 \quad(1,91)$ & $0,340 \quad(4,23)$ \\
\hline d3s2 & 2,052 & 2,047 & 2,032 & 1,550 & 1,203 & 2,039 \\
\hline & $0,201 \quad(10,20)$ & $0,202 \quad(10,14)$ & $0,201 \quad(10,13)$ & $0,342 \quad(4,53)$ & $0,306 \quad(3,93)$ & $0,331 \quad(6,17)$ \\
\hline
\end{tabular}

\footnotetext{
${ }^{90}$ A tabela contém os mesmos modelos e segue o mesmo padrão de apresentação da Tabela 8.
} 


\begin{tabular}{|c|c|c|c|c|c|c|c|c|}
\hline \multirow{2}{*}{ d3s3 } & 1,525 & 1,516 & 1,502 & \multicolumn{2}{|c|}{0,941} & \multicolumn{2}{|c|}{0,600} & 1,434 \\
\hline & $0,215 \quad(7,09)$ & $0,216 \quad(7,03)$ & $0,215 \quad(7,00)$ & 0.352 & $(2.68)$ & 0.316 & $(1.90)$ & $0.340 \quad(4.22)$ \\
\hline \multirow{2}{*}{ ln_sed } & 0,018 & 0,019 & 0,019 & \multicolumn{2}{|c|}{-} & \multicolumn{2}{|c|}{-} & - \\
\hline & $0,004 \quad(5,04)$ & $0,004 \quad(5,12)$ & $0,004 \quad(5,11)$ & - & - & - & - & - \\
\hline \multirow{2}{*}{$\ln \_c p$} & $-0,003$ & $-0,003$ & $-0,003$ & \multicolumn{2}{|c|}{ - } & \multicolumn{2}{|c|}{ - } & - \\
\hline & $0,003 \quad(-1,27)$ & $0,003 \quad(-1,24)$ & $0,003 \quad(-1,25)$ & - & - & - & - & - \\
\hline \multirow{2}{*}{ ln_ca } & $-0,001$ & $-0,001$ & $-0,001$ & \multicolumn{2}{|c|}{$\begin{array}{l}- \\
-\end{array}$} & \multicolumn{2}{|c|}{ - } & - \\
\hline & $0,003 \quad(-0,49)$ & $0,003 \quad(-0,44)$ & $0,003 \quad(-0,45)$ & - & - & - & - & - \\
\hline \multirow{2}{*}{ ln_stl } & 0,003 & 0,003 & 0,003 & & . & & & - \\
\hline & $0,005 \quad(0,51)$ & $0,005 \quad(0,51)$ & $0,005 \quad(0,50)$ & - & - & - & - & - \\
\hline $\ln s+2$ & 0,008 & 0,008 & 0,008 & & 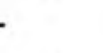 & & & - \\
\hline In_sL2 & $0,004 \quad(1,93)$ & $0,004 \quad(1,92)$ & $0,004 \quad(1,91)$ & - & - & - & - & - \\
\hline $\ln \mathrm{st} 3$ & 0,017 & 0,017 & 0,017 & & - & & & - \\
\hline & $0,005 \quad(3,12)$ & $0,005 \quad(3,14)$ & $0,005 \quad(3,14)$ & - & - & - & - & - \\
\hline ln sol & 0,006 & 0,006 & 0,006 & & 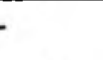 & & & - \\
\hline m_sol & $0,004 \quad(1,68)$ & $0,004 \quad(1,68)$ & $0,004 \quad(1,68)$ & - & - & - & - & - \\
\hline In so2 & $-0,001$ & $-0,001$ & $-0,001$ & & 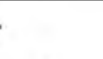 & & & - \\
\hline [1]SOL & $0,003 \quad(-0,49)$ & $0,003 \quad(-0,40)$ & $0,003 \quad(-0,45)$ & - & - & - & - & - \\
\hline In $s 03$ & $-0,015$ & $-0,015$ & $-0,015$ & & - & & & - \\
\hline III_SOS & $0,003 \quad(-5,47)$ & $0,003 \quad(-5,44)$ & $0,003 \quad(-5,43)$ & - & - & - & - & $-\quad-$ \\
\hline$C D A g$ & - & - & - & & 009 & & & $-0,009$ \\
\hline 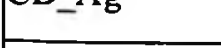 & - & - & - & 0.002 & $(-3.60)$ & 0.002 & $(-3.46)$ & $0.002 \quad(-3.75)$ \\
\hline cons & 2,365 & 2,217 & 1,880 & & 88 & & & 8,027 \\
\hline$-\infty \omega$ & $5,013 \quad(0,47)$ & $5,037 \quad(0,44)$ & $5,022 \quad(0,37)$ & 5.021 & (1.83) & 4.989 & $(1.50)$ & $4.986 \quad(1.61)$ \\
\hline$N^{\circ}$ Obs. & 60.288 & 60.300 & 60.288 & & 223 & & & 60.232 \\
\hline siema c & - & - & - & & 92 & & & 1,361 \\
\hline prena_c & - & - & - & & 554 & & & 0,063 \\
\hline rho & - & - & - & & 02 & & & $\begin{array}{c}0,360 \\
0,021\end{array}$ \\
\hline LR test rho $=0$ & - & - & - & & 0,52 & & 0,77 & $1.151,37$ \\
\hline p-value & - & - & - & & xo & & & 0,000 \\
\hline
\end{tabular}

As Figura 34 a 36 trazem as probabilidades de utilização do redesconto over para os modelos Logit. 
Figura 34 - Logit - Modelo 1

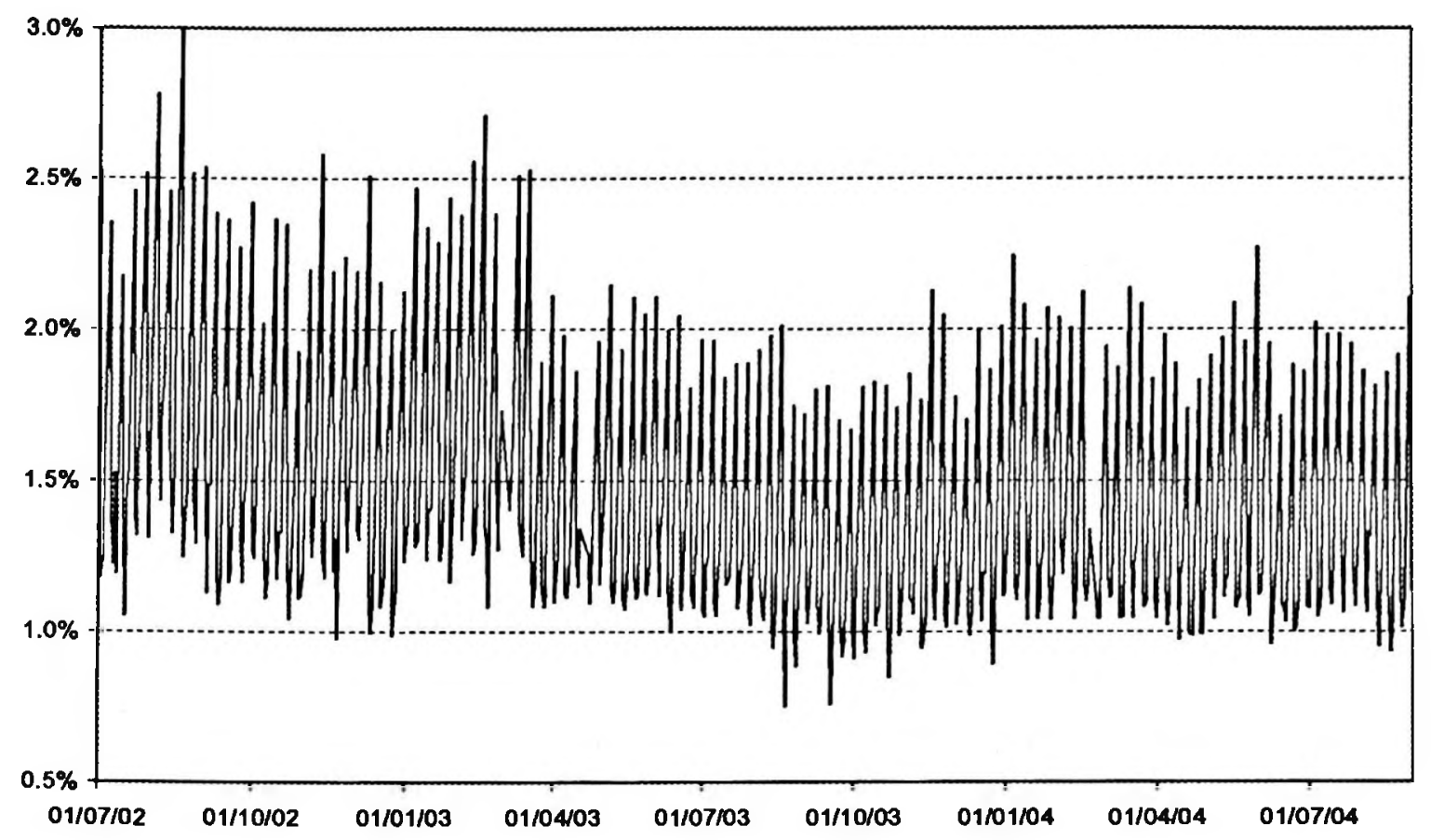

Figura 35 - Logit - Modelo 1, Q1 e Q3

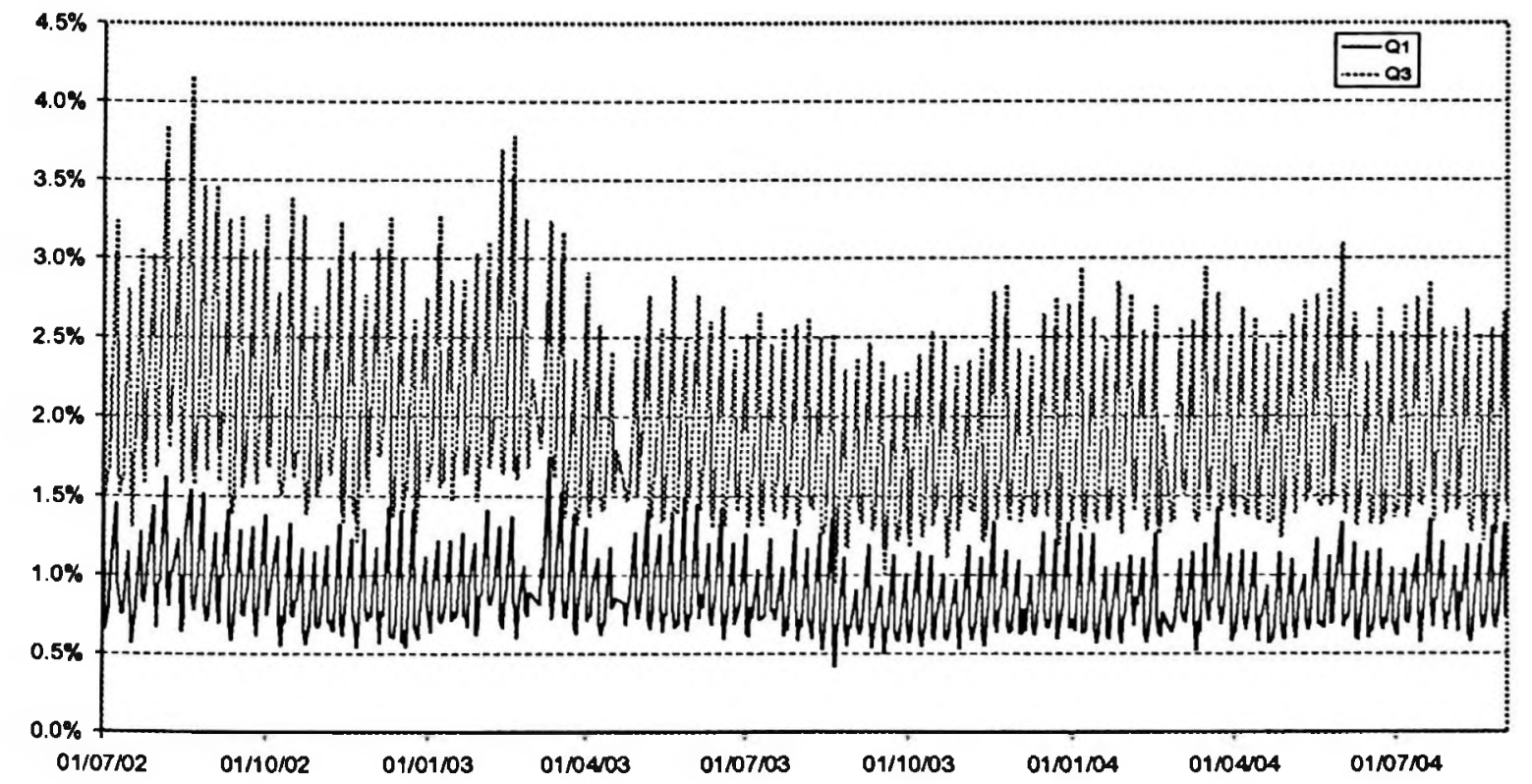


Figura 36 - Logit - Modelo 4

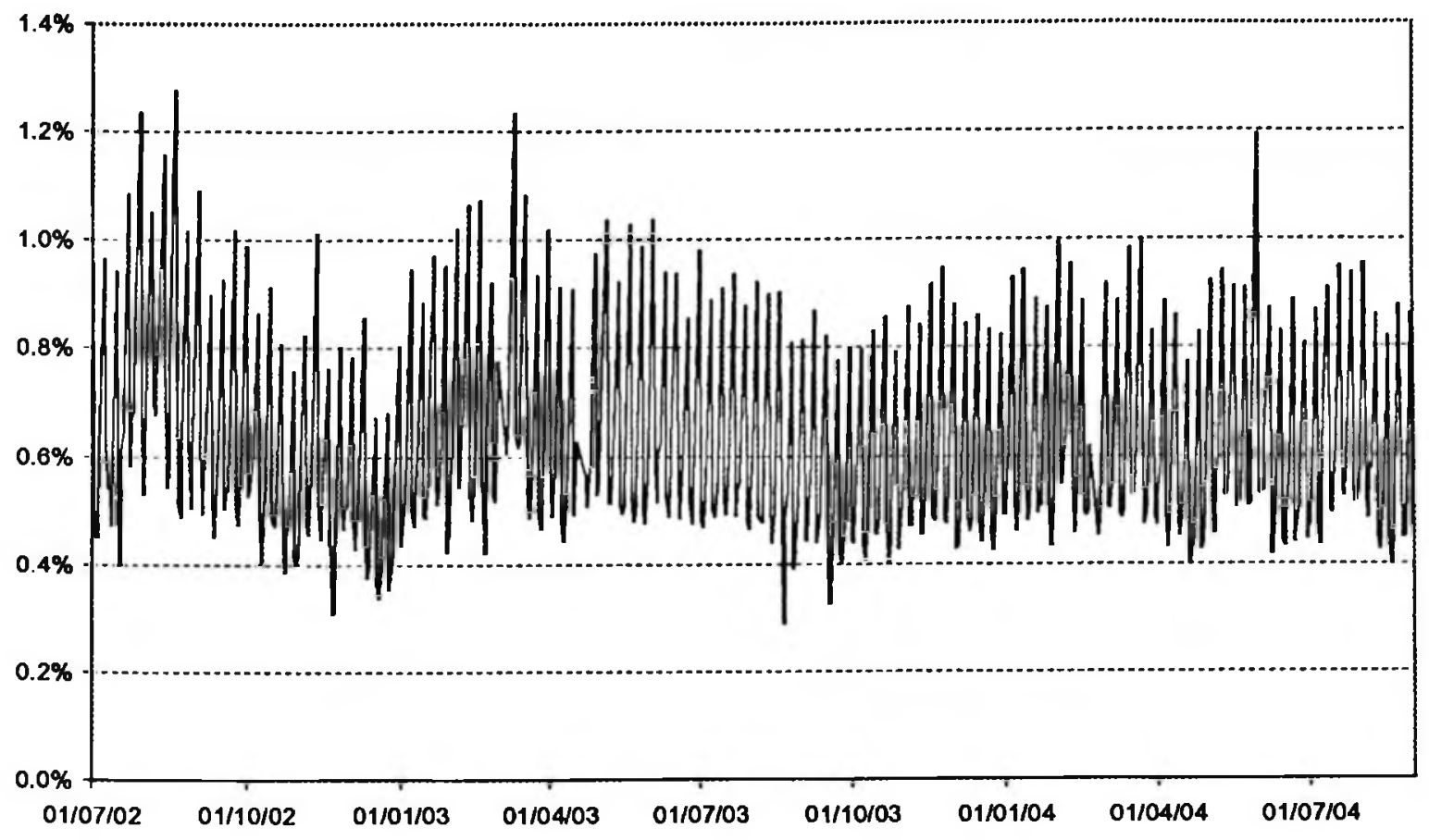

A tabela a seguir apresenta as probabilidades médias de utilização do Redescoconto para os modelos Probit e Logit.

Tabela 19 - Probabilidade Média - Modelos Probit e Logit

\begin{tabular}{|c|c|c|}
\hline \multirow{2}{*}{ Modelo } & \multicolumn{2}{|c|}{ Probabilidade Média } \\
\cline { 2 - 3 } & Probit & Logit \\
\hline 1 & $1,394 \%$ & $1,395 \%$ \\
\hline 2 & $1,394 \%$ & $1,395 \%$ \\
\hline 3 & $1,394 \%$ & $1,395 \%$ \\
\hline \hline 4 & $1,388 \%$ & $0,604 \%$ \\
\hline 5 & $1,386 \%$ & $0,579 \%$ \\
\hline 6 & $1,391 \%$ & $0,603 \%$ \\
\hline
\end{tabular}


A tabela 20 apresenta os efeitos marginais obtidos pelos modelos Logit' marginais da taxa de redesconto obtidos pelo modelos Logit para o período iniciado em $1^{\circ}$ de julho de 2002 foram maiores do que os efeitos estimados para o período iniciadio em 22 de abril de 2002 (para um aumento de 1 p.p. na taxa de redesconto haveria uma queda de 1,39 p.p. em média na probabilidade de utilização do redesconto contra uma queda de 0,22 p.p.).

Em relação aos dias do periodo de cumprimento, os dias com maior probabilidade de utilização do redesconto foram os mesmos, havendo apenas uma diminuição no efeito marginal: de 6,04 p.p. para 5,54 p.p. para a segunda segunda-feira; 5,95 p.p. para 5,49 p.p. para a primeira segunda-feira e 4,61 p.p. para 4,09 para a primeira sexta-feira.

Tabela 20 - Efeitos Marginais - Modelo Logit

\begin{tabular}{|c|c|c|c|c|c|c|}
\hline Variável & MODELO 1 & MODELO 2 & MODELO 3 & MODELO 4 & MODELO 5 & MODELO 6 \\
\hline \multirow{2}{*}{ dga* } & 0,0423 & 0,0473 & 0,0579 & $-0,0020$ & 0,0012 & $-0,0018$ \\
\hline & $0,0204 \quad(2,07)$ & $0,0226 \quad(2,10)$ & $0,0273 \quad(2,12)$ & $0,0020 \quad(-1,01)$ & $0,0025 \quad(0,50)$ & $0,0022 \quad(-0,82)$ \\
\hline \multirow{2}{*}{ dgb* } & 0,0325 & 0,0367 & 0,0457 & 0,0006 & 0,0011 & $-0,0024$ \\
\hline & $0,0171 \quad(1,90)$ & $0,0189 \quad(1,94)$ & $0,0232 \quad(1,97)$ & $0,0029 \quad(0,22)$ & $0,0025 \quad(0,46)$ & $0,0021 \quad(-1,11)$ \\
\hline \multirow{2}{*}{ taxa_rdc } & $-0,0170$ & $-0,0169$ & $-0,0167$ & $-0,0121$ & $-0,0090$ & $-0,0116$ \\
\hline & $0,0084 \quad(-2,01)$ & $0,0084 \quad(-2,01)$ & $0,0084 \quad(-1,99)$ & $0,0039 \quad(-3,07)$ & $0,0031 \quad(-2,88)$ & $0,0040 \quad(-2,89)$ \\
\hline \multirow{2}{*}{ In_RSV } & & 0,0016 & 0,0011 & - & $-3,0 \mathrm{E}-05$ & $3,6 \mathrm{E}-05$ \\
\hline & - & $0,0003 \quad(4,66)$ & $0,0005 \quad(2,23)$ & - & $1,4 \mathrm{E}-04 \quad(-0,22)$ & $2,3 \mathrm{E}-04 \quad(0,16)$ \\
\hline \multirow{2}{*}{ ln_rsvL1 } & 0,0015 & & 0,0007 & $-4,7 \mathrm{E}-05$ & - & $3,6 \mathrm{E}-05$ \\
\hline & $0,0003 \quad(4,58)$ & - & $0,0005 \quad(1,62)$ & $1,8 \mathrm{E}-04 \quad(-0,26)$ & - & $2,2 \mathrm{E}-04 \quad(0,16)$ \\
\hline ln Exigivel & $-0,0015$ & $-0,0016$ & $-0,0018$ & $-1,4 \mathrm{E}-05$ & $-7,4 \mathrm{E}-05$ & $1,6 \mathrm{E}-04$ \\
\hline W_LAigive & $0,0004 \quad(-4,01)$ & $0,0004 \quad(-4,18)$ & $0,0004 \quad(-4,48)$ & $2,0 \mathrm{E}-04 \quad(-0,07)$ & $1,5 \mathrm{E}-04 \quad(-0,49)$ & $2,3 \mathrm{E}-04 \quad(0,72)$ \\
\hline In Comn & 0,0016 & 0,0016 & 0,0016 & 0,0011 & 0,0012 & 0,0008 \\
\hline & $0,0002 \quad(10,49)$ & $0,0002 \quad(10,51)$ & $0,0002 \quad(10,42)$ & $0,0001 \quad(9,13)$ & $0,0001 \quad(8,43)$ & $0,0001 \quad(6,51)$ \\
\hline In Exors & $-0,0015$ & $-0,0015$ & $-0,0015$ & $-0,0008$ & $-0,0007$ & $-0,0007$ \\
\hline$\mu$ _ExgCOMp & $0,0002 \quad(-10,61)$ & $0,0002 \quad(-10,65)$ & $0,0002 \quad(-10,58)$ & $0,0001 \quad(-8,18)$ & $0,0001 \quad(-7,15)$ & 0,0001 \\
\hline d lod & 0,0303 & 0,0300 & 0,0294 & 0,0068 & 0,0029 & 0,0134 \\
\hline & $0,0072 \quad(4,20)$ & $0,0072 \quad(4,18)$ & $0,0071 \quad(4,17)$ & $0,0036 \quad(1,89)$ & $0,0019 \quad(1,49)$ & $0,0053 \quad(2,53)$ \\
\hline & 0,0325 & 0,0322 & 0,0316 & 0,0074 & 0,0032 & 0,0144 \\
\hline Miss. & $0,0075 \quad(4,32)$ & $0,0075 \quad(4,29)$ & $0,0074 \quad(4,29)$ & $0,0038 \quad(1,97)$ & $0,0020 \quad(1,60)$ & $0,0056 \quad(2,59)$ \\
\hline & 0,0409 & 0,0408 & 0,0400 & 0,0099 & 0,0046 & 0,0182 \\
\hline usso & $0,0086 \quad(4,77)$ & $0,0086 \quad(4,75)$ & $0,0084 \quad(4,75)$ & $0,0045 \quad(2,22)$ & $0,0024 \quad(1,93)$ & $0,0065 \quad(2,78)$ \\
\hline
\end{tabular}

${ }^{91}$ A tabela contém os mesmos modelos e segue o mesmo padrão de apresentação da Tabela 13. 


\begin{tabular}{|c|c|c|c|c|c|c|}
\hline \multirow{2}{*}{ d2s $2 *$} & 0,0549 & 0,0544 & 0,0535 & 0,0145 & 0,0072 & 0,0253 \\
\hline & 0,0102 & 0,0102 & 0,0101 & $0,0057 \quad(2,53)$ & $0,0031 \quad(2,31)$ & 0,0084 \\
\hline \multirow{2}{*}{ d2s $3 *$} & 0,0278 & 0,0275 & 0,0269 & 0,0056 & 0,0022 & 0,0115 \\
\hline & $0,0069 \quad(4,04)$ & $0,0069 \quad(4,01)$ & $0,0067 \quad(4,00)$ & $0,0033 \quad(1,73)$ & $0,0017 \quad(1,27)$ & $0,0048 \quad(2,41)$ \\
\hline \multirow{2}{*}{ d2s $4^{*}$} & 0,0233 & 0,0233 & 0,0227 & 0,0044 & 0,0015 & 0,0096 \\
\hline & $0,0064 \quad(3,67)$ & $0,0064 \quad(3,66)$ & $0,0062 \quad(3,64)$ & $0,0029 \quad(1,50)$ & $0,0015 \quad(0,96)$ & $0,0043 \quad(2,23)$ \\
\hline \multirow{2}{*}{ d $2 \mathrm{~s} 5 *$} & 0,0274 & 0,0273 & 0,0267 & 0,0058 & 0,0023 & 0,0119 \\
\hline & $0,0069 \quad(3,97)$ & $0,0069 \quad(3,96)$ & $0,0068 \quad(3,95)$ & $0,0033 \quad(1,75)$ & $0,0018 \quad(1,31)$ & $0,0049 \quad(2,43)$ \\
\hline d2s6* & 0,0300 & 0,0300 & 0,0294 & 0,0066 & 0,0027 & 0,0131 \\
\hline$\alpha<s 0^{*}$ & $0,0072 \quad(4,20)$ & $0,0072 \quad(4,18)$ & $0,0070 \quad(4,17)$ & $0,0035 \quad(1,87)$ & $0,0019 \quad(1,46)$ & $0,0052 \quad(2,52)$ \\
\hline d3s2* & 0,0554 & 0,0550 & 0,0542 & 0,0147 & 0,0073 & 0,0256 \\
\hline & $0,0101 \quad(5,49)$ & $0,0101 \quad(5,45)$ & $0,0099 \quad(5,46)$ & $0,0058 \quad(2,54)$ & $0,0032 \quad(2,33)$ & $0,0084 \quad(3,04)$ \\
\hline d3s3* & 0,0314 & 0,0310 & 0,0305 & 0,0066 & 0,0027 & 0,0130 \\
\hline$(135)^{*}$ & $0,0073 \quad(4,31)$ & $0,0072 \quad(4,29)$ & $0,0071 \quad(4,28)$ & $0,0035 \quad(1,87)$ & $0,0019 \quad(1,46)$ & $0,0052 \quad(2,52)$ \\
\hline In sel & $1,9 \mathrm{E}-04$ & $1,9 \mathrm{E}-04$ & 1,9E-04 & - & - & - \\
\hline & $4,0 \mathrm{E}-05 \quad(5,06)$ & $4,0 \mathrm{E}-05 \quad(5,13)$ & $4,0 \mathrm{E}-05 \quad(5,12)$ & - & - & - \\
\hline $\ln \mathrm{cD}$ & $-3,4 \mathrm{E}-05$ & $-3,4 \mathrm{E}-05$ & $-3,4 \mathrm{E}-05$ & - & - & - \\
\hline & $3,0 \mathrm{E}-05 \quad(-1,26)$ & $3,0 \mathrm{E}-05 \quad(-1,24)$ & $3,0 \mathrm{E}-05 \quad(-1,25)$ & - & - & - \\
\hline $\ln \mathrm{ca}$ & $-1,4 \mathrm{E}-05$ & $-1,2 \mathrm{E}-05$ & $-1,2 \mathrm{E}-05$ & - & - & - \\
\hline & $3,0 \mathrm{E}-05 \quad(-0,49)$ & $3,0 \mathrm{E}-05 \quad(-0,44)$ & $3,0 \mathrm{E}-05 \quad(-0,45)$ & - & - & - \\
\hline In stl & $2,7 \mathrm{E}-05$ & $2,7 \mathrm{E}-05$ & $2,6 \mathrm{E}-05$ & - & - & - \\
\hline & $5,0 E-05 \quad(0,52)$ & $5,0 \mathrm{E}-05 \quad(0,51)$ & $5,0 \mathrm{E}-05 \quad(0,50)$ & - & - & - \\
\hline $\ln s t 2$ & $8,3 \mathrm{E}-05$ & $8,2 \mathrm{E}-0 \mathrm{~S}$ & $8,1 \mathrm{E}-05$ & - & - & - \\
\hline & $4,0 \mathrm{E}-05 \quad(1,94)$ & $4,0 \mathrm{E}-05 \quad(1,92)$ & $4,0 \mathrm{E}-05 \quad(1,91)$ & - & - & - \\
\hline ln st 3 & $1,7 \mathrm{E}-04$ & $1,7 \mathrm{E}-04$ & $1,7 \mathrm{E}-04$ & - & - & - \\
\hline DIIIS- & $5,0 \mathrm{E}-05 \quad(3,12)$ & $5,0 \mathrm{E}-05 \quad(3,13)$ & $5,0 \mathrm{E}-05 \quad(3,13)$ & - & - & - \\
\hline In sol & $6,0 \mathrm{E}-05$ & $6,0 \mathrm{E}-05$ & $6,0 \mathrm{E}-05$ & - & - & - \\
\hline II_SOI & $4,0 \mathrm{E}-05 \quad(1,68)$ & $4,0 \mathrm{E}-05 \quad(1,68)$ & $4,0 \mathrm{E}-05 \quad(1,68)$ & - & - & - \\
\hline $\ln$ so2 & $-1,3 \mathrm{E}-05$ & $-1,3 \mathrm{E}-05$ & $-1,2 \mathrm{E}-05$ & - & - & - \\
\hline & $3,0 \mathrm{E}-05 \quad(-0,49)$ & $3,0 \mathrm{E}-05 \quad(-0,46)$ & $3,0 \mathrm{E}-05 \quad(-0,45)$ & - & - & - \\
\hline ln so3 & $-1,5 \mathrm{E}-04$ & $-1,5 \mathrm{E}-04$ & $-1,5 \mathrm{E}-04$ & - & - & - \\
\hline & $3,0 \mathrm{E}-0 \mathrm{~S} \quad(-5,48)$ & $3,0 \mathrm{E}-05 \quad(-5,45)$ & $3,0 \mathrm{E}-05 \quad(-5,45)$ & - & $-\quad-$ & - \\
\hline InCD_Ag & - & - & - & $-4,0 \mathrm{E}-05$ & $-2,9 \mathrm{E}-05$ & $-4,2 \mathrm{E}-05$ \\
\hline & - & - & - & $1,0 \mathrm{E}-05 \quad(-3,40)$ & $1,0 \mathrm{E}-05 \quad(-3,09)$ & $1,0 \mathrm{E}-05 \quad(-3,44)$ \\
\hline $\mathrm{N}^{\circ} \mathrm{Obs}$ & 60.288 & 60.300 & 60.288 & 60.223 & 60.232 & 60.223 \\
\hline
\end{tabular}

(*) Efeito marginal para variação do valor da variável dummy de 0 para 1 . 


\section{A.3. Demanda por Redesconto, modelo Tobit.}

A tabela a seguir ${ }^{92}$ mostra os resultados das regressões do modelo Tobit. De maneira geral os resultados foram semelhantes aos obtidos pela amostra original.

Tabela 21 - Resultados do Modelo Tobit

\begin{tabular}{|c|c|c|c|c|c|c|}
\hline Variável & MODELO 1 & MODELO 2 & MODELO 3 & MODELO 4 & MODELO 5 & MODELO 6 \\
\hline \multirow{2}{*}{ dga } & 33,809 & 36,669 & 40,636 & $-7,830$ & $-22,086$ & 3,211 \\
\hline & $8,437 \quad(4,01)$ & $8,503 \quad(4,31)$ & $8,862 \quad(4,59)$ & $9,436 \quad(-0,83)$ & $10,286 \quad(-2,15)$ & $9,924 \quad(0,32)$ \\
\hline \multirow{2}{*}{ dgb } & 28,894 & 31,736 & 35,699 & $-7,094$ & $-25,181$ & $-0,929$ \\
\hline & $8,438 \quad(3,42)$ & $8,500 \quad(3,73)$ & $8,856 \quad(4,03)$ & $9,477 \quad(-0,75)$ & $10,514 \quad(-2,40)$ & $9,885 \quad(-0,09)$ \\
\hline \multirow{2}{*}{ taxa_rdc } & $-29,513$ & $-29,837$ & $-29,222$ & $-43,705$ & $-40,210$ & $-40,030$ \\
\hline & $13,331 \quad(-2,21)$ & $13,325 \quad(-2,24)$ & $13,325 \quad(-2,19)$ & $12,897 \quad(-3,39)$ & $12,897 \quad(-3,12)$ & $12,992 \quad(-3,08)$ \\
\hline \multirow{2}{*}{ ln_RSV } & & 2,943 & 2,054 & - & 0,092 & 0,030 \\
\hline & - & $0,559 \quad(5,27)$ & $0,776 \quad(2,65)$ & - & $0,682 \quad(0,13)$ & $0,762 \quad(0,04)$ \\
\hline In rsvL1 & 2,677 & - & 1,246 & 0,249 & - & 0,227 \\
\hline In_ISVLI & $0,550 \quad(4,87)$ & - & $0,765 \quad(1,63)$ & $0,694 \quad(0,36)$ & - & $0,752 \quad(0,30)$ \\
\hline & $-2,523$ & $-2,767$ & $-3,100$ & 0,291 & 1,622 & $-0,051$ \\
\hline & $0,606 \quad(-4,17)$ & $0,612 \quad(-4,52)$ & $0,647 \quad(-4,79)$ & $0,698 \quad(0,42)$ & $0,769 \quad(2,11)$ & $0,738 \quad(-0,07)$ \\
\hline In Comn & 2,721 & 2,747 & 2,764 & 2,215 & 2,406 & 3,751 \\
\hline & $0,301 \quad(9,05)$ & $0,301 \quad(9,12)$ & $0,301 \quad(9,18)$ & $0,337 \quad(6,58)$ & $0,354 \quad(6,79)$ & $0,391 \quad(9,60)$ \\
\hline & $-2,618$ & $-2,646$ & $-2,666$ & $-2,122$ & $-2,038$ & $-2,654$ \\
\hline & $0,282 \quad(-9,29)$ & $0,282 \quad(-9,37)$ & $0,282 \quad(-9,44)$ & $0,311 \quad(-6,82)$ & $0,312 \quad(-6,52)$ & $0,317 \quad(-8,37)$ \\
\hline dls4 & 22,587 & 22,526 & 22,262 & 13,435 & 11,269 & 23,255 \\
\hline & $3,286 \quad(6,87)$ & $3,285 \quad(6,86)$ & $3,282 \quad(6,78)$ & $4,592 \quad(2,93)$ & $4,793 \quad(2,35)$ & $4,357 \quad(5,34)$ \\
\hline d 1 s5 & 23,266 & 23,220 & 22,979 & 13,757 & 11,649 & 23,450 \\
\hline aiss & $3,281 \quad(7,09)$ & $3,281 \quad(7,08)$ & $3,277 \quad(7,01)$ & $4,603 \quad(2,99)$ & $4,800 \quad(2,43)$ & $4,357 \quad(5,38)$ \\
\hline d l s6 & 26,947 & 26,997 & 26,721 & 17,229 & 15,269 & 27,020 \\
\hline 0100 & $3,209 \quad(8,40)$ & $3,208 \quad(8,41)$ & $3,205 \quad(8,34)$ & $4,550 \quad(3,79)$ & $4,727 \quad(3,23)$ & $4,302 \quad(6,28)$ \\
\hline d2s 2 & 32,227 & 32,197 & 31,957 & 23,241 & 21,186 & 32,987 \\
\hline $0<32$ & $3,154 \quad(10,22)$ & $3,154 \quad(10,21)$ & $3,149 \quad(10,15)$ & $4,479 \quad(5,19)$ & $4,678 \quad(4,53)$ & $4,265 \quad(7,73)$ \\
\hline d2s 3 & 21,088 & 21,001 & 20,760 & 11,507 & 9,403 & 21,145 \\
\hline $0<35$ & $3,325 \quad(6,34)$ & $3,327 \ldots(6,31)$ & $3,323 \quad(6,25)$ & $4,645 \quad(2,48)$ & $4,825 \quad(1,95)$ & $4,376 \quad(4,83)$ \\
\hline d2s 4 & 19,102 & 19,182 & 18,875 & 8,900 & 6,755 & 18,637 \\
\hline & $3,385 \quad(5,64)$ & $3,382 \quad(5,67)$ & $3,380 \quad(5,58)$ & $4,681 \quad(1,90)$ & $4,860 \quad(1,39)$ & $4,432 \quad(4,21)$ \\
\hline $\mathrm{d} 2 \mathrm{~s} 5$ & 21,031 & 21,129 & 20,842 & 11,381 & 9,313 & 21,036 \\
\hline $0<35$ & $3,333 \quad(6,31)$ & $3,332 \quad(6,34)$ & $3,329 \quad(6,26)$ & $4,651 \quad(2,45)$ & $4,829 \quad(1,93)$ & $4,376 \quad(4,81)$ \\
\hline$d 2 s 6$ & 22,664 & 22,766 & 22,491 & 13,448 & 11,318 & 23,133 \\
\hline a 250 & $3,288 \quad(6,89)$ & $3,286 \quad(6,93)$ & $3,284 \quad(6,85)$ & $4,580 \quad(2,94)$ & $4,782 \quad(2,37)$ & $4,343 \quad(5,33)$ \\
\hline d3s 2 & 32,277 & 32,262 & 32,031 & 22,911 & 20,815 & 32,493 \\
\hline & $3,153 \quad(10,24)$ & $3,154 \quad(10,23)$ & $3,149 \quad(10,17)$ & $4,481 \quad(5,11)$ & $4,671 \quad(4,46)$ & $4,258 \quad(7,63)$ \\
\hline d3s3 & 23,199 & 23,073 & 22,867 & 13,165 & 11,089 & 22,726 \\
\hline
\end{tabular}

${ }^{92}$ A tabela contém os mesmos modelos e segue o mesmo padrão de apresentação da Tabela 11. 


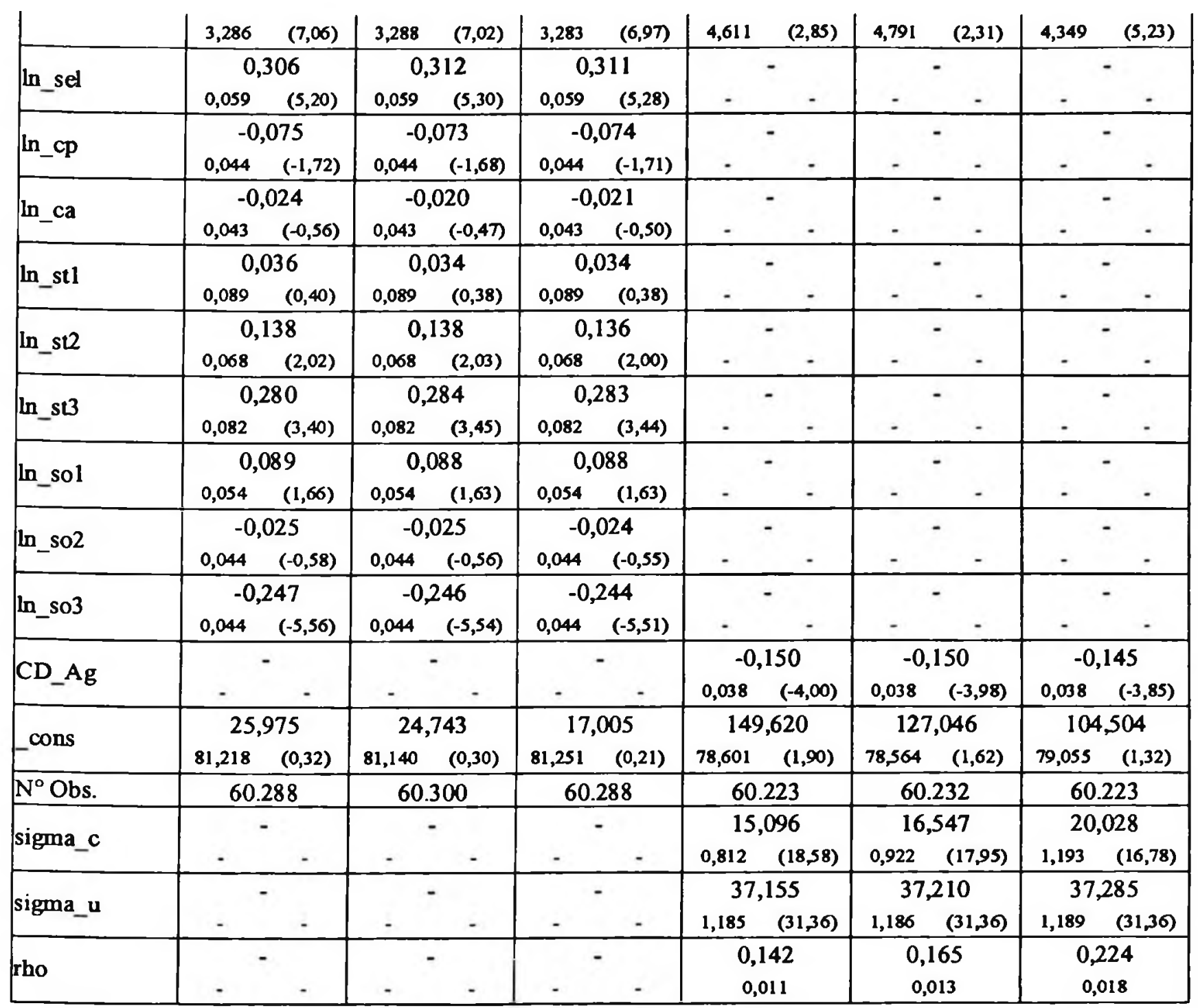

A tabela 22 apresenta os efeitos marginais obtidos pelos modelos Tobit ${ }^{93}$. Para o período iniciado em $1^{\circ}$ de julho, um aumento de 1 p.p. na taxa de redesconto implica em uma queda na demanda por redesconto entre R\$ $670.760,24$ a RS $893.263,11$ (contra R\$ $120.049,86$ a R\$ 191.515,57 na amostra iniciada em 22 de abril de 2002).

Para as dummies de dias do periodo de cumprimento do compulsório sobre depósitos à vista os efeitos marginais seriam: nos modelos 1 a 3 a demanda por redesconto, dada a 
exigibilidade de cumprimento do compulsório sobre depósitos à vista, seria de aproximadamente R\$ $1.965 .000,00$ (contra R\$ $2.960 .000,00$ para o período iniciado em 22 de abril de 2002) na segunda segunda-feira; R\$ 1.958.000,00 (contra R\$ 2.836.000,00) na primeira segunda-feira e R\$ $1.414 .000,00$ (contra R\$ $2.207 .000,00$ ) na primeira sexta-feira do periodo de cumprimento. Para os modelos 4 a 6, estes valores diminuem para aproximadamente R\$ 1.083.000,00 (contra RS $1.316 .000,00$ ), R\$ $1.115 .000,00$ (contra R\$ $1.370 .000,000$ ) e RS $727.000,00$ (contra R\$871.000,00), respectivamente.

Tabela 22 - Efeitos Marginais - Modelo Tobit

\begin{tabular}{|c|c|c|c|c|c|c|c|c|c|c|c|c|}
\hline Variável & MOI & LOO 1 & MOI & $\mathrm{LOO} 2$ & MOL & LOO 3 & MOI & LO 4 & MOI & LO 5 & MOI & JLO 6 \\
\hline ldga* & & 726 & & 36 & & 82 & & 140 & & & & 29 \\
\hline & 0,3439 & $(2,25)$ & 0,3834 & $(2,33)$ & 0,4610 & $(2,36)$ & 0.0448 & $(-0.98)$ & 0.0893 & $(0.53)$ & 0.1088 & $(0.30)$ \\
\hline dgh* & & 70 & & & & 29 & & 100 & & 89 & -0 , & 887 \\
\hline & 0,3002 & $(2,02)$ & 0,3363 & $(2,12)$ & 0,4075 & $(2,17)$ & 0.0451 & $(-0.89)$ & 0.0791 & $(0.24)$ & 0.0913 & $(-0.10)$ \\
\hline & & 96 & & 16 & -0 , & 146 & & 388 & & 398 & -0 , & 46 \\
\hline & 0,1443 & $(-2,22)$ & 0,1435 & $(-2,24)$ & 0,1434 & $(-2,19)$ & 0.0896 & $(-3.22)$ & 0.0976 & $(-3.07)$ & 0.1262 & $(-3.05)$ \\
\hline & & & & & & & & & & 24 & $0,($ & 03 \\
\hline & - & $\cdot$ & 0,0060 & $(5,32)$ & 0,0083 & $(2,66)$ & - & - & 0.0050 & $(-0.47)$ & 0.0073 & $(0.04)$ \\
\hline & & & & & & 34 & & & & & $0,($ & 22 \\
\hline & 0,0059 & $(4,90)$ & - & - & 0,0082 & $(1,63)$ & 0.0045 & $(0.36)$ & - & - & 0.0072 & $(0.30)$ \\
\hline & & & & & -0 , & 34 & & & & 15 & -0 , & 05 \\
\hline & 0,0065 & $(-4,19)$ & 0,0065 & $(-4,56)$ & 0,0069 & $(-4,84)$ & 0.0046 & $(0.42)$ & 0.0053 & $(-0.29)$ & 0.0071 & $(-0.07)$ \\
\hline In Comn & & & & & & & & & & & 0,0 & 60 \\
\hline & 0,0032 & $(9,31)$ & 0,0032 & $(9,39)$ & 0,0032 & $(9,45)$ & 0.0025 & (5.83) & 0.0029 & $(5.99)$ & 0.0039 & (9.25) \\
\hline In ExgComp & -0 & & -0 , & & -0 & 87 & & 40 & -0 & 140 & -0 , & 255 \\
\hline & 0,0030 & $(-9,53)$ & 0,0030 & $(-9,62)$ & 0,0030 & $(-9,70)$ & 0.0021 & $(-6.61)$ & 0.0024 & $(-5.92)$ & 0.0032 & $(-8.05)$ \\
\hline d $154 *$ & & & & & 0,4 & & & & & & 0, & \\
\hline & 0,1022 & $(4,44)$ & 0,1015 & $(4,43)$ & 0,1003 & $(4,40)$ & 0.0669 & (2.01) & 0.0668 & (1.82) & 0.1326 & (3.26) \\
\hline d $1 s 5^{*}$ & & & & & 0,4 & & & & & 70 & & 88 \\
\hline & 0,1054 & $(4,53)$ & 0,1048 & $(4,52)$ & 0,1035 & $(4,50)$ & 0.0686 & $(2.03)$ & 0.0684 & $(1.86)$ & 0.1342 & (3.27) \\
\hline d l s6* & & & & & & & & & & & & 04 \\
\hline & 0,1193 & $(5,14)$ & 0,1191 & $(5,14)$ & 0,1176 & $(5,11)$ & 0.0823 & (2.37) & 0.0813 & $(220)$ & 0.1552 & $(3.61)$ \\
\hline$d 2 s 2 *$ & & & & & & & & & & & 0,8 & 45 \\
\hline & 0,1434 & $(5,93)$ & 0,1427 & $(5,93)$ & 0,1411 & $(5,90)$ & 0.1119 & $(2.86)$ & 0.1095 & $(280)$ & 0.1995 & $(4.08)$ \\
\hline d 2 s3* & 0, & & & & 0 & & & & & & 0,3 & 83 \\
\hline & 0,0969 & $(4,18)$ & 0,0962 & $(4,17)$ & 0,0951 & $(4,14)$ & 0.0606 & (1.78) & 0.0606 & $(1.60)$ & 0.1202 & $(3.06)$ \\
\hline d2s4* & 0,3 & & 0,3 & & 0,3 & & & & 0, & & 0,3 & 22 \\
\hline
\end{tabular}

${ }^{93}$ A tabela contém os mesmos modelos e segue o mesmo padrão de apresentação da Tabela 14. 


\begin{tabular}{|c|c|c|c|c|c|c|}
\hline & $0,0908 \quad(3,83)$ & 0,0907 & 0,0894 & 0.0525 & 0.0529 & 0.1087 \\
\hline \multirow{2}{*}{$d 2 s 5^{*}$} & 0,4050 & 0,4063 & 0,3973 & 0,1067 & 0,0949 & 0,3665 \\
\hline & $0,0974 \quad(4,16)$ & $0,0974 \quad(4,17)$ & $0,0961 \quad(4,14)$ & $0.0604 \quad(1.77)$ & $0.0605 \quad(1.57)$ & $0.1201 \quad(3.05)$ \\
\hline \multirow{2}{*}{ d2s $6 *$} & 0,4563 & 0,4578 & 0,4485 & 0,1346 & 0,1224 & 0,4279 \\
\hline & $0,1026 \quad(4,45)$ & $0,1026 \quad(4,46)$ & $0,1013 \quad(4,43)$ & 0.0667 & $0.0668 \quad(1.83)$ & $0.1314 \quad(3.26)$ \\
\hline \multirow{2}{*}{ d3s2* } & 0,8528 & 0,8489 & 0,8368 & 0,3117 & 0,2966 & 0,7906 \\
\hline & $0,1436 \quad(5,94)$ & $0,1430 \quad(5,93)$ & $0,1416 \quad(5,91)$ & $0.1100 \quad(2.83)$ & 0.1070 & $0.1948 \quad(4.06)$ \\
\hline \multirow{2}{*}{ d3s3* } & 0,4734 & 0,4672 & 0,4601 & 0,1304 & 0,1194 & 0,4146 \\
\hline & $0,1046 \quad(4,53)$ & $0,1037 \quad(4,51)$ & $0,1026 \quad(4,48)$ & $0.0662 \quad(1.97)$ & $0.0660 \quad(1.81)$ & $0.1287 \quad(3.22)$ \\
\hline \multirow{2}{*}{ In_sel } & 0,0033 & 0,0034 & 0,0033 & - & - & - \\
\hline & $0,0006 \quad(5,19)$ & $0,0006 \quad(5,29)$ & $0,0006 \quad(5,27)$ & - & - & - \\
\hline $\ln \mathrm{cp}$ & $-0,0008$ & $-0,0008$ & $-0,0008$ & - & - & - \\
\hline & $0,0005 \quad(-1,72)$ & $0,0005 \quad(-1,68)$ & $0,0005 \quad(-1,71)$ & - & - & - \\
\hline In ca & $-0,0003$ & $-0,0002$ & $-0,0002$ & - & - & - \\
\hline & $0,0005 \quad(-0,56)$ & $0,0005 \quad(-0,47)$ & $0,0005 \quad(-0,50)$ & - & - & - \\
\hline In_stl & 0,0004 & 0,0004 & 0,0004 & - & - & - \\
\hline & $0,0010 \quad(0,40)$ & $0,0010 \quad(0,38)$ & $0,0010 \quad(0,38)$ & - & - & - \\
\hline In st2 & 0,0015 & 0,0015 & 0,0015 & - & - & - \\
\hline & $0,0007 \quad(2,02)$ & $0,0007 \quad(2,03)$ & $0,0007 \quad(2,00)$ & - & - & - \\
\hline $\ln s t 3$ & 0,0030 & 0,0031 & 0,0031 & - & - & - \\
\hline & $0,0009 \quad(3,39)$ & $0,0009 \quad(3,45)$ & $0,0009 \quad(3,44)$ & - & - & - \\
\hline $\ln$ sol & 0,0010 & 0,0009 & 0,0009 & - & - & - \\
\hline & $0,0006 \quad(1,66)$ & $0,0006 \quad(1,63)$ & $0,0006 \quad(1,63)$ & - & - & - \\
\hline $\ln$ so 2 & $-0,0003$ & $-0,0003$ & $-0,0003$ & - & - & - \\
\hline & $0,0005 \quad(-0,58)$ & $0,0005 \quad(-0,56)$ & $0,0005 \quad(-0,55)$ & - & - & - \\
\hline In so3 & $-0,0027$ & $-0,0026$ & $-0,0026$ & - & - & - \\
\hline (1) _ & $0,0005 \quad(-5,58)$ & $0,0005 \quad(-5,50)$ & $0,0005 \quad(-5,53)$ & $-\quad-$ & $-\quad-$ & $-\quad-$ \\
\hline CD_Ag & - & - & - & $-0,0010$ & $-0,0011$ & $-0,0014$ \\
\hline & - & - & - & $0.0003 \quad(-3.75)$ & $0.0003 \quad(-3.83)$ & $0.0004 \quad(-3.74)$ \\
\hline $\mathrm{N}^{\circ}$ Obs. & 60.288 & 60.300 & 60.288 & 60.223 & 60.232 & 60.223 \\
\hline
\end{tabular}

(*) Efeito marginal para variação do valor da variável dummy de 0 para 1 . 


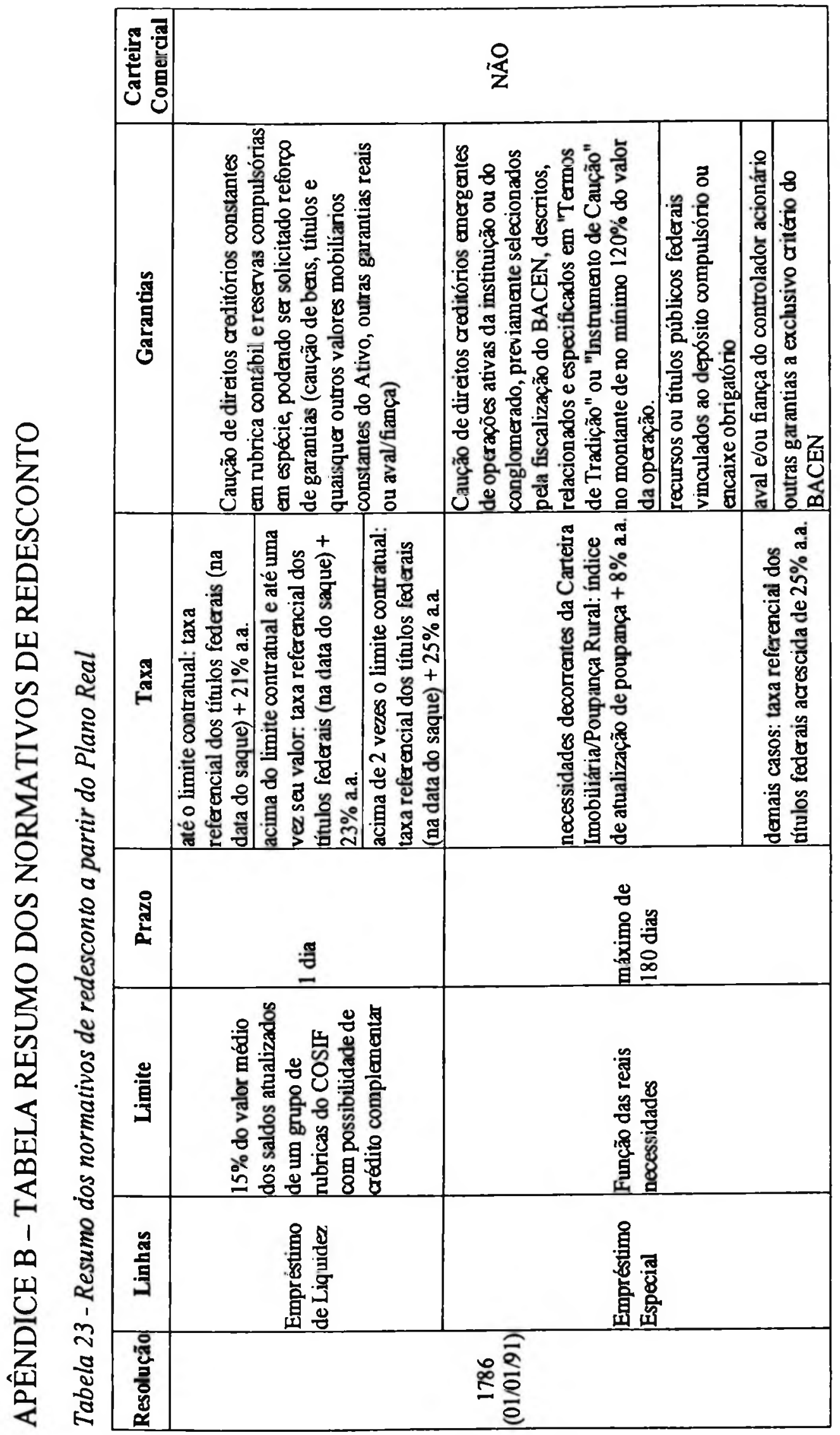




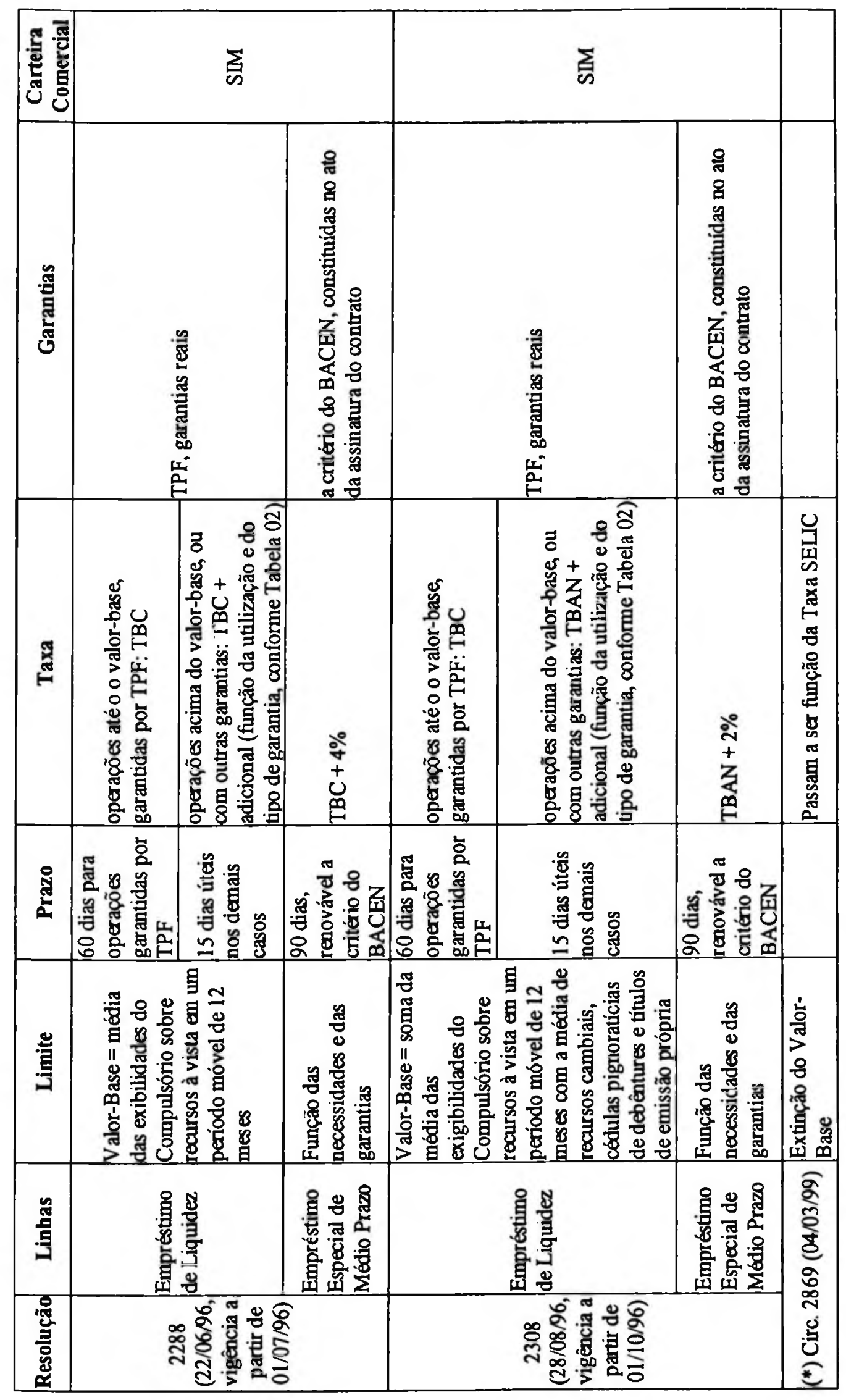




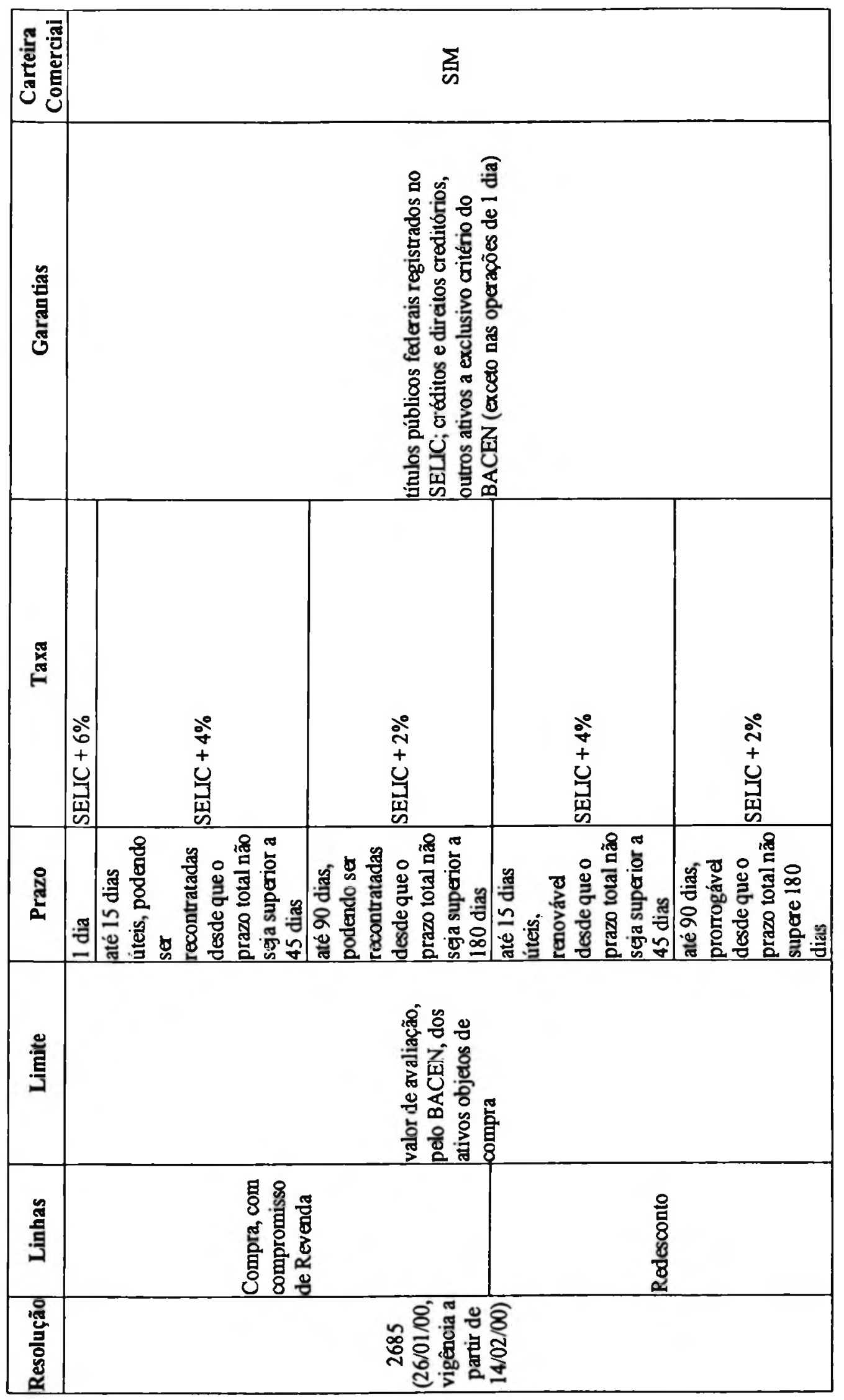

